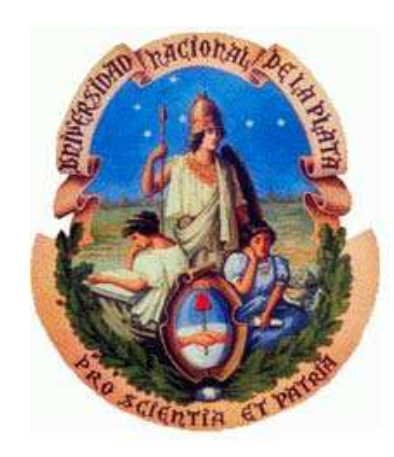

Facultad de Ciencias Naturales y Museo, Universidad Nacional de la Plata

\title{
Invasión del Estornino Pinto Sturnus vulgaris en el Noreste de la provincia de Buenos Aires: análisis de la competencia con aves nativas y potencialidad como transmisor de parásitos
}

Tesis presentada para optar por el título de Doctor en Ciencias naturales

\section{Lucia Mariel Ibañez}

Director: Diego Montalti

Co-director: Vanina D. Fiorini

La Plata, 2015 


\section{AGRADECIMIENTOS}

Quiero agradecer a mi director Diego Montalti por guiarme en esta profesión durante todos estos años de trabajo, por estar siempre presente cuando lo necesité, por ser paciente ante mis dudas y por incentivarme siempre a seguir adelante transmitiéndome tranquilidad y confianza.

A mi codirectora Vanina Fiorini por su aporte tan enriquecedor a esta tesis.

A todas las personas que colaboraron en la identificación de muestras de artrópodos y parásitos de este trabajo: Julia Díaz, María Inés Gamboa, Marcela Lareschi, Armando Cicchino, Osvaldo Di Iorio, Mariano Lucia y a los pasantes Romina Valente, Sofía Quiroga y Matías Fernández.

A toda la gente que algún día me acompañó en las salidas al parque Pereyra y me ayudó en la búsqueda de nidos o en la revisión de las cajas-nido, tareas que requieren tiempo y desgaste físico, entre ellos Pachi, Facundo, Emiliano, María, Clara, Blanca y Coki.

A Yeye y Silvia por permitirme trabajar en la EBAS, por ayudarme con la confección y colocación de las cajas-nido, por ofrecerme un espacio donde guardar las herramientas de trabajo y por ofrecerme un mate y una agradable charla en los escasos momentos de descanso.

A la gente de la ECAS por permitirme durante estos cuatro años trabajar en un lugar tan hermoso y tranquilo.

A la gente del laboratorio de Ornitología del Museo de la Plata por la buena onda y compañerismo.

A mi amigos de siempre por estar, por sus palabras de aliento y por distraerme en esos momentos en que lo único que ocupaba mi cabeza era la tesis.

Por último agradezco a mi familia, por su ayuda y apoyo constante, sin el cual no estaría hoy en este lugar, pero principalmente a Abril, el principal motor en mi vida, por su amor incondicional...

Esta tesis está dedicada a vos. 
RESUMEN 6

ABSTRACT 8

\section{CAPÍTULO 1: Introducción general}

Especies invasoras 10

La familia Sturnidae $\quad 13$

El Estornino Pinto 14

Distribución del Estornino Pinto a nivel mundial 17

Distribución del Estornino Pinto en la Argentina 18

Imparcto de la invasión del Estornino Pinto $\quad 21$

Daños económicos $\quad 21$

Competencia con aves nativas $\quad 22$

Problemas sanitarios ocasionados por el estornino $\quad 22$

Objetivos generales $\quad 23$

Objetivos particulares $\quad 23$

Área de estudio $\quad 24$

\section{CAPÍTULO 2: Nidificación del Estornino Pinto}

$\begin{array}{ll}\text { Introducción } & 27\end{array}$

Importancia de las características de las cavidades 28

Cavidades que utiliza el Estornino Pinto para nidificar 29

Materiales utilizados en la construcción de sus nidos 29

Objetivos del capítulo 31

Materiales y métodos $\quad 32$

Características de las cavidades utilizadas para nidificar $\quad 32$

Utilización de cajas-nido $\quad 33$

Materiales utilizados en la construcción de los nidos 34

Utilización de líquenes en los nidos $\quad 35$

Resultados

Cavidades que utiliza el Estornino Pinto para nidificar 35

$\begin{array}{ll}\text { Utilización de cajas-nido } & 37\end{array}$

Materiales utilizados en la construcción de los nidos $\quad 40$

Discusión

Utilización de líquenes en los nidos 43

Cavidades que utiliza el Estornino Pinto para nidificar 44

Utilización de cajas-nido $\quad 45$

Materiales utilizados por el Estornino Pinto en la construcción
de sus nidos

Utilización de líquenes en los nidos $\quad 46$

\section{CAPÍTULO 3: Densidad poblacional y competencia con aves nativas}

Introducción

Incremento poblacional del Estornino Pinto 50 
Competencia con aves nativas 51

Objetivos del capítulo $\quad 53$

Materiales y métodos

Muestreo de aves 53

Características de las cavidades utilizadas para nidificar $\quad 55$

Observaciones sobre competencia entre estorninos y
otras especies

Resultados

Muestreo de aves 56

Características de las cavidades utilizadas para nidificar $\quad 57$

Observaciones sobre competencia entre estorninos y otras
especies

$\begin{aligned} \text { especies } & 63 \\ \text { Uso de la misma cavidad por más de una especie } & 63\end{aligned}$

Defensa de cavidades $\quad 63$

Intento de usurpación de una cavidad 63

Usurpación de cavidades $\quad 64$

Discusión

Uso de las cajas-nido $\quad 64$

Densidad poblacional 64

Características de las cavidades utilizadas para nidificar $\quad 65$

y competencia interespecífica

\section{CAPÍTULO 4: Biología reproductiva del Estornino Pinto}

Introducción

Tamaño de la puesta $\quad 71$

Eclosión de huevos $\quad 71$

$\begin{array}{ll}\text { Reducción de nidada } & 72\end{array}$

Variables ambientales $\quad 72$

Morfometría de huevos $\quad 73$

$\begin{array}{ll}\text { Objetivos del capítulo } & 73\end{array}$

Materiales y métodos $\quad 74$

Análisis estadístico $\quad 75$

Resultados

Patrón estacional $\quad 77$

Parámetros reproductivos generales $\quad 78$

$\begin{array}{ll}\text { Comparación de los parámetros reproductivos entre años } & 79\end{array}$

Comparación de los parámetros reproductivos entre nidadas $\quad 81$

Comparación de los parámetros reproductivos entre nidadas
Tempranas y tardías

Reducción de nidada $\quad 83$

Discusión

Morfometría de huevos $\quad 84$

Tamaño de la puesta $\quad 85$

Eclosión de huevos $\quad 86$

$\begin{array}{ll}\text { Tamaño de la nidada } & 87\end{array}$

$\begin{array}{ll}\text { Reducción de nidada } & 87\end{array}$

Morfometría de huevos $\quad 88$

$\begin{array}{ll}\text { Conclusión } & 90\end{array}$ 


\section{CAPÍTULO 5: Efectos de las larvas de Philornis sobre la biología}

reproductiva del Estornino Pinto

Introducción

Efecto del clima sobre los pichones 93

Objetivos del capítulo $\quad 93$

Materiales y métodos $\quad 94$

Análisis estadístico $\quad 94$

Resultados

$\begin{array}{ll}\text { y no parasitados por Philornis } & 95\end{array}$

Efecto del parasitismo de Philornis y las variables

ambientales sobre los pichones

100

Comparación entre pichones parasitados y no parasitados

por Philornis 103

Discusión

\section{CAPÍTULO 6: Alimentación del Estornino Pinto}

Introducción

Alimentación del Estornino Pinto $\quad 112$

Objetivos del capítulo $\quad 113$

Materiales y métodos 113

Análisis estadístico $\quad 114$

Resultados

Variaciones estacionales y por edad en la alimentación

Discusión de los pichones

Conclusiones

\section{CAPÍTULO 7: Ecto y endoparásitos presentes en el Estornino Pinto}

Introducción

Relación parásito-hospedador

Endoparásitos

Ectoparásitos

Moscas ectoparásitas Philornis sp. 133

Objetivos del capítulo $\quad 134$

Materiales y métodos

Endoparásitos 135

Ectoparásitos $\quad 135$

Moscas ectoparásitas Philornis sp. 136

Resultados

$\begin{array}{ll}\text { Endoparásitos } & 137\end{array}$

Ectoparásitos 138

Moscas ectoparásitas Philornis sp. 139

Discusión

Endoparásitos 139

Ectoparásitos $\quad 142$

Moscas ectoparásitas Philornis sp. 143

$\begin{array}{ll}\text { Conclusión } & 145\end{array}$ 
CAPÍTULO 8: Discusión general

Consideraciones finales

CAPÍTULO 9: Referencias bibliográficas 


\section{RESUMEN DE LA TESIS}

El Estornino Pinto (Sturnus vulgaris) es un ave nativa de Europa, Oeste de Asia y norte de África que ha sido introducida en numerosos países y actualmente es considerada una de las 100 especies más invasoras del mundo. En la Argentina fue introducida en la década del 80 y a partir de ese momento se ha observado un aumento importante en la cantidad de ejemplares por bandada y una expansión a distintas provincias del país.

Entre noviembre de 2010 y octubre de 2011 se realizó un censo de aves en el parque Pereyra Iraola y una búsqueda de nidos de estorninos y de otras especies. Se determinó que actualmente el Estornino Pinto es la especie que nidifica en cavidades con mayor densidad en la zona (1,47 individuos/ha). Para nidificar utilizaron una gran variedad de cavidades, principalmente en árboles vivos pero también en árboles muertos y construcciones humanas como techos de viviendas y luminarias. Se observaron interacciones agresivas con dos parejas de carpinteros y con un hornero por el uso de estas cavidades. En estos casos el estornino no logró desplazar a las otras aves, pero por otro lado se registraron dos parejas de estornino nidificando en cavidades que unos días antes estaban siendo construidas carpinteros.

Durante cuatro temporadas reproductivas (septiembre-diciembre de 2010, 2011, 2012 y 2013) se realizó un estudio de la biología reproductiva del estornino mediante el uso de cajasnido. El Estornino Pinto fue la única especie que las utilizó. Dentro de las cajas construyeron un nido voluminoso utilizando principalmente gramíneas y ramas. También utilizaron hojas verdes, hojas secas, corteza, líquenes, clavel del aire, vainas de leguminosas, flores, crines y estiércol de caballo, bolitas de barro y materiales artificiales.

El tamaño de la puesta fue de 4,06 $\pm 0,13$ huevos por nido y el éxito de eclosión del $77,5 \%$. Nacieron en promedio 3,15 pichones por nido y se produjo reducción de nidada en el $37,9 \%$. En el $67 \%$ de los nidos donde nacieron pichones la totalidad de ellos murieron. La proporción de pichones que sobrevivieron por nido fue muy baja $(x=0,24)$ y disminuyó en las nidadas tardías, viendose afectada negativamente por la temperatura ambiental, mientras que las precipitaciones tuvieron un efecto positivo sobre la supervivencia de los pichones. La temperatura ambiental también tuvo un efecto subletal sobre los pichones, disminuyendo el peso asintótico alcanzado conforme aumentó la temperatura.

Los pichones fueron parasitados por larvas de Philornis mostrando la prevalencia más alta (61,82\%) registrada en aves de Argentina y con una intensidad media de 10,7 larvas por pichón. En el $60,7 \%$ de los nidos con pichones parasitados no sobrevivió ningún pichón. La proporción de pichones que sobrevivieron por nido varió en función de la edad a la que fueron 
parasitados, siendo menor cuando el parasitismo ocurrió a una edad más temprana, sin embargo, no se vió afectada por la intensidad de Philornis.

Se analizó el contenido estomacal de pichones y se observó que consumieron principalmente larvas y adultos de coleópteros, himenópteros y larvas de lepidópteros. En menor proporción consumieron alimento vegetal, encontrándose semillas de Morera Negra Morus nigra en el 48,7\% de los estómagos, por lo que el estornino podría estar actuando como un dispersor de especies vegetales exóticas. También se encontraron piedras en el 53\% de los estómagos. La proporción de artrópodos disminuyó y la de alimento vegetal y piedras aumentaron con el crecimiento de los pichones y al avanzar la temporada reproductiva.

Con respecto a los parásitos, se encontraron ooquistes de Isospora sp. (Coccidia) con una prevalencia del $26,8 \%$ en muestras de heces de pichones y huevos de cestode sólo en una muestra. También se extrajeron los ectoparásitos de pichones y juveniles de estornino muertos y de pichones vivos, encontrando sólo ácaros de la especie Ornithonyssus bursa. Todas estas especies son cosmopolitas y se encontraban previamente en la zona, por lo que el estornino no habría adquirido nuevas especies de parásitos, con excepción de Philornis, ni habría transmitido nuevos parásitos a las aves nativas

Esta tesis constituye el primer estudio sobre los distintos aspectos de la invasión del Estornino Pinto en la Argentina y aporta datos importantes para el conocimiento de la situación de esta especie en el Noreste de la provincia de Buenos Aires que podrían utilizarse en un futuro con el fin de implementar estrategias de control de la especie. 


\section{ABSTRACT}

The European starling is a bird native from Europe, Asia and North Africa. It has been introduced in several countries and nowadays is considered one of the $100^{\text {th }}$ most invasive species in the world. In Argentina it has been introduced in the $80^{\text {th }}$ and since then the number of individuals has increased and it has expanded to other provinces of the country.

Between November 2010 and October 2011 I made a bird census in the Pereyra Iraola park and searched for nests of starling and other species. The results show that nowadasys the European starling is the most abundant cavity nester in the area, with a density of 1,47 individuals/hectárea. Starlings used a great variety of cavities to nests, mainly in alive trees and also in dead trees and human constructions like roof of houses and luminaries. Aggressive interactions for the use of cavities with two pairs of woodpeckers and a Rufous Hornero Furnarius rufus were observed. In these cases the starling failed to displace the other birds, but other two pairs of starlings were seen nesting in cavities that some days ago woodpeckers were building. During four breeding seasons (between September and December of 2010, 2011, 2012 and 2013) a study of the breeding biology of the starling was realized using nestboxes. Starlings made a voluminous nest inside the cavity. The principal components of it were grass and branches but they also added green and dry leaves, bark, lichens, air plants, leguminous pods, flowers, horse hair and manure of horses, pellets of bark and artificial materials. The clutch size was $4,06 \pm 0,13$ eggs/nest and the hatching success was $77,5 \%$. On average 3.15 nestlings were born per nest and brood reduction was registered at 37,9\%. The entire brood died in the $67 \%$ of the nests where nestlings hatch. The proportion of nestlings that survived per nest was low $(x=0,24)$ and decreased in the later broods. It was negative affected by the environmental temperature while rainfall had a positive effect on nestling survival. The environmental temperature also had a subletal effect on nestlings, decreasing the asymptotic mass with the increase of temperature. The parasitism by Philornis showed the highest prevalence $(61,82 \%)$ registered in birds of Argentina and an average intensity of 10,7 larvae per nestling. In $60,7 \%$ of the nests with parasitized nestlings all of them died. The proportion of nestlings that survived per nest showed variations related to the age at which the nestlings were parasitized and was not affected by the intensity of Philornis. The gizzard contents of nestlings was analyzed. They consumed mainly larvae and adults of Coleoptera, Hymenoptera and larvae of Lepidoptera. Vegetable matter was found in a lower proportion. Seeds of black mulberry Morus nigra was found in the $48,7 \%$ of the samples, this would indicate that the starling could be acting as a seed disperser of exotic plants. Stones were 
found in the $53 \%$ of the gizzards. The proportion of arthropods decreased and the proportion of vegetable matter and stones increased with the growth of the nestlings and with the advance of the reproductive season. With regard to the parasites, ooquists of Isospora sp. (Coccidia) were found in nestling feces with a prevalence of $26,8 \%$ and eggs of cestods were found only in one sample. The ectoparasites were analyzed from dead nestlings and juvenils and from alive nestlings and the unique species found were Ornithonyssus bursa. All these species are cosmopolitan and were found previously in the study area so the starling would not have acquire new parasites from native birds except Philornis, nor would have transmitted new species to native birds.

This thesis is the first study about the different aspects of the invasion of the Starling in Argentina and provides important data for understanding the status of this species in the Northeast of Buenos Aires province. This information could be used in the future to implement control strategies for this invasive species. 


\section{CAPÍTULO 1: INTRODUCCION GENERAL}

\section{Especies invasoras}

La introducción de especies exóticas junto con la agricultura y la deforestación actualmente representan las amenazas más importantes para la conservación de las aves nativas y es una de las mayores causas de pérdida de biodiversidad en el mundo (Blackburn y Duncan 2001, Mc Neely 2001, Hilton-Taylor y col. 2009).

Las especies exóticas son generalmente introducidas en números bajos (Blackburn y col. 2009), y cuanto menor es el número de individuos, mayor es la probabilidad de que esa población se extinga rápidamente debido a eventos estocásticos (Duncan y col. 2003). Las poblaciones pequeñas se encuentran expuestas al efecto Allee por el cual, a bajas densidades la tasa de reproducción y la supervivencia decrecen afectando el crecimiento poblacional, lo que puede llevar a la extinción de la especie en la zona donde fue introducida (Sax y Brown 2000). Los mecanismos implicados en el efecto Allee son varios, entre ellos, la pérdida de heterocigosidad, efectos demográficos estocásticos (que provocan fluctuaciones en la razón de sexos) y una disminución en los encuentros entre parejas con capacidad de reproducirse (Courchamp y col. 1999). Un número poblacional mínimo inicial es indispensable para la supervivencia de la especie introducida en el nuevo sitio (Navas 1987) y para alcanzar este número generalmente son necesarios más de un evento de introducción antes de que la especie logre establecerse en el nuevo sitio (Sax y Brown 2000). Por ejemplo, el Gorrión Común (Passer domesticus) y el Estornino Pinto (Sturnus vulgaris) lograron establecerse y prosperar en Estados Unidos luego de varias introducciones fallidas y actualmente son las aves exóticas más exitosas en ese país (Parker y col. 2001).

El cuello de botella poblacional que atraviesan las especies introducidas reduce la variabilidad genética de esa población (Dlugosch y Parker 2008) y puede tener consecuencias importantes. Por un lado aumenta el apareamiento entre individuos emparentados, incrementando la expresión de alelos deletéreos, lo cual puede limitar el crecimiento poblacional y las probabilidades de que la población persista (Allendorf y Lundquist 2003, Briskie y Mackintosh 2004). Por otro lado, la reducción en la diversidad genética puede limitar la capacidad de adaptación y evolución de la especie introducida en el nuevo hábitat (Allendorf y Lundquist 2003). Sin embargo, cuando ocurren introducciones múltiples de la 
misma especie exótica, esta especie puede alcanzar una diversidad genética similar o incluso mayor a la de poblaciones nativas aumentando las probabilidades de éxito (Novak 2007).

Especie exótica e introducida son considerados términos sinónimos y se refieren a aquellas especies que no son nativas de una zona y que se encuentran allí debido a la acción humana (Prentis y col.y col 2008, Blackburn y coly col. 2009). Para que una especie exótica o introducida logre convertirse en invasora, debe atravesar una serie de pasos (Fig. 1).

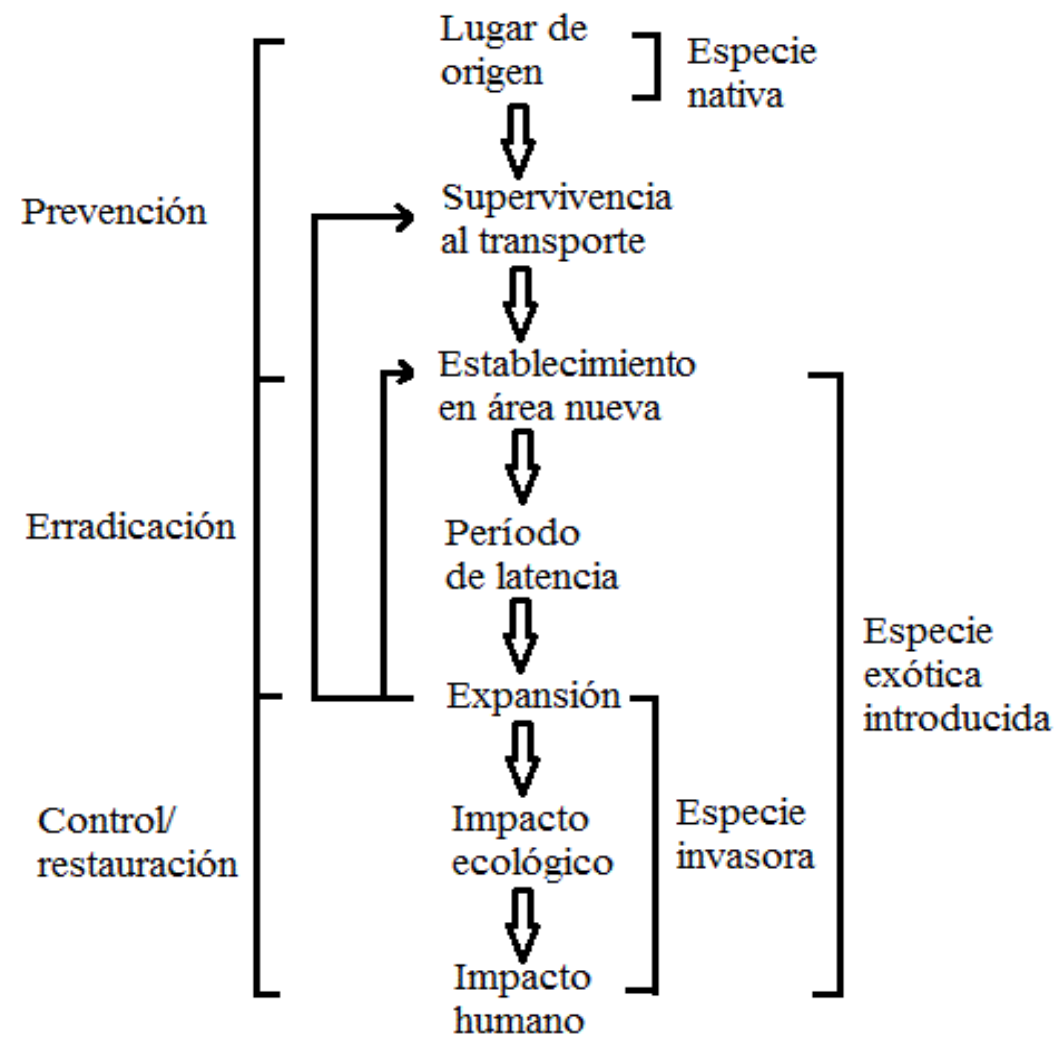

Fig. 1: Pasos que debe atravesar una especie antes de convertirse en invasora. Modificado de Parker y col. (2001).

En la zona donde se produce la introducción, la especie exótica podría encontarse con una resistencia ecológica que podría dificultar su supervivencia en el nuevo ambiente (Navas 1987). Esta resistencia está dada principalmente por tres factores: 1) los enemigos con los que pueda encontrarse (predadores, parásitos, enfermedades), 2) la disponibilidad de recursos y 3 ) las características ambientales (Duncan y col. 2003). La habilidad de una especie para responder a esos factores y a sus variaciones espaciales y temporales, determinan su capacidad como especie invasora (SantaMaría y col. 2009). La flexibilidad en el comportamiento es uno de los factores que afecta la respuesta de la especie introducida a las 
nuevas condiciones por lo que las especies que utilizan una mayor variedad de recursos (en cuanto a alimentación y ambientes) presentan mayores probabilidades de aclimatarse al nuevo ambiente y sobrevivir al explotar una mayor variedad de nichos, a diferencia de las especies especialistas que presentan limitaciones adaptativas al enfrentarse a nuevas condiciones ambientales (Sol y Lefebvre 2000, Duncan y col. 2003). Además, las especies con una tasa de crecimiento poblacional mayor también presentan mayores probabilidades de establecer poblaciones viables cuando son introducidas en un nuevo sitio (Blackburn y col. 2009) y suelen mostrar un crecimiento poblacional abrupto luego de que su tamaño supera cierto umbral mínimo de densidad (Veit y Lewis 1996). Las especies sinantrópicas son aquellas mayormente asociadas al hombre y a los ambientes urbanizados (McKinney 2006). Se ha demostrado que la flexibilidad en el comportamiento y un comportamiento oportunista les permite a estas aves adaptarse rápidamente a las nuevas condiciones aumentando probabilidades de establecerse exitosamente una vez liberadas (Sol y Lefebvre 2000). Al mismo tiempo, la introducción de estas especies en distintos sitios se ve facilitada debido a que suelen expandirse por todo el planeta acompañando la expansión del hombre (Mc Kinney 2006). Con la urbanización la diversidad y abundancia de aves nativas disminuye y las exóticas llegan a representar más del 80\% del total de las aves (Clegeau y col. 1998, Faggi y Perepelizin 2006), produciéndose una homogeneización de la avifauna en las distintas ciudades del mundo (Mc Kinney 2006).

Cuando una especie introducida logra establecer una población sustentable en la naturaleza se la denomina especie naturalizada (Manchester y Bullock 2000). Cuando se expanden a otras áreas a partir del punto de introducción y se vuelven abundantes estas especies son consideradas invasoras (Kolar y Lodge 2001).

Una vez que la especie exótica alcanza una determinada densidad, empieza a afectar la zona invadida (Shea y Chesson 2002) y puede generar cambios dramáticos en la estructura o función del ecosistema (Hobbs y coly Mooney 1998). Las especies exóticas pueden generar distintos tipos de efectos negativos, por ejemplo mediante el desplazamiento de especies nativas debido a la competencia por recursos (Mc Nelly 2001). También puede ocurrir la introducción concomitante de enfermedades que trae la especie introducida de los sitios de donde proviene. Estas podrán ser transmitidas a la fauna nativa que podría ser especialmente susceptible por no haber desarrollado estrategias de comportamiento e inmunológicas que les permitan evitar el agente patógeno, evitar sus efectos negativos o sobrevivir a la enfermedad (Sol y Lefebvre 2000).

Una vez que la especie exótica supera cierto tamaño poblacional controlarla resulta una tarea muy compleja, siendo necesarias una importante inversión de tiempo y dinero. 
Erradicarla es prácticamente imposible y siempre está presente la posibilidad de perjudicar a la fauna nativa y al ecosistema si no hay una adecuada planificación de las medidas de manejo (Zavaleta y col. 2001). Dentro de la familia Sturnidae varias especies se han adaptado a los ambientes modificados por el hombre (Craig y Feare 2009). Dos de estas especies, el Estornino Pinto y el Miná Común se encuentran incluídas dentro de la lista de las 100 especies invasoras más dañinas del mundo. (Lowe 2000).

\section{La familia Sturnidae}

La especie objeto de la presente tesis es el Estornino Pinto, ubicado dentro de la Familia Sturnidae. Varias especies de esta familia se han adaptado a los ambientes modificados por el hombre (Craig y Feare 2009). Dos de estas especies, el Estornino Pinto y el Miná Común Acridotheres tristis se han convertido en invasoras y se encuentran incluídas dentro de la lista de las 100 especies invasoras más dañinas del mundo (Lowe 2000).

La familia Sturnidae pertenece al orden Passeriformes y se encuentra conformada por 26 géneros que abarcan 114 especies (Lovette y Rubinstein 2007).

Tradicionalmente a esta familia se la vinculaba a otras. Por ejemplo, a fines del siglo XIX se lo vinculaba a la familia Corvidae (Sibley y Ahlquist 1984), posteriormente se la emparentaba con la familia Promeropidae (Sibley y Ahlquist 1974), Turdidae y Muscicapidae (Sibley y Ahlquist 1984) pero finalmente se confirmó su relación con las familias Turdidae y Buphagidae por medio de análisis moleculares (Lovette y Rubinstein 2007). Cinco especies de la familia de distribuciones insulares se extinguieron y cuatro se encuentran en peligro crítico (IUCN 2014).

La mayoría de las especies de la familia son de color negro y varias de ellas presentan plumaje iridiscente. El dimorfismo sexual no es común en la familia (solo 25 especies presentan un dimorfismo sexual marcado), así como tampoco es habitual el dimorfismo entre juveniles y adultos (Craig y Feare 2009). Nidifican en cavidades y en general presentan huevos manchados con un fondo azulado. Solo seis especies de tres géneros construyen nidos cerrados fuera de cavidades y cuatro géneros, incluyendo Sturnus, ponen huevos sin manchas. A diferencia de otras aves que nidifican en cavidades la familia Sturnidae construye nidos voluminosos dentro de la cavidad y la mayoría de las especies presentan huevos crípticos. Estas características son típicas de especies que nidifican en nidos abiertos, por lo tanto las especies actuales habrían derivado de un ancestro que construía nidos abiertos (Feare 1984).

La mayoría de la especies son gregarias (Sibley 2001, Craig y Feare 2009), se alimentan tanto de material vegetal como animal, principalmente insectos y otros invertebrados pero 
también consumen frutos, néctar, granos y huevos de otras aves y se observa una tendencia a la alimentación en el suelo, para lo cual cuentan con especializaciones en las patas, dedos, cráneo y pico (Feare 1984, Sibley 2001, Craig y Feare 2009).

La distribución natural de la familia se concentra principalmente en África y el Sudeste de Asia (Feare 1984) habitando ambientes muy diversos como bosques, sabanas, pastizales y zonas montañosas donde superan los $4000 \mathrm{~m}$ de altura (Craig y Feare 1984). Las especies que se han adaptado a los ambientes modificados por el hombre, aprovechan los campos de cultivos y ciudades (Craig y Feare 1984, Sibley 2001).

Al género Sturnus anteriormente se le atribuían 16 especies (Feare 1984, Sibley 2001), pero estudios moleculares posteriores trasladaron 10 de estas especies al género Acridotheres y otras cuatro a los géneros Creatophora, Leucopsar y Pastor. La clasificación actual restringe el género Sturnus a sólo dos especies, $S$. vulgaris y $S$. unicolor que poseen pequeñas diferencias genéticas (Zuccon y col. 2008).

\section{El Estornino Pinto}

El Estornino Pinto adulto es un ave de tamaño mediano, de aproximadamente $20 \mathrm{~cm}$ de longitud y una masa corporal de 75 a 100 g (Feare 1984). Presenta una cola corta, el pico es fuerte, con una longitud de $25 \mathrm{~mm}$ especializado para extraer larvas e insectos del suelo (Tinbergen 1981). Las alas son relativamente largas y terminan en punta, están adaptadas a vuelos veloces y maniobras bruscas (Feare 1984). Las plumas de la corona, garganta y nuca son lanceoladas. Fuera de la temporada reproductiva el plumaje es principalmente negro con numerosas pintas color crema en todas las plumas del cuerpo. En la cabeza y garganta presentan algunas plumas iridiscentes verdes y púrpuras. El pico es marrón y las patas marrones-rojizas (Fig. 2.a.). En época reproductiva desaparecen gran cantidad de las pintas y el plumaje presenta iridiscencias púrpura en la cabeza y garganta y verdes en el manto, rabadilla y pecho. El pico en esta época es amarillo y las patas rosadas (Fig. 2.b.) (Craig y Feare 2009).

El dimorfismo sexual en el Estornino Pinto es poco evidente, lo que dificulta el sexado de los especímenes. Las diferencias se encuentran principalmente en el ojo, pico y plumas de la garganta y el pecho. Las hembras poseen un iris anaranjado claro, bien distinguible de la pupila, mientras que el iris de los machos es marrón oscuro y no puede distinguirse de la pupila. Otra diferencia se encuentra en el color de la base del pico, que en época reproductiva, en las hembras es de color rosado (Fig. 3.a.) mientras que en los machos es azul grisáceo (Fig. 3.b) (Coleman 1973, Feare, 1984, Smith y col 2005). Las plumas del pecho y la garganta son de mayor longitud en los machos que en las hembras y en los adultos que en los juveniles, por 
lo que este carácter puede ser utilizado para distinguir estorninos de un año de edad de estorninos de dos años o más (Williams 1991).

Cuando los estorninos abandonan el nido, presentan una coloración uniforme marrón opaca que podría tener una función críptica (Feare 1984).

En cuanto a la reproducción los estorninos nidifican en cavidades ya existentes. Estas cavidades pueden ser generadas por la degradación de ramas o troncos de árboles muertos o añejos, o construidas por aves que construyen sus propias cavidades, como por ejemplo las aves de la familia Picidae (Ingold 1994). También nidifican en cavidades artificiales como ranuras o huecos en construcciones humanas o cajas-nido en las ciudades o en el campo (Kessel 1957, Moeed y Dawson 1974, Lumsden 1976, Feare 1984).

La alimentación del Estornino Pinto es omnívora, con diferencias entre la temporada reproductiva y la temporada invernal. En el período de cría son predominantemente insectívoros. Los ítems principales en su dieta son larvas de lepidópteros y coleópteros, pero también incorporan una amplia variedad de invertebrados incluyendo dípteros, isópodos, himenópteros, ortópteros, hemípteros, homópteros y arácnidos (Coleman 1977, Tinbergen 1981, Feare 1984, Moore 1986, Maccarone 1987).

En el período de post-cría incorporan a su alimentación una amplia variedad de alimentos vegetales como granos, frutas (uvas, melocotones, arándanos, frutillas, higos y manzanas) (Johnson y Glahn 1994) y brotes de cereales, leguminosas y gramíneas, atacando a los cultivos en muchas ocasiones (Coleman 1977, Feare 1984, Summers 1985, Feare y Douville de Franssu 1992). En la década del 60 en Alemania se registraban pérdidas económicas de 2.500.000 USD anuales por ataques de estorninos a cultivos de uvas y cerezas (De Grazio 1978).

En España provocan graves daños a los cultivos de uvas y aceitunas (Feare y Douville de Franssu 1992).

También causan daños en campos de golf al arruinar el suelo en búsqueda de larvas de insectos (Johson y Glahn 1994).

Durante el día se dispersan en grupos más pequeños para alimentarse y por la noche se reúnen en los denominados "dormideros" que son árboles con follaje denso o un pequeño bosque (Marples 1934) (Fig. 4) donde encuentran un microclima con temperaturas más altas, protección contra el viento y una menor exposición (Lustick y Kelty 1979). Los dormideros se forman en la época invernal especialmente en sectores urbanizados (Clergeau y col. 1998). En Europa se ha estimado que algunos dormideros rurales contienen alrededor de 2.000.000 de estorninos, mientras que en Israel el número asciende a más de 8.000.000 (Craig y Feare 1984). 
Suelen congregarse en bandadas mixtas, compartiendo el dormidero con otras especies como el Sargento Alirrojo (Agelaius phoeniceus), el Tordo Cabecipardo (Molothrus ater), el Zanate Común (Quiscalus quiscula) (Lyon y Caccamise 1981), el Zanate Canadiense (Euphagus carolinus), el Zorzal Robín (Turdus migratorius) y el Zanate de Brewer (Euphagus cyanocephalus) (Garner 1978). Los estorninos muestran una gran flexibilidad para la elección de sitios de dormidero y pueden rápidamente cambiar de sitio según la disponibilidad de estos sitios (Kessel 1957). Este comportamiento explicaría en parte su éxito como especie invasora (Clergeau y Quenot 2007). Antes de posarse en el dormidero realizan vuelos acrobáticos complejos con maniobras sincronizadas entre los individuos de la bandada (Attanasi y col. 2014) como estrategia para evitar predadores (Carere y col. 2009, Hildenbrandt y col. 2010).

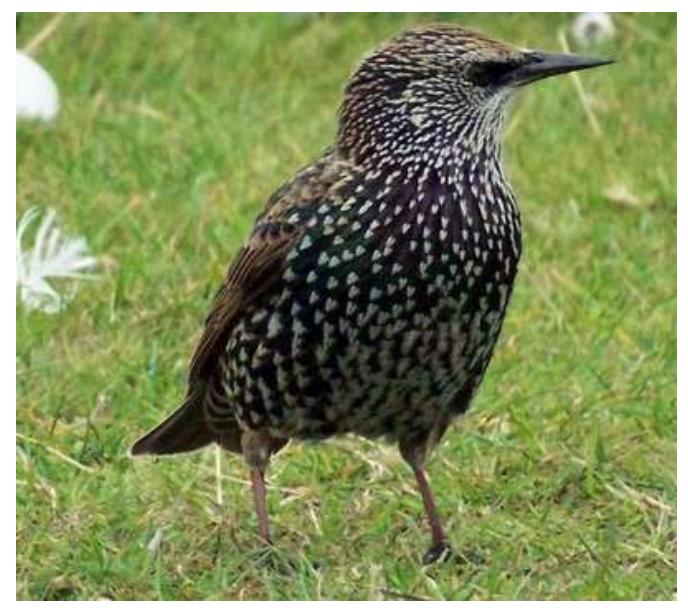

A)

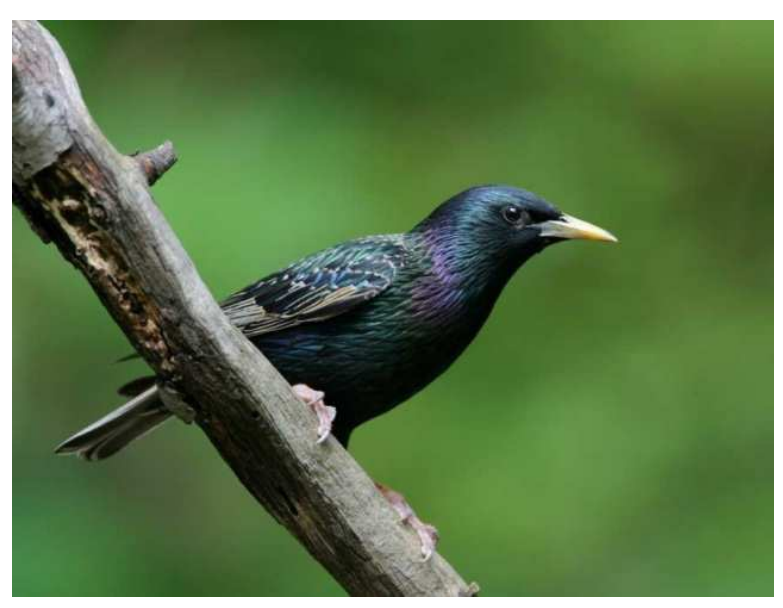

B)

Fig. 2: A) Estornino Pinto con plumaje invernal B) Estornino Pinto con plumaje reproductivo.

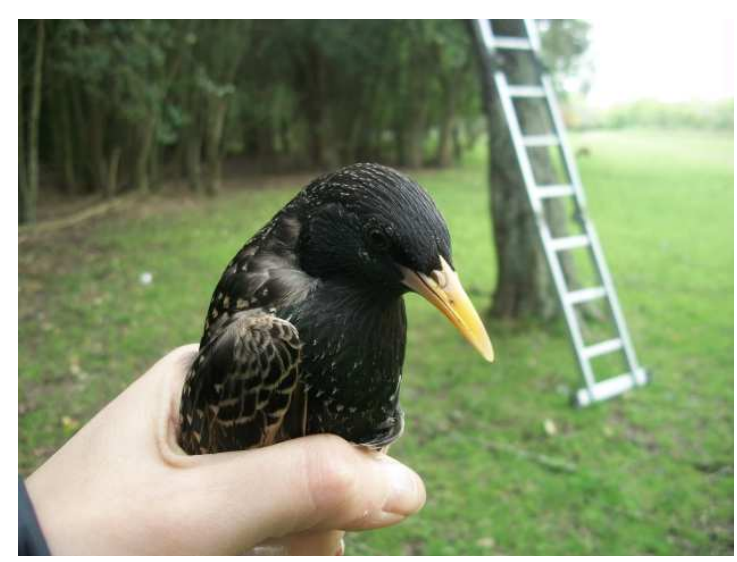

A)

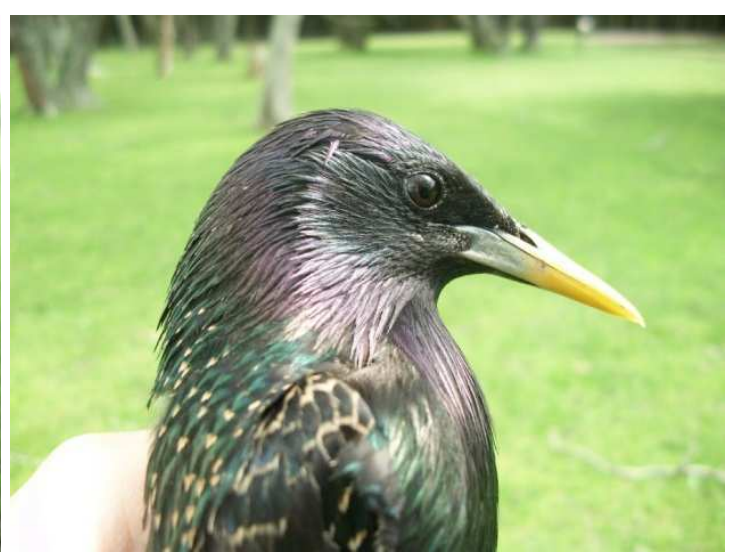

B)

Fig. 3: A) Estornino Pinto hembra, B) Estornino Pinto macho. 


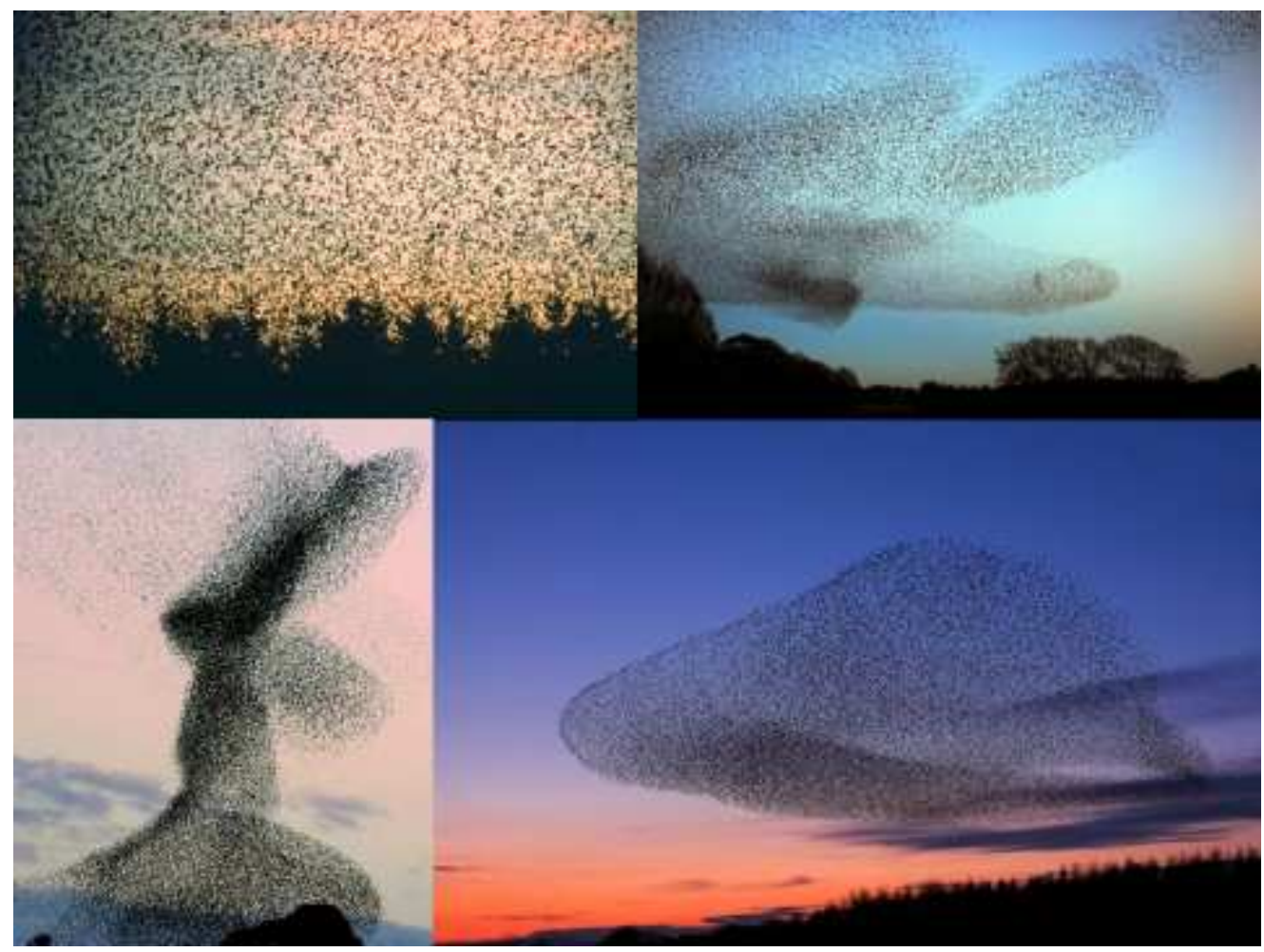

Fig. 4: Bandadas de estorninos en Norteamérica.

\section{Distribución del Estornino Pinto a nivel mundial}

El Estornino Pinto es nativo de Europa, oeste de Asia y Norte de África (Feare 1984). Fue introducido numerosas veces en distintas partes del mundo y algunas introducciones fracasaron, como es el caso de Venezuela y Rusia (Long 1981). En Nueva Zelanda fue introducido en 1862 y en 1875 ya se registraban bandadas de cientos de miles de individuos (Wood 1924). En Jamaica en una ocasión intentaron introducirlo sin éxito hasta que en un segundo intento la especie logró establecerse exitosamente. En Estados Unidos el estornino fue introducido al menos ocho veces antes de lograr establecer una población estable (Sax y Brown 2000). Finalmente en 1890 fueron liberados 80 ejemplares por Eugene Scheifflen, un admirador de Shakespeare, que quiso liberar en Nueva York a todas las especies de aves mencionadas en los libros de su autor preferido (Feare 1984). Al año siguiente, fueron liberados otros 40 ejemplares (Wood 1924) y a partir de ese momento el estornino se expandió por toda Norteamérica. Hacia el año 1952 ya era una especie con poblaciones estables en el sur de Canadá, el noreste de México y en la totalidad de Estados Unidos, con excepción del estado de Florida (Kessel 1953). Actualmente es el ave más abundante y con mayor distribución en Norteamérica (Duncan y col. 2003). En el continente americano también se registra en las Islas Bahamas, la península Yucatán, Puerto Rico, Jamaica y Cuba, 
se cree que estas poblaciones se expandieron a partir del núcleo original liberado en Estados Unidos (Linz 2007). Actualmente el Estornino Pinto presenta la mayor distribución mundial de todas las especies del género, con numerosas subespecies (Craig y Feare 1984) (Fig. 5).

A pesar de ser una de las aves más abundantes del mundo y considerarse plaga en muchos países, en Inglaterra, Finlandia y algunas áreas del norte de Europa sus poblaciones se encuentran en decrecimiento. Las causas principales se encontrarían en las modificaciones en los ambientes rurales y en la disminución en la ganadería (Gregory y col. 2002, Robinson y col 2005, Robinson y col 2006). Con la intensificación y especialización de la agricultura ocurre una disminución en la cantidad de invertebrados que viven en el suelo, por lo tanto los estorninos adultos deben trasladarse mayores distancias para obtener alimento para los pichones, disminuyendo la frecuencia de alimentación y en consecuencia el éxito reproductivo (Solonen y col. 1991, Bruun y Smith 2003).

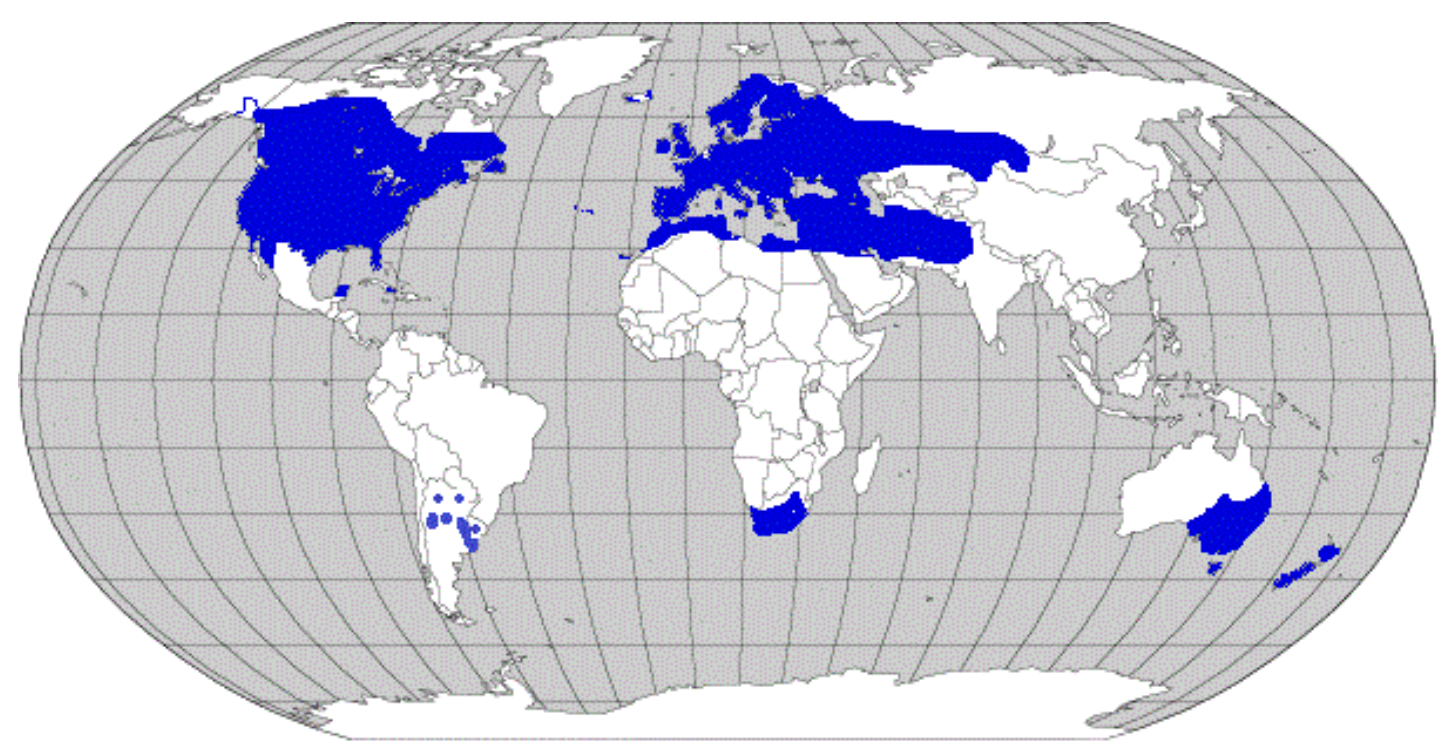

Fig. 5: Distribución mundial actual del Estornino Pinto.

\section{Distribución del Estornino Pinto en la Argentina}

Los primeros registros del Estornino Pinto en la Argentina se realizaron en la zona de Punta Lara en 1983 (Navas 2002). Cuatro años después se observaron tres estorninos en el Rosedal, en el barrio de Palermo, en la Ciudad Autónoma de Buenos Aires (Pérez 1988) y en octubre del siguiente año, Schmidtutz y Agulián (1988) realizaron el primer registro de nidificación de la especie en ese barrio de la Ciudad de Buenos Aires. Desde ese momento, en 
numerosas ocasiones se ha vuelto a registrar la presencia de estorninos solos o en grupos, alimentándose o transportando alimento hacia alguna cavidad (Di Giacomo y col. 1993, Rebolo Ifrán y Fiorini 2010). Durante las primeras observaciones se contabilizaban pocos ejemplares (Di Giácomo y col. 1993) pero en el año 2003 ya se observaban grupos de hasta 950 individuos (Peris y col. 2005). Un estudio realizado en el año 2008 estimó un tamaño poblacional de 4600 individuos en las plazas y parques de la Ciudad Autónoma de Buenos Aires (Rebolo Ifrán y Fiorini 2010). Actualmente se observan numerosas bandadas de cientos y hasta mil ejemplares en la Ciudad Autónoma de Buenos Aires, en la ciudad de La Plata, y en el Gran Buenos Aires (localidad de Pereyra, obs. personal). Peris y col. (2005) observaron ejemplares en el río San Javier (Santa Fé), en Cerrito y Villa Urquiza (Entre Ríos) y en Mar del Plata (Buenos Aires), 400-475 km. al norte y $375 \mathrm{~km}$. al sur del sitio donde se registraron por primera vez. Posteriormente Jensen (2008) obtuvo cinco nuevos registros en el sudeste de Entre Ríos (Peris y col. 2005). Según Jensen y col (2008) las poblaciones de las provincias de Santa Fé, Entre Ríos y SE de la provincia de Buenos Aires tuvieron un origen diferente a las del NE bonaerense. Estas podrían provenir de otras liberaciones (Navas 2002).

En los últimos años aumentaron notablemente los registros de estorninos en distintas provincias argentinas. A partir de 2008 se comenzaron a observar estorninos en la provincia de Córdoba, donde se lo registró nidificando (Klavins y Álvarez 2012). En Resistencia, Chaco se observó un individuo con plumaje nupcial pero no pudo comprobarse si estaba nidificando (Grilli y col. 2011). En Tucumán se observaron ejemplares en distintas localidades, a partir de que 18 estorninos se escaparan de una incautación (Ortiz y col. 2013).

En Guaymallén, Mendoza, Zanotti (2013) observó estorninos en reiteradas ocasiones en aparente actividad reproductiva. En una ocasión se encontraban en un área suburbana con olivares y viñedos. En San Carlos, San Juan, se encontró un nido de estornino en una zona de viñedos y frutales (Lucero 2013). Hasta el año 2008 en Sudamérica el Estornino Pinto sólo había sido registrado en Argentina. En 2008 se lo empezó a observar en Uruguay y en 2010 se obtuvo el primer registro de estorninos nidificando en ese país (Mazzulla 2013). 


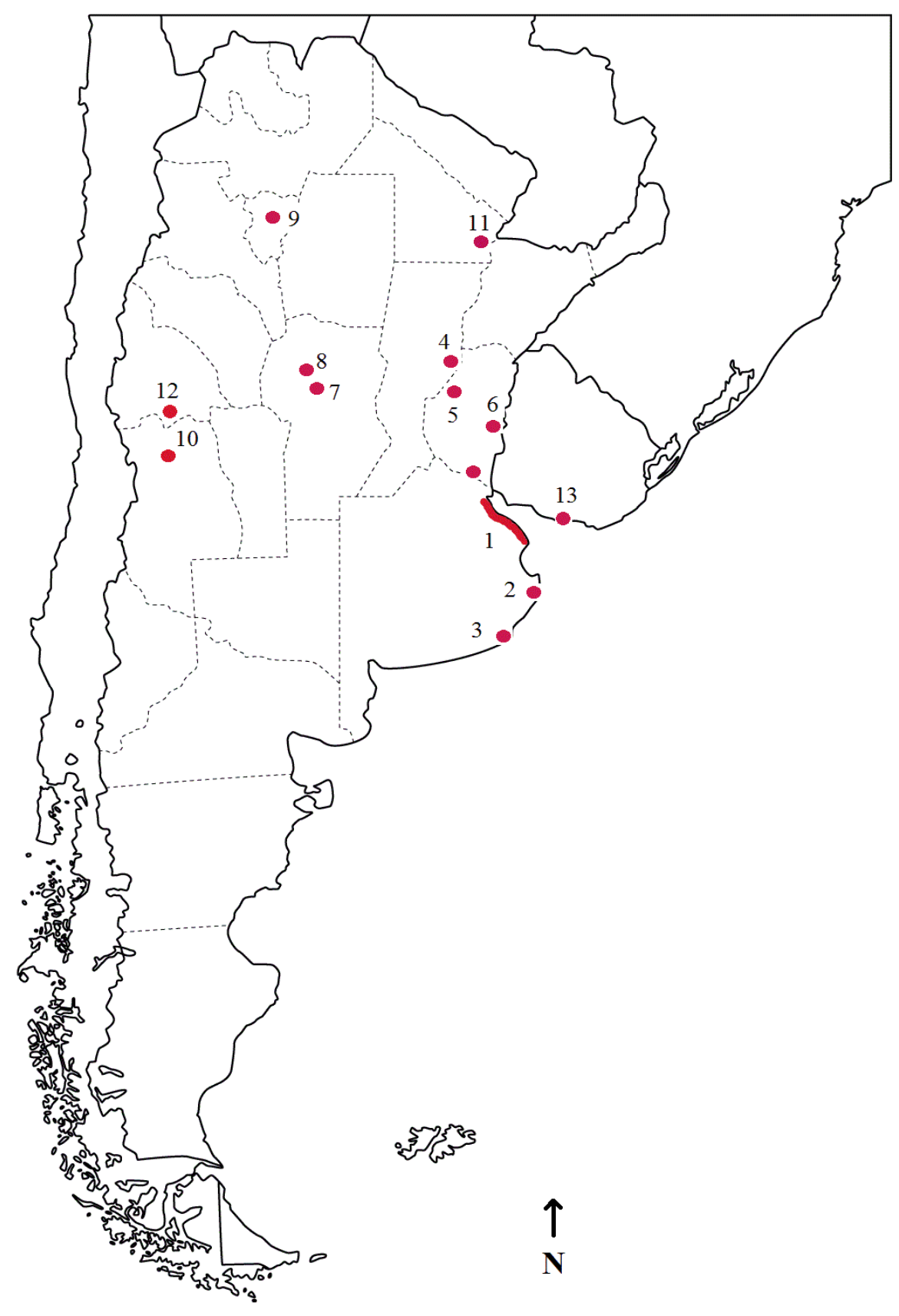

Fig. 6: Distribución del Estornino Pinto en Argentina y Uruguay. Los puntos rojos indican las localidades donde fue registrada la especie. 1) Ciudad Autónoma de Buenos Aires, La Plata y alrededores, 2) Mar de Ajó, 3) Mar del Plata, 4) San Javier, Santa Fé 5) Cerrito, Entre Ríos, 6) Sudeste de Entre Ríos, 7) Córdoba capital 8) La cumbre, Córdoba, 9) Tucumán, 10) Guaymallén, Mendoza, 11) Chaco, 12) San Juan y 13) Montevideo, Uruguay. 


\section{Impacto de la invasión del Estornino Pinto}

\section{Daños económicos}

Estudios realizados en Estados Unidos, hallaron que finalizada la época reproductiva los estorninos se reúnen en inmensas bandadas e incorporan en mayor medida a su alimentación ítems vegetales como frutas, semillas y brotes. Entre los frutos cultivados que más consumen en ese país se encuentran uvas, duraznos, arándanos, frutillas, higos, manzanas y cerezas. Para obtenerlos suelen atacar campos de cultivos. También se alimentan de maíz maduro y arrancan brotes de trigo dañando las plantaciones (Wood 1924, Lindsey 1939, Johnson y Glahn 1994, Tracey y Saunders 2003, Conover y Dolbeer 2007). Los juveniles consumen más frutos que los adultos debido a su dificultad para localizar y extraer insectos del suelo, por este motivo son los que generan los mayores daños a los cultivos y en consecuencia, las mayores pérdidas económicas (Feare 1984, Tracey y Saunders 2003).

Las pérdidas en cultivos de cereales suelen ser más localizadas y generalmente ocurren cerca de dormideros cuando los estorninos regresan al atardecer (Feare y Douville de Fransseau 1992). En Estados Unidos se observan importantes pérdidas en los campos de trigo y a pesar de que varias especies de aves se observan habitualmente en estos campos, Stickley y col. (1976) comprobaron que las pérdidas son causadas principalmente al consumo de brotes de trigo por parte de los estorninos. Dolbeer y col. (1998) obtuvieron resultados similares cuando analizaron el daño producido por bandadas mixtas de aves y observaron que a pesar de que los estorninos formaban el $9 \%$ de las bandadas, eran las aves que mayor daño causaban a los cultivos de trigo. Bergman y col. (2000) estimaron que entre 1990 y 1997 los estorninos causaron pérdidas de USD 13.500.000 en Estados Unidos principalmente por daños a la agricultura, siendo el ave más dañina entre 25 aves que provocan pérdidas económicas en ese país. Posteriormente Pimentel y col. (2005) estimaron que las pérdidas anuales por daño a la agricultura causados por estorninos son de aproximadamente USU 800.000.000. En estas cifras no están incorporados los gastos para la prevención de daños.

Otro lugar donde suelen alimentarse los estorninos es en feedlots (corrales de engorde de ganado), donde encuentran fácilmente disponibles grandes cantidades de alimento proteico (Hardy 1990). Dolbeer y col. (1978) observaron que la presencia de estas aves en los feedlots Estados Unidos aumentaba al avanzar el invierno y que el problema no era solo el consumo del alimento para el ganado, sino también la contaminación por excrementos de las aves. Además de la amplia diversidad de alimentos que consume, el estornino es una especie altamente adaptable por su capacidad de cambiar sus áreas de invernada y de modificar su 
comportamiento dentro de estas áreas en respuesta a cambios en la disponibilidad de alimento (Feare y Douville de Fransseau 1992).

\section{Competencia con aves nativas}

El hombre no es el único perjudicado por la invasión del estornino, otro de los principales problemas es la competencia con otras aves por cavidades para nidificar, principalmente con especies de la familia Picidae (pájaros carpinteros). Esto ha sido registrado por varios autores (Wood 1924, Troeschler 1976, Peterson y Gauthier 1985, Weitzel 1988, Ingold 1989, 1994, 1996, Mazgajski 2003, Rebolo Ifrán y Fiorini 2010). Debido a la competencia con estorninos algunas de estas especies podrían haber sido desplazadas de sus áreas de reproducción (Weitzel 1988), otras podrían retrasar el comienzo de la nidificación, lo cual podría ocasionar una disminución en su éxito reproductivo (Mazgajski 2003), y otras podrían haber modificado el tipo de cavidades utilizadas para nidificar (Peterson y Gauthier 1985).

\section{Problemas sanitarios ocasionados por el estornino}

En cuanto a los problemas sanitarios en sus áreas de distribución natural el estornino ha sido asociado a numerosas enfermedades que pueden afectar a los humanos y al ganado así como a otras especies de aves. Entre ellas se incluyen las enfermedades bacteriales salmonelosis aviar (Salmonella typhimurium y S. gallinarum), clamidiosis (Chlamydophila psittaci), gastroenteritis del cerdo (Pestivirus sp.), paratuberculosis o enfermedad de Johne (Mycobacterium avium), tuberculosis bovina (Mycobacterium bovis), Scherichia coli, cólera aviar (Pasteurella multocida), las enfermedades fúngicas blastomicosis, histoplasmosis (Histoplasma capsulatum), los hongos queratinofilicos Chrysosporium sp., Scopulariopsis brevicaulis y Trichophyton terrestre, las enfermedades protozoarias toxoplasmosis (Toxoplasma gondii) y coccidiosis (Isospora sp.) y enfermedades virales como la enfermedad de Newcastle (paramixovirus) y el virus del Oeste del Nilo (flavivirus) (Camin y col. 1998, Clark y McClean 2003, Linz y col. 2007). Varias de estas enfermedades, como la enfermedad de Johne, la gastroenteritis del cerdo, la bacteria Scherichia coli y el hongo Histoplasma capsulatum han sido registradas en estorninos en Norteamérica. La presencia de estorninos en las ciudades y las grandes cantidades de heces que se acumulan bajo los dormideros podrían favorecer la transmisión de algunas de estas enfermedades al hombre (Camin y col. 1998). Además, el alimentarse frecuentemente en feedlots favorece la transmisión de enfermedades al ganado a la vez que pueden trasladar patógenos de un feedlot a otro, como se observa en Estados Unidos (LeJeune y col. 2008, Carlson y col. 2011), mientras que su hábito de formar 
grupos heteroespecíficos para alimentarse facilitaría la transmisión de patógenos a otras especies de aves (Sommer 1937).

La presencia de enormes bandadas de estorninos y otras especies de aves en los aeropuertos de Estados Unidos, ha sido la causa de importantes accidentes aéreos (Barras y col. 2003). La colisión de estas aves con aviones al momento del despegue o aterrizaje puede generar daños a los aviones y causar accidentes que en los peores casos ha ocasionado la pérdida de vidas humanas (Linz y col 2007) En Estados Unidos deben invertirse cifras millonarias en reparación de máquinas y logística para el control de las aves. Entre 1990 y 2001 se registraron 852 colisiones en 46 estados (Barras y col. 2003).

Alrededor del mundo se utilizan técnicas variadas para prevenir los daños causados por estorninos. Entre ellas se encuentran técnicas no letales, por ejemplo el ahuyentamiento mediante el uso de pirotecnia o ultrasonidos, pero estas técnicas suelen ser temporales. También se utilizan repelentes químicos, protección física de la zona atacada, captura y matanza de estorninos (Johson y Glahn 1994, Dolbeer y col. 1995, Linz y col. 2007).

En base a estos antecedentes y debido a la expansión y crecimiento poblacional del estornino a partir de su introducción en Argentina, en el año 1998, la Secretaría de Recursos Naturales y Desarrollo Sustentable, dependiente del Ministerio de Desarrollo Social y Medio Ambiente dictó la Resolución 974/98: "Declarase como dañinas y perjudiciales para las actividades productivas a las especies de aves, Estornino Pinto y Crestado".

\section{OBJETIVOS GENERALES}

Estudiar la invasión del Estornino Pinto en el Noreste de la provincia de Buenos Aires, analizando su biología reproductiva, la competencia con aves nativas y los parásitos que presentan.

\section{OBJETIVOS PARTICULARES}

a) Determinar si existe competencia por las cavidades para nidificar entre el Estornino Pinto y las aves nativas.

b) Analizar los materiales que el estornino utiliza para construir sus nidos.

c) Estudiar la biología reproductiva del Estornino Pinto en el NE de la provincia de Buenos Aires.

d) Analizar el impacto del parasitismo por larvas de moscas parásitas Philornis sp. en el éxito reproductivo y en el crecimiento de los pichones del Estornino Pinto. 
e) Analizar la alimentación del Estornino Pinto.

f) Identificar las especies de endo y ectoparásitos del Estornino Pinto en Argentina.

\section{Área de estudio}

El estudio se realizó en el Parque Provincial Reserva Forestal Pereyra Iraola (3450’ S, $\left.58^{\circ} 05^{\prime} \mathrm{O}\right)$, Berazategui, provincia de Buenos Aires, Argentina y fue declarada Reserva de la biosfera por la UNESCO (http://www.ambiente.gov.ar/?IdArticulo=1492). Constituye un pulmón verde de 10.248 hectáreas que incluye bosques de especies autóctonas y exóticas y casi 1.800 hectáreas de pajonales inundables. Se encuentran más de 120 especies de árboles principalmente exóticas. Entre estas se destacan los eucaliptos (Eucaliptus sp.), Acacia Negra (Gleditzia triacanthos), pinos (Pinus sp.), cipreses (Cupressus sp.), Falsa Acacia (Robinia pseudoacacia), araucarias (Araucaria sp.), Tipa (Tipuana tipu), Almez (Celtis occidentalis), fresnos (Fraxinus sp.), Ligustro (Ligustrum lucidum) y Morera Negra (Morus nigra). En menor proporción se encuentran especies nativas como Tala, (Celtis ehrenbergiana), Espinillo (Acacia caven), Ceibo (Erytrina crista-galli) y Sauce Criollo (Salix humboldtiana) (Ministerio de Asuntos Agrarios 2007). El área núcleo constituye un Área de Importancia para la Conservación de las Aves (sitio AICA) en la Argentina (http://www.avesargentinas.org.ar/cs/conservacion/aicas/home.html) y dista $40 \mathrm{Km}$. de la Ciudad de Buenos Aires y $20 \mathrm{Km}$. de La Plata (Fig. 7). El clima de la región es templado húmedo, con temperaturas medias de $23{ }^{\circ} \mathrm{C}$ en el mes más cálido y de $9{ }^{\circ} \mathrm{C}$ en el más frío. El promedio de la precipitación anual es de $900 \mathrm{~mm}$ (Ministerio de Asuntos Agrarios 2007).

El estonino pinto es una especie bien establecida en esta zona (obs. pers.) y forma parte de la gran variedad de avifauna presente en el área (Moschione y Barrios 1995). 


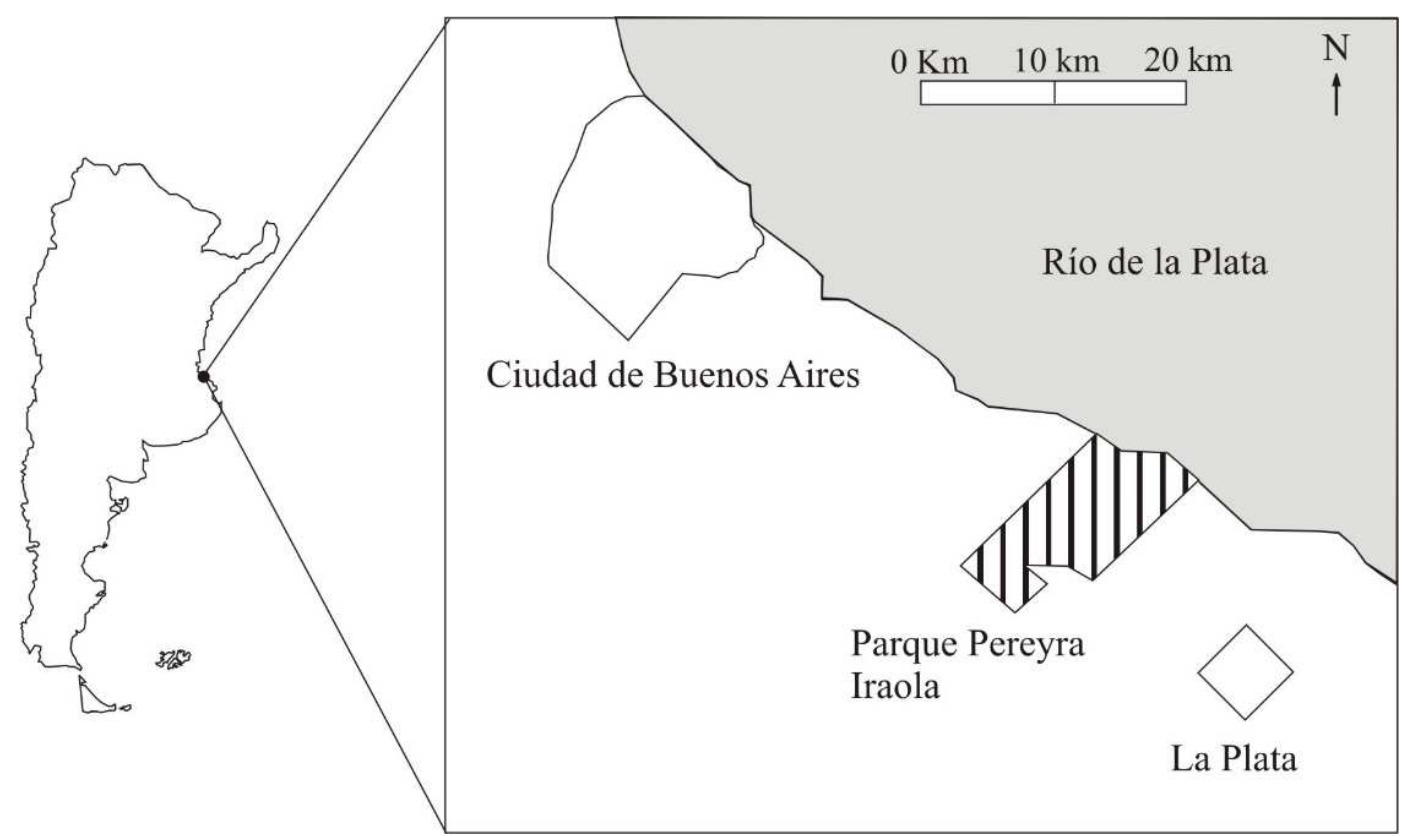

Fig. 7: Ubicación del parque Pereyra Iraola.

El estudio se realizó en tres sectores del parque Pereyra Iraola, uno es la Estación de Cría de Animales Silvestres (E.C.A.S.) que se encuentra emplazada sobre 230 hectáreas y alberga animales autóctonos y exóticos asilvestrados. Consta de distintos ambientes, como bosques, talares, zonas parquizadas y lagunas. El segundo sector fue la Estación Biológica de Aves Silvestres (E.B.A.S.). La E.B.A.S. se encuentra emplazado sobre 11 hectáreas parquizadas, donde funciona un centro de cría de aves rapaces y contiene 5 jaulones al aire libre con diversas especies de Falconiformes y Strigiformes. El tercer sector analizado fueron 110 hectáreas en la zona circundante al antiguo Casco de la Estancia Santa Rosa (C.E.S.R.) donde actualmente se encuentran oficinas del Ministerio de Asuntos Agrarios. Es una zona con tránsito humano moderado, además de recibir una abundante afluencia de gente durante los fines de semana y días feriados (Fig. 8). 


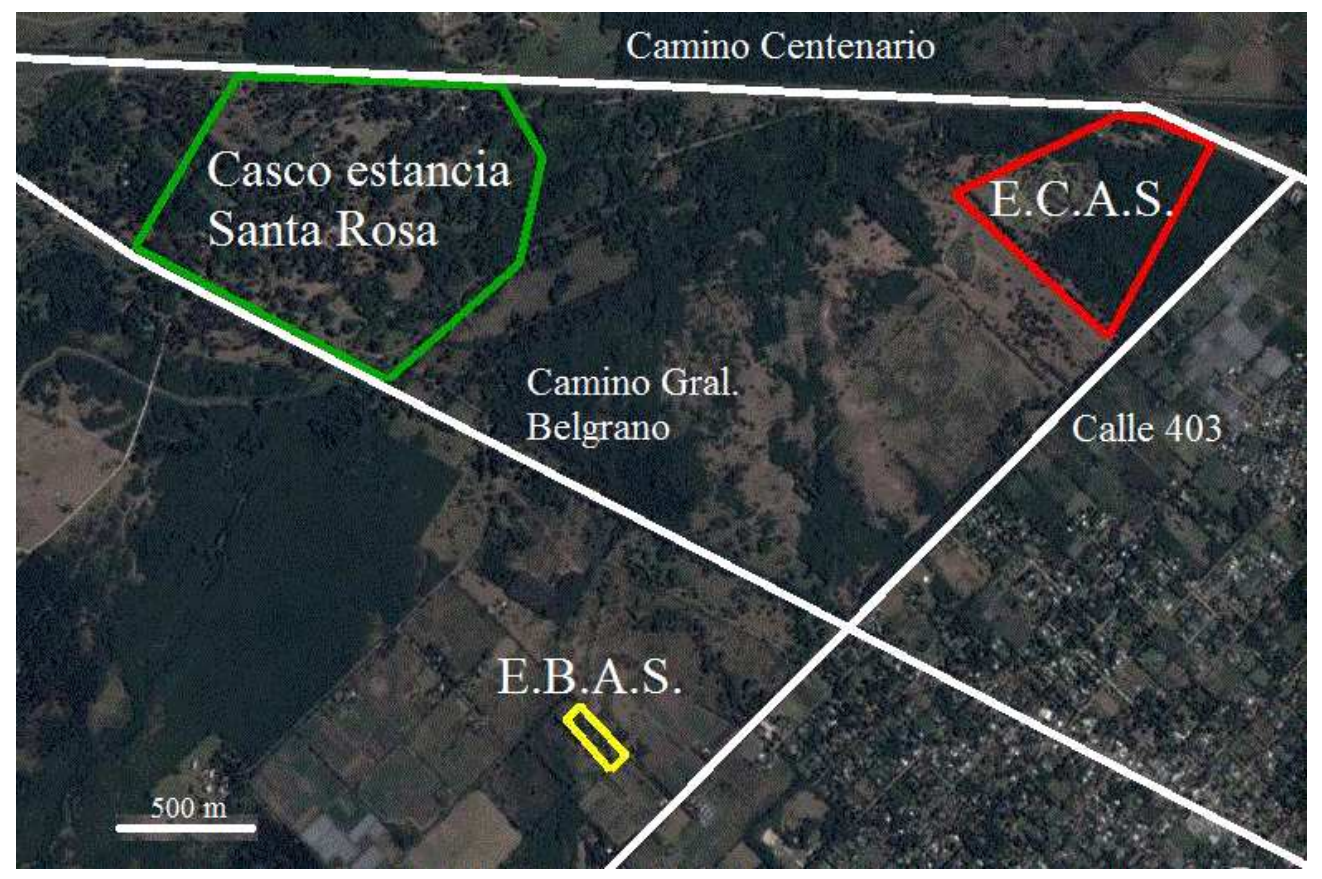

Fig. 8: Sectores del parque Pereyra Iraola donde se realizó el estudio. E.C.A.S.: Estación de Cría de Animales Silvestres, E.B.A.S.: Estación Biológica de Aves Silvestres. 


\section{CAPÍTULO 2: NIDIFICACIÓN DEL ESTORNINOPINTO}

\section{INTRODUCCIÓN}

Las características de la nidificación de las distintas especies de aves se encuentran determinadas por presiones de selección como la presencia de predadores, las inclemencias climáticas y la atracción de la pareja (Mainwaring y col. 2014). Dentro de los distintos taxones se observa una gran variabilidad en la nidificación, tanto en la localización del nido, como en su estructura y composición (Hansell 2010). Conocer estas diferencias nos permite entender parte de la historia de vida de las aves (Martin 1988, Martin y Li 1992). Por ejemplo, el tamaño de la nidada y la supervivencia de los pichones suele ser menor en las especies con nidos que presentan un mayor riesgo de predación, como los ubicados en el suelo o a baja altura y en los nidos abiertos con respecto a los construidos dentro de cavidades (Slagsvold 1982, Martin 1988, Gjerdrum y col. 2005).

Se reconocen tres tipos principales de nidos: los nidos abiertos, los nidos cerrados (con un techo, construidos por las aves) (Collias 1997) y los nidos en cavidades (en árboles, cajasnido, construcciones humanas). A su vez, dentro del grupo de aves que nidifican en cavidades se reconocen principalmente dos tipos, las que construyen sus propias cavidades (nidificadores primarios, ej: carpinteros) y las que utilizan cavidades preexistentes (nidificadores secundarios), las cuales pueden haber sido fabricadas por otras aves o generadas naturalmente por caída de ramas, grietas en la corteza $u$ otros procesos de degradación de los árboles (Aitken y Martin 2007). De acuerdo a esto, las aves que construyen cavidades son componentes clave del ecosistema debido a que proveen de un recurso fundamental a otras especies que requieren de cavidades preexistentes para reproducirse o refugiarse (Martin y col. 2004). Las aves que nidifican en cavidades (tanto las que las construyen como las que no lo hacen) se ven beneficiadas por diversos factores como ser una menor exposición a los predadores y a las inclemencias climáticas (Nice 1957, Best y Stauffer 1980, Peterson y Gauthier 1985, Rendell y Robertson 1989, Collias 1997). Sin embargo, se ven perjudicadas por otros factores como la pérdida de pichones por hipertermia, una mayor abundancia de parásitos en los nidos y la competencia por sitios para nidificar (Nilsson 1986, Collias 1997). A pesar de estas desventajas, el éxito reproductivo es mayor en 
aves que nidifican en cavidades con respecto a las aves que nidifican en nidos abiertos (Nice 1957, Collias 1997). El límite en la disponibilidad de cavidades además de generar competencia intra e interespecífica favorecería un mayor esfuerzo reproductivo por parte de las aves que requieren de este recurso (Martin y Li 1992). La disponibilidad de sitios para nidificar puede limitar la posibilidad de reproducirse de las especies que no construyen sus propias cavidades (Martin y col. 2004, Cornelius y col. 2008). En cambio, los nidificadores primarios tienen la ventaja de poder elegir donde construir su cavidad de acuerdo a las características del árbol y del ambiente (Martin y col. 2004, Ardia y col. 2006).

\section{Características de las cavidades.}

Algunas características de las cavidades como la altura, el volumen interno y el tamaño de la entrada, son variables que determinan el uso de las mismas por parte de las aves (Van Balen y col. 1982, Rendell y Robertson 1989). Por ejemplo, varios autores encontraron que distintas especies de aves eligen para nidificar cavidades ubicadas a mayor altura (Nilsson 1984, Burger y Gochfield 2000, Cornelius 2008), lo cual podría asociarse a que el acceso de los predadores al nido se ve limitado por la altura a la que se encuentra la cavidad (Ludvig y col. 1995, Sockman 1997). Otra característica que limita el acceso de predadores al nido es el tamaño de la entrada de la cavidad y en consecuencia, esta variable se encuentra relacionada a la tasa de predación y al éxito reproductivo (Van Balen 1982, Peterson y Gauthier 1985). El tamaño de la entrada a la cavidad también limita el tamaño del ave que puede ingresar y por este motivo disminuye la competencia entre especies de aves de diferentes tamaños corporales (Peterson y Gauthier 1985, Renton y Brightsmith 2009). También se observó que algunas aves prefieren cavidades en árboles con un diámetro del tronco mayor, reflejando la elección de árboles más fuertes (Burger y Gochfield 2000, Cornelius 2008).

Mazgajski (2003) observó que los estorninos eligen las cavidades más profundas con respecto a otras de menor profundidad y si existe un nido viejo dentro de la cavidad lo extraen total o parcialmente aumentando la profundidad del mismo, y logrando que los huevos y pichones queden menos accesibles a los predadores. La extracción del nido viejo a su vez disminuye la carga parasitaria de ectoparásitos con los que tendrán que convivir los pichones.

Finalmente, la orientación de la entrada a la cavidad puede otorgar beneficios termorregulatorios dependiendo de la exposición al viento y al sol, generando en el nido un microclima que influye en los pichones y sus padres y afecta el éxito reproductivo (Inouye 1981). Sin embargo, la importancia de la orientación depende de las condiciones ambientales (Ardia y col. 2006) y de distintas características de la cavidad como el volumen interno y el tamaño de la entrada (Rendell y Robertson 1994). 


\section{Cavidades que utiliza el Estornino Pinto para nidificar}

El Estornino Pinto utiliza para nidificar cavidades tanto naturales como artificiales. Las cavidades naturales son generadas principalmente por la degradación de troncos en árboles muertos o vivos (Dobkin y col. 1995), o construidas por aves que construyen sus propias cavidades como los carpinteros (Wesolowski 1989, Kerpez y Smith 1990, Ingold 1996, 1998). Las cavidades artificiales pueden ser cualquier oquedad en construcciones humanas o cajasnido, tanto en las ciudades como en el campo (Kessel 1957, Moeed y Dawson 1979, Feare 1984). También se han registrado estorninos excavando cavidades en médanos en la arena (Craig y Feare 2009) nidificando en nidos de Urraca Común (Pica pica), en grietas en acantilados, en madrigueras, bajo piedras en las costas, en grietas en el suelo y en latas y cajas en basurales, pero estos registros son anecdóticos (Kessel 1957). En la Argentina se lo observó nidificando en cavidades en árboles, en nidos de Hornero (Furnarius rufus) (Zamorano y col. 2002, Narosky y Carman 2009, Rebolo Ifrán y Fiorini 2010, Rizzo 2010, Turienzo y Di Iorio 2010,) y en cavidades contruidas por carpinteros (Schmidtutz y Agulián 1988, Di Giácomo y col. 1993, Rebolo Ifrán y Fiorini 2010).

El conocimiento de las características de las cavidades que utiliza el Estornino Pinto para nidificar es de gran importancia para poder estimar qué zonas, por poseer cavidades acordes a las necesidades de esta especie, podrían estar en riesgo de ser invadidas y con qué aves podría estar compitiendo por sitios para nidificar.

\section{Materiales utilizados en la construcción de los nidos}

Además del sustrato del nido, de su ubicación y de las características ambientales del sitio de nidificación, otros factores como la estructura y composición del nido poseen un gran efecto sobre el éxito reproductivo de las aves (Skowron y Kern 1980, Alabrudziñska y col. 2003). Estas características de los nidos son el resultado de distintas presiones de selección, como la protección frente a predadores o el aislamiento de huevos y pichones ante factores climáticos adversos (Hansell 2000, Alabrudziñska y col. 2003).

La estructura del nido presenta características propias en cada especie y puede contener hasta cuatro capas diferentes: la estructural, (que le da forma y firmeza al nido), la exterior o decorativa (se encuentra fuera de la estructural y modifica la apariencia del nido), la de fijación del nido (permite asegurar la posición del nido, no está presente en especies que nidifican en cavidades) y una cuarta capa denominada de revestimiento que se encuentra en contacto con los huevos y pichones y tiene una función específica, por ejemplo, aislamiento térmico (Hansell 2000). 
La composición del nido constituye un buen indicador del uso del hábitat y de los requerimientos de las aves al momento de la reproducción, debido a que cada material tiene una función específica (Hansell 2000, Vera y col. 2009). Por ejemplo, Hilton y col. (2004) demostraron que las plumas son el material que mejor cumple la función de aislante térmico mientras que el pasto es el material con menor eficacia para esta función. Por su parte Winkler (1993) observó que en nidos de Golondrina bicolor (Tachycineta bicolor) en los cuales se extrajeron las plumas, la tasa de crecimiento de los pichones era menor y presentaban infestaciones más altas de ácaros y piojos que los pichones en nidos donde había plumas. Otro material que diversas especies de aves (entre ellas el Estornino Pinto) suelen agregar a los nidos es el material vegetal verde, principalmente hojas. Entre sus posibles funciones se especula que las mismas podrían evitar la proliferación de ectoparásitos (Wimberger 1984, Clark y Mason 1985, Clark y Mason 1988), poseer efecto bactericida (Mennerat y col. 2009a), ser indicadoras de la calidad del macho o atraer a la pareja (Brouwer y Komdeur 2004). Se han encontrado efectos beneficiosos de los compuestos volátiles presentes en las plantas verdes sobre los pichones al estimular elementos del sistema inmunológico como linfocitos y basófilos, además de aumentar los niveles de hematocrito (Gwinner y col. 2000, Mennerat y col. 2009b) y de hemoglobina en sangre (Clark y Mason 1988). También se observó un efecto positivo sobre la masa corporal y el crecimiento de los pichones en los nidos en los que utilizaron plantas verdes (Gwinner y col. 2000, Mennerat y col. 2009b). En cuanto al estornino, varios autores demostraron que los machos agregan plantas al nido para atraer a la pareja, (Fauth y col. 1991, Gwinner 1997, Brouwer y Komdeur 2004).

Otro categoría, dentro del material verde utilizado frecuentemente en la construcción de los nidos, son los líquenes (De la Peña 1995, Hansell 1996, 2000, 2007, Chatellenaz y Ferraro 2005). Se han planteado algunas posibles funciones de los líquenes en los nidos. Una de ellas es la función críptica que se obtiene cuando las aves utilizan los líquenes para recubrir parcial o totalmente el nido (Chatellenaz y Ferraro 2000, Hansell 2000). De esta forma el nido pasa desapercibido en su entorno al ser observado contra la vegetación (Perrins 1979). Además, la capacidad de reflejar la luz de los líquenes podría actuar como un camuflaje disruptivo que dificulte el reconocimiento del nido por predadores al verlos desde una posición inferior (Hansell 1996). Por último, la utilización de líquenes en la zona de unión del nido a la rama permitiría que este pase desapercibido al percibirse como una prolongación de la rama y no como un elemento adicional (Hansell 1996). Otra posible función de los líquenes sería la de actuar como reguladores de la temperatura al reflejar la radiación y previniendo que el agua entre al nido (Hansell 2000). 
Una función que fue estudiada en relación al uso de plantas verdes por parte de los estorninos es la de atracción de la pareja (Brouwer y Komdeur 2004). Los líquenes forman parte del material verde que agregan los estorninos al nido (Kessel 1957, Feare 1984) por lo tanto también podrían tener una función relacionada a la atracción de la pareja por parte de los machos, pero esta posible función de los líquenes no fue estudiada en estorninos.

Por otro lado, se estima que el $50 \%$ de los líquenes que han sido estudiados, sintetizan sustancias con algún grado de actividad antimicrobiana (Dayan y Romagni 2001). Se reconocen más de 350 compuestos secundarios en los líquenes que son producidos por el hongo y secretados a la superficie de la hifa donde se depositan en forma de cristales (Tay y col. 2004). Varios de estos compuestos, entre ellos el ácido úsnico, que ha sido uno de los más estudiados, poseen capacidad antifúngica, herbicida, antibacteriana, antiviral, antiprotozoaria, antimicótica (Dayan y Romagni 2001, Cocchietto y col. 2002,), antiparasitaria (Jiménez-Cardoso y col. 2006, Fritis y col. 2013) e insecticida (Dayan y Romagni 2001, Cetin y col. 2008, 2012, Uysal y col. 2009, Vinayaka y col. 2009, Yildirim y col. 2012a, 2012b). En estudios realizados en laboratorio se han encontrado efectos letales del ácido úsnico en larvas de distintas especies de dípteros (Cetin y col. 2008, 2012, Vinayaka y col. 2009). En base a estos resultados Cetin y col. (2008) sugieren que debería investigarse el uso de compuestos de líquenes para ser utilizados como insecticidas. Sería esperable que los líquenes en los nidos de las aves posean alguna función contra larvas de dípteros, pero hasta el momento no hay estudios donde se investigue esta función.

\section{OBJETIVOS DEL CAPÍTULO}

a) Describir las características de las cavidades naturales que utiliza el Estornino Pinto para nidificar en el parque Pereyra Iraola.

b) Analizar la utilización de cajas-nido con respecto a distintas características de su ubicación.

c) Determinar el material que utiliza el estornino para construir sus nidos.

d) Determinar las especies de líquenes que el Estornino Pinto utiliza en la construcción del nido y analizar si su presencia se correlaciona con una menor cantidad de larvas de mosca del género Philornis, uno de los ectoparásitos más frecuentes en los nidos de estornino. 


\section{MATERIALES Y MÉTODOS}

Durante las temporadas reproductivas 2010 y 2011 se recorrió la zona circundante al antiguo casco de la estancia Santa Rosa en búsqueda de nidos de estorninos. Además se buscaron nidos en la ECAS durante las temporadas reproductivas 2010, 2011, 2012 y 2013. Los nidos se localizaron por observación directa de aves saliendo de una cavidad o mediante el seguimiento de parejas.

Una cavidad se consideró nido activo si se escuchaban llamadas de pedido de alimento de los pichones, si se veían pichones asomándose en la entrada o si el comportamiento de los adultos indicaba anidación (adulto entrando reiteradamente a la cavidad transportando alimento en el pico) (Cockle y col. 2011).

Para los nombres comunes y científicos de las aves de Argentina en todos los capítulos se siguió a Navas y col. (1991) y para los de las especies de otras partes del mundo se siguió a del Hoyo (2009).

\section{Características de las cavidades utilizadas para nidificar}

Se determinó si la cavidad fue construida por carpinteros (simétrica, circular o levemente ovalada) o por degradación natural (bordes irregulares o con evidencia de la rotura de una rama).

Se registraron las características de las cavidades y de los árboles que utilizaron los estorninos para nidificar a través de las siguientes variables: especie vegetal donde se encuentra la cavidad, altura del árbol, diámetro a la altura del pecho (DAP), ancho de la copa y altura y orientación de la cavidad.

La altura del árbol se obtuvo a partir de la siguiente ecuación: $\mathrm{H}=\mathrm{h}+\mathrm{Ca}$.Tan $\alpha$, donde $\mathrm{Ca}$ es la distancia en metros entre el árbol y el observador, obtenida con una cinta métrica, $\mathrm{h}$ es la altura desde el suelo hasta los ojos del observador y $\alpha$ es el ángulo formado entre el extremo superior del árbol y el eje horizontal a la altura de los ojos del observador, obtenido con un clinómetro. Para medir la altura de las cavidades se utilizó el mismo método pero tomando como ángulo $\alpha$ al formado entre la entrada a la cavidad y el eje horizontal a la altura de los ojos del observador (Fig. 2.1.).

El DAP se obtuvo tomando el perímetro del árbol con una cinta métrica y obteniendo el radio mediante la ecuación $\mathrm{p}=2 \Pi . \mathrm{r}$

El ancho de la copa se midió con una cinta métrica extrapolando los extremos al nivel del suelo. Las orientaciones de las entradas a las cavidades se midieron con una brújula. 
Para determinar si las orientaciones de las cavidades se distribuyeron uniformemente o si las aves utilizaron preferentemente cavidades con una orientación en particular se realizó un test de Rao (Rao 1976) que permitió corroborar la uniformidad de datos circulares.

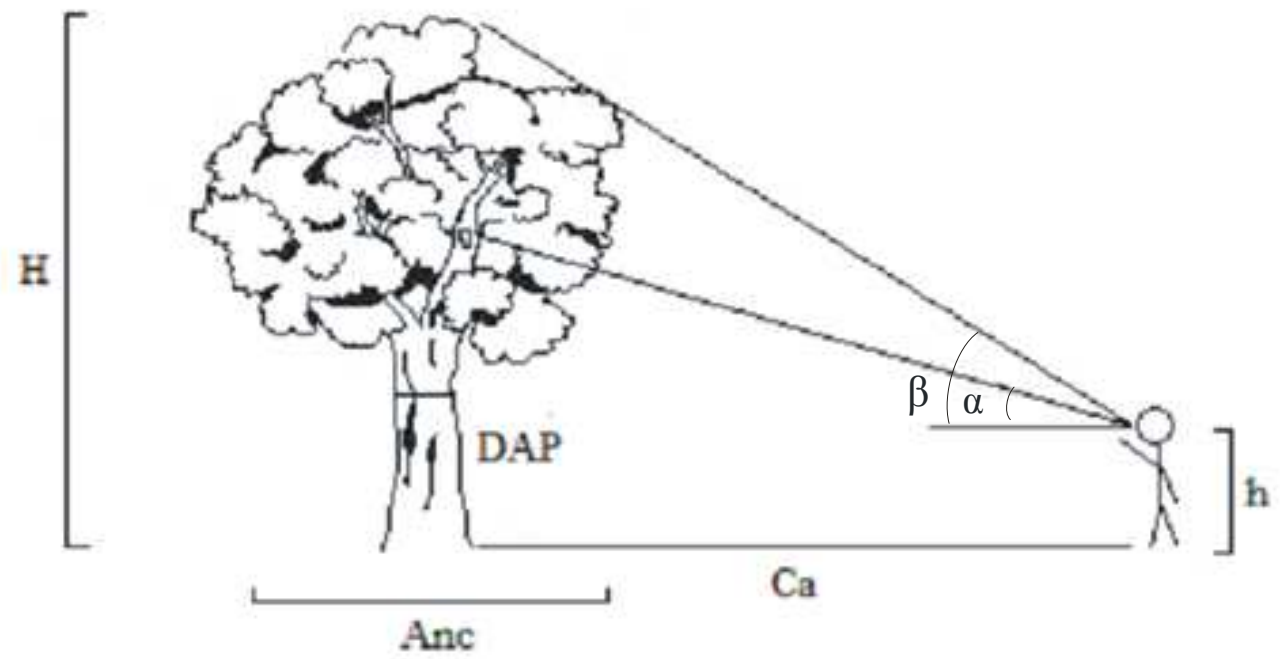

Fig. 2.1.: Medidas registradas de los árboles donde se encontraron cavidades con nidos activos. H: altura del árbol, h: altura desde el suelo hasta los ojos del observador, Ca: distancia del observador a la base del árbol, Anc: ancho de la copa, DAP: diámetro a la altura del pecho.

\section{Utilización de cajas-nido}

Las cajas-nido fueron colocadas en los árboles a una altura de entre 2 y 3,6 metros sobre el suelo. Fueron construidas con madera de pino y presentan una tapa móvil para facilitar la observación del nido y la extracción de huevos, pichones y nidos. En la Fig. 2.2. se observa el diseño de las cajas-nido con sus medidas.

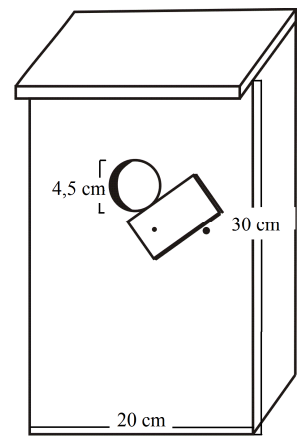

Fig. 2.2: medidas de las cajas-nido utilizadas para el estudio de reproducción del estornino en el parque Pereyra Iraola, Provincia de Buenos Aires. 
En julio de 2010 se colocaron 30 cajas-nido en la ECAS y 12 en la EBAS. Las cajas fueron colocadas sobre árboles con excepción de una en la EBAS que se colocó en un poste de luz y otra en la ECAS que se colocó sobre un alambrado. Al finalizar la temporada reproductiva 2010, debido a que las cajas del EBAS tuvieron una tasa muy baja de ocupación, fueron trasladadas al ECAS.

Además en el año 2011 se colocaron ocho cajas-nido nuevas, sumando un total de 50 cajas-nido.

En las temporadas reproductivas 2010 y 2011 se determinaron las siguientes variables relacionadas con la ubicación de las cajas-nido: especie vegetal donde se colocó la caja, altura, DAP y ancho de la copa del árbol, distancia a la caja-nido más cercana y orientación de la entrada de la caja-nido. Se utilizaron los mismos métodos empleados para la medición de las variables de las cavidades naturales.

Para determinar si existieron diferencias en las características de la ubicación de las cajas-nido que determinen su utilización por parte de los estorninos se realizó una regresión logística utilizando como variable dependiente dicotómica la utilización de la caja-nido (si se concretó la construcción de un nido o si no fue utilizada) y como variables regresoras la altura de la caja-nido, la distancia a la caja-nido más cercana, el ancho de la copa, el DAP y la altura del árbol donde se colocó la caja-nido. En este análisis no se consideraron las cajas-nido colocadas en la EBAS para eliminar el error debido al efecto por variaciones en el ambiente.

\section{Materiales utilizados por el estornino en la construcción de los nidos}

Al final de las temporadas reproductivas 2010 y 2011 se extrajeron 54 nidos de las cajasnido, con el fin de analizar la composición del material utilizado por los estorninos para la construcción de los nidos. Se obtuvo el peso de cada nido con una balanza (precisión: 1g) y se tomaron las siguientes medidas: largo, ancho, alto. Con estos datos se obtuvo el volumen de cada nido calculado como el volumen de un elipsoide según la ecuación:

Volumen nido $=\mathrm{a} \cdot \mathrm{b} \cdot \mathrm{c} \cdot 4 / 3 \mathrm{pi}$

Siendo a, b y c las longitudes de los semiejes de los elipsoides.

El material que conformaba los nidos se separó en los distintos ítems. Se obtuvo el peso y el volumen de cada grupo y se calculó el porcentaje de volumen ocupado por cada material en el nido. Se realizó un Análisis de Componentes Principales (ACP) para evaluar cuáles fueron los materiales del nido que influyeron en mayor medida en la varianza de la composición de los nidos. Para este análisis se utilizaron los datos de los materiales que ocuparon en el nido un porcentaje del volumen mayor al 5\%. 


\section{Utilización de líquenes en los nidos}

En la temporada reproductiva 2013 cada vez que se encontró un liquen en el nido durante la revisión de las cajas-nido se recolectó una porción para ser determinado específicamente y analizar la presencia de compuestos secundarios. Debido a que los datos no cumplían con los supuestos del ANOVA, a pesar de aplicarles diversas transformaciones, se comparó a través del test no paramétrico de Mann-Whitney la carga parasitaria de Philornis de nidos con y sin líquenes. Para esto se consideraron los pichones nacidos luego del agregado de los líquenes y no se tuvieron en cuenta nidadas posteriores o anteriores.

Se realizó la determinación específica de los líquenes por observación macroscópica y microscópica de talos, reacciones puntuales con los reactivos $\mathrm{K}(\mathrm{KOH})$ y $\mathrm{C}(\mathrm{NaClO})$ y reacción bajo luz ultravioleta (Wirth 1995). Las especies se determinaron según Kashiwadani y Kalbj (1993) y Scutari (1992). Se analizó la presencia de ácido úsnico de la especie más abundante (Ramalina celastri) mediante cromatografía de capa delgada (TLC) según Culberson (1972).

Un ejemplar de cada una de las especies de líquenes encontradas en los nidos fueron depositados en el Instituto de Botánica Carlos Spegazzini con el siguiente rótulo: Ramalina aspera Räsänen Lps48646, Ramalina celastri (Spreng.) Krog y Swinscow Lps 48647, Xanthoria parietina(L.) Beltr. Lps 48648, Teloschistes chrysophthalmus (L.) Beltr. Lps 48649, (Facultad de Ciencias Naturales y Museo, Universidad Nacional de la Plata) y tres nidos se depositaron en la colección de la Sección Ornitología de la División Zoología Vertebrados del Museo de la Plata, (FCNyM, UNLP), La Plata, Argentina.

\section{RESULTADOS}

\section{Cavidades utilizadas por el Estornino Pinto para nidificar}

Se encontraron 75 nidos de estorninos en cavidades, 65 se encontraban en árboles $(86,7 \%)$, de los cuales $50(76,9 \%)$ eran árboles vivos y $15(23,1 \%)$ eran árboles muertos. Diez nidos (13,3\% del total) se encontraron en construcciones humanas: tres en luminarias, uno en un poste de luz, tres bajo techos de viviendas, uno en un caño de ventilación en la pared de una vivienda y dos en ranuras en un arco de piedra que cruza el camino Centenario (Fig. 2.3 a). Cuatro de los árboles secos que utilizaron cayeron durante una tormenta luego de la temporada reproductiva.

De las cavidades encontradas en árboles, 6 (9\%) fueron construidas por carpinteros. 
Los árboles más utilizados para nidificar por los estorninos fueron principalmente cipreses Cuppressus sp., $(\mathrm{n}=15)$, Acacia negra Glenditzia triacantos $(\mathrm{n}=8)$ y Plátano Platanus acerifolia $(\mathrm{n}=6)$. En menor proporción utilizaron pinos Pinus $\mathrm{sp} .,(\mathrm{n}=3)$, Tala Celtis ehrenbergiana, $(\mathrm{n}=3)$, Tilo Tilla platyphyllos, $(\mathrm{n}=3)$, Eucalipto Eucaliptus $\mathrm{sp} .,(\mathrm{n}=2)$, Álamo Populus sp., $(\mathrm{n}=1)$, Roble común Quercus robur, $(\mathrm{n}=1)$ y Falsa acacia Robinia pseudoacacia, $(\mathrm{n}=1)$ (Fig. 2.3 b). Se observó que los estorninos suelen construir sus nidos muy cercanos a otros de la misma especie. En cinco ocasiones se encontraron más de un nido de estornino en el mismo árbol. Dos cipreses y un árbol seco poseían dos nidos de estorninos y un ciprés, tres nidos. La mayor cantidad de nidos de estornino en un árbol fueron seis que se encontraron en una Acacia negra.

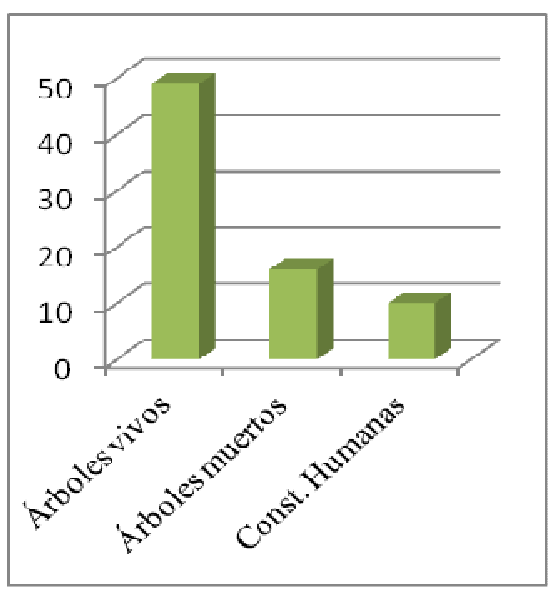

A)

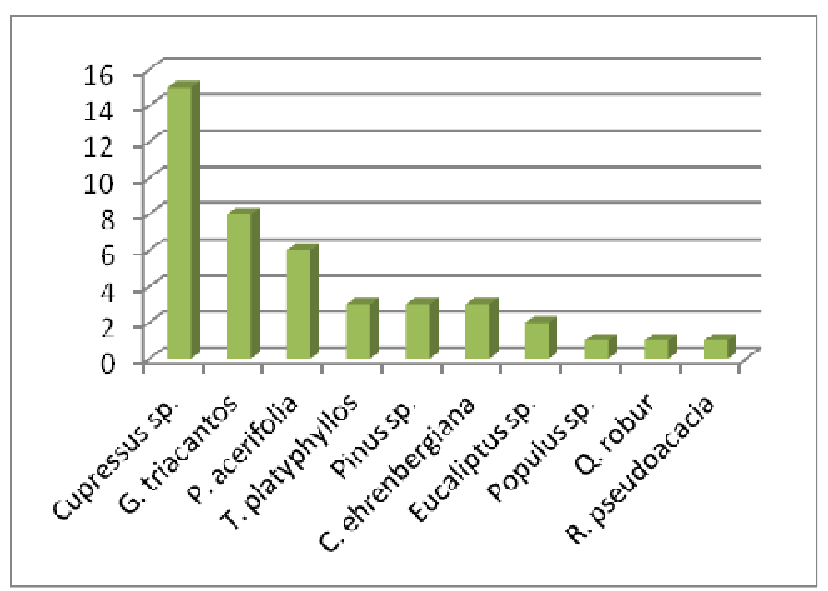

B)

Fig. 2.3: A) Cantidad de cavidades utilizadas por los estorninos en árboles vivos, muertos y construcciones humanas. B) Especies de árboles utilizados por el estornino para nidificar.

\begin{tabular}{lll}
\hline Característica & $\mathrm{X} \pm \mathrm{EE}$ & Mín - máx \\
\hline Altura árbol & $18,17 \pm 1,08$ & $3,52-37,94$ \\
DAP & $1,02 \pm 0,06$ & $0,23-2,83$ \\
Ancho copa & $12,90 \pm 1$ & $0-26,7$ \\
Altura cav. & $7,29 \pm 0,55$ & $1-17,98$ \\
\hline
\end{tabular}

Tabla 2.1: Altura del árbol, diámetro a la altura del pecho (DAP), ancho de la copa y altura de las cavidades utilizadas por el Estornino Pinto para nidificar en el parque Pereyra Iraola, Provincia de Buenos Aires. 
La orientación media fue de $23,15^{\circ} \mathrm{N}$ y no se encontraron diferencias significativas en las orientaciones de las cavidades (Rao's U: 132,1, p=0,46) (Fig. 2.4.)

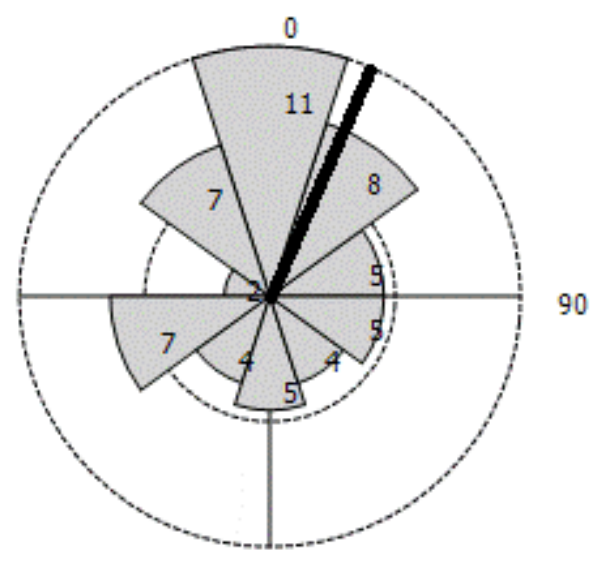

Fig. 2.4.: Orientaciones de las cavidades utilizadas por el Estornino Pinto. El 0 indica el Norte y la línea gruesa la orientación media $\left(23,15^{\circ} \mathrm{N}\right)$. Los números dentro de los conos indican la cantidad de nidos con cada orientación.

\section{Utilización de cajas-nido}

En la temporada reproductiva 2010 fueron utilizadas por el estornino 26 de las 42 (62\%) cajas-nido instaladas (Fig. 2.5 a y b).

En la ECAS fueron utilizadas 23 cajas-nido (77\%), 14 en una primera nidada y 15 en la segunda. Seis fueron reutilizadas. En dos de las cajas que no fueron utilizadas se encontró material como hojas, pequeñas ramas y plumas en escasa cantidad, sin llegar a conformar un nido. En la EBAS fueron utilizadas cuatro cajas-nido. En dos de ellas se construyó un nido pero luego fue abandonado, en una tercera se encontró material de construcción en escasa cantidad. Otra caja fue utilizada exitosamente por una pareja de estorninos, donde dos pichones lograron emplumar e independizarse.

En la tabla 2.1 se muestran la altura de la caja-nido, distancia a otras cajas-nido, DAP, ancho de la copa y altura del árbol de las cajas-nido utilizadas y no-utilizadas por estorninos.

El modelo de regresión logística no encontró ninguna asociación significativa entre las variables predictoras y la probabilidad de uso de las cajas (Intercepto $=71,92, p=0,87$, DAP: $x^{2}=0,55, \mathrm{p}=0,46$, distancia a otras cajas-nido: $x^{2}=0,02, \mathrm{p}=0,87$, altura del árbol: $x^{2}=3,35, \mathrm{p}=$ 0,56 , ancho de copa donde se colocaron las cajas-nido: $x^{2}=0,15, \mathrm{p}=0,70$, altura de la cavidad: $x^{2}=0,48, p=0,49$. 


\begin{tabular}{|l|c|l|c|l|}
\hline & \multicolumn{2}{|c|}{$\begin{array}{c}\text { Cajas-nido ocupadas } \\
(\mathrm{n}=49)\end{array}$} & \multicolumn{2}{c|}{$\begin{array}{c}\text { Cajas-nido no ocupadas } \\
(\mathrm{n}=17)\end{array}$} \\
\hline & $\mathrm{X} \pm \mathrm{EE}$ & \multicolumn{1}{|c|}{ Mín - máx } & $\mathrm{X} \pm \mathrm{EE}$ & \multicolumn{1}{|c|}{ Mín - máx } \\
\hline Altura caja & $3,06 \pm 0,04$ & $2,57-3,60$ & $3,40 \pm 0,14$ & $2-3,64$ \\
\hline Altura árbol & $14,29 \pm 0,75$ & $7,86-30,14$ & $14,45 \pm 1,58$ & $7,86-30,14$ \\
\hline DAP & $0,52 \pm 0,04$ & $0,15-1,56$ & $0,59 \pm 0,13$ & $0,10-2,30$ \\
\hline Ancho copa & $10,76 \pm 0,50$ & $0-20$ & $11,73 \pm 1,41$ & $2,50-21$ \\
\hline $\begin{array}{l}\text { Distancia a } \\
\text { otras cajas }\end{array}$ & $14,60 \pm 2,04$ & $0,75-65$ & $15,52 \pm 4,12$ & $1,10-65$ \\
\hline
\end{tabular}

Tabla 2.2: Características de la ubicación de las cajas-nido ocupadas y no ocupadas.

DAP: diámetro a la altura del pecho.

En la ECAS se observaron diferencias cualitativas en cuanto al ambiente donde estaban ubicadas las cajas-nido. Cinco de las cajas no utilizadas se encontraban ubicadas en una zona de bosque de Ligustro Ligustrum lucidum, con árboles de diámetro pequeño y muy agrupados, mientras que las cajas utilizadas se encontraron en ambientes con presencia principalmente de las siguientes especies de árboles: Acacia negra (Gleditzia triachantos), Paraíso (Phytolacca dioica), Casuarina (Casuarina sp.), Falsa acacia (Robinia pseudoacacia), Tala (Celtis ehrenbergiana) y Almez (Celtis australis). Otra de las cajas no utilizadas estaba sobre un alambrado aislada del resto de cajas y de otros árboles.

En la temporada reproductiva 2011 fueron utilizadas todas las cajas-nido aunque en tres de ellas se inició la construcción del nido sin llegar a finalizarla. En la temporada reproductiva 2012 fueron utilizadas todas las cajas-nido pero en cuatro los estorninos no terminaron de construir el nido y en la temporada 2013 fueron utilizadas la totalidad de las cajas-nido. En todos los casos la especie que ocupó las cajas fue el estornino y no se registró competencia con otras especies por el uso de las mismas. 

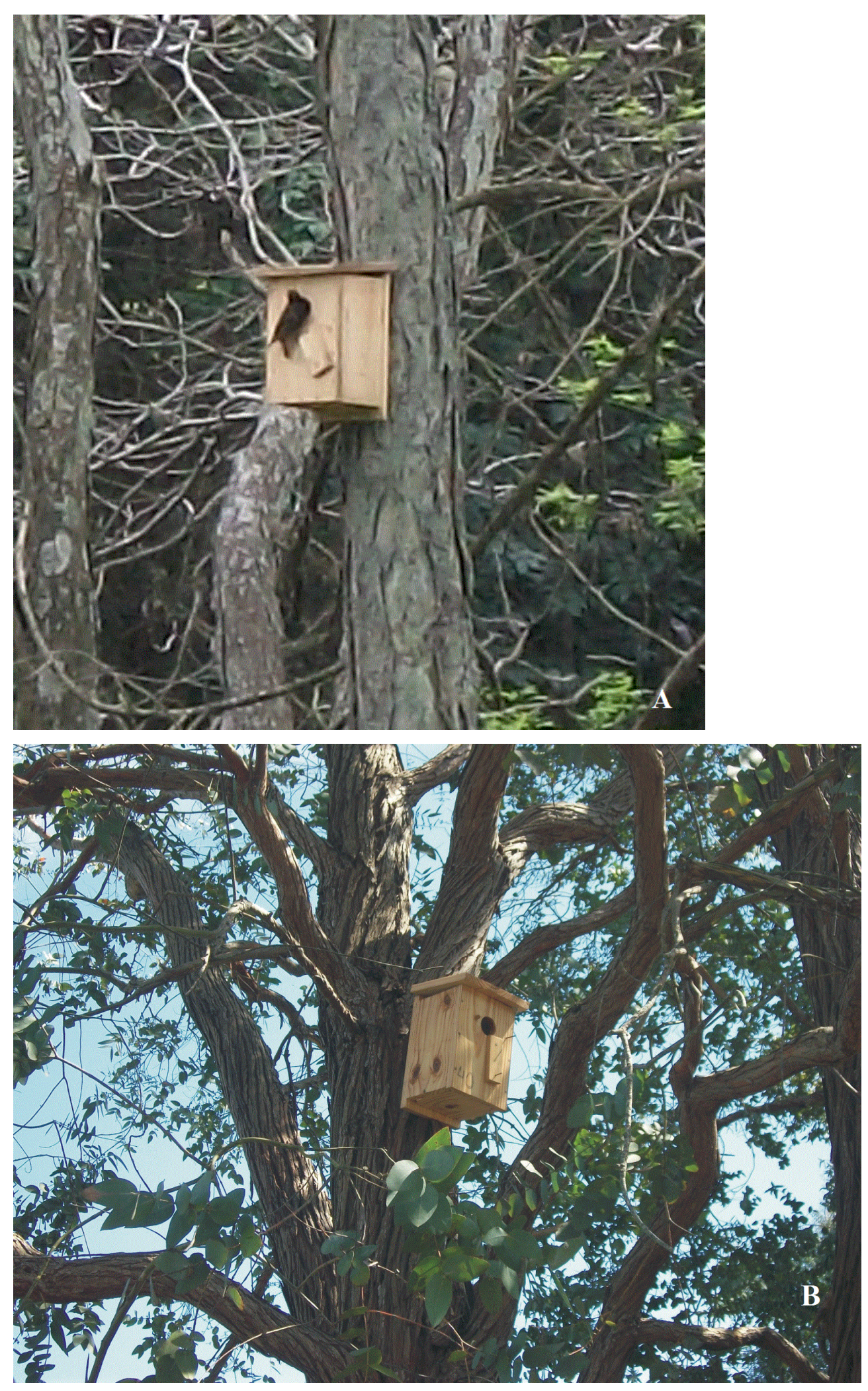

Fig. 2.5: A) estornino ingresando a una caja-nido. B) caja-nido sobre un árbol en la EBAS 


\section{Materiales utilizados en la construcción de los nidos}

Los nidos presentaron forma de copa abierta ahuecados en un lateral. El volumen de los nidos fue $1.670 \pm 770 \mathrm{~cm} 3$.

Utilizaron una gran variedad de materiales (Fig. 2.6). Al inicio de la construcción del nido los estorninos colocaron hojas verdes, líquenes y plumas en la caja (Fig. 2.7 c y Fig. 2.8). Posteriormente construyeron la estructura del nido utilizando principalmente hojas y tallos de gramíneas, corteza, ramas, hojas verdes y hojas secas (Fig. 2.7 a y b), las cuales a simple vista, parecerían provenir de las especies vegetales en los alrededores de las cajas-nido. Entre estas especies se encontraron Almez común, Acacia negra, Falsa acacia, Casuarina, Eucalipto y Ciprés. Para reforzar la estructura utilizaron raíces y la zona inferior de tallos de gramíneas junto a sus raíces. Sobre el nido agregaron un colchón de plumas. En total se encontraron $81,76 \pm 70$ plumas/nido. Las plumas más utilizadas fueron de palomas, gansos, ñandúes, loros, chimangos, caranchos y furnáridos (Fig. 2.7d). Todas estas aves se encuentran en abundancia en la zona. En dos nidos se observó que las barbas de las plumas habían sido cortadas conservando sólo el raquis. También utilizaron flores, vainas de Acacia negra y de Falsa acacia, raíces, líquenes, musgos, clavel del aire (Tillandsia sp.), bolitas de barro, estiércol y crines de caballo y materiales artificiales (papel, cartón, tiras de plástico, nylon) en cantidades menores al 5\%.

\begin{tabular}{llll}
\hline Material & Media \pm E.E. & Mín - máx & Frec. Obs. \\
\hline Gramíneas & $18,10 \pm 1,37$ & $0-47,31$ & 0,91 \\
Ramas & $13,79 \pm 0,90$ & $0-30,77$ & 0,96 \\
Plumas & $13,50 \pm 1,23$ & $0-40,07$ & 0,89 \\
Hojas verdes & $12,25 \pm 1,23$ & $0-46,25$ & 0,94 \\
Corteza & $11,14 \pm 0,80$ & $0-26$ & 0,93 \\
Hojas secas & $10,35 \pm 1,10$ & $0-39,57$ & 0,94 \\
Bases Gram. & $5,83 \pm 0,85$ & $0-23,02$ & 0,56 \\
Flores & $3,55 \pm 0,46$ & $0-12,96$ & 0,72 \\
Líquenes & $3,11 \pm 0,47$ & $0-16,25$ & 0,70 \\
Raíces & $2,63 \pm 0,43$ & $0-15,38$ & 0,52 \\
Vainas Leg. & $1,65 \pm 0,50$ & $0-17,49$ & 0,24 \\
Clavel del aire & $0,57 \pm 0,19$ & $0-5,36$ & 0,19 \\
\hline
\end{tabular}


Tabla 2.3: Proporción del volumen de cada material utilizado por el estornino para construir sus nidos.

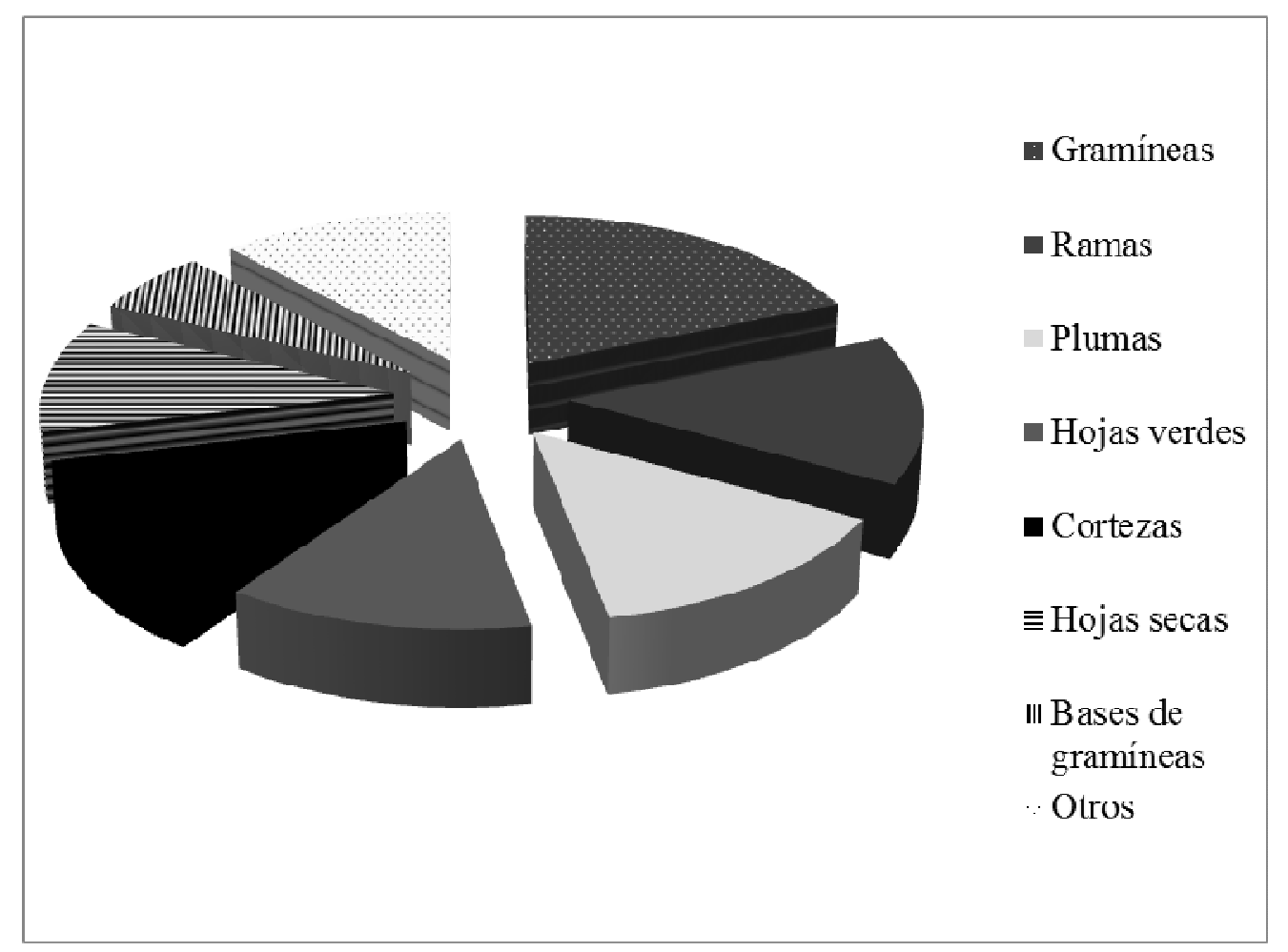

Fig. 2.6: Materiales utilizados en la construcción de los nidos de estornino.

En el ACP los primeros dos Componentes Principales (CP) explicaron más del 50\% de la varianza en la composición de los nidos. Los materiales que más influyeron en la variabilidad del CP 1 (que explicó el 36\% de la variabilidad) fueron las gramíneas y las plumas (Tabla 2.4).

\begin{tabular}{llllllll} 
& PC 1 & PC 2 & PC 3 & PC 4 & PC 5 & PC 6 & PC 7 \\
\cline { 2 - 7 } Ramitas & 0,07 & 0,41 & 0,46 & 0,04 & 0,28 & 0,72 & $-0,10$ \\
Gramíneas & 0,71 & $-0,28$ & $-0,41$ & 0,31 & 0,13 & 0,24 & $-0,30$ \\
Bases gram & 0,10 & 0,73 & $-0,31$ & 0,33 & $-0,50$ & $-0,05$ & 0,08 \\
Hojas secas & $-0,11$ & $-0,36$ & 0,43 & 0,75 & $-0,30$ & 0,04 & 0,15 \\
Hojas verdes & $-0,33$ & 0,22 & $-0,15$ & 0,48 & 0,65 & $-0,32$ & $-0,26$ \\
Plumas & 0,54 & 0,20 & 0,7 & $-0,06$ & 0,03 & $-0,56$ & $-0,18$
\end{tabular}




\begin{tabular}{llllllll} 
Corteza & 0,27 & 0,06 & $-0,06$ & 0,08 & 0,38 & $-0,05$ & 0,88 \\
\hline Eigenvalue & 321136 & 125204 & 106088 & 93550,50 & 73616,70 & 60824,10 & 42371,30 \\
\% varianza & 39,03 & 15,22 & 12,89 & 11,37 & 8,95 & 7,39 & 5,15 \\
Var. Acum. & 35,13 & 50,35 & 63,24 & 74,61 & 83,56 & 90,95 & 96,10
\end{tabular}

Tabla 2.4: Coeficientes del PCA, eingenvalues, porcentaje de la varianza explicada por cada componente y varianza acumulada para cada $\mathrm{CP}$.
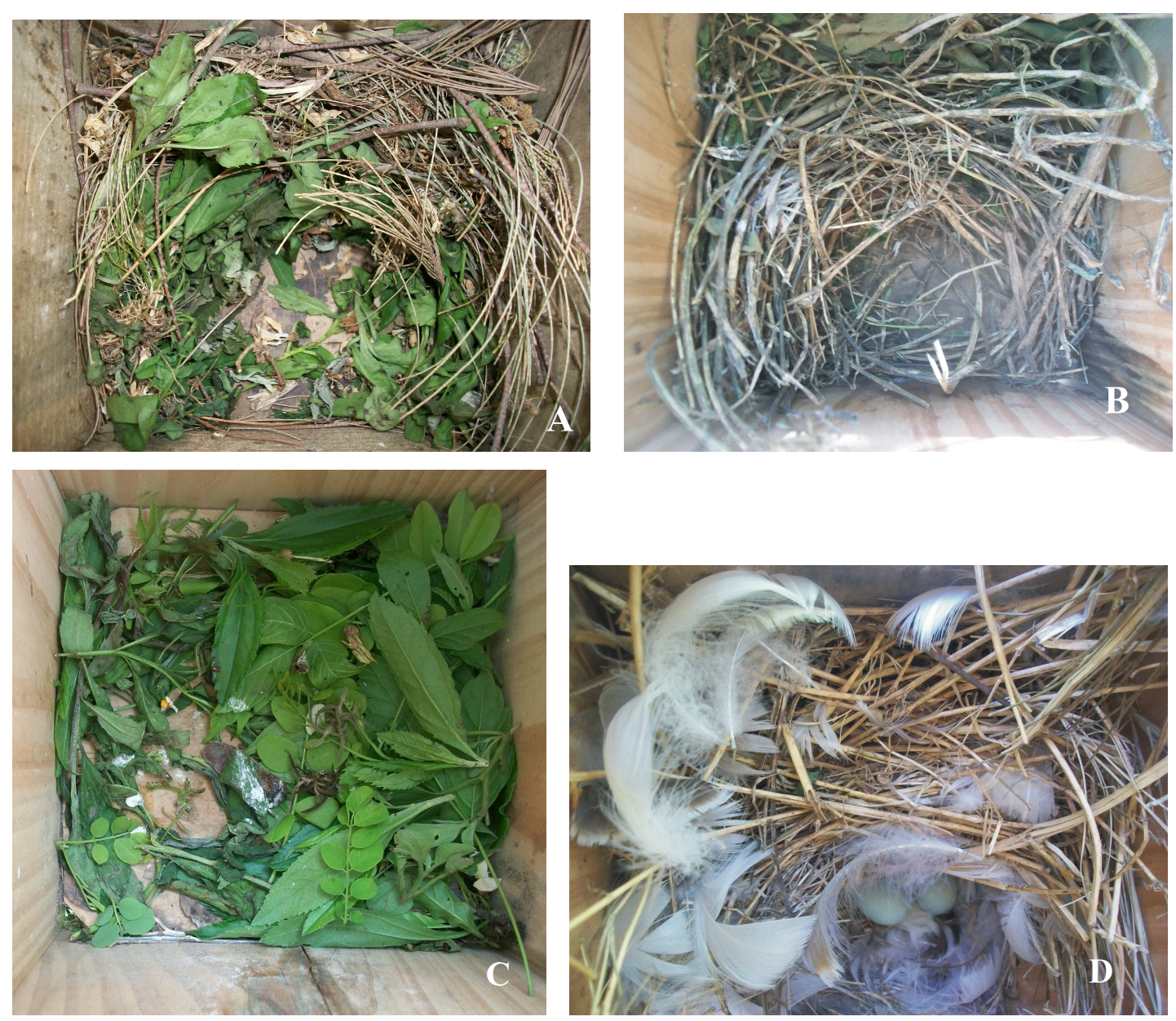

Fig. 2.7: Nidos de estornino en cajas-nido A) nido construído principalmente con Casuarina sp. y hojas verdes, B) nido construido principalmente con ramas, C) hojas verdes en caja-nido antes de comenzar con la construcción del nido y D) nido con plumas y huevos. 


\section{Utilización de líquenes en los nidos}

Se registraron líquenes en 26 de los 50 (52\%) nidos de estornino de la temporada reproductiva 2013 que pertenecieron a las siguientes especies: Ramalina celastri, $R$. aspera, Xanthoria parietina y Teloschistes chrysophthalmus.

En el 96,2 \% de los nidos se encontró la especie Ramalina celastri (Fig. 2.8), mientras las otras tres especies de líquenes se hallaron cada una en un solo nido ( $3,9 \%$ de los nidos).

Los estorninos utilizaron talos completos o trozos de líquenes principalmente en dos etapas: al comienzo de la construcción del nido antes de colocar otros materiales y luego de finalizada la construcción del mismo, antes de la puesta de los huevos.

La exposición de los talos a la luz ultravioleta mostró un brillo anaranjado en las puntas de las lacinias que indicaría la presencia ácido úsnico. Sin embargo estos no fueron detectados por cromatografía de capa delgada en los especímenes de $R$. celastri, lo cual indicaría que de encontrarse estos metabolitos, estarían en muy pequeñas cantidades.

Nacieron pichones en 14 nidos donde utilizaron líquenes y en 25 nidos en los que no los utilizaron. En los nidos donde los estorninos utilizaron líquenes se registró una carga parasitaria de 6,70 \pm 2,75, (0 - 35,25) larvas/pichón, $n=14$ nidos. En los nidos donde los estorninos no utilizaron líquenes, la carga parasitaria fue de 4,62 $\pm 1,22$, ( 0 - 23) larvas/pichón, $\mathrm{n}=25$ nidos. No se encontraron diferencias significativas en la carga parasitaria de Philornis sp. (Mann-Whitney, U: 159, p=0,8).
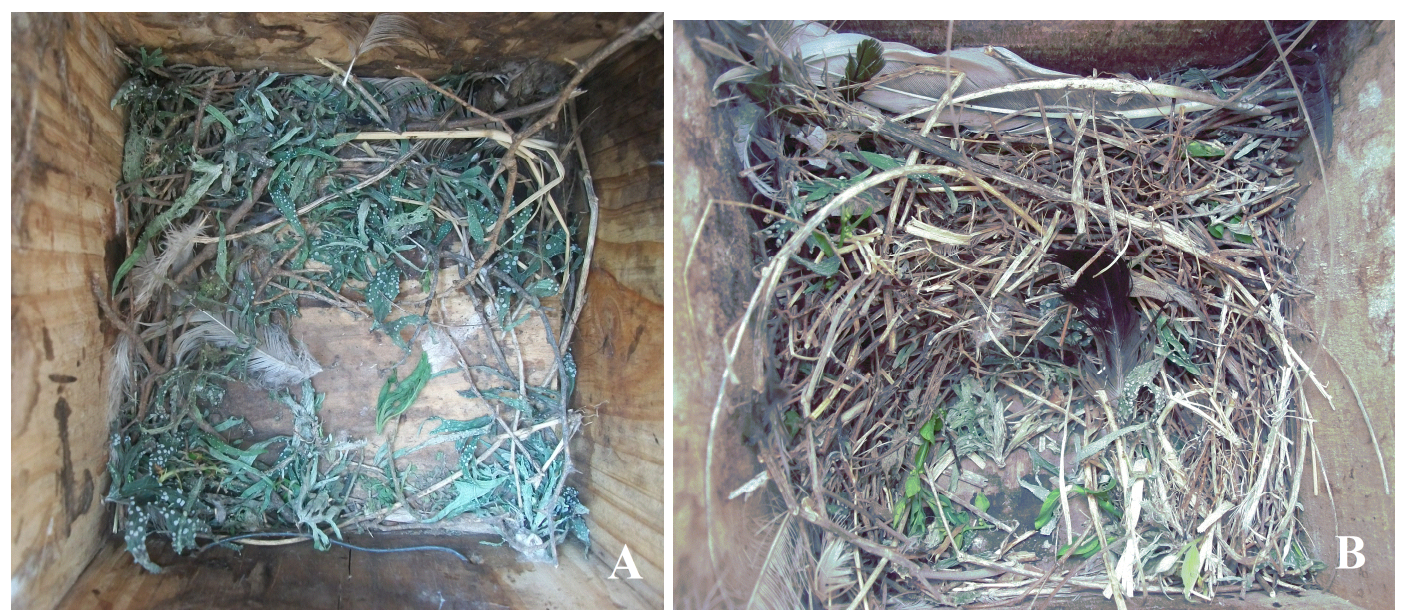
Fig. 2.8: Caja-nido con líquenes de la especie Ramalina celastri utilizados por el Estornino Pinto al comienzo de la construcción del nido. A) caja-nido con líquenes agregados antes de la construcción del nido, B) nido completo con líquenes.

\section{DISCUSION}

\section{Cavidades utilizadas para nidificar por el estornino}

El Estornino Pinto demostró ser un ave generalista en relación al tipo de cavidades utilizadas para nidificar. En el parque Pereyra Iraola utilizó cavidades tanto naturales como artificiales, cavidades en árboles vivos, en árboles muertos, fabricadas por carpinteros y generadas por degradación natural. También utilizó cajas-nido y cavidades en construcciones humanas como techos de viviendas, luminarias y postes de luz. Esto coincide con las observaciones realizadas por otros autores acerca de la nidificación del estornino en otras partes del mundo (Kessel 1957, Moeed y Dawson 1979, Feare 1984, Schmidtutz \& Agulián 1988, Di Giácomo y col. 1993, Craig y Feare 2009).

En el parque Pereyra el promedio de la altura de las cavidades utilizadas por el estornino fue mayor a la observada en Estados Unidos por Kerpez y Smith (1990) y por Ingold y Ingold (1984) y menor a la observada por Gutzwiller y Anderson (1987) y por Stauffer y Best (1982) en el mismo país. En cuanto a la altura y el DAP de los árboles donde se encontraron los nidos, la media observada en trabajos realizados en Norteamérica y Colombia fue menor a la observada en el parque Pereyra Iraola. Este resultado podría reflejar la variabilidad entre las especies y los aspectos fisonómicos de la vegetación donde se encuentran las cavidades del presente sitio de estudio respecto a la de los otros trabajos.

En el parque Pereyra el 76,9\% de las cavidades en árboles utilizadas por estorninos se encontraron en árboles vivos y el $23,1 \%$ en árboles muertos. Dobkin y col. (1995) encontraron una diferencia significativa en el uso de árboles vivos y muertos, con una notable preferencia por árboles vivos. En cuanto al agente de formación de la cavidad Wesolowski (2007) observó que en Polonia los estorninos utilizan con mayor frecuencia los nidos construidos por carpinteros que de los generados por degradación natural. Por el contrario, en el presente trabajo se encontró que en el parque Pereyra, sólo el 9\% de las cavidades utilizadas para nidificar por los estorninos, fueron realizadas por carpinteros. Esta diferencia en el uso de cavidades de distinto origen podría deberse a la diferencia en disponibilidad de cada tipo de cavidad de ambas áreas de estudio. 
En cuanto a la orientación de la entrada a las cavidades varios trabajos indican que las aves utilizan cavidades con la orientación que les otorgue beneficios termorregulatorios. Inouye (1976) observó que en Estados Unidos dos especies de carpinteros: el Carpintero Escapulario Colaptes auratus y el Chupasavia Norteño Sphyrapicus varius, orientan sus cavidades preferentemente hacia el sur. Rendell y Robertson (1994) y Ardia y col. (2006) observaron una preferencia de la Golondrina bicolor por las cavidades orientadas hacia el S$\mathrm{SE}$ en Estados Unidos. En el hemisferio norte las cavidades con esta orientación reciben el calor del sol durante una mayor cantidad de horas al día y una mejor ventilación otorgándole de esta manera beneficios termorregulatorios a los nidos (Rendell \& Robertson 1994). En el mismo país cinco especies de carpintero tienden a fabricar sus cavidades orientándolas hacia el norte, de esta manera los nidos se mantienen más frescos que los nidos orientados hacia el sur (Conner 1975, Inouye y col. 1981, Zwartjes y Nordell 1998). Aunque en el mismo país las aves tienen preferencias por distintas orientaciones, estas diferencias se encontrarían relacionadas a las características ambientales de las distintas zonas (Inouye 1981) y tanto las especies que orientan sus nidos hacia el norte como las que los orientan hacia el sur, obtendrían beneficios termorregulatorios. Van Balen (1982) observó que los estorninos utilizan con menor frecuencia las cavidades con orientación O-NO. Ingold y Ingold (1984) y Rendell y Robertson (1994) no encontraron preferencias por parte de los estorninos en cuanto a la orientación de las cavidades o cajas-nido. Los datos obtenidos en este trabajo muestran una mayor utilización de cavidades con orientación Norte y Noreste, que podría verse relacionada a principios de termorregulación, debido a que en la zona de estudio esta orientación permite una mayor exposición al sol. Sin embargo las diferencias en las orientaciones de las cavidades no fueron significativas.

\section{Utilización de cajas-nido}

En la ECAS no se observó una preferencia de los estorninos por cajas-nido en cuanto a la ubicación de las mismas ni en cuanto a las características de los árboles, pero se observó que evitaron el bosque de ligustro. Estos bosques presentan árboles muy agrupados con un diámetro de tronco muy pequeño donde no suelen formarse cavidades que les permitan nidificar a las aves. Esta observación concuerda con Pell y Tidemann (1997), quienes observaron que el estornino evita los boques más densos. Un factor que podría haber influenciado la baja utilización de cajas-nido en la EBAS es la baja disponibilidad de árboles añosos con cavidades naturales que se encuentran en el lugar, ya que es una zona de quintas donde predominan los terrenos cultivados (Ministerio Asuntos Agrarios 2007). Otro factor que pudo haber afectado el uso de cavidades en la EBAS fue la presencia de avispas que 
construyeron panales en 3 de las $12(25 \%)$ cajas-nido. Otro insecto himenóptero ha demostrado ser un competidor agresivo en el uso de cajas-nido, ocupando el $10 \%$ de las utilizadas por Pell y Tidemann (1997) en un estudio sobre reproducción en Australia.

\section{Materiales utilizados por el estornino en la construcción de los nidos}

Feare (1984) describió al nido como una estructura voluminosa constituida principalmente por gramíneas secas que en menor medida puede contener otros materiales como pequeñas ramas y hojas de pino. En el parque Pereyra también observamos que las gramíneas son el material principal en los nidos pero a diferencia de lo observado por Feare, las ramas también se encontraron en una proporción alta. Estos dos materiales constituyen la capa estructural del nido. Los siguientes materiales que se encontraron en mayor proporción en los nidos fueron plumas y hojas verdes. Estos materiales, junto con líquenes, flores, materiales artificiales, etc. son agregados principalmente antes de comenzar con la construcción del nido (Fig. 2.7 c) y al finalizarla (Fig. 2.7 b) (Kessel 1957, Feare 1984, Fauth y col. 1991, Brouwer y Komdeur 2004, Gwinner 1997). Brouwer y Komdeur (2004) demostraron que este comportamiento está relacionado a la atracción de la pareja por parte de los machos. Además cumplirían la función de estimular a que la pareja comience con la puesta (Feare 1984). Las plumas también fueron utilizadas para formar un colchón en el interior del nido antes de iniciar la puesta (Fig. 2.7 d), esto se encontraría relacionado a una función de termorregulación de huevos y pichones (Hilton y col. 2004). Las cortezas y las hojas secas también forman parte de la capa estructural, mientras que las bases de gramíneas, las raíces y el clavel del aire tendrían una función de unión de los distintos materiales.

\section{Utilización de líquenes en los nidos}

En los nidos de estornino se encontaron cuatro especies de líquenes: Ramalina celastri $R$. aspera, Xanthoria parietina y Teloschistes chrysophthalmus. $R$. celastri se encontró en 11 nidos mientras que las otras especies se encontraron en un nido cada una.

Los ascomycetes liquenizados del género Ramalina (Ramalinaceae) son conocidos por su potente acción antibacteriana y antimicótica (Tay y col. 2004). Sin embargo R. celastri en el parque Pereyra Iraola presentó una concentración muy escasa de compuestos secundarios al igual que fue registrado por Kashiwadani \& Kalbj (1993) en Brasil. Sin embargo, se observan variaciones en la presencia de compuestos secundarios en los líquenes de acuerdo a distintas variables ambientales como luz, temperatura y humedad. Por lo tanto, una misma especie de líquen pueden presentar distintas concentraciones de compuestos secundarios en distintas 
zonas de acuerdo a las características ambientales de cada sitio (Cocchietto y col. 2002. Estudios realizados en laboratorio en los que se analizaron diferentes extractos de líquenes, entre ellos el ácido úsnico, han mostrado ser efectivos contra distintos estadios larvales de dípteros como Aedes aegypti (Vinayaka y col. 2009), Culiseta longiareolata (Cetin y col. 2012), Culex pipiens (Cetin y col. 2008) y adultos de Drosophila melanogaster (Uysal y col. 2009) a concentraciones altas de los compuestos (Uysal y col. 2009, Vinayaka y col. 2009). El brillo anaranjado que se observó en las puntas de las lacinias podría estar relacionado con la presencia de una escasa cantidad de ácido úsnico en los líquenes utilizados por los estorninos. La falta de un efecto contra las larvas de Philornis en los pichones podría deberse a esta escasa concentración o a que estos ectoparásitos no se ven afectados por este tipo de compuestos.

En la Argentina los líquenes son utilizados por distintas especies de aves para la construcción de sus nidos. El Suirirí Común (Suiriri suiriri), el Fio fío Copetón Elaenia flavogaster, el Fio fío Grande Elaenia spectabilis, el Fiofío Pico corto Elaenia parvirrostris, el Zorzal Colorado Turdus rufiventris, la Monterita Cabeza negra Poospiza melanoleuca el Picaflor Bronceado Hylocharis chrysura, el Suirirí Pico corto Sublegatus modestus, el Piojito Común Serpophaga subcristata y el Pitiayumí Parula pitiayumí construyen nidos abiertos y los recubren externamente con líquenes exclusivamente o junto a otros materiales. El Churrinche Pyrocephalus rubinus, el Pepitero de collar Saltator aurantiirostris, el Tuquito Gris Empidonomus aurantioatrocristatus y el Anambé Grande Pachyramphus validus nidifican en nidos abiertos utilizando para su construcción líquenes junto a otros materiales. El Cuclillo Canela Coccyzus melacoryphus construye un nido abierto depositando líquenes en su interior. El Chotoy Schoeniophylax phryganophilus y el Canastero Chaqueño Asthenes baeri, contruyen nidos cerrados y utilizan líquenes para tapizar la cámara del nido. El Picochato Grande Tolmomyias sulphurescens construye un nido globular constituido casi íntegramente por líquenes. Al menos cuatro de estas especies (Picochato Grande, Anambé Grande, Suirirí Común, Pitiayumí y Fíofío Pico corto) utilizan líquenes del género Ramalina. Los líquenes utilizados por el resto de las especies de aves pertenecen a otros géneros o no fueron determinados (De la Peña 1995, Chatellenaz y Ferraro 2000, Chatellenaz y Ferraro 2005). Los líquenes que recubren el nido externamente cumplirían una función críptica, termorregulatoria o evitarían el ingreso de agua al nido (Hansell 2000). La utilización de líquenes para recubrir el nido en especies que nidifican en nidos abiertos cumplen una función diferente a la de especies que nidifican en nidos cerrados, en este último caso los líquenes son colocados dentro del nido, por lo cual se descartan las hipótesis relacionadas a una función críptica (Hansell 2000). La función de los líquenes dentro de nidos cerrados o en cavidades no 
había sido estudiada hasta el momento. En este trabajo los estorninos agregaron líquenes en el momento previo a comenzar la construcción del nido, junto con otros materiales como plumas y hojas verdes, por lo que los líquenes podrían ser utilizados por el macho para atraer a la pareja.

En la zona donde se encuentran las cajas/nido se encuentran varias especies de líquenes, entre ellas Usnea strigosa y Parmotrema conferendum (Obs. pers.). Además, otras especies como Ramalina peruviana, Teloschistes chrysophthalmus, Xanthoria parietina, Parmotrema conferendum, Teloschistes flavicans, Parmotrema conferendum y Punctelia constantimontium fueron citadas en el Parque Pereyra y en zonas cercanas al ECAS como Punta Lara y los alrededores de La Plata (Osorio 1979, Calvelo y Liberatore 2002). Sin embargo se observó que el Estornino Pinto solo utilizó Ramalina celastri con una frecuencia alta en los nidos. Las especies encontradas presentan una amplia distribución a nivel mundial exceptuando Ramalina aspera que solo se encuentra en Sudamérica (Rosato y Scutari 2000, Feurer 2007). Todas estas especies crecen sobre corteza de árbol sin ningún tipo de selectividad como así también sobre postes de madera, por estas características son muy comunes de encontrar en lugares con arbolado nativo o exótico (Scutari 1992, Kashiwadani y Kalbj 1993, Rosato y Scutari 2000) como lo es el ambiente del área de trabajo.

La escasez de compuestos secundarios con efectos antiparasitarios en los líquenes y la similitud en la carga parasitaria entre pichones de nidos con y sin líquenes no coincide con la hipótesis que vincula la utilización de líquenes en los nidos con una función antiparasitaria, al menos contra las moscas del género Philornis, aunque no se descarta un efecto contra otros parásitos.

Para concluir, podemos afirmar que el estornino ha encontrado en el parque Pereyra un lugar con abundancia de cavidades adecuadas para nidificar, a la vez que aprovecha una gran variedad de materiales presentes en la zona para construir sus nidos. La utilización de cajasnido es una herramienta muy útil que permitió obtener una gran cantidad de datos sobre distintos aspectos de la biología reproductiva del Estornino Pinto en Argentina.

Sin embargo, debe considerarse el aporte de nuevos individuos a la población debido al uso de las cajas-nido. En este estudio la supervivencia de pichones fue muy baja, por lo que el aporte de nuevos individuos no fue significativo. Además debe considerarse que un gran porcentaje de estorninos mueren durante el primer año de vida sin llegar a reproducirse. En este trabajo no se analizó la tasa de mortalidad durante el primer año de vida pero en Estados Unidos y Europa presenta valores entre el 50 y el 70\% y en Nueva Zelanda del 33\% (Flux y Flux 1981). De todas maneras, si las cajas-nidos no hubieran estado presentes, los estorninos 
probablemente hubieran buscado otras cavidades para reproducirse y para esto podrían haber desplazado a parejas de carpinteros de sus nidos o podrían haber competido con otras especies.

De acuerdo a los resultados de esta tesis el uso de cajas-nido para control poblacional es ampliamente recomendado. Dado el gran uso de las mismas por parte de los estorninos esta herramienta podría ser utilizada para capturar parejas reproductivas o eliminar huevos y pichones y de esta manera disminuir su éxito reproductivo y la incorporación de nuevos individuos a la población. Debido a que no se registró el uso de cajas-nido por parte de otra especie, este método presenta la ventaja de afectar sólo a la especie blanco. Asimismo podría aumentarse el número de cajas-nido y de esta manera tener un impacto mayor sobre la población. 


\section{CAPÍTULO 3: DENSIDAD POBLACIONAL Y COMPETENCIA CON AVES NATIVAS}

\section{INTRODUCCIÓN}

\section{Incremento poblacional del Estornino Pinto}

Distintos factores actúan para que una especie exótica logre establecerse y se convierta en invasora en el área donde fue introducida. Estos factores están relacionados a las características propias de la especie, al evento de introducción y a las características particulares de la zona donde la especie es introducida (Blackburn y col. 1999). En cuanto a las características de la especie, algunas que favorecen su condición de invasora son: poseer un tamaño corporal pequeño, una alta tasa de reproducción, habitar distintos ambientes, formar bandadas numerosas, dispersarse rápidamente, ser generalista (tanto en la alimentación como en la reproducción) y aprovechar los recursos del hombre (Holway y Suarez 1999, McKinney y Lockwood 1999). Además de los rasgos propios de la especie, la cantidad de eventos de introducción así como la cantidad de individuos liberados en cada evento y la cantidad de áreas donde se producen las liberaciones también afectan la probabilidad de que la especie logre establecer una población invasora (Veltman y col. 1996). Una vez liberada la especie, distintas características del área donde es introducida como las variables climáticas, la vegetación, la competencia por recursos, los predadores y los parásitos influyen en la probabilidad de que la especie pueda establecerse y aumentar su número poblacional (Blackburn y col 2009).

El Estornino Pinto ha logrado establecer poblaciones en distintos países donde fue introducido mostrando un crecimiento poblacional explosivo en algunos de ellos. Por ejemplo, Feare (1984) estimó que la población de estorninos en Estados Unidos sería de aproximadamente 200 millones de ejemplares que se reprodujeron a partir del núcleo original de 100 individuos en sólo 90 años. En Nueva Zelanda en tan solo once años se observó un incremento poblacional de cientos de miles de estorninos a partir de unos pocos ejemplares (Wood 1924). En Argentina en las primeras observaciones luego de su introducción se observaban escasos ejemplares (Di Giácomo y col. 1993, Navas 2002), pero en pocos años se registró un aumento importante en el número de estorninos por bandada (Peris y col. 2005). Hasta el momento la densidad del Estornino Pinto solo ha sido estimada en época 
reproductiva en parques en la Ciudad de Buenos Aires (Rebolo Ifrán y Fiorini 2010). En la ciudad de La Plata y alrededores en los últimos años se ha observado un importante incremento en la cantidad de estorninos (obs. pers.) pero esto aún no ha sido cuantificado.

\section{Competencia con aves nativas}

Los animales viven en asociaciones complejas dentro de sus comunidades. La estructura $\mathrm{y}$ función de estas comunidades se encuentran determinadas por interacciones intra e interespecíficas de predación y competencia y por la disponibilidad de recursos (Martin 1987, Martin y col. 2004). Durante el proceso de invasión, la búsqueda de estos recursos puede generar interacciones con nuevas especies e impactar en distinto grado sobre la fauna nativa, que en casos extremos pueden causar la extinción de especies a escala local (Holway y Suarez 1999, Sax y col. 2000). Por lo tanto, la disponibilidad de recursos influye en gran medida en el establecimiento de las especies exóticas (Shea y Chesson 2002) y la intensidad de la competencia por los mismos se encuentra positivamente correlacionada con la densidad poblacional de las especies competidoras (Newton 1998).

Para las especies que nidifican en cavidades, pero que no las construyen (nidificadores secundarios), la disponibilidad de cavidades es un recurso imprescindible para mantener su población, de manera que si las cavidades son escasas puede verse limitado el éxito reproductivo de estas especies (Martin y Li 1992, Ingold 1996). Sin embargo un exceso de cavidades no garantiza la falta de competencia, debido a que no todas las cavidades son adecuadas para que nidifiquen las aves y las distintas especies presentan preferencias por cavidades con determinadas características (Van Balen y col. 1982). Cuando las cavidades disponibles son limitadas suele existir competencia entre especies y afecta de distinta manera a las especies que construyen sus cavidades (nidificadores primarios) y a las que utilizan cavidades preexistentes. En este último caso si el ave es desplazada de su nido tendrá que encontrar otra cavidad con las características adecuadas y esto dependerá de la disponibilidad de este recurso en la zona. Por otro lado, las especies que construyen sus cavidades pueden volver a construir una nueva (Mazgajski 2000, Martin y col. 2004), aunque este nuevo proceso de construcción puede retrasar su reproducción afectando su éxito reproductivo (Mazgajski 2003).

El estornino, al igual que muchas otras especies exóticas se encuentra asociado a ambientes altamente modificados por el hombre (Duncan y col. 2003), donde la diversidad e intensidad de especies nativas suele ser baja (Blair 1996, Faggi y Perepelizin 2006). Por este motivo varios autores han restado importancia a la competencia entre aves nativas y exóticas (Blackburn y col. 2009). Sin embargo, en la época reproductiva el estornino suele trasladarse 
de la ciudad a zonas periurbanas (obs. pers.), lo que podría aumentar la probabilidad de competir con aves nativas.

Se han realizado diversos estudios de la interacción entre estorninos y otras especies. Mazgajski (2003) observó que debido a la utilización de cavidades por los estorninos, los carpinteros debían buscar nuevos sitios para nidificar y en consecuencia retrasaban su período de cría y su éxito reproductivo disminuía. Weitzel (1988) observó en Nevada, Estados Unidos, que de 14 parejas de 10 especies de aves nativas, ninguna volvió a reproducirse en la zona de estudio desde la aparición de los estorninos. Cuando fueron eliminados y no se permitió que anidaran, las especies nativas volvieron a nidificar en el lugar. Peterson y Gauthier (1985) también evaluaron la ocupación de cavidades en una comunidad con presencia de estorninos y la compararon con esa misma comunidad 30 años antes (McLaren 1963). El porcentaje de cavidades ocupadas por los estorninos había aumentado y las características de los sitios utilizados por las especies nativas de la zona habían variado. Koenig (2003) comparó las densidades de 27 especies nativas que utilizan cavidades, antes y después de la invasión de los estorninos y encontró que sólo una sufrió una declinación en su tamaño poblacional potencialmente atribuible a la presencia de los estorninos.

En Australia el estornino compite con varias especies de aves nidificadoras de cavidades secundarias como el Perico Elegante Platycercus elegans, el Perico Multicolor Platycercus eximius y el Perico Dorsirrojo Psephotus haematonotus y el Miná Común Acridotheres tristis, resultando la especie ganadora en el 59\% de las interacciones con loros y perdiendo siempre en la competencia con el Miná Común (Pell y Tidemann 1997).

También se ha observado competencia por cavidades en Estados Unidos y Europa con distintas especies de carpinteros, como el Carpintero Escapulario Colaptes auratus (Ingold 1996, 1998), el Carpintero Bellotero Melanerpes formicivorus, el Carpintero de Carolina $M$. carolinus, el Carpintero Cabecirrojo M. erythrocephalus (Ingold 1989, Troeschler 1976), el Pico Velloso Picoides villosus (Troeschler 1976), el Pico Picapinos Dendrocopos major, el Pico Mediano D. medius (Mazgajski 1994) y el Carpintero del Gila M. uropigialis (Kerpez y Smith 1990). En algunas ocasiones se observaron interacciones de gran agresividad cuando los estorninos intentaron usurpar nidos de carpinteros (Kilham 1958). En Estados Unidos, el Azulejo Oriental Sialia sialis, ha sufrido un decrecimiento poblacional de aproximadamente el $90 \%$ en 40 años que fue atribuido en gran parte a la competencia con el estornino y el Gorrión Común por cavidades para nidificar (Zeleny 1977).

En el parque Pereyra Iraola existen varias especies de aves que nidifican en cavidades como carpinteros, chincheros, ratonas, lechuzas, loros (Ibañez y col. 2011), etc. con las cuales el estornino podría estar compitiendo. La estimación de densidad de estorninos y otras aves 
permite conocer la situación actual de las especies en la zona y sienta las bases para realizar futuras comparaciones que permitan determinar variaciones poblacionales de las especies. Además, la determinación de las características de las cavidades que utilizan las distintas especies de aves permite estimar potenciales competidores por sitios para nidificar.

\section{OBJETIVOS DEL CAPÍTULO}

a) Estimar la densidad de las aves que nidifican en cavidades en la zona de estudio.

b) Comparar las características de las cavidades que utilizan para nidificar las distintas especies de aves.

c) Determinar si existe competencia por el uso de cavidades entre el Estornino Pinto y otras aves.

\section{MATERIALES Y MÉTODOS}

\section{Muestreo de aves}

Entre noviembre de 2010 y octubre de 2011 se realizaron estimaciones de abundancia de aves por el método de transectas lineales. Se recorrieron 13 transectas en total, dos en la Estación Biológica de Aves Silvestres (E.B.A.S.) (Fig. 3.1a), cuatro en la Estación de Cría de Animales Silvestres (E.C.A.S) (Fig. 3.1b) y siete en el Casco de la estancia Santa Rosa (C.E.S.R.) (Fig. 3.1c). Cada transecta se recorrió cada 15 días entre las 7 y las 11 de la mañana, a una velocidad constante de 17 metros/minuto, con un total de 23 repeticiones por transecta. En total las transectas sumaron 3.045 metros, 1.720 en el CESR, $925 \mathrm{~m}$ en la ECAS y 400 m en la EBAS.

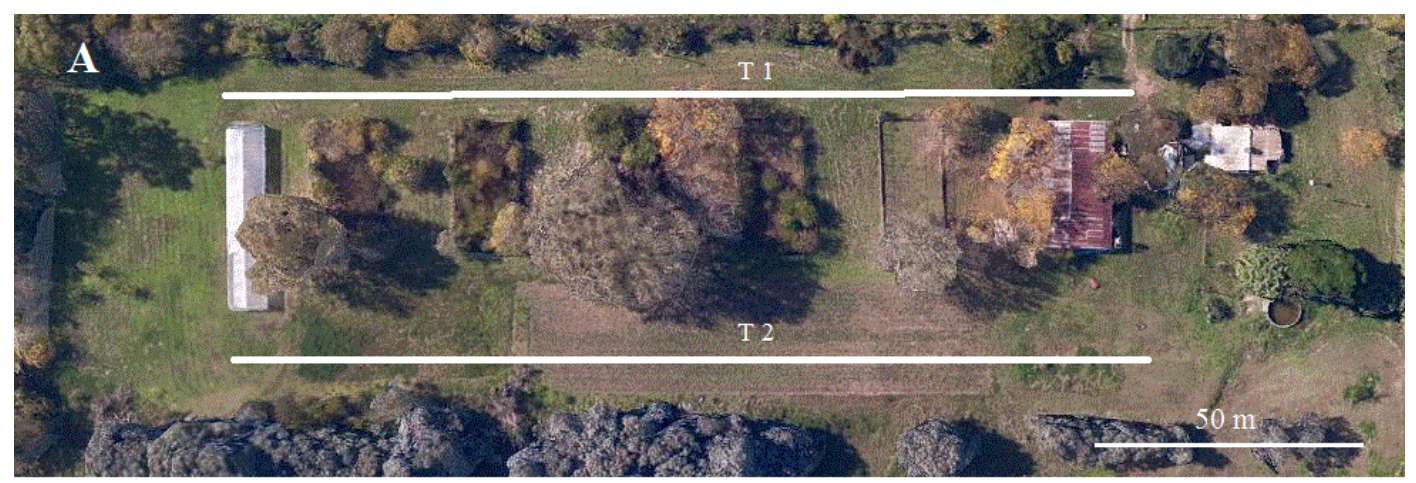



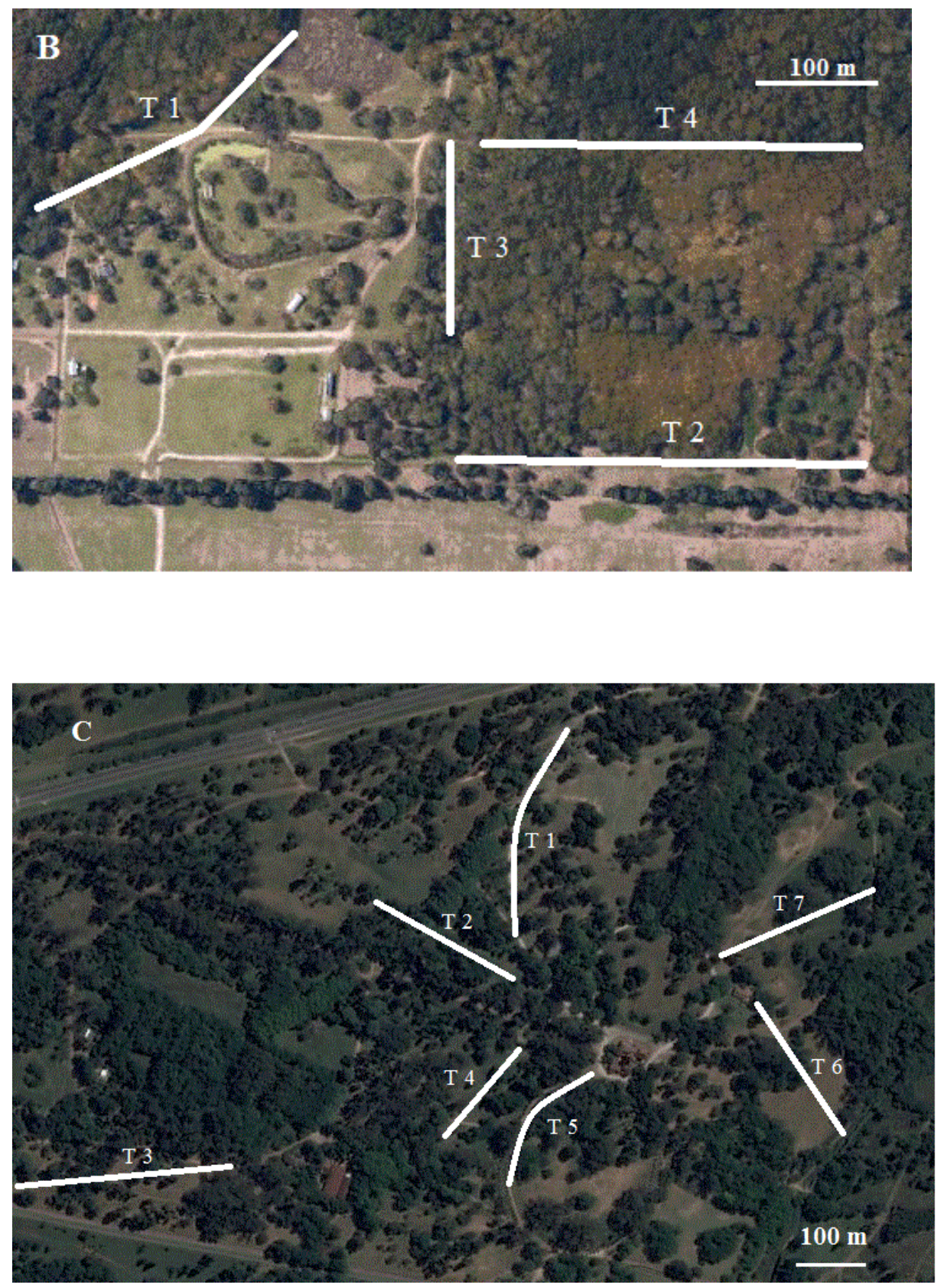

Fig. 3.1: Transectas recorridas en los tres sectores del parque Pereyra Iraola donde se realizó el muestreo: A) transectas en la E.B.A.S., B) transectas en la E.C.A.S. C) transectas en el casco de la estancia Santa Rosa.

Al recorrer las transectas se registró la especie de ave, la distancia en metros desde el observador y el ángulo formado entre el observador y el ave con respecto a la línea de transecta. Con estos datos se obtuvo la distancia perpendicular del ave a la línea de transecta. Para estimar la densidad de estorninos y de otras especies se utilizó el software Distance 6.0. 
(Thomas y col. 2010) que permite obtener un coeficiente de detectabilidad de cada especie con el cual se corrigen los valores de densidad observados a partir de las distancias entre los ejemplares y la línea de transecta. Se basa en la aplicación de la siguiente fórmula:

Coeficiente de detectabilidad $\mathrm{sp}_{\cdot \mathrm{i}}=\mathrm{nA} \times \mathrm{f}(0) / 2 \mathrm{~L}$,

donde $\mathrm{n}$ es el número de individuos observados, A es el área de muestreo, L es la longitud de la transecta y $\mathrm{f}(0)$ es la probabilidad de detección calculada a partir de las distancias perpendiculares de observación (Thomas y col. 2010).

\section{Características de las cavidades utilizadas para nidificar}

Luego del recorrido de las transectas para estimar abundancia de las especies, y durante salidas adicionales se realizó una búsqueda de nidos de las especies que nidifican en cavidades en la zona. Una cavidad era considerada como un nido activo si se escuchaban llamadas de pedido de alimento por parte de los pichones, si se los veía asomándose en la entrada, o si se observaba a los adultos entrando reiteradamente a la cavidad transportando alimento en el pico (Cockle 2011). Además, cuando se encontraba un nido de hornero observaba si estaba siendo utilizado para nidificar por alguna especie.

Se determinaron las características de las cavidades y de los árboles donde las aves nidificaron (especie vegetal donde se encontró el nido, altura del árbol, altura de la cavidad, orientación, diámetro a la altura del pecho (DAP) y ancho de la copa) siguiendo la metodología explicada en el Capítulo 2: Nidificación del Estornino Pinto.

Para realizar los análisis estadísticos los datos de las cavidades se separaron en tres grupos: el grupo 1 conformado por las cavidades utilizadas por estorninos, el grupo 2 conformado por las cavidades utilizadas por psitácidos (Chiripepé Cabeza verde Pyrrhura frontalis, Loro Maitaca Pionus maximiliani, Calancate Cara roja Aratinga mitrata, Calancate Ala roja Aratinga leucophthalmus y Loro Hablador Amazona aestiva y el grupo 3 conformado por las cavidades utilizadas por otras especies (Carpintero.Real Común Colaptes melanolaimus, Carpintero Campestre C. campestris, Chinchero Chico Lepidocolaptes angustirrostris, y Músico Agelaioides badius.

Para determinar si las orientaciones de las cavidades se distribuyeron uniformemente o si las aves utilizaron cavidades con una orientación en particular se realizó un test de Rao (Rao 1976) que permitió corroborar la uniformidad de datos circulares. Este análisis se realizó por un lado para todas las especies en conjunto (estornino, loros, chinchero, músico, carpintero real y campestre) y por otro lado agrupando las especies diferentes al estornino. 
Posteriormente se compararon las orientaciones de los nidos de estorninos con las del resto de las especies mediante un análisis de Watson-Williams (Hammer y col. 2009).

Debido a que los datos no cumplían con los supuestos del ANOVA luego de aplicarles diversas transformaciones, se analizaron mediante el test no paramétrico de Kruskal-Wallis para comparar las características de las cavidades naturales utilizadas por los tres grupos. En los casos en que se encontraron diferencias significativas en alguna de las variables se realizaron contrastes a posteriori para determinar entre qué grupos se encontraban las diferencias.

Se realizó un Análisis de Componentes Principales (ACP) utilizando como variables la altura del árbol, el DAP, el ancho de la copa del árbol y la altura de las cavidades con el fin de reducir las dimensiones del conjunto de datos analizados y determinar si los ejemplares de las distintas especies de aves estudiadas se agruparon en cuanto a las características de las cavidades que utilizan para nidificar. Para realizar este análisis se utilizó el software Past (Paleonthological Statistics) 1.8 (Hammer y col. 2001).

Se obtuvo el coeficiente de Spearman para determinar si existió una correlación entre la densidad de las especies que nidifican en cavidades y la cantidad de nidos encontrados en la zona. Sólo se analizaron las especies de las cuales se encontraron nidos en cavidades en árboles.

\section{Observaciones sobre competencia entre estorninos y otras especies}

Cada vez que se encontró un nido de estornino o de otra especie que nidifica en cavidades se realizaron observaciones de 15 minutos sobre cada nido y si se detectaba una interacción entre estorninos y otra especie se permaneció observando la situación durante el tiempo que esta se extendiera. En las salidas posteriores volvía a observarse el nido para determinar si se encontraba nidificando alguna de las especies competidoras y si se reiteraban las interacciones entre especies.

\section{RESULTADOS}

\section{Muestreo de aves}

Las especies que nidifican en cavidades registradas en las tres zonas de estudio fueron: Chinchero Chico, Ratona Común Troglodytes aedon, Jilguero Dorado Sicalis flaveola, Carpintero Campestre, Carpintero-Real Común, Golondrina Parda Progne tapera, Golondrina Ceja Blanca Tachycineta leucorrhoa, Alilicucu Común, Chiripepé Cabeza Verde, Loro Maitaca, Calancate Cara Roja, Calancate Ala Roja y Loro Hablador. 
La especie que presentó mayor densidad fue el Estornino Pinto, con una densidad de 1,47 $\pm 0,18$ estorninos/ha. Con menor densidad se encontraron el Chiripepé Cabeza Verde, el Calancate Cara Roja, el Calancate Ala Roja y el Loro Maitaca. Con una densidad menor y similar entre sí se encontraron el Chinchero Chico y la Ratona Común. Las especies con menor densidad en las zonas de estudio fueron el Carpintero-Real Común y el Carpintero Campestre (Tabla 3.1.). El Loro Hablador no se registró durante el recorrido de las transectas por lo tanto no se pudo obtener su densidad en la zona. Esta especie fue observada en un sector del parque Pereyra por donde no pasaban transectas, cuando estaba concluyendo el período del muestreo de aves.

\section{Características de las cavidades utilizadas para nidificar}

Se registraron 105 nidos activos, de los cuales 75 pertenecieron a estorninos y 40 a otras especies de aves: seis de carpinteros (cuatro de Carpintero-Real Común y dos de Carpintero Campestre), siete de Chinchero Chico (Fig. 3.2a), 1 de Músico, 11 de Chiripepé Cabeza Verde (Fig. 323b), 5 de Calancate Ala Roja (Fig. 3.2c), 4 de Loro Maitaca, 3 de Calancate Cara Roja (Fig. 3.2d) y 3 de Loro Hablador.
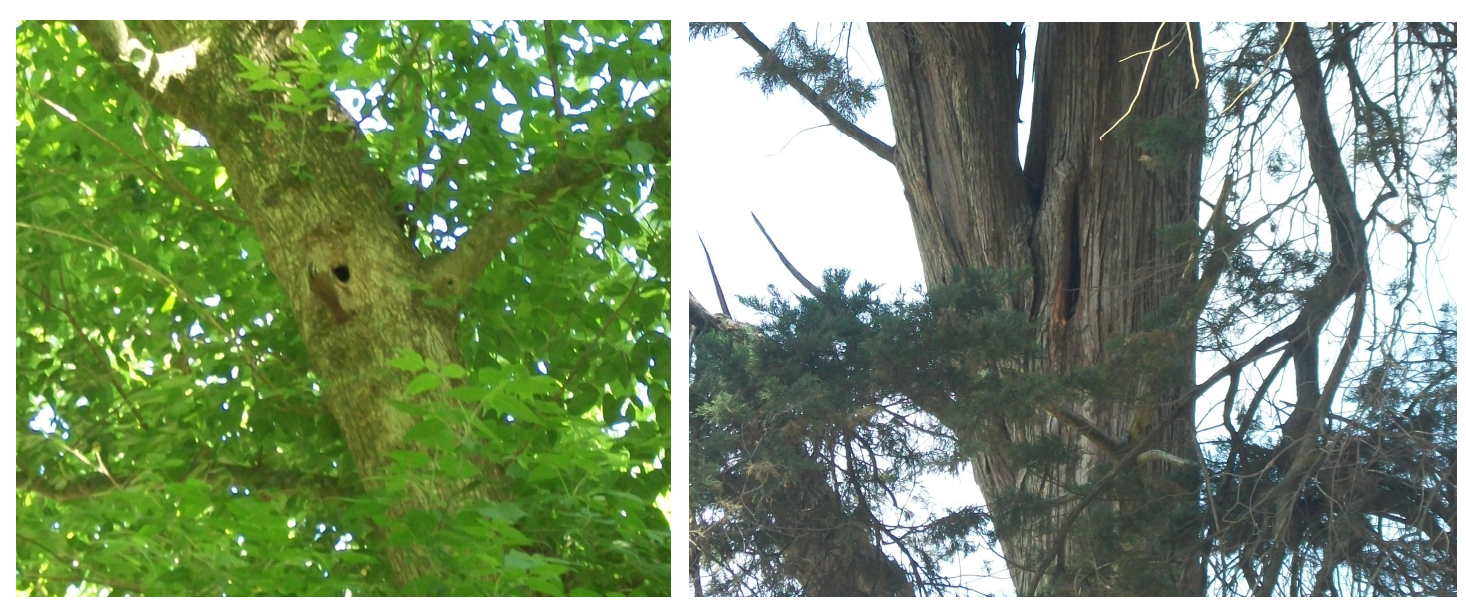

A)

B) 


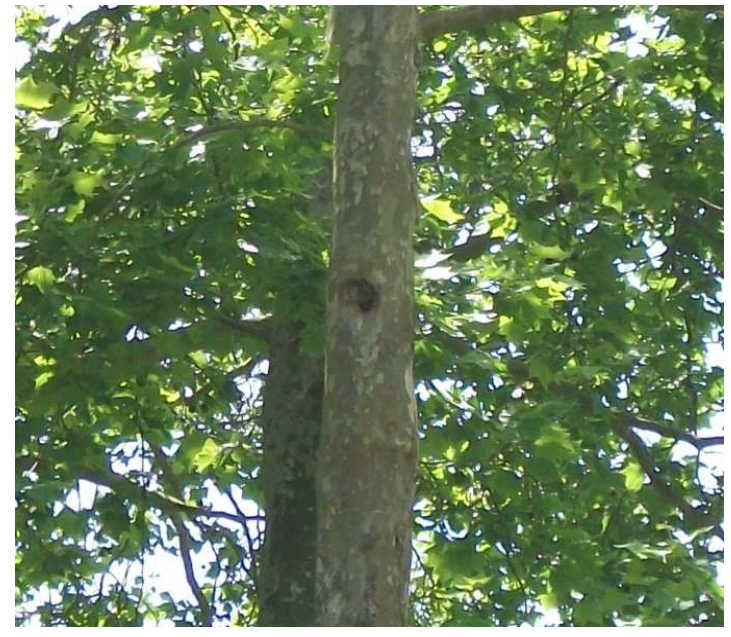

C)

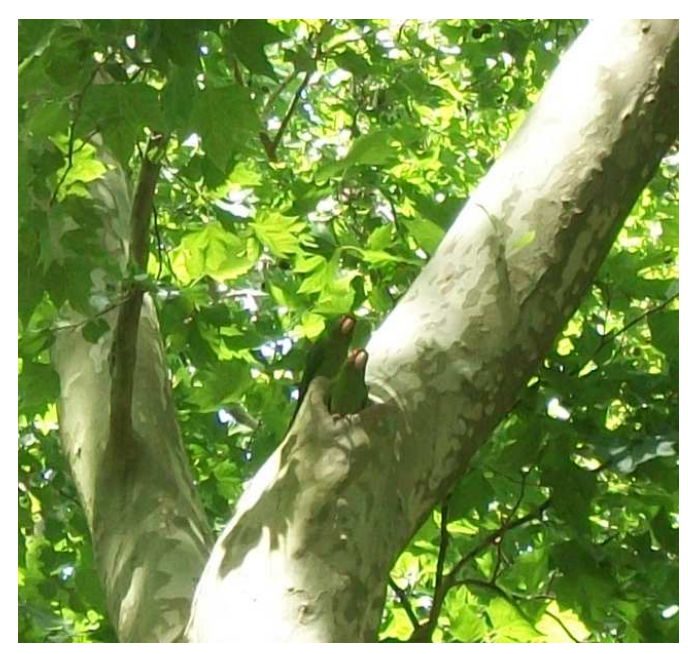

D)

Fig. 3.2: Cavidades en árboles utilizadas por distintas especies de aves para nidificar en el parque Pereyra Iraola. A) cavidades utilizada por una pareja de Chinchero Chico, B) cavidad utilizada por una pareja de Calancate Ala Roja, C) cavidad utilizada por una pareja de Chiripepé Cabeza Verde y D) cavidad utilizada por una pareja de Calancate Cara Roja.

Se encontró una correlación positiva marginalmente no significativa entre la densidad y el número de nidos encontrado para cada especie (Correlación de Spearmann, $r_{s}=0,67, p=$ 0,07) (Tabla 3.1.y Fig. 3.3). Evidentemente este resultado se ve en gran medida afectado por los datos de una sola especie, el estornino. Al eliminar estos datos no se observó una correlación entre la cantidad de nidos y la densidad de las especies (Correlación de Spearmann, $\left.\mathrm{r}_{\mathrm{s}}=0,50, \mathrm{p}=0,25\right)$.

\begin{tabular}{lll}
\hline Especie & Densidad (inds/ha) & $N$ nidos \\
\hline Estornino Pinto & $1,47 \pm 0,18$ & 76 \\
Chiripepé Cabeza Verde & $0,99 \pm 0,29$ & 11 \\
Loro Maitaca & $0,20 \pm 0,08$ & 4 \\
Calancate Cara Roja & $0,65 \pm 0,26$ & 3 \\
Calancate Ala Roja & $0,39 \pm 0,22$ & 5 \\
Chinchero Chico & $0,18 \pm 0,04$ & 7 \\
Carpintero-Real Común & $0,08 \pm 0,03$ & 4 \\
Carpintero Campestre & $0,02 \pm 0,09$ & 2 \\
\hline
\end{tabular}

Tabla 3.1.: Densidad de especies que nidifican en cavidades y cantidad de nidos encontrados en el área de estudio. 


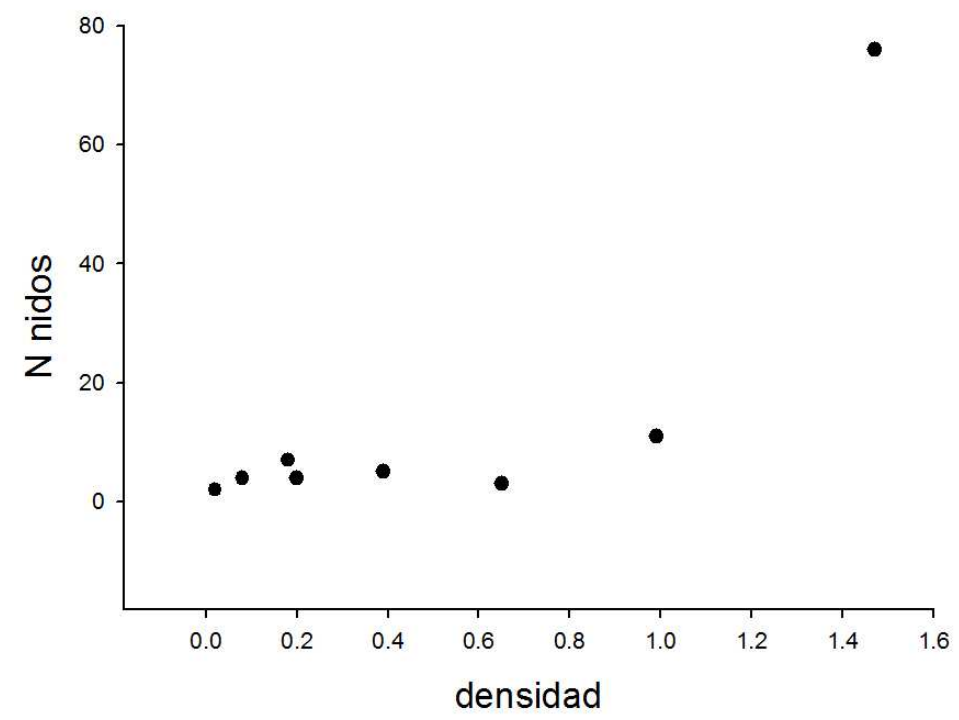

Fig. 3.3: Densidad de las distintas especies de aves (Individuos/hectárea) en relación a la cantidad de nidos registrados para cada especie.

Se encontraron diferencias significativas en la altura de la cavidad utilizada por los distintos grupos de especies (Kruskall-Wallis: $\mathrm{n}=102, \mathrm{H}=12,13, \mathrm{p}<0,01$ ) (Fig. 3.4). El test a posteriori mostró que estas diferencias se encontraban entre el grupo 1 y el grupo 3 (estorninos y otras especies) $(\mathrm{p}=0,03)$ y entre el grupo 2 y el 3 (psitácidos y otras especies) $(\mathrm{p}<0,01)$. No se encontraron diferencias significativas en el DAP (Kruskall-Wallis: $n=101$, $\mathrm{H}=2,42, \mathrm{p}=0,29$ ), en el ancho de la copa de los árboles (Kruskall-Wallis: $\mathrm{n}=101, \mathrm{H}=3,64$, $\mathrm{p}=0,16)$ ni en la altura de los árboles entre los distintos grupos de especies (Kruskall-Wallis: $\mathrm{n}=100, \mathrm{H}=5,23, \mathrm{p}=0,07)$.

En la tabla 3.2 se observan las medidas de las cavidades y de los árboles donde se encontraron las cavidades de cada especie. 


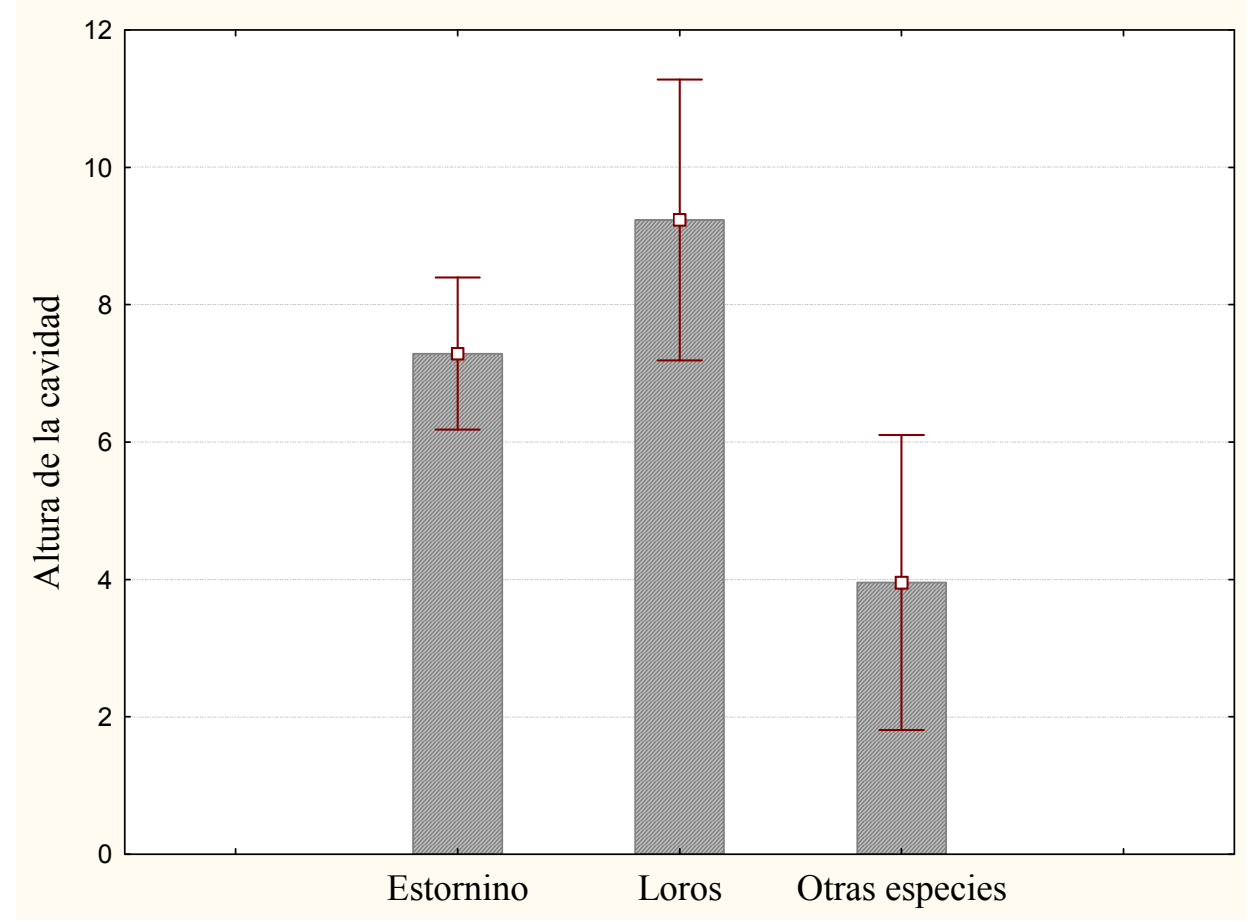

Fig. 3.4: Promedio y error de las alturas de las cavidades del Estornino Pinto, de las distintas especies de loros y de otras especies que nidifican en cavidades en el parque Pereyra Iraola.

\begin{tabular}{lllll}
\hline & $\begin{array}{l}\text { Altura cavidad } \\
\text { X E.E. }\end{array}$ & $\begin{array}{l}\text { Altura árbol } \\
\text { X } \pm \text { E.E. }\end{array}$ & $\begin{array}{l}\text { D.A.P. } \\
\text { X } \pm \text { E.E. } \\
\text { Especie }\end{array}$ & $\begin{array}{l}\text { Ancho copa } \\
\text { X E.E. }\end{array}$ \\
\hline S. vulgaris & $7,29 \pm 0,55$ & $18,17 \pm 1,08$ & $1,02 \pm 0,06$ & $12,90 \pm 1$ \\
\hline$(\mathrm{n}=63)$ & $(1-17,98)$ & $(3,52-37,94)$ & $(0,23-2,83)$ & $(0-26,70)$ \\
\hline C. melanolaimus & $7,51 \pm 1,82$ & $17,91 \pm 2,74$ & $0,6 \pm 0,09$ & $12,19 \pm 19,91$ \\
$\mathrm{n}=4$ & $(1-9,2)$ & $(12,18-22,29)$ & $(0,27-0,7)$ & $(10,2-13,6)$ \\
\hline C. campestris & $6,88 \pm 3,41$ & $12,63 \pm 8,04$ & $0,8 \pm 0,15$ & $7,38 \pm 7,37$ \\
$\mathrm{n}=2$ & $(3,46-10,29)$ & $(4,59-20,67)$ & $(0,66-0,95)$ & $(0-14,75)$ \\
\hline L. angustirrostris & $1,83 \pm 0,62$ & $17,71 \pm 3,48$ & $1,46 \pm 0,22$ & $15,06 \pm 2,58$ \\
$\mathrm{n}=7$ & $(0,64-5,32)$ & $(5,65-32,06)$ & $(0,47-2,3)$ & $(8,69-28,52)$ \\
\hline A.badius $\mathrm{n}=1$ & 8,84 & 17,58 & 1,1 & 0 \\
\hline P. frontalis & $8,1 \pm 1,51$ & $22,51 \pm 2,11$ & $0,96 \pm 0,12$ & $16,97 \pm 1,76$ \\
\hline $\mathrm{n}=11$ & $(1,15-18,07)$ & $(11,36-35,49)$ & $(0,53-1,74)$ & $(10,25-30)$ \\
\hline
\end{tabular}




\begin{tabular}{lllll}
\hline P. maximiliani & $8,00 \pm 2,55$ & $17,48 \pm 5$ & $0,66 \pm 0,07$ & $31,10 \pm 10,19$ \\
\hline $\mathrm{n}=4$ & $(1,53-13,88)$ & $(7,67-29)$ & $(0,45-0,76)$ & $(16,69-45,5)$ \\
\hline A. mitrata & $12,29 \pm 3,21$ & $22,43 \pm 5,99$ & $1,04 \pm 0,22$ & $29,16 \pm 1,87$ \\
\hline $\mathrm{n}=3$ & $(7,79-18,50)$ & $(14,43-34,14)$ & $(0,74-1,46)$ & $(25,55-31,68)$ \\
\hline A. leucophtalma & $10,62 \pm 1,84$ & $22,93 \pm 5,08$ & $0,81 \pm 0,09$ & $15,02 \pm 4,06$ \\
\hline $\mathrm{n}=4$ & $(7,26-15,63)$ & $(12,34-36,22)$ & $(0,59-0,96)$ & $(6,58-25,66)$ \\
\hline A. aestiva & $10,15 \pm 4,52$ & $23,69 \pm 4,21$ & $0,7 \pm 0,13$ & $15,40 \pm 1,30$ \\
\hline $\mathrm{n}=3$ & $(4,72-19,12)$ & $(17,15-31,56)$ & $(0,46-0,93)$ & $(14,02-18)$ \\
\hline
\end{tabular}

Tabla 3.2.: Características de las cavidades y los árboles que utilizaron las distintas especies de aves para nidificar en el parque Pereyra Iraola.

El test de Rao mostró una mayor utilización de cavidades con orientación Noreste al analizar los nidos de todas las especies en conjunto (Rao's U: 156,3, p<0,01), con una orientación media de $15,80^{\circ} \mathrm{N}$ (Fig. 3.5a).

No se encontraron diferencias significativas en las orientaciones de los nidos utilizados por estorninos con respecto a las utilizadas por los otros dos grupos de especies (Test de Watson-Williams, $\mathrm{U}=0,51, \mathrm{p}=0,48, \mathrm{n} 1=58, \mathrm{n} 2=36$ ). La media de las orientaciones para los estorninos fue de $23,15^{\circ} \mathrm{N}$ (ver Capítulo 2 : Nidificación) y para los grupos 2 y 3 en conjunto de $336,79^{\circ} \mathrm{N}$ (U de $\mathrm{Rao}=249, \mathrm{p}=0,11$ ) (Fig. 3.5b).

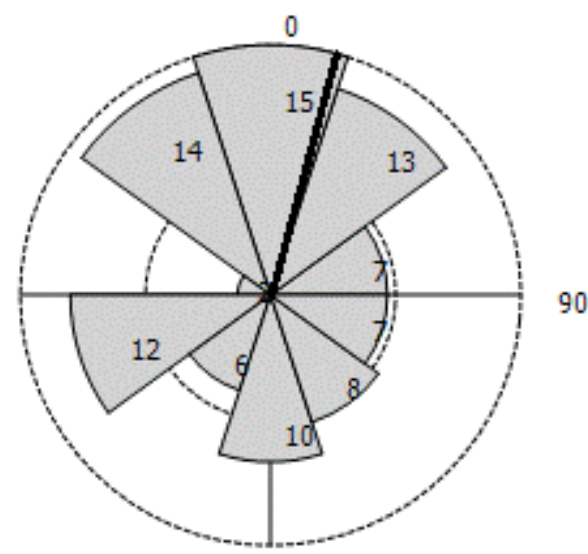

A)

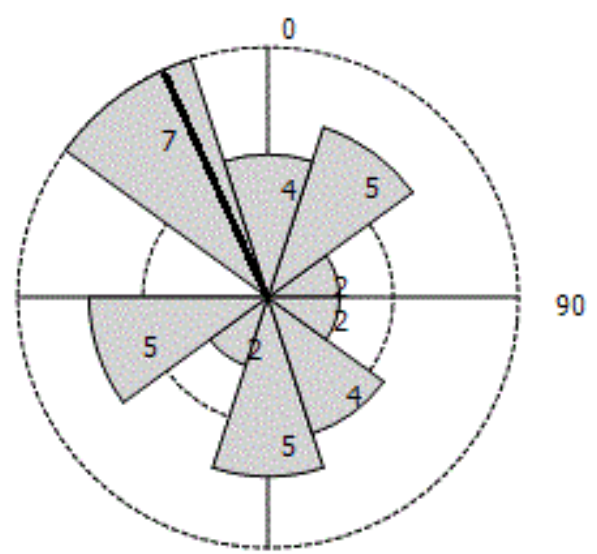

B) 
Fig. 3.5: A) Orientación de las cavidades naturales de todas las especies en conjunto. B) orientaciones de las cavidades para los grupos 2 y 3 en conjunto. El gráfico de las orientaciones de las cavidades utilizadas por los estorninos se puede observar en la Fig. 2.4 del Capítulo 2. La línea gruesa muestra la orientación media. El 0 indica el Norte. Los números dentro de los conos indican la cantidad de nidos con cada orientación.

En el Análisis de Componentes Principales la sumatoria de los tres primeros componentes explicaron el 99,89\% de la variabilidad total. El Componente Principal (CP) 1 y el CP 2 se encontraron principalmente asociados a la altura del árbol y el ancho de la copa. El CP 1 explicó el 69,02\% de la variabilidad, el CP 2 el 22,08\% y el CP 3, el 8,79\%. Ninguno de los componentes principales mostró una agrupación por grupo taxonómico (Fig. 3.6).

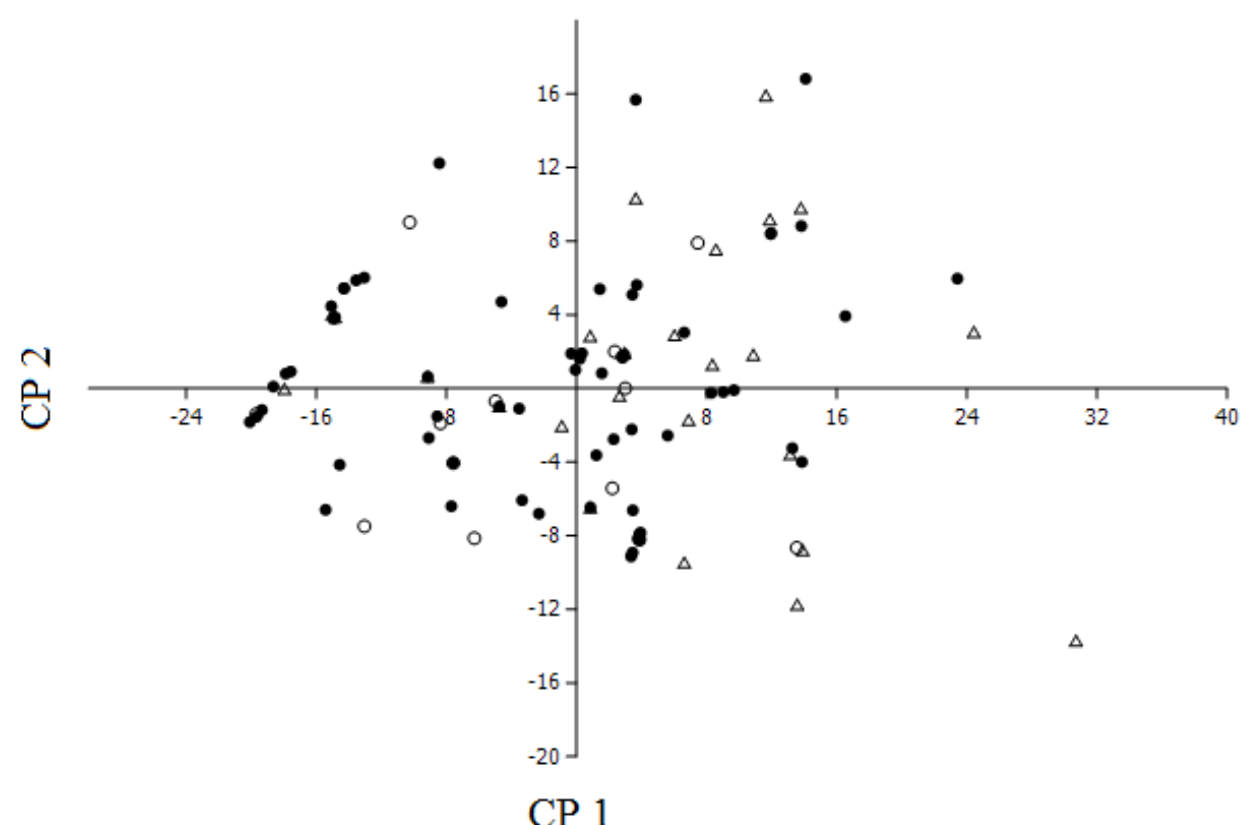

Fig. 3.6: Gráfico de componentes principales (CP) 1 versus CP 2. Los círculos negros representan las cavidades utilizadas por los estorninos para nidificar, los triángulos las cavidades utilizadas por psitácidos Chiripepé Cabeza Verde, Loro Maitaca, Calancate Cara Roja, Calancate Ala Roja, Loro Hablador) y los círculos vacíos las cavidades utilizadas por otras especies (Chinchero Chico, Músico, Carpintero-Real Común, Carpintero Campestre).

No se registró la utilización de nidos de hornero por estorninos. Se encontraron cinco nidos de hornero donde nidificaron golondrinas parda y de ceja blanca, otro nido de hornero 
fue ocupado por una pareja de Jilguero Dorado. Cuatro $(66,67 \%)$ de estos nidos se encontraban en sectores donde había estorninos nidificando.

\section{Observaciones sobre competencia entre estorninos y otras especies}

Uso de la misma cavidad por más de una especie: Durante la temporada reproductiva 2010 una cavidad ubicada sobre un ciprés fue utilizada por una pareja de estorninos y finalizada la reproducción fue ocupada por una pareja de Chiripepé Cabeza verde. Otra cavidad, también ubicada sobre un ciprés fue utilizada por un Calancate Ala roja durante la temporada reproductiva 2011 y al año siguiente se encontraba nidificando una pareja de estorninos. Una cavidad ubicada sobre un tilo (Tilia platyphyllos) que fue utilizada durante el 2011 por estorninos, en el 2012 la utilizó una pareja de carpinteros campestres. En marzo de 2011 se observó un ejemplar de Alilicucú Común dentro de una de las cavidades en la cual anteriormente había nidificado una pareja de estorninos. No se pudo comprobar si el Alilicucu Común estaba nidificando.

Defensa de cavidades: El 15 de septiembre de 2011 se registraron dos interacciones con carpinteros por el uso de cavidades para nidificar, en una ocasión una pareja de CarpinteroReal Común estaba construyendo una cavidad en un árbol mientras cinco estorninos se encontraban a cinco metros posados sobre unas ramas. Luego la pareja de carpinteros abandonó el lugar y los estorninos se acercaron a la cavidad e ingresaron reiteradas veces. En otra ocasión una pareja de Carpintero Campestre se encontraba sobre un tronco seco con una cavidad. Cerca se encontraban nueve estorninos posados sobre ramas y postes. Los estorninos intentaban acercarse y los carpinteros los perseguían por periodos breves, de menos de 30 segundos, luego de lo cual retornaban a la cavidad. Este comportamiento se repitió 13 veces en el transcurso de una hora. Por momentos ambos integrantes de la pareja perseguían a varios estorninos y a veces se separaban para ahuyentarlos. Los estorninos no mostraban un comportamiento agresivo, se alejaban unos metros pero no abandonaban el lugar, provocando que los carpinteros manifestaran un comportamiento de vigilancia y defensa constante de la cavidad. El 20 de septiembre, se volvieron a observar las parejas de Carpintero-Real Común y de Carpintero Campestre y no se observaron estorninos en las cercanías.

Intento de usurpación de cavidad: En octubre de 2011 se observó un intento de usurpación de un nido de hornero cuando cinco estorninos se posaron sobre una rama a ambos lados del nido, uno de ellos se acercó y asomó la cabeza dentro del nido, en ese momento 
salió de adentro un hornero realizando vocalizaciones y agitando sus alas manifestando de esta manera un comportamiento de defensa del nido. Los estorninos retrocedieron y durante unos segundos permanecieron en ramas cercanas observándolo para finalmente abandonar el lugar. Durante los meses siguientes se observó la presencia del hornero en el nido y no se registraron más interacciones. Este nido se encontraba en un sector con cajas-nido que ocuparon los estorninos y con seis nidos de estorninos en cavidades naturales.

Usurpación de cavidades: En la ECAS en octubre y noviembre de 2012 entre las 10 y las 11 am se observaron dos parejas de Carpintero-Real Común construyendo cavidades para nidificar durante varios días y antes de finalizar la construcción las cavidades fueron ocupadas por parejas de estorninos que se reprodujeron exitosamente. No se volvieron a observar a los carpinteros en esas cavidades.

Uso de las cajas-nido: Con respecto a las cajas-nido no se observó ninguna interacción entre especies por el uso de las mismas. Durante los cuatro años de estudio en tres ocasiones se observaron chincheros ingresar a las cajas-nido mientras se encontraban vacías pero sólo permanecían unos segundos adentro. También se observó en dos ocasiones cerca del final de la temporada reproductiva del estornino a músicos ingresar a las cajas-nido mientras había pichones de estornino adentro pero segundos después se retiraron y no se los volvió a observar.

\section{DISCUSIÓN}

\section{Densidad poblacional}

El Estornino Pinto es la especie que presentó la mayor densidad entre las aves que nidifican en cavidades en la zona de estudio, registrándose una gran cantidad de parejas reproduciéndose, lo que demuestra que la especie presenta una población bien establecida en la zona. El Chinchero Chico, la Ratona Común, el Carpintero Campestre, el Carpintero-Real Común, la Golondrina Parda, la Golondrina Ceja Blanca y el Alilicucu Común son especies nativas de la zona de estudio. El Chiripepé Cabeza Verde, el Loro Maitaca, el Calancate Cara Roja, el Calancate Ala Roja y el Loro Hablador son todos psitácidos nativos de la Argentina pero exóticos para el área de estudio. Su rango normal de distribución se encuentra en el Norte del país y su presencia en el parque Pereyra Iraola podrían provenir de liberaciones efectuadas por organismos provinciales en la ECAS (Chébez 2006). El Gorrión es la única 
especie introducida en al Argentina que se observó durante el muestreo de aves y que nidifica en cavidades.

Los valores de densidad del estornino registrados en el parque Pereyra son muy similares a los registrados en otras partes del mundo. Clergeau y col. (1998) registró una densidad de $1,42 \pm 0,33$ estorninos/ha en primavera en la ciudad de Rennes, Francia, mientras que el mismo autor en la ciudad de Québec (Canadá) registró una densidad de 1,30 $\pm 0,15$ estorninos/ha. En Roma, Italia, Sorace (2001) observó que la densidad de estorninos en un parque urbano era de 0,65 estorninos/ha. En Gran Bretaña las densidades de estorninos ascienden a 1,79 estorninos/ha en zonas urbanas y 2,20 estorninos/ha en zonas suburbanas (Robinson y col. 2005). Hasta el momento en la Argentina sólo se realizó un trabajo en el cual se estimó la densidad de estorninos en distintos parques de la ciudad de Buenos Aires, donde se registró una densidad de 2,21 \pm 0,09 estorninos/ha (Rebolo Ifrán y Fiorini 2010). Los resultados obtenidos en el parque Pereyra Iraola muestran que a 30 años de su introducción en la Argentina, la densidad del estornino es similar o mayor a la que se observa en otras partes del mundo donde esta especie es nativa. En Canadá, donde el estornino fue introducido hace aproximadamente 120 años la densidad poblacional es levemente menor a la registrada en el parque Pereyra Iraola. En este último país, así como en Francia y parte de Gran Bretaña, el estornino es considerado plaga principalmente por los daños que provoca a la agricultura (Feare y col. 1992). Teniendo en cuenta que a 30 años de su introducción en la Argentina esta especie ya alcanzó densidades similares a los de otras partes del mundo y que se encuentra en expansión en el país, en poco tiempo podríamos encontrarnos ante una situación similar a la que se observa en aquellos países donde el estornino ocasiona grandes pérdidas económicas.

\section{Características de las cavidades utilizadas para nidificar y competencia interespecífica}

Hasta el momento solo se registraron dos interacciones entre estorninos y carpinteros y una entre estorninos y horneros, resultando en todos los casos el estornino la especie perdedora. Sin embargo, los estorninos habrían desplazado a dos parejas de carpinteros que estaban construyendo sus cavidades. Las causas del bajo registro de eventos de competencia podrían encontrarse por un lado en la diferencia en la altura de las cavidades que utiliza cada especie y en segundo lugar, en que los árboles del parque Pereyra Iraola por el momento podrían proveer de sitios de nidificación a las distintas especies sin ser necesaria la competencia.

Dos especies de psitácidos, el Chiripepé Cabeza Verde y el Calancate Ala Roja utilizaron cavidades que también utilizaron los estorninos pero en el primer caso la utilizaron finalizada la reproducción del estornino y en el segundo caso los estorninos la utilizaron al año 
siguiente. Hasta el momento no se registraron interacciones directas entre el estornino y estas especies. El análisis de Kruskal-wallis no mostró diferencias entre estorninos y psitácidos en las características de las cavidades que utilizan para nidificar. Además el Análisis de Componentes Principales no mostró un agrupamiento en cuanto a las características de las cavidades que utilizan para nidificar las distintas especies que nidifican en cavidades en la zona, lo cual sugiere que todas estas utilizan cavidades con características similares, por lo cual se esperaría que exista competencia entre ellas si las cavidades fueran escasas. Sin embargo, para las especies que conformaron el grupo 3 (carpinteros, chincheros y músico) el número de cavidades encontradas para cada especie fue muy bajo, por lo que no se pudo evaluar cada una por separado. En el caso de los chincheros observamos que la altura de las cavidades que utilizaron fue notablemente menor y el DAP de los árboles mayor a los de las cavidades que utilizan las otras especies, sin embargo el haber encontrado sólo siete cavidades de esta especie no permitió evaluar estadísticamente si estas diferencias fueron significativas. Sin embargo, los chincheros frecuentaban y tenían nidos en la zona donde se encontraban las cajas-nido y no se observaron interacciones entre esta especie y estorninos.

En Suecia, Nilsson (1984) observó que las cavidades más altas eran utilizadas en mayor medida por las especies numéricamente dominantes. Los datos obtenidos en el parque Pereyra Iraola concuerdan con Nilsson, debido a que el estornino y los loros, que fueron los grupos con mayores densidades en la zona utilizaron cavidades a mayor altura que las otras especies que se encuentran en inferioridad numérica.

Al evaluar las orientaciones de las cavidades utilizadas por todas las especies en conjunto se observó que la mayoría presentaban orientación norte y no se observó una diferencia en las orientaciones de las cavidades utilizadas por el estornino y el resto de las especies. En la zona de estudio la orientación Norte les proporciona a las aves una mayor exposición al sol con posibles beneficios termorregulatorios para los huevos y pichones.

Numerosos estudios en Europa y Norteamérica demuestran la competencia entre el estornino y otras especies de aves que nidifican en cavidades. En Europa Mazgajski (2000) observó que el 25\% de los nidos de Trepador Azul (Sitta europea) fueron usurpados por estorninos y sólo el $20 \%$ de los trepadores que fueron desplazados de sus nidos lograron posteriormente nidificar con éxito. Mazgajski (2003) observó que en las zonas donde la competencia con estorninos era mayor, la reocupación de nidos por el Pico Picapinos disminuía y debían excavar nuevos nidos, disminuyendo su éxito reproductivo. En el Oeste de Estados Unidos el estornino compite exitosamente por cavidades en árboles con el Carpintero Bellotero. En respuesta a la pérdida del nido, estos carpinteros fabrican más cavidades (Troetschler 1976). En esa misma región Kerpez y Smith (1990) registraron competencia con 
el Carpintero del Gila por cavidades construidas en cactus (Carnegiaea gigantea) por los carpinteros. Wesolowski (2007) observó que de una comunidad de aves que nidifican en cavidades la especie que utilizó para nidificar en mayor porcentaje $(60 \%)$ cavidades construidas por carpinteros fue el Estornino Pinto, mientras que otras especies utilizaron principalmente cavidades generadas por degradación natural. En el Sudeste de Estados Unidos, Ingold (1989) observó que el 52\% de las cavidades utilizadas por el Carpintero de Carolina y el $7 \%$ de las utilizadas por el Carpintero Cabecirrojo fueron usurpadas por estorninos. En el Noreste de Estados Unidos el estornino compite por cavidades con el Carpintero Escapulario y en consecuencia esta especie retrasa su reproducción, lo que provoca una disminución en el tamaño de las nidadas, en la cantidad de pichones y de volantones (Ingold 1996, 1998). En el período 1990-1992 se registró una pérdida del 39\% de nidos de Carpintero de Carolina, del 15\% de nidos de Carpintero Cabecirrojo y del 14\% de Carpintero Escapulario debido a la competencia con estorninos (Ingold 1994). En el período 1994-1996 la usurpación de cavidades de Carpintero Escapulario por parte de estorninos ascendía al 68\% (Ingold 1998). Martin y col. (2004) observaron una baja tasa de usurpación de nidos de carpinteros por parte de los estorninos debido a que las cavidades utilizadas por carpinteros se encontraban a menor altura que las utilizadas por estorninos y los estorninos utilizaban árboles vivos en mayor proporción que la disponibilidad en relación a los árboles muertos.

En el parque Pereyra Iraola pudimos comprobar que podría existir competencia entre el Estornino Pinto y los Carpinteros Campestre y Real, pero hasta el momento los registros son escasos en comparación con los de Europa y Norteamérica (Troeschler 1976, Ingold 1989, Kerpez y Smith 1990, Mazgajski 1994) y no permiten obtener resultados concluyentes. En nuestro país se encuentran 21 especies de carpinteros, muchos de los cuales se distribuyen en la misma zona donde se encuentra el Estornino Pinto y con los cuales podría estar compitiendo o podría comenzar a competir cuando aumente la densidad poblacional del estornino, debido a que si las cavidades generadas por degradación natural no llegaran a satisfacer los requerimientos de la población de Estornino Pinto podrían comenzar a utilizar una mayor cantidad de cavidades construidas por carpinteros. Además la expansión poblacional del estornino podría tornarlo un potencial competidor para nuevas especies.

En cuanto a la competencia con psitácidos, en Australia la competencia entre el estornino y el Perico Dorsirrojo por cavidades para nidificar son poco frecuentes debido a diferencias en el ambiente utilizado preferentemente por cada especie (Pell y Tidemann 1997). En el parque Pereyra Iraola observamos que al menos dos especies de psitácidos (el Chiripepé Cabeza Verde y el Calancate Ala Roja) pueden utilizar las mismas cavidades que el estornino. Por 
este motivo, aunque aún no se han observado interacciones, estas especies son potenciales competidores del estornino.

A pesar de que en la zona donde nidificaron los estorninos los nidos de hornero son abundantes, no se registraron ocupaciones de nidos de hornero por estorninos. Esto podría indicar una preferencia de los estorninos por cavidades en árboles, construcciones humanas o cajas-nido en lugar de por nidos cerrados de esa especie.

Hasta el momento, en la Argentina los registros de interacciones agresivas entre los estorninos y aves nativas son escasos (ver Ruda Vega 2004). En un estudio realizado en la ciudad de Buenos Aires, Rebolo Ifrán y Fiorini (2010) detectaron que el $30 \%$ de las cavidades utilizadas para nidificar por los estorninos habían sido construidas por carpinteros y en estos casos, los estorninos desplazaron a los individuos que las estaban utilizando. En la provincia de Mendoza, Zanotti (2013) registró la competencia por una cavidad entre estorninos y una pareja de Carpintero Real y finalmente los carpinteros abandonaron el lugar.

En Europa, a pesar de que existe competencia con varias especies de aves por cavidades para nidificar, las interacciones son menos intensas que en Norteamérica, probablemente debido a que en Europa estas especies han vivido simpátricamente durante siglos y han logrado desarrollar estrategias para evitar la competencia. La competencia es mayor en Norteamérica, donde el estornino fue introducido a fines del siglo XIX y las interacciones entre las distintas especies son muy recientes en términos evolutivos (Mazgajski 2000).

En Suecia Nilsson (1984) observó que al incrementarse la densidad del Trepador Azul (Sitta europaea) también aumentó la competencia con el Estornino Pinto y en consecuencia comenzó a registrarse una mayor proporción de intentos de nidificación fallidos por parte del trepador. En el parque Pereyra Iraola un aumento poblacional del estornino y de otras especies en la zona podría generar en un futuro una baja disponibilidad de cavidades, aumentando la competencia por las mismas y afectando el éxito reproductivo de las especies competidoras. A pesar de que en el presente trabajo no se observaron nidos de hornero ocupados por estorninos, en otras zonas de la Provincia de Buenos Aires sí se han registrado (Rizzo 2010) y sería posible especular que una baja disponibilidad de cavidades por individuo, podría promover la utilización de nidos de hornero por estorninos.

El parque Pereyra Iraola se encuentra conformado por un mosaico de ecosistemas con diferentes grados de antropización. La flora nativa del lugar presenta problemas de conservación causados principalmente por la invasión de especies exóticas (Ministerio de Asuntos Agrarios). Particularmente la zona del parque Pereyra Iraola en la que se realizó este estudio presenta un grado intermedio de intervención antropogénica, con una importante implantación de especies vegetales exóticas y presencia de personas y vehículos 
especialmente los fines de semana y feriados. Estas modificaciones del hábitat y el disturbio ambiental afectan a todas las aves que habitan el lugar, tanto a las introducidas como a las nativas. Las aves nativas se encuentran por primera vez con nuevas condiciones donde los recursos alimenticios y los sitios para nidificar son diferentes a los que encontraban naturalmente. Ante las mismas condiciones la respuesta de las distintas especies puede ser diferente. El estornino es un ave con una gran capacidad invasora que se ha establecido exitosamente en numerosas áreas con características muy diferentes, mostrando una gran capacidad de adaptación a los distintos recursos alimenticios y sitios de reproducción, por lo que se espera que tenga una mayor facilidad para adaptarse a las condiciones del parque Pereyra Iraola que las aves nativas que no han enfrentado situaciones similares en el pasado. En la zona de estudio se encuentran principalmente especies vegetales exóticas que forman parte de la vegetación en distintos países del mundo donde el estornino es nativo y de otros sitios donde se ha establecido exitosamente. Entre estas especies, los cipreses, plátanos y la Acacia Negra fueron los árboles más utilizados para nidificar por el estornino en este trabajo. Esto representa una ventaja adicional para el estornino con respecto a las aves nativas de la zona, quienes se encuentran con estas especies vegetales por primera vez. Particularmente, la situación de los nidificadores primarios es la más complicada si tenemos en cuenta que no sólo deben enfrentarse a modificaciones en su hábitat sino también a la competencia por cavidades con especies exóticas provenientes tanto de Eurasia como del norte de la Argentina. En cambio, el estornino ha competido por cavidades con otras especies desde tiempos remotos y esto le ha llevado a desarrollar estrategias evolutivas para ganar la competencia. Sin embargo el encuentro con especies competidoras con las que nunca compartió el territorio representa un nuevo desafío para esta especie exótica.

Esta situación constituye un nuevo filtro evolutivo que determinará que algunas especies se adapten a estas nuevas condiciones o que algunas se extingan. El estudio de este ecosistema a largo plazo es importante para conocer la respuesta de las distintas especies ante los cambios y los efectos sobre las distintas poblaciones.

Para concluir, se pudo determinar que el estornino es actualmente el ave que nidifica en cavidades más abundante en el parque Pereyra Iraola. Las cavidades que utiliza presentan características similares a las que utilizan otras aves de la zona, lo que las convierte en potenciales competidoras, especialmente de los carpinteros, con quienes ya se registraron situaciones de competencia y usurpación de dos cavidades. Por este motivo es importante que las autoridades tomen medidas de control sobre la población del estornino para evitar que esta 
especie invasora comience a competir con otras especies y para atenuar el impacto sobre las especies con las que ya podría estar compitiendo. También es necesario continuar con los estudios para determinar efectivamente el impacto de la presencia del Estornino Pinto sobre el éxito reproductivo de la comunidad de aves que anidan en cavidades y el nivel real de competencia por cavidades. 


\section{CAPÍTULO 4: BIOLOGÍA REPRODUCTIVA DEL ESTORNINO PINTO}

\section{INTRODUCCIÓN}

La reproducción es un factor crítico en los ciclos de vida de las aves y está íntimamente relacionado a las fluctuaciones en los números poblacionales (Newton 1998). El tamaño de la nidada, el cuidado parental, la supervivencia de huevos y pichones, las tasas de crecimiento, las tasas de depredación son algunos de los principales parámetros reproductivos que influyen en la dinámica poblacional de las aves (Roff 1992).

\section{Tamaño de la puesta}

El tamaño de puesta es un rasgo de la historia de vida de las aves muy importante ya que impone un límite a la cantidad máxima de descendientes que pueden producir (Winkler y col. 2002). Las diferencias en el tamaño de la puesta se encuentran a nivel intra e interespecífico y se agrupan en dos categorías principales: diferencias ecológicas (relacionadas con el ambiente y con variaciones estacionales) y taxonómicas (Yom-Tov 1994, Young 1994). En cuanto a las variaciones estacionales, en distintas especies de aves se observó que el tamaño de puesta disminuye cuando la puesta se inicia más tarde durante la temporada reproductiva (Rickleffs 1979, Young 1994, Brown y Brown 1999). Esto podría estar relacionado a una disminución en la condición física de los padres luego de haber realizado nidadas previas (Haywood y Perrins 1992, Young 1994, Verhulst y col. 1995,) o a una fluctuación en las condiciones ambientales, como una menor disponibilidad de alimentos (Lack 1954, Young 1994).

El tamaño de puesta también puede variar latitudinalmente. Se ha observado que las aves que nidifican a menores latitudes ponen una menor cantidad de huevos que aquellas que lo hacen a mayores latitudes. Esta variación latitudinal se ha documentado en numerosas especies (Murray 1985, Yom-Tov y col. 1994, Young 1994), entre ellas el Estornino Pinto (Kessel 1957, Feare 1984).

\section{Eclosión de huevos}

Si bien el tamaño de la puesta impone el límite máximo de pichones que pueden nacer en una nidada, pueden ocurrir fallas en la eclosión que generen que el número de pichones en el 
nido sea menor al tamaño de la puesta. Estas fallas en la eclosión pueden encontrarse determinadas por varios factores como infertilidad, defectos genéticos del desarrollo, fallas en el intercambio de gases y vapor de agua, en el régimen de incubación o por destrucción mecánica (Webb 1987). Las especies de aves, tanto introducidas como nativas, que han atravesado un cuello de botella importante, han mostrado fallas en la eclosión más altas que especies que no pasaron por este proceso (Briskie \& Mackintosh 2004). Sin embargo, se desconoce si ocurrieron múltiples eventos de introducción de la especie lo cual podría haber incrementado la variabilidad genética de los individuos presentes actualmente en la zona de estudio, lo que podría favorecer una menor falla en la eclosión.

\section{Reducción de nidada}

En muchas aves paseriformes la incubación se inicia antes de completar la puesta de los huevos (Clark y Wilson 1981). Cuando esto ocurre, el desarrollo embrionario de los huevos comienza a distintos tiempos y eclosionan de manera asincrónica (Stouffer y Power 1991) estableciéndose una jerarquía entre los pichones donde aquellos que nacieron primero presentan un mayor peso corporal y en consecuencia una ventaja competitiva respecto a los hermanos que nacieron después y en consecuencia son más pequeños (Seddon y Van Heezik 1991). La hipótesis de la reducción de nidada ("brood reduction") propuesta por Lack (1954) considera que la eclosión asincrónica es un mecanismo que permite maximizar la calidad de los pichones. Los pichones que nacen primero son más grandes y activos y por lo tanto piden alimento con mayor intensidad que los pichones más pequeños, en consecuencia los padres alimentan con mayor frecuencia a los pichones más grandes (Braun y Hunt 1983). Cuando estos están satisfechos disminuyen su pedido de alimento y los padres comienzan a alimentar a los pichones más pequeños (Ricklefs 1965). Cuando la disponibilidad de alimentos es alta toda la nidada puede ser alimentada, pero cuando el alimento es escaso sólo los pichones más grandes sobreviven y los más pequeños (generalmente los últimos en eclosionar) mueren por inanición (Lack 1954, Stouffer y Braun 1995).

Como ocurre en la mayoría de las especies altriciales, el Estornino Pinto presenta una eclosión asincrónica (Dunnet 1955, Feare 1984). En consecuencia, varios autores han registrado que la reducción de nidada es frecuente (Dunnet 1955, Collins y de Vos 1966, Stouffer y Power 1991, Stouffer y Braun 1995).

\section{Variables ambientales}

La temperatura ambiental tiene consecuencias importantes en las distintas etapas de la reproducción de las aves. Por un lado, el momento de inicio de la puesta se encuentra 
determinado por la temperatura ambiental, de manera que en los años en que se observan temperaturas primaverales más elevadas, la puesta de huevos se adelanta (Slagsvold 1976, Dunn y Winkler 1999). Durante el período de puesta, las temperaturas ambientales bajas producen un aumento de la tasa de pérdida de calor del huevo, generando un mayor gasto energético por parte de los padres durante la incubación. Además temperaturas muy altas aumentan el riesgo de un desarrollo anormal del embrión y disminuyen su viabilidad (Deeming y Ferguson 1991).

\section{Morfometría de huevos}

El tamaño de los huevos se encuentra determinado en gran medida por factores hereditarios (Moss y Watson 1982) y varía considerablemente intra e interespecíficamente (Amundsen y Stokland 1990). Estas variaciones pueden observarse entre distintos años, estaciones, de acuerdo al tamaño de la puesta, de acuerdo a la posición en la secuencia de la puesta y entre las distintas hembras de una población (Parsons 1976, Howe 1976, Slagsvold 1982). Numerosos trabajos han demostrado que el tamaño y la calidad de los huevos tienen un efecto sobre distintos parámetros reproductivos como el éxito de eclosión, el peso de los pichones al nacer, la tasa de crecimiento y la supervivencia de los pichones (Howe 1976, Martin 1987, Amundsen y Stokland 1990, Williams 1994, Perrins 1996).

La biología reproductiva del Estornino Pinto ha sido ampliamente estudiada en distintas partes del mundo como en Europa, donde el estornino es un ave nativa, (Lack 1948 a, Dunnet 1955, Luniak 1977, Ojanen 1979, Feare 1984, Feare y Forrester 2002), en Nueva Zelanda, donde fue introducido hacia 1862 (Moeed y Dawson 1979, Källander y Karlsson 1993) y en Norteamérica, donde fue introducida a finales del siglo XIX (Moore 1984, Royall 1966, Kessel 1957, Rickleffs 1979, Collins y de Vos 1966). Sin embargo, es importante estudiarla en cada lugar donde esta especie es introducida debido a que en cada sitio debe enfrentar condiciones particulares que determinarán su éxito reproductivo.

\section{OBJETIVOS DEL CAPÍTULO}

a) Describir distintos parámetros de la biología reproductiva del Estornino Pinto (período de nidificación, tamaño de las puestas, éxito de eclosión, supervivencia de pichones) en el parque Pereyra Iraola.

b) Determinar si existen diferencias interanuales, entre la primera y la segunda nidada y entre nidadas tempranas y tardías en los distintos parámetros reproductivos del Estornino Pinto. 
c) Evaluar si la temperatura máxima y las precipitaciones afectan el tamaño de la nidada, el éxito de eclosión, y el éxito del nido.

d) Analizar el efecto de la temperatura máxima, las precipitaciones y el tamaño de la nidada sobre la ocurrencia de reducción de nidada.

e) Determinar si existen variaciones en el tamaño de los huevos entre años y nidadas y analizar posibles correlaciones entre el tamaño de los huevos y el éxito de eclosión.

\section{MATERIALES Y MÉTODOS}

Durante las temporadas reproductivas 2010, 2011, 2012 y 2013 se realizó un estudio sobre la biología reproductiva del Estornino Pinto utilizando 30 cajas-nido en el 2010 y 50 los siguientes años.

Las cajas-nido fueron revisadas cada 1-4 días entre los meses de agosto y diciembre con excepción del primer año que comenzaron a revisarse en octubre. En cada visita al nido se registró la etapa del ciclo reproductivo (construcción, puesta, incubación, pichones) (Fig. 4.1). Los huevos eran numerados con marcador indeleble el día que se los veía por primera vez. El peso de los huevos se obtuvo con una pesola de $10 \mathrm{~g}$ y se midieron el ancho y largo con calibre digital. El volumen de los huevos se estimó mediante la siguiente fórmula: $\mathrm{V}=\mathrm{K} \times \mathrm{L}$ $\times \mathrm{A}^{2}$ (Hoyt 1979), donde $\mathrm{V}$ es el volumen, L la longitud del huevo, A el ancho y K una constante especie específica. En este caso se utilizó $\mathrm{K}=0,51$ (Greigh-Smith 1986). Los pichones fueron individualizados a mediante marcas en sus tarsos.

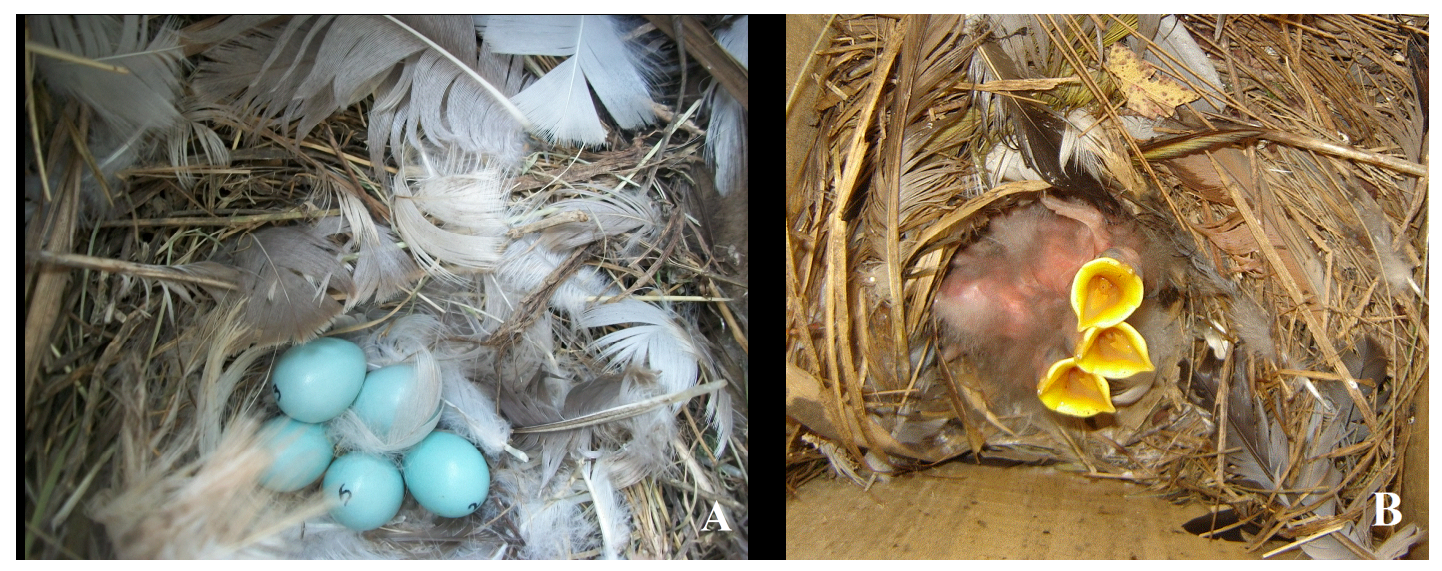

Fig. 4.1: Contenido de dos cajas-nido. A) nido con cinco huevos de estornino en período de incubación, B) nido con tres pichones de estornino de dos días de edad. 
En cada nido se registraron las siguientes variables: tamaño de la puesta (número de huevos por nido), cantidad de huevos que llegaron al final de la incubación, tamaño de la nidada (cantidad de pichones que nacieron en cada nido) y cantidad de pichones que sobrevivieron por nido.

Se calculó la proporción de huevos que llegaron al final de la incubación en relación a la cantidad de huevos puesto, se calculó el éxito de eclosión como la cantidad de pichones nacidos en relación a la cantidad de huevos que llegaron al final de la incubación. En estos cálculos se excluyeron 5 nidos (año 2010) que al ser visitados por primera vez ya tenían pichones. La supervivencia de los pichones se calculó como la cantidad de pichones que abandonaron el nido exitosamente en relación a los pichones nacidos en cada nido. Se determinó el éxito del nido considerando exitosos a los nidos donde se completó la puesta y produjo al menos un volantón.

Se determinó si hubo reducción de nidada en cada nido considerando que hubo cuando el pichón más pequeño o los dos más pequeños de la nidada murieron antes de cumplir una semana de vida mientras que sus hermanos siguieron vivos. No se consideraron en los análisis de reducción de nidada los nidos donde la cantidad pichones fue igual a $1 \mathrm{ni}$ los nidos donde todos los pichones murieron entre una visita y la siguiente. En el siguiente capítulo veremos que se realizó un experimento en el cual se colocó insecticida en 28 nidos de las temporadas reproductivas 2012 y 2013. Estos nidos solo fueron considerados para calcular el tamaño de la puesta y quedaron excluidos para el resto de los análisis.

Los pichones encontrados muertos en los nidos se extrajeron y se conservaron en freezer a $-20^{\circ} \mathrm{C}$ para analizar la alimentación y los ectoparásitos (Ver capítulo 6 y 7).

El período reproductivo se dividió en dos etapas, una primera iniciada a fines de septiembre y durante el mes de octubre y una segunda etapa transcurrida en los meses de noviembre y diciembre. En los nidos donde una misma pareja tuvo dos intentos reproductivos a las nidadas iniciadas durante la primera etapa se las consideró primeras nidadas y segundas nidadas a las iniciadas en la segunda etapa. En los casos de parejas con un único intento reproductivo a las nidadas iniciadas en la primera etapa se las consideró tempranas y tardías a las inicidas durante la segunda etapa.

\section{Análisis estadístico}

El tamaño de las puestas, la cantidad de pichones nacidos y la cantidad de pichones que sobrevivieron siguieron distribuciones normales por lo que se utilizaron test de Student y Análisis de la Varianza (ANOVA) para analizar las diferencias de estas variables entre la 
primera y la segunda etapa de la temporada reproductiva dentro de cada año y entre años respectivamente.

La proporción de huevos que llegaron al final de la incubación en relación a los huevos puestos, el éxito de eclosión y la proporción de pichones que sobrevivieron en relación a los pichones nacidos no siguieron distribuciones normales luego de realizar diversas transformaciones de los datos por lo que se utilizó la prueba de Kruskall-Wallis para realizar las comparaciones de estos parámetros reproductivos entre los distintos años. Para realizar las comparaciones entre nidadas tempranas y tardías se utilizó un análisis de Mann-Whitney. Los datos utilizados en estos análisis fueron los de las nidadas donde ocurrió un único intento reproductivo para evitar la falta de independencia de los datos.

En los nidos donde la pareja tuvo dos nidadas se realizaron análisis pareados de Wilcoxon para evaluar las diferencias en los distintos parámetros reproductivos entre la primera y la segunda nidada.

El volumen de los huevos se promedió por nido para evitar el efecto de pseudoréplicas de los huevos puestos por la misma hembra. Los datos de todas las nidadas de cada año se agruparon y compararon mediante un ANOVA para evaluar diferencias interanuales en el volumen de los huevos. Al no encontrarse diferencias significativas en este análisis, los datos de todos los años se agruparon para comparar el volumen de los huevos entre nidadas tempranas y tardías (en nidos donde sólo se produjo un evento reproductivo) mediante un test de $\mathrm{T}$ y entre la primera y la segunda nidada (en los nidos donde ocurrieron dos eventos reproductivos) mediante una prueba de $\mathrm{T}$ apareada.

Para evaluar si el tamaño de la puesta, el éxito de eclosión, la proporción de pichones que sobrevivieron por nido y el éxito del nido varía en función de la temperatura máxima y las precipitaciones se utilizaron modelos lineales generalizados mixtos (GLMM). Para esto el período reproductivo se agrupó en quincenas ( 28 de septiembre a 15 de octubre, 16 de octubre a 31 de octubre, 1 de noviembre a 15 de noviembre, 16 de noviembre a 30 de noviembre y 1 de diciembre a 15 de diciembre) y se consideró el promedio de la temperatura máxima y la sumatoria de las precipitaciones de la quincena en la que se inició la puesta en cada nido. En todos los casos la temperatura y las precipitaciones se incluyeron como efectos fijos y la pareja como efecto aleatorio. Para analizar el éxito del nido se consideró 1 si el nido produjo al menos un volantón y 0 si los pichones murieron o los huevos no eclosionaron. En los análisis de éxito de eclosión, proporción de pichones que sobrevivieron por nido y éxito del nido se utilizaron modelos con distribución de errores binomial y para el tamaño de la nidada 
se utilizó un modelo con distribución Poisson y enlace logarítmico. Para obtener un modelo mínimo adecuado se empleó el procedimiento de selección hacia atrás, removiendo las variables menos significativas en orden decreciente de $P$ dentro del mismo nivel (R Development Core Team 2012, Pinheiro y Bates 2000).

Los datos climáticos (temperatura máxima y precipitaciones) se obtuvieron de la estación meteorológica Quilmes ( $\left.34^{\circ} 44^{\prime} 42 \mathrm{~S}, 58^{\circ}{ }^{1} 4^{\prime} 53 \mathrm{O}\right)$.

Se evaluó si el volumen del huevo se correlacionó con el éxito de eclosión obteniendo el coeficiente de correlación de Spearman. Para esto se utilizaron los datos de los huevos de las nidadas únicas y de las primeras nidadas en los casos en que hubo una nidada posterior para mantener la independencia de los datos.

\section{RESULTADOS}

\section{Patrón estacional}

Las primeras puestas de las diferentes temporadas reproductivas comenzaron el 28 de septiembre en el año 2010, el 5 de octubre en el 2011, el 25 de septiembre en el 2012 y el 7 de octubre en el 2013. El fin de las temporadas reproductivas (día en el que se encontraron los últimos pichones vivos en un nido) fueron el día 6 de diciembre en el 2010, el 23 de diciembre en el 2011, el 17 de diciembre en el 2012 y el 27 de diciembre en el 2013.

El patrón del número de puestas que comenzaron en cada quincena mostró que durante la primera quincena de octubre un gran número de nidos comenzaron sincrónicamente. En la segunda quincena de octubre se observó un descenso abrupto en el número de puestas iniciadas. Luego durante el mes de noviembre se observó un segundo pico en el número de puestas iniciadas, mayormente en la primera quincena pero que continuó a lo largo del mes. En esta segunda puesta la sincronía entre nidos fue menor debido a que muchas de las primeras nidadas fracasaron y las parejas volvieron a poner huevos en un segundo intento reproductivo. En estos casos, la puesta se adelantó con respecto a los nidos exitosos donde los pichones alcanzaron a independizarse exitosamente, lo cual ocurrió hacia mediados de noviembre (Fig. 4.2). La aparición de nuevas puestas en diciembre fueron esporádicas y solo se registraron siete casos durante los cuatro años de estudio, de los cuales ningún pichón sobrevivió. Solo un pichón nacido en esta fecha alcanzó los siete días de edad mientras que el resto no sobrevivió más allá de los tres días. 


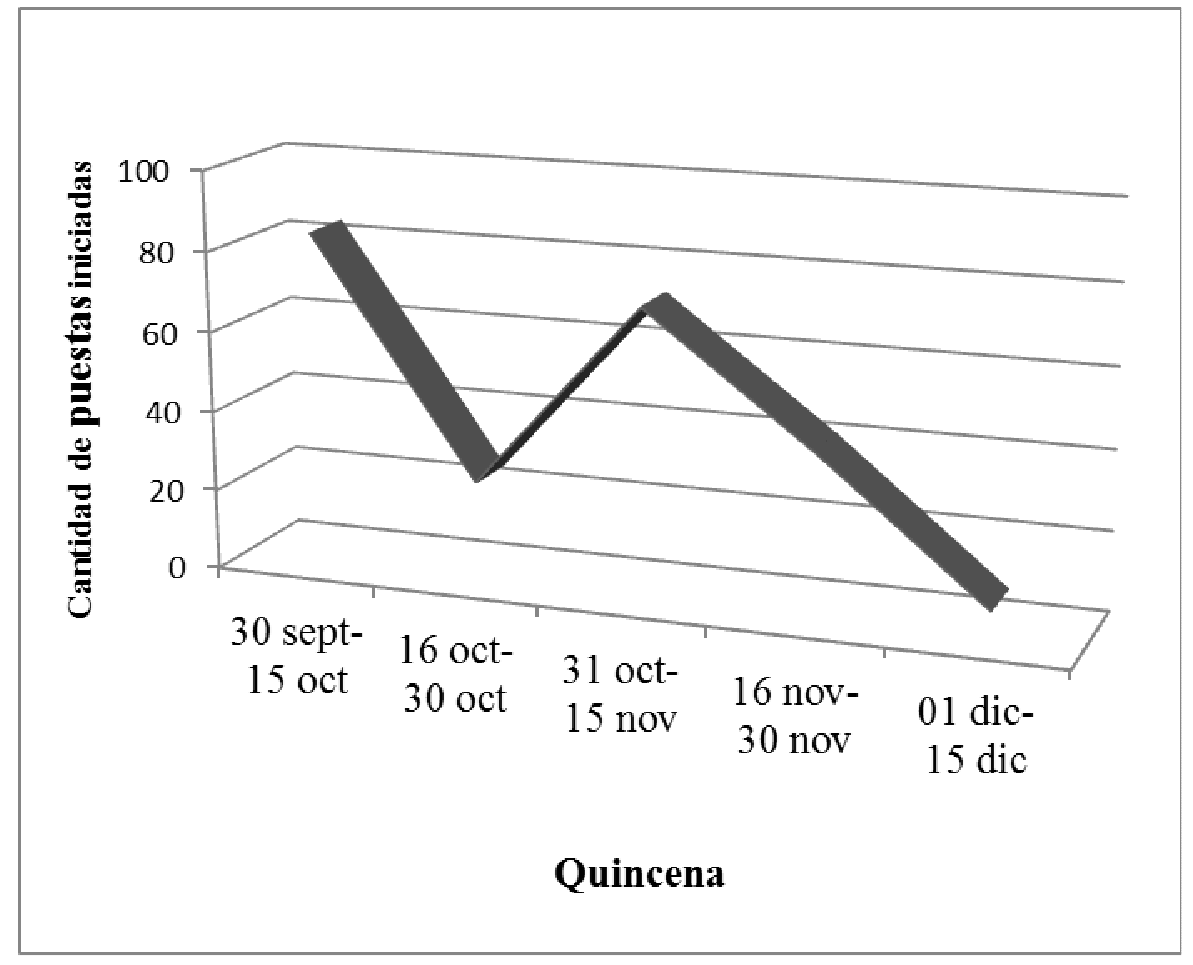

Fig. 4.2: Cantidad de nidos en los que se inició la puesta durante la temporada reproductiva.

\section{Parámetros reproductivos generales}

Se produjeron puestas en 209 nidos durante los cuatro años de estudio. Además en 19 nidos se inició la puesta pero fue abandonada luego de poner uno o dos huevos. El tamaño de puesta más frecuente fue de 4 huevos y en segundo lugar de 5. Las puestas de 1 y 6 huevos fueron poco frecuentes, registrándose sólo en 11 nidos con una puesta de seis huevos $(5,6 \%)$ y un nido donde sólo pusieron un huevo y eclosionó (Fig. 4.3 A). En el 83\% de los nidos donde se produjo la puesta, al menos un huevo llegó al final de la incubación. El porcentaje de huevos por nido que llegó al final de la incubación fue del 79\%. El éxito de eclosión total fue del $77,5 \%$ y la supervivencia de pichones por nido del $23 \%$.

Los pichones permanecieron en el nido entre 19 y 25 días. El número de pichones por nido más frecuente fue de cuatro pichones por nido y en segundo lugar de tres pichones. Sólo en un nido nacieron seis pichones en las cuatro temporadas reproductivas estudiadas (Fig. 4.3 B). En el 33\% de los nidos donde nacieron pichones (47 de 144 nidos) al menos sobrevivió un pichón y teniendo en cuenta todos los nidos donde se completó la puesta, el éxito total fue del $21 \%$. 
Durante los cuatro años de estudio sólo en cuatro de los 144 nidos donde nacieron pichones $(3 \%)$ la pérdida de la nidada pudo atribuirse a la depredación. En el resto de los nidos los pichones sufrieron un debilitamiento progresivo.
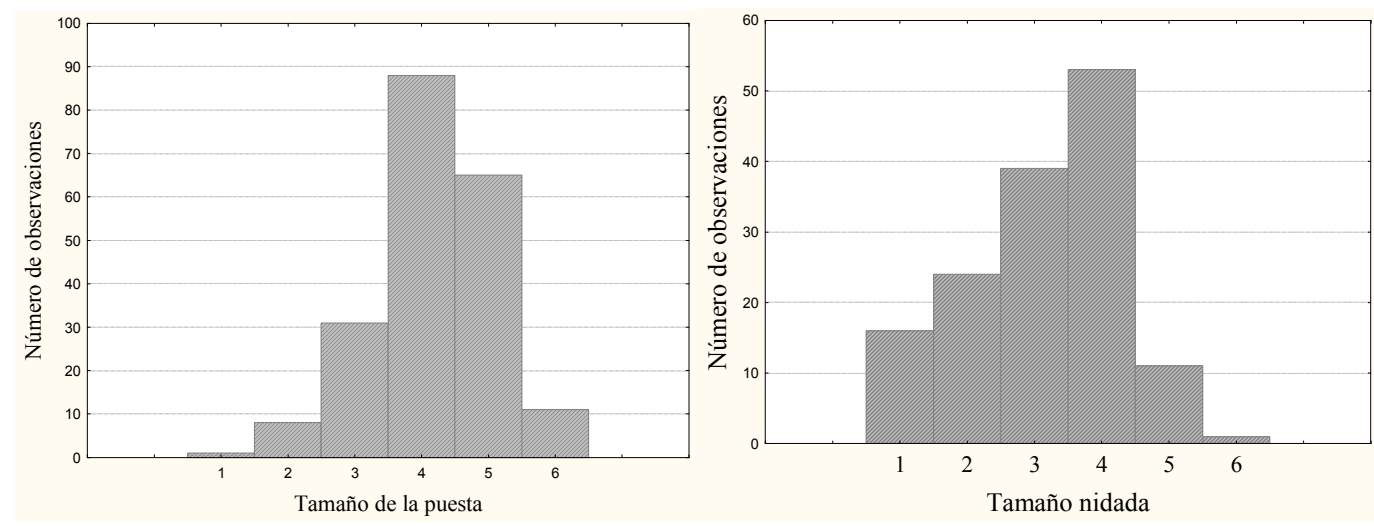

A)

B)

Fig. 4.3: Frecuencia de observación de A) tamaño de la puesta y B) número de pichones por nido en las cuatros temporadas reproductivas.

\section{Comparación de los parámetros reproductivos entre años}

Se observó una gran diferencia en el éxito de los nidos en los distintos años de estudio. En el año 2010 sólo el 9\% de los nidos fueron exitosos ( 2 de 23), en el 2011 el 9\% (5 de 54), en el 2012 el 37\% (24 de 65 nidos) y en el 2013 el 25\% (16 de 64) (Fig. 4.4). Tanto el porcentaje de nidos exitosos como la supervivencia de los pichones por nido fue mayor en el 2012 con respecto a los otros años (supervivencia de pichones por nido: Kruskal-Wallis: $\mathrm{H}=$ $32,82, P<0,01, N=145)($ Fig 4.5$)$.

No se encontraron diferencias significativas en el tamaño de la puesta (ANOVA: $F=$ $2,11, P=0,10)$, en la proporción de huevos que llegaron al final de la incubación (KruskalWallis: $\mathrm{H}=1,74, P=0,63, N=194)$ ni en el éxito de eclosión (Kruskal-Wallis: $\mathrm{H}=4,33, P=$ $0,23, N=140$ ) entre los distintos años. La cantidad de pichones nacidos por nido no varió significativamente (ANOVA: $F=1,98, P=0,12$ ) pero se encontraron diferencias en la cantidad de pichones que lograron independizarse (ANOVA: $F=7,26, P<0,01$ ) entre los distintos años. (Tabla 4.1). 


\begin{tabular}{lllll}
\hline Año & Tamaño puesta & Éxito eclosión & Pichones nacidos & $\begin{array}{l}\text { Proporción de } \\
\text { pichones que } \\
\text { sobrevivieron }\end{array}$ \\
\hline 2010 & $4,19 \pm 0,15(3-6)$, & $0,69 \pm 0,06(0,25-$ & $2,96 \pm 0,21(1-4)$, & $0,07 \pm 0,05(0-1)$ \\
& $N=21$ & $1)$, & $N=23$ & $N=23$ \\
& & $N=19$ & & \\
\hline 2011 & $4,44 \pm 0,12(2-6)$, & $0,76 \pm 0,05(0-1)$, & $3,51 \pm 0,22(1-6)$, & $0,12 \pm 0,05(0-1)$, \\
& $N=54$ & $N=39$ & $N=37$ & $N=37$ \\
\hline 2012 & $4,08 \pm 0,11(2-6)$, & $0,79 \pm 0,04(0-1)$, & $2,92 \pm 0,17(1-4)$, & $0,54 \pm 0,07(0-1)$, \\
& $N=65$ & $N=38$ & $N=38$ & $N=37$ \\
\hline 2013 & $3,68 \pm 0,16(1-6)$, & $0,82 \pm 0,03(0,25-$ & $3,15 \pm 0,16(1-5)$, & $0,17 \pm 0,04(0-$ \\
& $N=64$ & $1)$, & $N=46$ & $0,67)$, \\
& & $N=46$ & & $N=46$ \\
\hline Total & $4,06 \pm 0,13(1-6)$, & $9,78 \pm 0,27(0-1)$, & $3,15 \pm 0,10(1-6)$, & $0,24 \pm 0,03(0-1)$, \\
& $N=204$ & $N=142$ & $N=144$ & $N=143$ \\
\hline
\end{tabular}

Tabla 4.1: tamaño de la puesta, éxito de eclosión, tamaño de la nidada y proporción de pichones que sobrevivieron en los cuatro años de estudio. Se muestra la media \pm e.e., entre paréntesis mínimo y máximo y finalmente el $N$ o tamaño muestral.

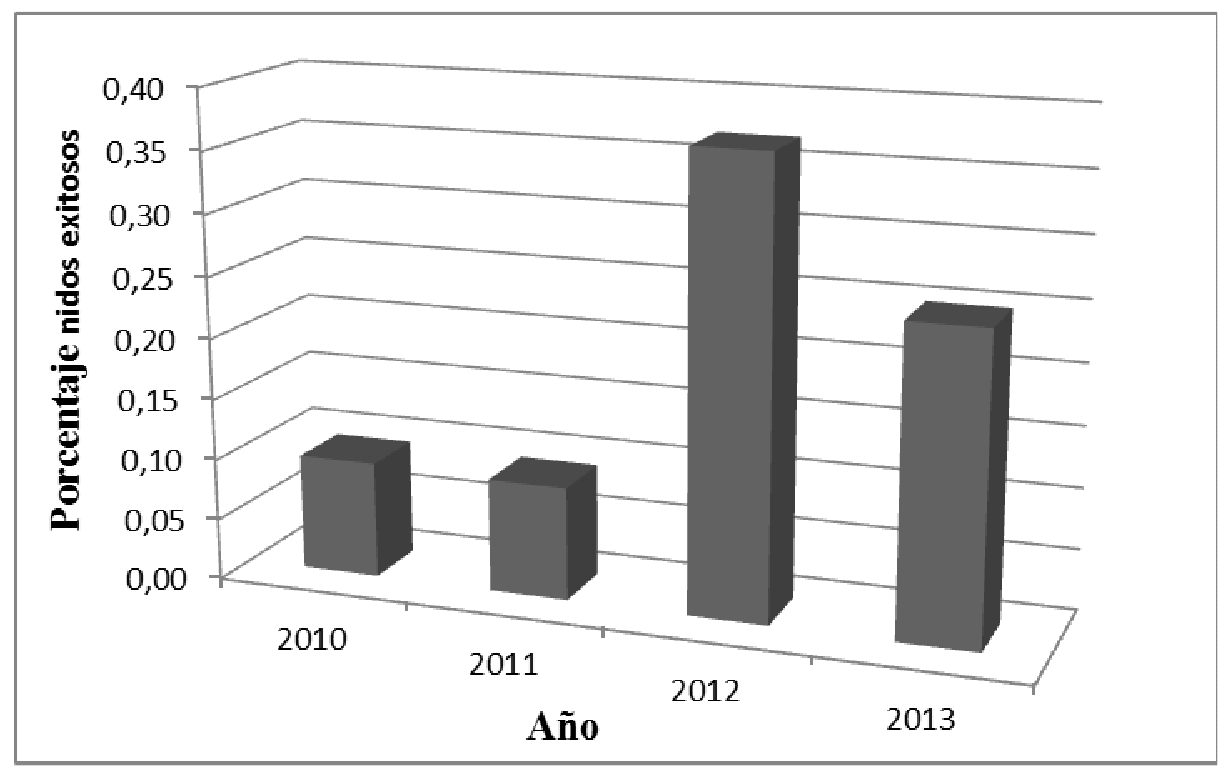


Fig. 4.4: Porcentaje de nidos exitosos y nidos que fracasaron en las distintas temporadas reproductivas.

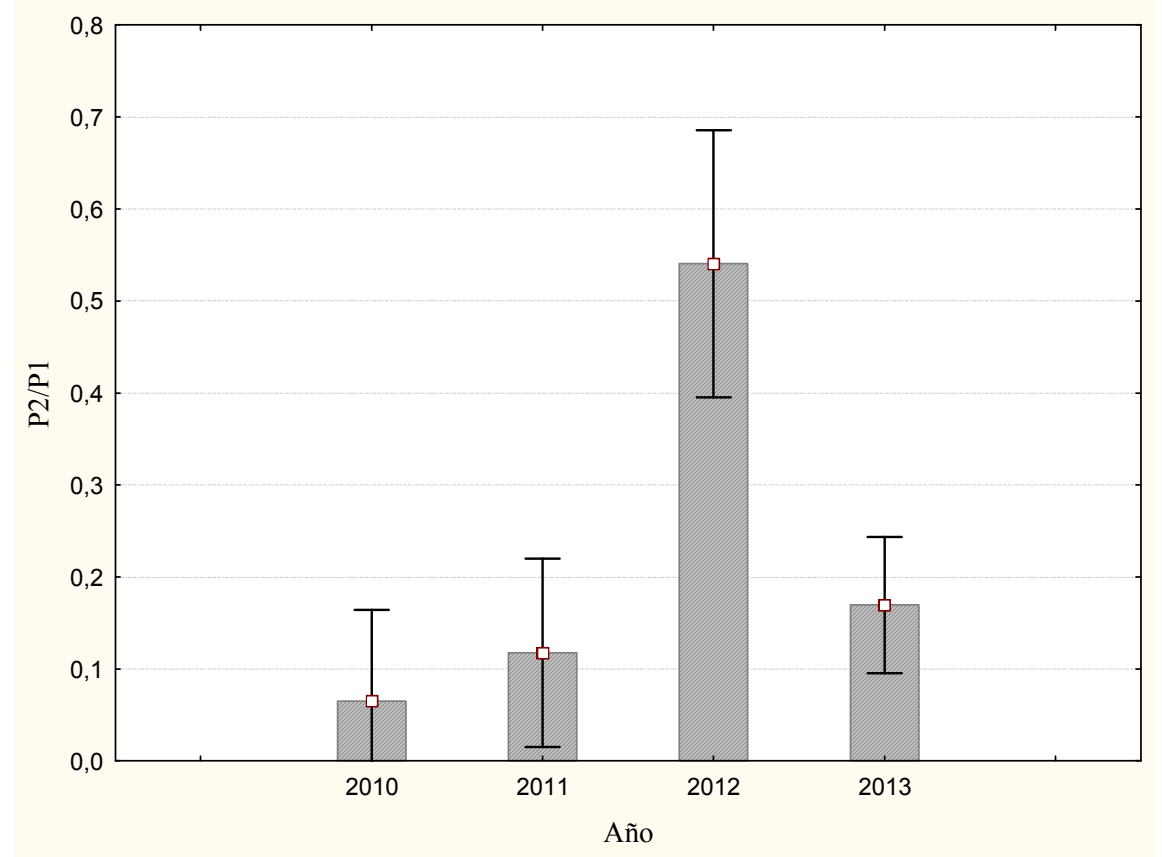

Fig. 4.5: Supervivencia de pichones en los cuatro años de estudio.

\section{Comparación de los parámetros reproductivos entre nidadas}

Analizando las cuatro temporadas juntas, el éxito total del nido fue del 38\% (21 de 55 nidos) para la primeras nidada y de 16\% para la segunda nidada (9 de 55) (Fig. 4.6 A). El porcentaje de nidos con pichones exitosos fue de $62 \%$ en la primera nidada y de $20 \%$ en la segunda. No se observaron diferencias significativas en el tamaño de la puesta (Test de Wilcoxon, $Z=1,61$, $P=0,11$ ), en la proporción de huevos que llegaron al final de la incubación en relación al tamaño de la nidada (Test de Wilcoxon, $Z=0,52, P=0,60$ ) en el éxito de eclosión (Test de Wilcoxon, $Z=0,82, P=0,41$ ) ni en la cantidad de pichones nacidos (Test de Wilcoxon, $Z=$ $0,70, P=0,48)$ entre la primera y la segunda nidada. La supervivencia de pichones por nido fue mayor en la primera nidada que en la segunda (Test de Wilcoxon, $Z=-3,18, P<0,01$ ) (Tabla 4.2, Fig. 4.6 B). 


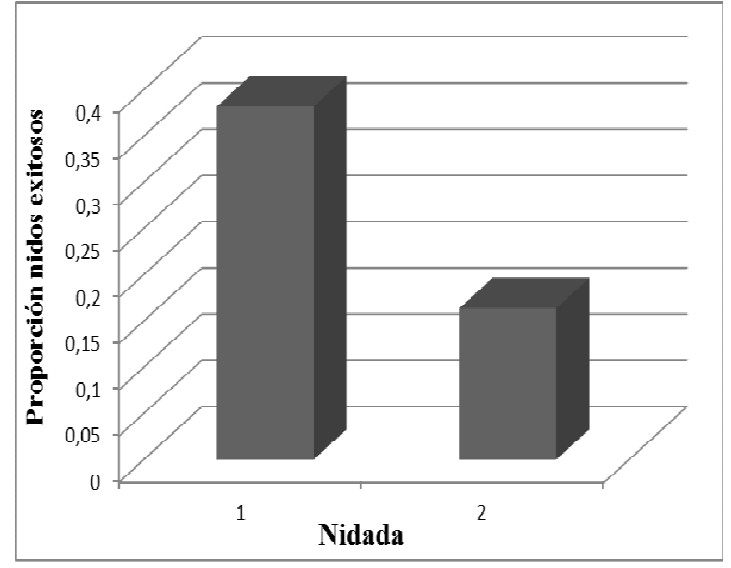

A)

Fig. 4. 6: A) Proporción de nidos exitosos. pichones nacidos en la primera y la segunda nidada.$$
\text { pichones nacidos en la primera y la segunda nidada. }
$$

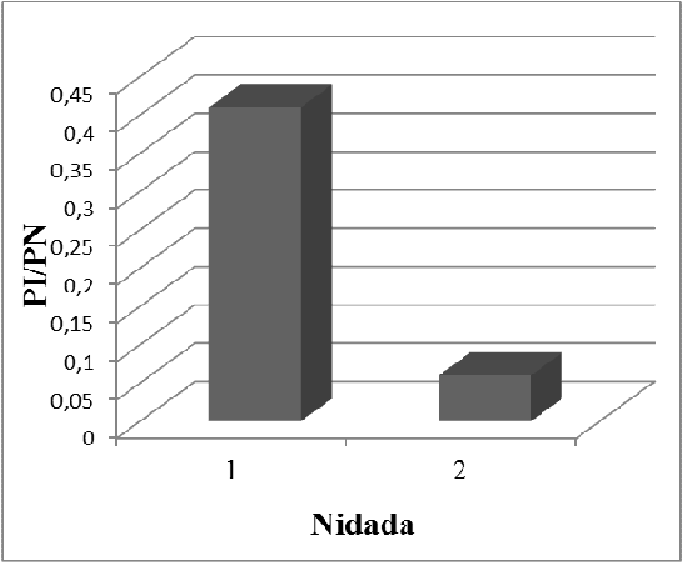

B)

) $\mathrm{PI} / \mathrm{PN}=$ pichones que se independizaron /

\begin{tabular}{llllll}
\hline Nidada & $\begin{array}{l}\text { Tamaño } \\
\text { puesta }\end{array}$ & Éxito eclosión & $\begin{array}{l}\text { Pichones } \\
\text { nacidos }\end{array}$ & $\begin{array}{l}\text { Proporción de } \\
\text { pichones que } \\
\text { sobrevivieron }\end{array}$ \\
\hline 1ra & $3,85 \pm 0,13$ & $0,81 \quad \pm$ & 0,05 & $3,11 \pm 0,21$ & $0,41 \pm 0,08$ \\
& $(2-6)$, & $(0,25-1)$ & $(1-5)$ & $(0-1)$ \\
& $4 N=55$ & $N=24$ & & $4 N=26$ & $N=26$ \\
\hline 2 da & $4,13 \pm 0,13$ & $0,76 \quad \pm$ & 0,05 & $2,92 \pm 0,24$ & $0,06 \pm 0,04$ \\
& $(1-6)$, & $(0,25-1)$ & & $(1-5)$ & $(0-0,67)$ \\
& $5 N=55$ & $N=24$ & & $4 N=26$ & $N=26$ \\
\hline
\end{tabular}

Tabla 4.2: tamaño de la puesta, éxito de eclosión y supervivencia de pichones en la primera y segunda nidada. Se muestra la media \pm e.e., entre paréntesis mínimo y máximo y finalmente el $N$ o tamaño muestral.

\section{Comparación de los parámetros reproductivos entre nidadas tempranas y tardías}

Al considerar sólo los nidos donde se produjo un único intento reproductivo no se observaron diferencias significativas en el tamaño de la nidada, (Test de $\mathrm{t}: U:-1,02, P=0,31$ ) enla proporción de huevos que llegaron al final de la incubación (Man-Whitney: $\mathrm{U}=451, P=$ 0,42 ), en el éxito de eclosión (Man-Whitney: $U=293,5, P=0,16$ ) y en la cantidad de pichones 
nacidos por nido (Test de t: $U: 0,55, P=0,58$ ) entre las nidadas tempranas (fecha de iniciación hasta el 31 de octubre) y las nidadas tardías (iniciadas en noviembre y diciembre). En las nidadas tempranas la supervivencia de pichones fue significativamente mayor que en las nidadas tardías (Man-Whitney: $\mathrm{U}=288,5, P=0,02$ ) (Tabla 4.3).

\begin{tabular}{cllll}
\hline Nidadas & Tamaño puesta & Éxito eclosión & Pichones nacidos & $\begin{array}{l}\text { Proporción de } \\
\text { pichones que } \\
\text { sobrevivieron }\end{array}$ \\
\hline Tempra & $4,27 \pm 0,15$ & $0,84 \quad \pm \quad 0,05$ & $3,38 \pm 0,22$ & $0,33 \pm 0,08$ \\
nas & $(2-6)$, & $(0,20-1)$ & $(1-5)$ & $(0-1)$ \\
& $N=33$ & $N=24$ & $4 N=24$ & $N=24$ \\
\hline \multirow{2}{*}{ Tardías } & $4,47 \pm 0,13$ & $0,74 \quad \pm \quad 0,04$ & $2,21 \pm 0,20$ & $0,12 \pm 0,05$ \\
& $(3-6)$, & $(0,20-1)$ & $(1-5)$ & $(0-1)$ \\
& $N=40$ & $N=34$ & $4 N=34$ & $N=34$ \\
\hline
\end{tabular}

Tabla 4.3: tamaño de la puesta, éxito de eclosión y proporción de pichones que sobrevivieron por nido en las nidadas tempranas y tardías. Se muestra la media \pm e.e., entre paréntesis mínimo y máximo y finalmente el $N$ o tamaño muestral.

\section{Reducción de nidada}

Se produjo reducción de nidada en el 37,9\% de los nidos (47 de 124 nidos). En el 72,3\% de los nidos (34 de 47 nidos) murió un pichón y en el 25,5\% (12 de 47 nidos) murieron los dos pichones más pequeños de la nidada. La edad media a la cual se produjo la muerte de estos pichones fue de 2,90 $\pm 0,30$ días. En la primera nidada se produjo reducción de nidada en 11 de 31 nidos (35\%) y en la segunda nidada en 19 de 36 nidos (53\%), esta diferencia no fue significativa (test de Fisher: $\mathrm{p}=0,22$ ).

En los nidos donde sólo se produjo una nidada la reducción de nidada se observó en 6 de 23 (26\%) nidadas tempranas y en 15 de 31 (48\%) nidadas tardías (test de Fisher: $\mathrm{p}=0,16$ ).

El GLMM no mostró un efecto de las variables climáticas ni del tamaño de la nidada sobre la reducción de nidada. Las diferencias en el tamaño de la puesta y en el éxito de eclosión no fueron explicadas por la temperatura máxima y las precipitaciones. En cambio, la temperatura máxima mostró un efecto sobre el éxito del nido (Tabla 4.4). 


\begin{tabular}{llcccc}
\hline Variable respuesta & Efectos fijos & Estimador & E.E. & $\mathrm{Z}$ & $\mathrm{P}$ \\
\hline \multirow{2}{*}{$\begin{array}{l}\text { Tamaño de la } \\
\text { puesta }\end{array}$} & Intercepto & 1,27 & 0,48 & 2,65 & $<0,01^{*}$ \\
& Tmáx & 0 & 0,02 & 0,25 & 0,8 \\
& $\mathrm{Pp}$ & 0 & 0 & 0,01 & 0,99 \\
\hline \multirow{3}{*}{ Éxito de eclosión } & Intercepto & 1,81 & 1,66 & 1,09 & 0,28 \\
& Tmáx & $-0,03$ & 0,06 & $-0,47$ & 0,64 \\
& Pp & 0 & 0 & 0,81 & 0,42 \\
\hline \multirow{3}{*}{ Éxito del nido } & Intercepto & 5,76 & 3,17 & 1,82 & 0,07 \\
& Tmáx & $-0,36$ & 0,13 & $-2,81$ & $<0,01 *$ \\
& Pp & 0.01826 & 0,01 & 1,79 & 0,07 \\
\hline \multirow{3}{*}{$\begin{array}{l}\text { Reducción de } \\
\text { nidada }\end{array}$} & Intercepto & $-8,86$ & 4,42 & $-1,00$ & 0,05 \\
& Tmáx & 0,27 & 0,15 & 1,87 & 0,06 \\
& Pp & 0,02 & 0,01 & 1,8 & 0,07 \\
& Tamaño & & & & 0,69 \\
\hline
\end{tabular}

Tabla 4.4: Modelo lineal mixto generalizado que evalúa la variación en distintos parámetros reproductivos. Se muestra el estimador, el error estándar, el valor de $Z$ y $p$ para cada efecto fijo. Los valores significativos están marcados con un asterisco.

\section{Morfometría de huevos}

Se midieron 847 huevos de 221 nidos. Los huevos presentaron una coloración azulada variando desde celeste claro hasta turquesa, aunque en pocas nidadas los huevos fueron de color blanco. El largo promedio de los huevos fue de 28,76 $\pm 0,11 \mathrm{~mm}$ (mínimo= 25,70, máximo = 32,52), el ancho de $21 \pm 0,06 \mathrm{~mm}($ mínimo=19,40, máximo=23,75), el peso de $6,53 \mathrm{~g} \pm 0,54($ mínimo $=5,07$, máximo $=9,25)$ y el volumen de $6,76 \pm 0,06 \mathrm{~cm}^{3}($ mínimo $=4,75$, máximo $=8,44)$.

No se encontraron diferencias en el volumen de los huevos entre años al evaluar la totalidad de los huevos de cada temporada (ANOVA: $F=0,55, P=0,65$ ).

La prueba de T pareada no mostró diferencias significativas en el volumen de los huevos entre los huevos de la primera nidada y los de la segunda nidada (Test de $\mathrm{t}$ : $\mathrm{t}=-0,52, P=0,7$, $x 1=6,77, x 2=6,82, N=55$ ). Tampoco se observaron diferencias significativas entre los huevos pertenecientes a nidadas tempranas y tardías (Test de $\mathrm{t}: \mathrm{t}=0,36, P=0,72, x 1=6,80$, $\left.x 2=6,75, N^{1}=33, N^{2}=40\right)$. 
No se observó una correlación entre el volumen de los huevos y el éxito de eclosión $\left(\mathrm{r}_{\mathrm{s}}=0,07\right.$, $N=92, P=0,53)$.

\section{DISCUSIÓN}

En este trabajo el éxito de los nidos fue muy bajo, especialmente durante la segunda nidada. La predación ha sido considerada la principal causa de pérdida de huevos y pichones en una gran cantidad de especies de aves (Martin 2007) por lo tanto, los escasos registros de predación sugieren que otros factores o la interacción de estos estarían afectando de manera significativa el éxito de los nidos en el parque Pereyra Iraola.

Sólo en el $40 \%$ de los nidos se produjeron dos nidadas a diferencia de lo que se observa en otras áreas, donde el patrón típico es de dos nidadas durante el período reproductivo, siendo común la presencia de una tercera nidada intermedia (Lack 1948 a, Dunnet 1955, Kessel 1957, Feare 1984). Sin embargo en algunas zonas de Europa como el norte de Suiza (Lundberg 1987) y en algunas zonas del norte de Finlandia (Ojanen y col.1979) los estorninos sólo producen una nidada, de manera similar a lo observado en Argentina.

\section{Tamaño de la puesta}

El tamaño medio de la puesta en el parque Pereyra Iraola en la primera nidada $(x=3,85)$ $\mathrm{y}$ en toda la temporada reproductiva $(\mathrm{x}=4,06)$ se encuentran entre los valores más bajos registrados en los estudios de reproducción del estornino realizados en Norteamérica, Europa y Nueva Zelanda, donde la media del tamaño de la primera puesta es de entre 3,9 y 5,5 huevos por nido y entre 4,1 y 5,82 en el total de las puestas (Lack 1948 a, Dunnet 1955, Kessel 1957, Feare 1984, Collins y de Vos 1966, Luniak 1977, Ojanen 1979, Ricklefs 1979, Moore 1984, Källander y Karlsson 1993). En las aves, generalmente se produce una disminución en el tamaño de la puesta en la segunda nidada que puede atribuirse a variaciones en ciertas condiciones ambientales (como diferencias en la disponibilidad de alimento), o al desgaste de las hembras tras sucesivos intentos reproductivos (Lack 1948, Verhulst y col. 1995, Monaghan y Nager 1997). Al estudiar la biología reproductiva del estornino, tanto en Norteamérica como en Europa se registró una disminución en la cantidad de huevos por nido en la segunda puesta (Kessel 1957, Rickleffs 1979 y Collins y de Vos 1966, Lack 1948 a, Ojanen 1979, Feare 1984). De manera contraria, los resultados de esta tesis muestran un leve aumento en los valores de la media del tamaño de la puesta de la segunda nidada con respecto a la primera (primera nidada: $x=3,85$ huevos, segunda nidada: $x=4,13$ ). Esto podría relacionarse a un mayor esfuerzo reproductivo por parte de los estorninos durante la segunda 
puesta, influenciado por la baja supervivencia de pichones por nido $(x=0,41)$ de la primera nidada. Dos casos similares fueron observados en estorninos en Norteamérica por Moore (1984) y por Royall (1966).

El tamaño de puesta más frecuente para el Estornino Pinto es de tres a seis huevos por nido, pero se han reportado excepciones. Kessel registró nidadas con siete, ocho y nueve huevos, mientras que en Holanda se observaron puestas de hasta diez (Lack 1948 a). En este trabajo el tamaño de puesta máximo fue de seis huevos y las puestas de este tamaño fueron poco frecuentes $(5,6 \%)$. Cerca de un $20 \%$ de los huevos por nido no llegó al final de la incubación, una importante causa de pérdida de huevos en este período es el parasitismo intraespecífico, en el que una hembra coloca un huevo propio en un nido de otra hembra de la misma especie (Evans 1988). Durante el recorrido de la zona donde estaban las cajas-nido utilizadas en este estudio solían aparecer huevos rotos o enteros en el suelo. Esto también fue registrado por otros autores y se debería a casos de parasitismo intraespecífico en los que una hembra parásita saca un huevo de los presentes en el nido que va a parasitar para poner uno propio (Kessel 1957, Lombardo et al. 1989).

Otro caso de parasitismo de cría es el interespecífico, donde el parasitismo ocurre entre hembras de distinta especie. El éxito reproductivo de algunas especies de aves de la zona se ve afectado por este tipo de parasitismo (Reboreda et al. 2003). El Tordo Renegrido es una especie que parásita que presenta alrededor de 250 hospedadores (Lowther 2010), entre ellas varias especies de aves de la provincia de Buenos Aires (Reboreda et al. 2003). A pesar de que el Tordo Renegrido es una especie común en la ECAS (Obs. pers.), hasta el momento no se registró ningún caso de parasitismo por esta especie en los nidos de estornino pero podría convertirse en un futuro hospedador.

\section{Eclosión de huevos}

En varias especies de aves altriciales se ha observado que las puestas más adelantadas en el período reproductivo son más numerosas y exitosas (Martin 1995). Esto no se observó en el parque Pereyra Iraola, donde no se encontraron diferencias significativas en el éxito de eclosión entre la primera y segunda nidada, a pesar de que hubo una pequeña disminución (primera nidada $=81$ y segunda nidada $=76 \%$ ). Los valores de la primera nidada son levemente menores a los registrados por otros autores en Norteamérica. Por ejemplo en Canadá, el éxito de eclosión es del 90,2\% para la primera nidada y $89,5 \%$ en la segunda (Collins y de Vos 1966). En Estados Unidos, Rickleffs (1979) registró un éxito de eclosión de entre 84 y $90 \%$ en la primera nidada y entre 65 y $85 \%$ en la segunda en los distintos años, 
mientras que en ese mismo país Kessel (1957) registró un éxito de eclosión del 90 y 80\% para la primera y segunda nidada respectivamente. Tanto los valores de Norteamérica como de Argentina muestran una leve disminución en el éxito de eclosión en la segunda nidada.

Briskie y Mackintosh (2004) analizaron las fallas en la eclosión de distintas especies de aves nativas y exóticas en Nueva Zelanda que atravesaron cuellos de botellas de distintos tamaños y observaron que las especies con una población de menos de 150 individuos presentaban mayores fallas en la eclosión que las especies en las que el tamaño poblacional fue mayor a 150 individuos. En ese trabajo, la media de la falla de eclosión en las especies exóticas introducidas que fueron liberadas en números menores a 150 individuos fue de $21,6 \%$. Este valor coincide con el registrado en los nidos del parque Pereyra Iraola donde la falla en la eclosión fue del $22,5 \%$. Las especies nativas que no atravesaron ningún cuello de botella presentan solo un 3\% de fallas en la eclosión. Esta diferencia en las fallas de eclosión entre ambos grupos estarían relacionadas a una pérdida en la diversidad genética, una mayor endogamia y en consecuencia a la dificultad de purgar alelos deletéreos de las especies que sufrieron una reducción importante en su tamaño poblacional. Sin embargo, estos valores son similares a los que se registran en poblaciones de estorninos de Europa y Asia, donde los valores de las fallas en la eclosión más frecuentes se encuentran entre 10 y $20 \%$ durante la primera nidada, observándose un aumento en las fallas durante la segunda nidada (Feare 1984, Dunnet 1955, Luniak 1977). En Norteamérica las fallas en la eclosión son menores a lo registrado en las otras áreas incluyendo Argentina, con valores entre 1 y 16\%.

En Argentina si bien no existen registros de introducciones múltiples probablemente los estorninos observados en las distintas provincias provengan de distintas liberaciones o escapes debido a la distancia entre los puntos donde se registraron y a que no existe una continuidad en la distribución del estornino entre estos puntos. Sin embargo, los estorninos que se registran en las distintas localidades de Buenos Aires podrían provenir de distintos eventos de introducción lo que podría haber incrementado la variabilidad genética de la población. Sin embargo, esto no ha sido confirmado y requiere de futuros análisis moleculares.

Una hipótesis alternativa para las fallas de eclosión podría ser la relacionada a altas abundancias de ectoparásitos presentes en los nidos, especialmente durante la segunda nidada. En concordancia con esta hipótesis Clayton y Tompkins (1995) observaron que el éxito de eclosión de la Paloma Doméstica Columba livia se reducía en más del 75\% en los nidos con altas intensidades de ácaros debido a que la irritación causada por los ácaros a los padres provocaba una disminución en la frecuencia de incubación por parte de estos. 


\section{Tamaño de la nidada}

La cantidad de pichones nacidos no mostró diferencias entre la primera nidada y la segunda, a diferencia de lo observado en otros trabajos donde la cantidad de pichones que nacen disminuye en la segunda parte del período reproductivo (Lack 1948 a, Dunnet 1955, Kessel 1957, Feare 1984, Collins y de Vos 1966). Esta disminución coincide con la disminución en el tamaño de la puesta en esos países. En este trabajo no se observaron diferencias significativas en el tamaño de la nidada ni de la puesta.

La cantidad de pichones en ambas nidadas es menor en Argentina (3,11 pichones/nido en la primera nidada y 2,92 pichones/nido en la segunda) que en otros países, donde se observaron nidos con una media de entre 3,7 y 4,7 pichones en la primera nidada y de 3,3 y 4 en la segunda. Solo se registró una excepción en Estados Unidos donde Kessel (1957) observó un promedio de 2,9 pichones por nido durante la segunda nidada, valor similar al registrado en el parque Pereyra Iraola. El bajo número de pichones por nido en este trabajo sería principalmente un reflejo de la menor cantidad de huevos por nido en Argentina.

Lack (1954) sugiere que el tamaño de la nidada reflejaría el número máximo de pichones que los padres puedan alimentar. Sin embargo, no sólo importa la cantidad de pichones que sobreviven para el éxito reproductivo de la pareja sino también el peso con el cual abandonan el nido debido a que las chances de sobrevivir y llegar a reproducirse son mayores en los pichones más grandes (Feare 1984). Sin embargo en este trabajo, no solo fue bajo el número de pichones por nido sino también la supervivencia de estos y la cantidad de nidos que produjeron al menos un volantón. En la primera nidada el porcentaje de nidos con pichones exitosos fue notablemente mayor al de la segunda (éxito primera nidada $=62 \%$, segunda nidada $=20 \%$ ). En Estados Unidos el éxito de los nidos fue de $54-71 \%$ en la primera nidada y de $12-44 \%$ en la segunda (Ricklefs 1979). Los valores más bajos registrados en ese trabajo fueron una excepción al éxito que suele observarse en ese país debido a que ocurrieron en un año donde una fuerte tormenta provocó una alta mortalidad de pichones. En Inglaterra, Feare (1984) observó que entre el 80 y el $100 \%$ de los nidos donde nacieron pichones en las primeras nidadas y entre el 25 y el $81 \%$ de los nidos de segundas nidadas fueron exitosos.

\section{Reducción de nidada}

La reducción de nidada en el estornino fue registrada por numerosos autores (Lack 1948a, Dunnet 1955, Collins y de Vos 1966, Royall 1966). En el parque Pereyra Iraola se observó que el $37,9 \%$ de los nidos donde nacieron pichones sufrieron una reducción de nidada que no se encontró afectada por las variables climáticas ni por el tamaño de la nidada. Otros autores sugieren que cuando la nidada es numerosa la pérdida del o los pichones más 
pequeños por inanición sería una estrategia que permitiría evitar la pérdida de todos los pichones en momentos de escasez de alimento (Ricklefs 1967, Howe 1976, Broun y Hunt 1983, Martins y Wright 1993, Stouffer y Braun 1995).

En cuanto a la supervivencia de pichones en el parque Pereyra Iraola se registraron valores llamativamente bajos en ambas nidadas (primera nidada: $41 \%$, segunda nidada: $6 \%$ ) en comparación con los estudios realizados tanto en zonas donde el estornino es nativo como en zonas donde fue introducido. En Norteamérica la supervivencia de pichones es de entre $64 \%$ y $99 \%$ en la primera nidada y entre $18 \%$ y $96 \%$ en la segunda (Kessel 1957, Collins y de Vos 1966, Royall 1966). En Europa sobreviven entre el 82\% y el 96\% de los pichones que nacen en la primera nidada y entre el $67 \%$ y el $85 \%$ de los que nacen en la segunda (Dunnet 1957, Feare 1984, Feare y Forrester 2002).

\section{Morfometría de huevos}

Las medidas morfométricas y el peso de los huevos $(\operatorname{largo}=28,76 \mathrm{~mm}$, ancho $=21,06$ $\mathrm{mm}$, peso $=6,53$, volumen $=6,76 \mathrm{~cm}^{3}$ ) fueron menores a los registrados en Estados Unidos por Rickleffs $(1977,1984)$, quien registró un largo de 30,08 mm, un ancho de 21,17 y una masa media de 7,19 g. Por su parte en ese mismo país Kessel (1957) registró valores más cercanos a los de este trabajo, con una media de 29,2 mm de largo y 21,1 mm de ancho. En Nueva Zelanda Cassey et al. (2005) registraron una media de 29,1 x 20,9 mm de huevos de estorninos introducidos y observaron que el volumen de estos es significativamente menor que en las poblaciones de Reino Unido de donde proceden, donde la media es de 29,7 x 21,2 mm. Congdon y Briskie (2010) analizaron las variaciones morfológicas de los huevos de distintas especies de aves introducidas en Nueva Zelanda que atravesaron grandes cuellos de botella y encontraron que 6 de 13 especies en el país donde fueron introducidas presentaban huevos con tamaños menores en comparación a los huevos de las mismas especies en sus áreas de origen. En la Argentina observamos que el tamaño de los huevos es menor a los de los estorninos en Estados Unidos y en Europa, esto podría ser causado por la importante disminución en el número poblacional y consecuente pérdida de variabilidad genética al ser introducidos en este país.

Las variaciones en el tamaño de los huevos en relación al éxito de eclosión se han estudiado en distintas especies de aves. Algunos autores observaron una relación positiva entre estas variables (Eeva y Lehikoinen 1995, Krist 2011) mientras que en otros trabajos, al igual que en este, no se encontró esta relación (Meathrel et al. 1993, Robertson y Cooke 1993). 


\section{Conclusión}

El éxito reproductivo en el parque Pereyra Iraola es muy bajo en comparación con el éxito de esta especie en otras regiones del mundo donde es nativa y también donde fue introducida. Se esperaría que la falta de predación y de parasitismo de cría por parte de otras especies favorezca el éxito reproductivo del estornino, sin embargo la alta mortalidad de pichones indica que otros factores están afectando su supervivencia. En el capítulo 5 se analiza el efecto de las variables climáticas y del parasitismo por larvas de Philornis sobre la supervivencia de los pichones. 


\section{CAPÍTULO 5: EFECTOS DE LARVAS DE PHILORNIS SOBRE LA BIOLOGÍA REPRODUCTIVA DEL ESTORNINO PINTO}

\section{INTRODUCCIÓN}

Los parásitos pueden causar distintos tipos de daño en su hospedador, desde heridas tisulares hasta la muerte (Newton 1998). Al mismo tiempo existe una amplia diversidad de parásitos que pueden afectar a un mismo hospedador y que interactúan con este y entre ellos (Atkinson y col. 2008). Los costos del parasitismo son importantes a nivel poblacional especialmente cuando afectan el éxito reproductivo (Sheldon y Verhulst 1996). Los parásitos también pueden afectar a sus hospedadores de manera indirecta, por ejemplo, las aves que pierden una proporción de sus nutrientes debido a sus parásitos, se verán más afectados si deben enfrentarse a una época con escasez de alimentos que las aves no parasitadas, y a su vez, podrían ser más vulnerables al contagio de otras enfermedades (Newton 1998).

Dentro de los parásitos de aves, un caso particular lo constituyen las moscas del género Philornis que presentan estadios larvales que parasitan a pichones de aves (Arendt $1985 \mathrm{~b}$, Uhazy y Arendt 1986, Couri et al 2005). El parasitismo por larvas de Philornis puede afectar el éxito reproductivo de las aves al retrasar el crecimiento y desarrollo (Arendt 1985 a, Fessl 2006 a, Rabuffetti y Reboreda 2007, Antoniazzi y col. 2011, Norris y col. 2010, Segura y Reboreda 2011, Quiroga y Reboreda 2012, Olah y col. 2013), producir anemia (Dudaniec y Kleindorfer 2006, Fessl y col. 2006 a) y disminuir la supervivencia de los pichones (Fessl y Tebich 2002, Fessl 2006 a, Rabuffetti y Reboreda 2007, Antoniazzi y col. 2011, Quiroga y Reboreda 2012). Las aves adultas también pueden ser parasitadas por Philornis pero el impacto sobre ellas es menor (Arendt 1985b).

La infestación por Philornis puede ocurrir desde el mismo día que nacen, unas horas luego de la eclosión (Spalding y col. 2002) y pueden sufrir varias infestaciones a lo largo del período reproductivo observándose simultáneamente larvas de distintos estadios dentro de un mismo nido.

Las larvas de las especies de Philornis presentes en el área de estudio son subcutáneas en todos sus estadios, viviendo durante todo su desarrollo bajo la piel de los pichones, respirando 
a través de un orificio y alimentándose de sus tejidos y células (Uhazy y Arendt 1986, Young 1993). Al emerger en su último estadio producen lesiones cutáneas y escoriaciones (Nores 1995). Además las larvas de Philornis pueden producir un efecto indirecto al facilitar la transmisión de infecciones bacterianas (Olah et al 2013).

El grado en que el parasitismo afecta al hospedador se ve influenciado por distintas variables como la especie hospedadora, la especie de Philornis, la edad del hospedador, las variables climáticas, etc. (Dudaniec y Kleindorfer, 2006). La intensidad y la latencia del parasitismo (edad a la que los pichones son parasitados) son dos factores que interactúan para determinar el impacto del parasitismo de Philornis sp. sobre el crecimiento y la supervivencia de los pichones (Dudaniec y Kleindorfer 2006, Segura y Reboreda 2011). En este sentido se ha observado en algunas especies que cinco o seis larvas son suficientes para causar la muerte (Arendt 1985b, Delannoy y Cruz 1991).

Algunas variables ambientales como la temperatura, las precipitaciones o la humedad influyen en la prevalencia e intensidad del parasitismo por Philornis (Arendt 1985b, Nores 1995). En consecuencia, el aumento en la temperatura ambiental que se produce al avanzar la temporada reproductiva sería la causa de una mayor intensidad de parasitismo en los pichones que nacen en una segunda nidada con respecto a los que nacen más temprano en el período reproductivo.

El impacto del parasitismo sobre una especie es mayor en los hospedadores que son parasitados por primera vez (Dudaniec y Kleindorfer 2006). Por ejemplo, en las islas Galápagos, donde Philornis es una especie introducida, se registra un $76 \%$ de mortalidad en pichones de aves nativas causada por este parásito, siendo el valor más alto registrado. La muerte de las aves se debe a un efecto combinado del daño tisular provocado por las larvas y a la anemia causada por la alimentación de las mismas (Dudaniek \& Kleindorfer 2006). A diferencia de las especies de Philornis encontradas en Argentina, cuyas larvas presentan hábitos hematófagos y viven durante todos sus estadios de manera subcutánea, las especies presentes en Galápagos presentan larvas que transcurren sus últimos estadios libres en el nido, y presentan hábitos semihematófagos (Dudaniec y Kleindorfer 2006, Fessl y col. 2006 b).

En Argentina se han observado efectos letales y subletales de Philornis en distintas especies de aves nativas como Calandria Mimus saturninus, Ratona Común Troglodytes aedon y Cardenal Común Paroaria coronata (Rabuffetti y Reboreda, 2007, Segura y Reboreda 2011, Quiroga y Reboreda 2012) pero hasta el momento no ha sido estudiado el efecto de Philornis sobre una especie de ave exótica. Dado que el área de distribución original del estornino no coincide con la distribución de Philornis, esta especie de ave introducida se ha convertido recientemente en un nuevo hospedador de Philornis. Por este motivo se espera que los efectos del parasitismo sobre el 
estornino sean mayores a los que se observan en aves nativas que han convivido con 2 durante un largo tiempo por lo cual podrían haber adquirido estrategias coevolutivas que les permitan evitar el parasitismo o disminuir sus efectos adversos una vez parasitadas.

\section{Efecto del clima sobre los pichones}

Luego de la eclosión las condiciones climáticas del nido son indispensables en el balance de energía por parte de los pichones. La temperatura ambiental influye en el microclima que se genera dentro del nido, en nidos con temperaturas más bajas, los pichones deben derivar una mayor energía a la termorregulación, la cual no será invertida en otros procesos como el crecimiento y el desarrollo del sistema inmune. En nidos con un microclima más cálido el reparto de energía favorece el crecimiento y la respuesta inmunológica frente a posibles infecciones (Dawson y col. 2005).

Los cambios en las condiciones ambientales también pueden influir en el crecimiento y la supervivencia de pichones a través de un efecto directo sobre sus demandas metabólicas y mediante efectos indirectos (McCarty y Winkler 1999, Remes y Martin 2002). Por ejemplo, la disponibilidad de alimento es una variable que se ve afectada por las variaciones climáticas ambientales, como la temperatura y las precipitaciones, al influir en la disponibilidad de insectos y sus larvas (Pearce-Higgins 2010, Blackshaw y Moore 2012), que constituyen los ítems principales en la alimentación de muchas especies de aves, entre ellas de los pichones de estornino (Tinbergen 1981, Westerterp 1982, Moore 1986). En relación a esto, Lack (1968) observó que la abundancia de artrópodos al momento de máximo requerimiento de alimento por parte de los pichones de distintas especies de aves es un factor que determina del éxito reproductivo de las aves.

\section{OBJETIVOS DEL CAPÍTULO}

a) Evaluar distintos parámetros del parasitismo de Philornis (prevalencia, intensidad de parasitismo, latencia de parasitismo) en pichones de Estornino Pinto.

b) Analizar las variaciones en la intensidad de parasitismo de Philornis a lo largo de la temporada reproductiva, entre años y entre nidadas.

c) Evaluar el efecto del parasitismo de Philornis y de las variables climáticas en el crecimiento y la supervivencia de pichones parasitados y no parasitados.

d) Analizar si existe una relación entre variables climáticas y la intensidad de parasitismo de Philornis. 


\section{MATERIALES Y MÉTODOS}

Durante el estudio de la reproducción del estornino llevado a cabo durante las temporadas reproductivas 2010, 2011, 2012 y 2013 las cajas-nido se revisaron cada 1-4 días y se registró la presencia y cantidad de larvas de Philornis en los pichones de Estornino Pinto.

Debido a la alta prevalencia e intensidad de parasitismo y a la alta mortalidad observada en las temporadas 2010 y 2011, en los siguientes dos años (temporadas 2012 y 2013) se realizó un experimento para evaluar el efecto del parasitismo de Philornis sobre el crecimiento y la supervivencia de los pichones. Con el objetivo de evitar que un grupo fuera parasitado por Philornis se utilizó un insecticida (deltametrina 0,02\%) en 28 nidos que alcanzaron la etapa de incubación de huevos. El insecticida se colocó uno o dos días antes de la eclosión y 15 días después cuando los pichones tenían dos semanas de edad. Para aplicar el insecticida se extrajeron los huevos o pichones y se roció con un aerosol el nido, las paredes internas y externas y la tapa de la caja-nido, que se dejó abierta para permitir la ventilación. Luego de transcurridos 15 minutos se volvieron a colocar en el nido. Cada vez que se revisó una caja-nido con o sin insecticida se tomaron las medidas corporales estándar del ala y tarso de los pichones utilizando un calibre digital y se pesaron con balanza de resorte (Pesola, 1 y $10 \mathrm{~g}$ dependiendo de la masa corporal).

\section{Análisis estadístico}

La prevalencia de parasitismo se calculó como la proporción de nidos parasitados por Philornis en relación a la nidos totales en los que nacieron pichones. La intensidad de parasitismo por pichón y la latencia de parasitismo (días que transcurrieron desde el nacimiento del primer pichón hasta que se detectó la primera larva de Philornis) entre años se analizaron mediante la prueba no paramétrica de Kruskal-Wallis debido a que los datos no seguían una distribución normal luego de aplicarles diversas transformaciones. La intensidad de parasitismo por pichón entre la primera y segunda nidada se analizó mediante un análisis apareado de Wilcoxon y con una pruebade Mann-Whitney entre nidadas tempranas y tardías. Para efectuar los cálculos de prevalencia e intensidad y realizar estas comparaciones no se consideraron los nidos donde se colocó insecticida.

Para evaluar si la proporción de pichones que sobrevivieron por nido y la supervivencia de cada pichón variaron en función del parasitismo de Philornis se realizaron GLMMs con 
distribución de error binomial y función de enlace logit. Para analizar el efecto sobre la primera variable se incorporaron como efectos fijos la temperatura máxima, las precipitaciones, el promedio de la intensidad de Philornis por nido y la latencia de parasitismo. La pareja se incorporó al modelo como efecto aleatorio. El efecto del parasitismo sobre la supervivencia se evaluó incorporando la temperatura máxima, las precipitaciones, la intensidad de Philornis de cada pichón y la latencia de parasitismo como efectos fijos e incorporando a la pareja y a la nidada ( 1 o 2$)$ como factores aleatorios.

Para evaluar el efecto del clima sobre la intensidad de Philornis se realizó un GLMM con distribución de errores binomial negativa incorporando la temperatura máxima y las precipitaciones como efectos fijos y la pareja como efecto aleatorio.

Además se observó si el promedio de la temperatura máxima y las precipitaciones de cada temporada reproductiva se relacionaron a la intensidad de parasitismo. Los datos de temperatura y precipitaciones se obtuvieron de la estación meteorológica de Quilmes (34 $44^{\prime}$ $\left.\mathrm{S}, 58^{\circ} 14^{\prime} \mathrm{O}\right)$ (http://www.climasurgba.com.ar/).

\section{Crecimiento y supervivencia de pichones parasitados y no parasitados por Philornis}

Se colocó insecticida en 28 de los 143 nidos donde los estorninos pusieron huevos en las temporadas reproductivas 2012 y 2013 (en 18 nidos de la primera temporada y 10 de la segunda). Sólo en uno de los 28 nidos donde se colocó insecticida no nacieron pichones. En 16 nidos no parasitados donde se aplicó el insecticida sobrevivieron pichones. No se consideraron los nidos con pichones no parasitados donde no se aplicó insecticida para evitar incorporar al análisis un error adicional relacionado a diferencias en el crecimiento y supervivencia de pichones debido al efecto del insecticida sobre otras variables, como otros ectoparásitos que puedan encontrarse en el nido. Tampoco se consideraron cuatro nidos donde se aplicó insecticida y que igualmente fueron parasitados por Philornis. Con estos datos se realizaron curvas de crecimiento de la masa corporal, cuerda del ala y tarso de los pichones. La curva de crecimiento de los pichones se estimó ajustando los valores de los pesos diarios a una función logística (Ricklefs 1967).

$$
\mathrm{P}=\mathrm{A} /\left(1+\mathrm{e}\left(-\mathrm{K}\left(\mathrm{t}-\mathrm{t}_{0}\right)\right)\right)(1)
$$

donde $\mathrm{A}$ es la asíntota de la curva, $\mathrm{K}$ es la constante de crecimiento de la ecuación logística y t es el punto de inflexión o la edad de máximo crecimiento (Ricklefs 1967).

La tasa de crecimiento del peso, de la cuerda del ala y del tarso fueron calculados a partir de esta función al igual que la asíntota de la de la cuerda del ala. El peso y la longitud del 
tarso alcanzaron un crecimiento máximo entre los 15 y 16 días de edad y debido a que los pichones fueron medidos hasta el día 20 (edad aproximada a la que abandonan el nido), el peso asintótico y la asíntota del tarso fueron calculados como el promedio de las mediciones de los tres días posteriores a alcanzar el peso o la longitud máxima respectivamente e incluidos en la ecuación (1) para calcular la tasa de crecimiento. La tasa instantánea de crecimiento en el momento de crecimiento máximo fue calculada como:

$$
\text { Gmáx }=\mathrm{K} * \mathrm{~A} / 4 \text { (Richner 1991) }
$$

Los datos de la tasa de crecimiento, peso asintótico y tasa de crecimiento máxima de los pichones de cada nido fueron promediados para evitar el efecto de pseudoréplica, debido a que los pichones en un mismo nido se encuentran influenciados por distintos factores como el material del nido, la temperatura interna del nido, el cuidado de los padres, etc.

Con los parámetros promedio se construyeron las curvas de crecimiento generales de los pichones parasitados y no parasitados. Se realizaron en total 101 curvas de crecimiento de pichones de 44 nidos que lograron independizarse. De estos, 59 pichones de 28 nidos fueron parasitados por Philornis y 42 pichones de 16 nidos no fueron parasitados. Ochenta pichones de 30 nidos pertenecieron a nidadas de la temporada reproductiva 2012 y 21 pichones de 14 nidos pertenecieron a la temporada 2013. Las curvas de crecimiento de los pichones de los años 2010 y 2011 no pudieron obtenerse debido a una cantidad insuficiente de nidos con pichones que sobrevivieron (2010: $n=2,2011: n=5)$.

Las tasas de crecimiento (K), tasa de crecimiento máxima (Gmáx) y las asíntotas (A) del peso, cuerda del ala y tarso así como la intensidad de parasitismo por pichón y por nido no seguían una distribución normal se decidió realizar pruebas no paramétricas para realizar las comparaciones de estas variables. Para comparar el crecimiento y la intensidad de parasitismo por pichón entre nidos parasitados y no parasitados se realizaron análisis de Mann-Whitney.

Las diferencias en la frecuencia de nidos exitosos entre pichones parasitados y no parasitados por Philornis se evaluaron con una prueba de Fisher.

Para evaluar si el crecimiento de los pichones de estornino difirió en función del parasitismo de Philornis, el tamaño de la nidada, la temperatura máxima y las precipitaciones se realizaron modelos lineales generalizados (GLM) con distribución de errores Gaussiana y enlace de identidad. Las variables respuesta fueron la tasa de crecimiento del peso, el peso asintótico y la tasa de crecimiento del ala. El parasitismo de Philornis se incorporó al modelo como una variable dicotómica (parasitado $=1$, no parasitado $=0$ ). Esta variable junto a la temperatura máxima y las precipitaciones se incorporaron como factores fijos. Para ajustar el 
modelo se realizó una selección hacia atrás eliminando una por una las variables menos significativas.

Para realizar estos análisis se utilizó el software Statistica 7.1 (StatSoft Inc. 2003) y el software R versión 2.15.1 (R Development Core Team 2012).

\section{RESULTADOS}

La prevalencia de parasitismo por larvas de Philornis durante las cuatro temporadas reproductivas fue del 61,82\% (89 de 144 nidos) (Fig. 5.1). La mayor prevalencia se registró en la temporada 2011 (Tabla 5.1, Fig. 5.2). El éxito reproductivo en los nidos parasitados fue muy bajo en las temporadas reproductivas 2010 y 2011 y aumentó en las dos temporadas siguientes. En 2010 en el 87,5\% de los nidos parasitados (14 nidos de 16) no sobrevivió ningún pichón, en el 2011 en el 80,7\% (21 nidos de 26), en el 2012 en el 32\% (8 nidos de 25) y en el 2013 en el 50\% (11 de 22 nidos). El total de nidos parasitados por Philornis que fracasaron fue del 60,7\% (54 de 89 nidos).

La intensidad de parasitismo por pichón fue de 10,7 $\pm 0,9$ larvas en los cuatro años combinados y varió entre los distintos años (Kruskal-Wallis $=124, \mathrm{n}=89, \mathrm{df}=3, \mathrm{p}<0,01$ ) (Fig. 5.3 y 5.4). Las diferencias se observaron entre la temporada reproductiva 2011 y las temporadas $2012(\mathrm{z}=2,9, \mathrm{p}=0,03)$ y $2013(\mathrm{z}=3,15, \mathrm{p}<0,01)$ (Tabla 5.1, Fig. 5.3 y 5.4). La latencia de parasitismo fue de 5,15 \pm 0,33 días (rango: $1-19, \mathrm{n}=89$ nidos) y difirió entre años (Kruskal-Wallis $=20,9, \mathrm{n}=89, \mathrm{p}<0,01$ ), en la temporada 2011 los pichones fueron parasitados a una edad menor que en la temporada $2012(\mathrm{z}=4,12, \mathrm{p}<0,01)$ que en la temporada $2013(z=3,05, p=0,01)$ y que en la temporada $2010(z=3,32, p<0,01)$ (Tabla 5.1).

\begin{tabular}{lllll}
\cline { 2 - 5 } & 2010 & 2011 & 2012 & 2013 \\
\hline Prevalencia & $69,6 \%(16$ de 23$)$ & $70,3 \%(26$ de 37$)$ & $65,8 \%(25$ de 38$)$ & $47,8 \%(22$ de 46$)$ \\
Larvas/pichón & $11,57 \pm 2,73$ & $14,11 \pm 1,42$ & $8,69 \pm 1,38$ & $8,45 \pm 1,67$ \\
media \pm E.E. & $(1,5-48,75)$ & $(2-26,67)$ & $(2-33)$ & $(2-35,25)$ \\
Latencia & $5,5 \pm 0,5$ & $3,23 \pm 0,39$ & $6,76 \pm 0,83$ & $5,32 \pm 0,53$ \\
media \pm E.E. & $(1-9)$ & $(1-11)$ & $(1-19)$ & $(2-12)$ \\
\hline
\end{tabular}

Tabla 5.1: Prevalencia, intensidad de parasitismo por pichón y latencia de parasitismo de Philornis en los distintos años de estudio. Entre paréntesis se muestran los valores mínimo y máximo. 

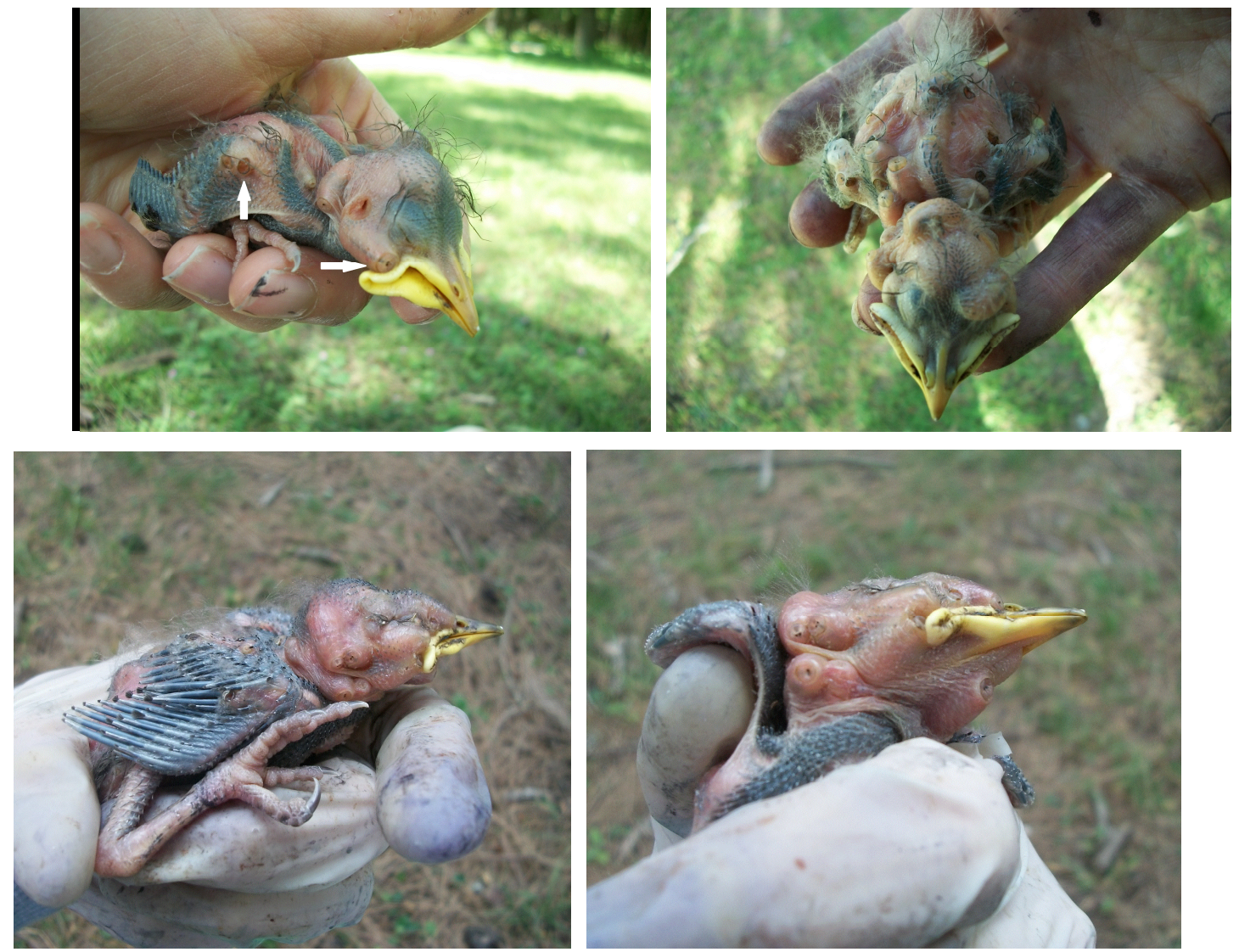

Fig. 5.1: Pichones de estornino de ocho días de edad parasitados por larvas de Philornis. En la foto superior izquierda la flecha horizontal muestra el espiráculo de una larva y la flecha vertical muestras lesiones ocasionadas por larvas luego de abandonar al pichón. 


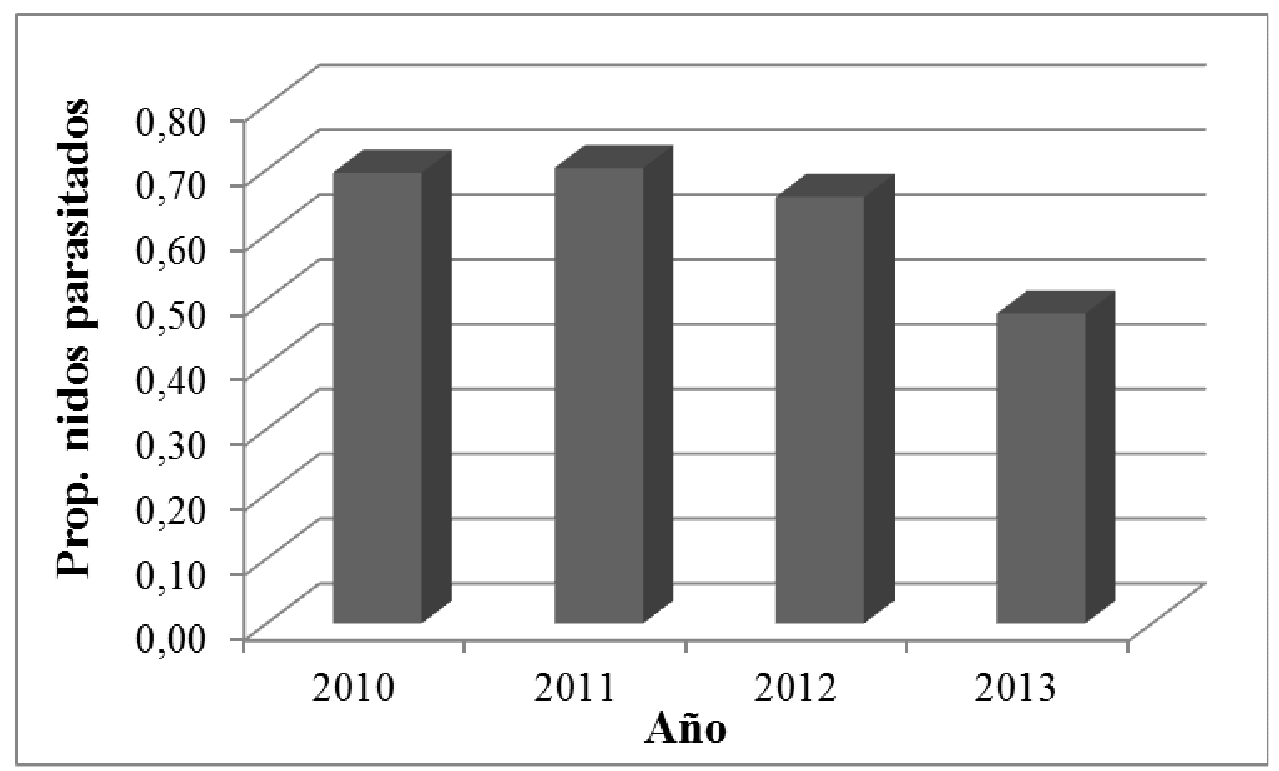

Fig.5.2: Proporción de nidos de Estornino Pinto parasitados por Philornis en los distintos años de estudio.

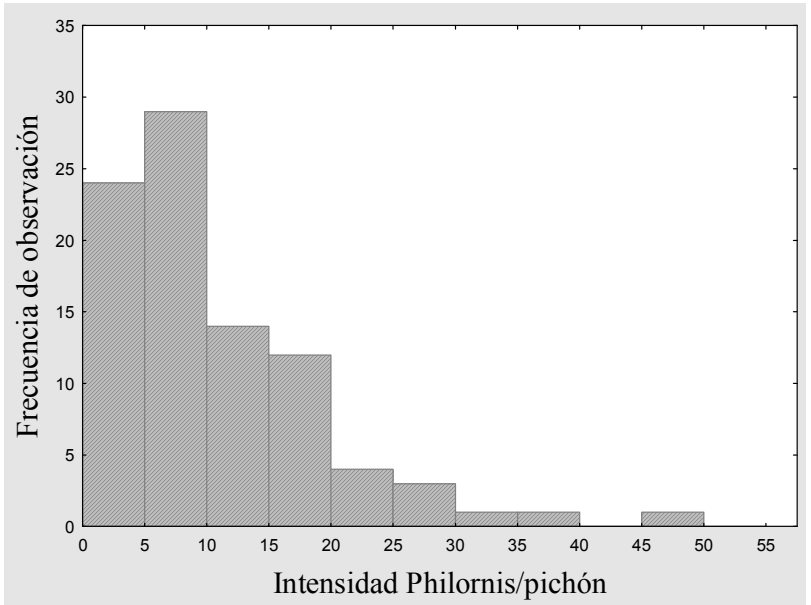

Fig. 5.3: Frecuencia de observación de la intensidad de parasitismo por pichón. 


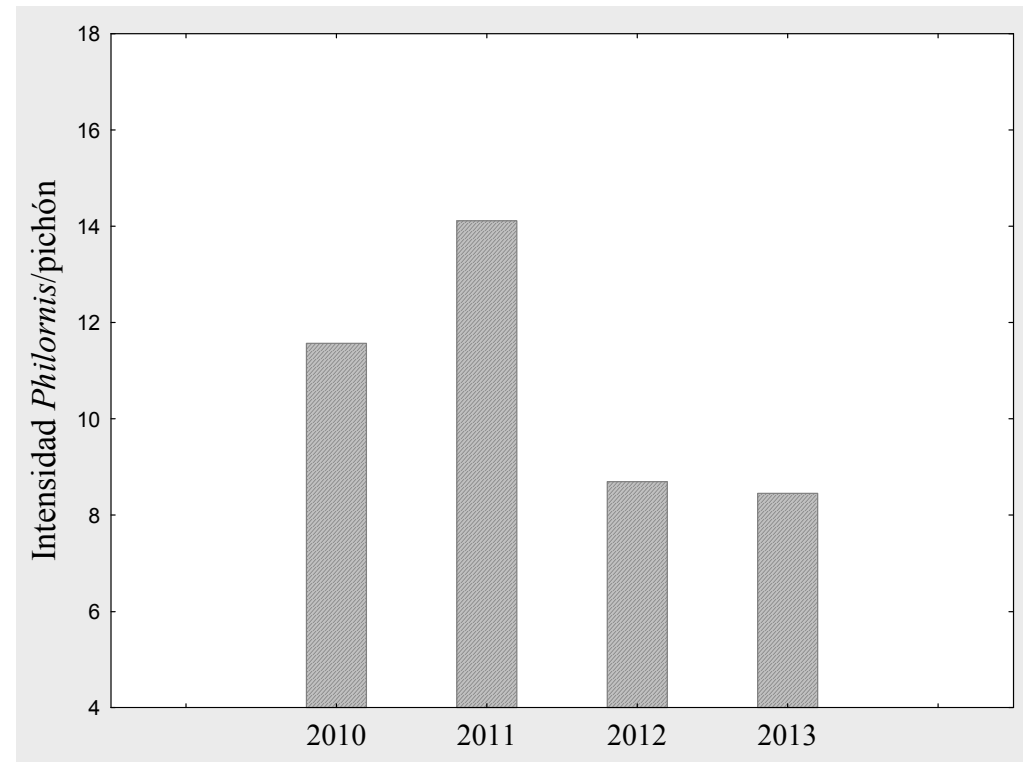

Fig. 5.4: Promedio de la intensidad de parasitismo por pichón en los cuatro años de estudio.

En los nidos donde se produjeron dos nidadas y ambas fueron parasitadas, la intensidad de parasitismo por pichón fue de 6,61 $\pm 1,27$ larvas en la primera nidada y de 12,22 $\pm 3,01$ en la segunda, siendo esta diferencia marginalmente no significativa (Wilcoxon: $Z=1,87, P=0,06$, $N=11)$.

Teniendo en cuenta los nidos donde se produjo una sólo nidada, la intensidad de parasitismo fue de 8,47 $\pm 1,2$ larvas/pichón en las nidadas tempranas y de 12,96 $\pm 2,72$ en las nidadas tardías (Mann-Whitney: $U=272, P=0,95, N 1=19, N 2=22$ ).

\section{Efecto del parasitismo de Philornis y las variables ambientales sobre los pichones}

La proporción de pichones que sobrevivieron por nido aumentó cuando los pichones fueron parasitados a una edad más avanzada (Fig. 5.5) y se vió afectada negativamente por la temperatura máxima (Fig. 5.6). Las precipitaciones afectaron la supervivencia de los pichones aunque el valor de p de esta relación se encontró en el límite de significancia convencional. Ninguna de las variables climáticas explicó las variaciones en la intensidad de Philornis (Tabla 5.2) 


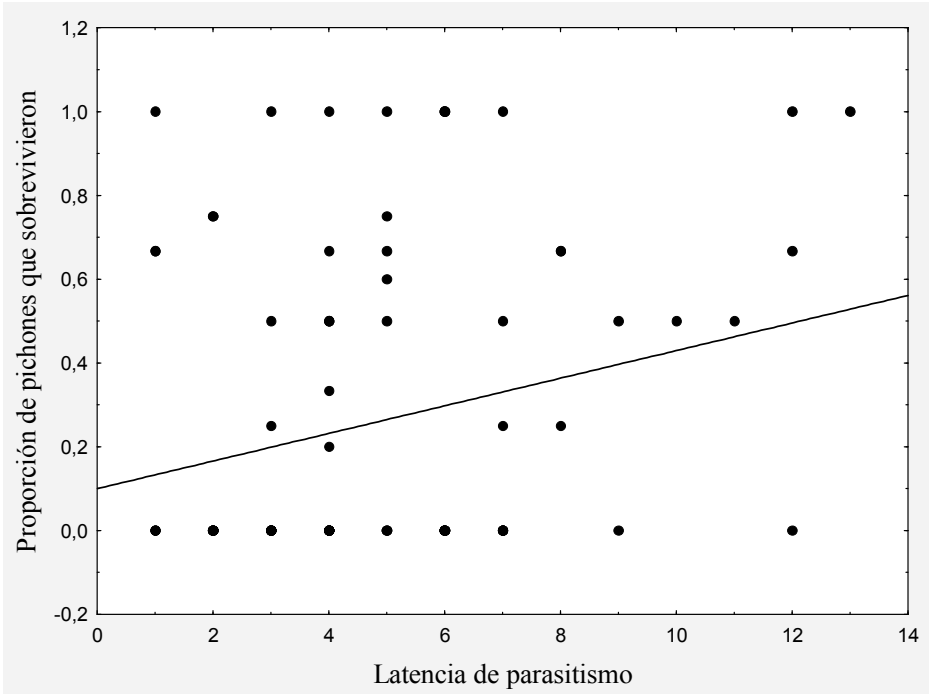

Fig. 5.5 Proporción de pichones que sobrevivieron por nido en relación a la latencia de parasitismo.

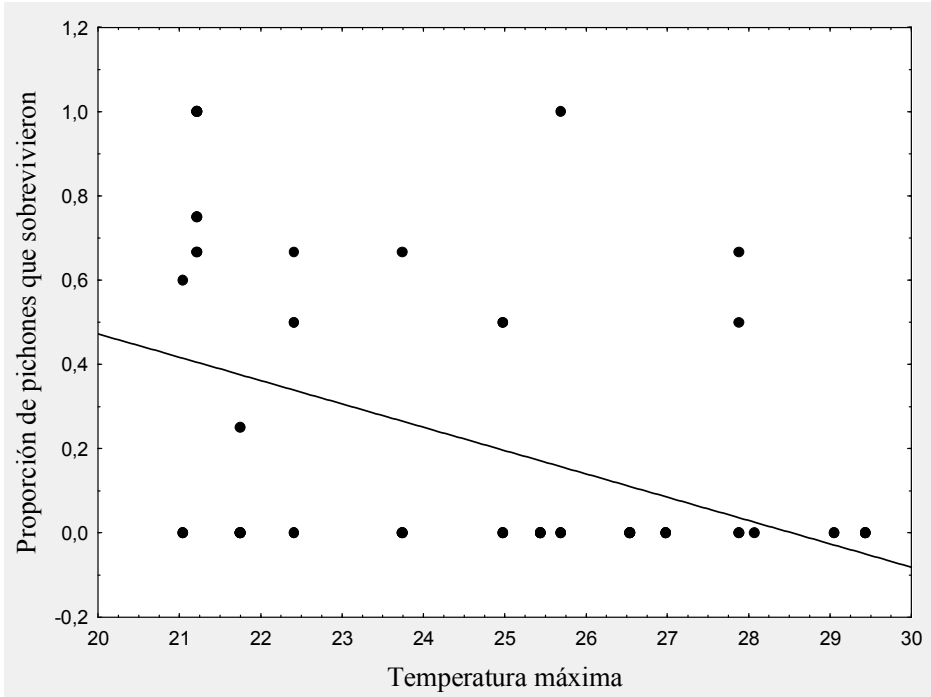

Fig. 5.6: Proporción de pichones que sobrevivieron por nido en relación a la temperatura máxima ambiental.

\begin{tabular}{llcccc}
\hline Variable respuesta & & & & & \\
\hline & Efectos fijos & Estimador & E.E. & $\mathrm{Z}$ & $\mathrm{P}$ \\
& Intercepto & 10,91 & 6,3 & 1,74 & 0,08 \\
Proporción de pichones que & & & & & \\
sobreviveron & Tmáx & $-0,84$ & 0,36 & $-0,235$ & $0,02^{*}$ \\
& $\mathrm{Pp}$ & 0,17 & 0,02 & 0,89 & 0,37
\end{tabular}




\begin{tabular}{llcccc} 
& Intensidad Philornis x nido & $-0,03$ & 0,1 & $-0,33$ & 0,74 \\
& Latencia & 0,51 & 0,23 & 2,19 & $0,03^{*}$ \\
\hline & Intercepto & & & & \\
& Tmáx & 7,12 & 28,94 & 0,25 & 0,81 \\
Supervivencia de pichones & $-0,77$ & 1,05 & $-0,74$ & 0,46 \\
& Pp & 0,08 & 0,04 & 1,9 & $0,05^{*}$ \\
& Intensidad Philornis x & & & & \\
& pichón & 0,14 & 0,09 & 1,46 & 0,15 \\
& Latencia & 0,39 & $-0,55$ & $-0,25$ & 0,132 \\
\hline & & & & & \\
& Intercepto & 5,8 & 2,63 & 2,2 & 0,03 \\
Intensidad de Philornis & Tmáx & $-0,18$ & 0,11 & $-1,75$ & 0,08 \\
& Pp & $-0,02$ & 0,01 & $-1,63$ & 0,1 \\
\hline
\end{tabular}

Tabla 5.2: Modelo lineal mixto generalizado que evalúa la variación en la proporción de pichones que sobrevivieron por nido, en la supervivencia y la intensidad de Philornis. Se muestra el estimador, el error estándar, el valor de $Z$ y $p$ para cada efecto fijo. Los valores significativos están marcados con un asterisco.

$\mathrm{Al}$ analizar las precipitaciones en los distintos años observamos que la temporada 2012 fue significativamente más lluviosa que el resto, con 410,8 mm totales durante el período reproductivo. Esto coincide con que ese año fue el de mayor porcentaje de nidos con pichones exitosos (63\%). En los años 2010 y 2011 se registraron escasas precipitaciones, 93 y 79,7 mm respectivamente, y el éxito de los nidos fue notablemente bajo (9\% para el 2010 y 13,5\% para el 2012), mientras que en el año 2013 las precipitaciones fueron de $34,8 \mathrm{~mm}$ y el porcentaje de nidos exitosos fue del 35\% (Fig. 4.9 A).

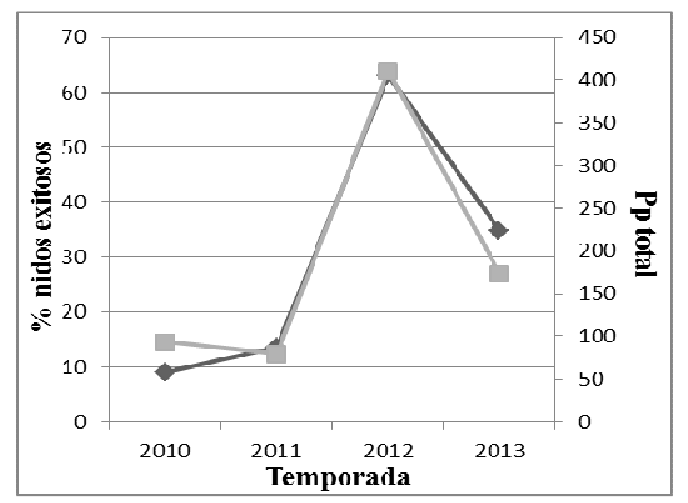

Fig. 5.7: Porcentaje de nidos con pichones exitosos en relación a las precipitaciones totales en cada temporada reproductiva. 


\section{Comparación entre pichones parasitados y no parasitados por Philornis}

Durante las temporadas reproductivas 2012 y 2013, de los 47 nidos parasitados, 28 $(59,6 \%)$ fueron exitosos y en 19 (40,42\%) no sobrevivió ningún pichón. De los 21 nidos no parasitados, 16 fueron exitosos $(76,19 \%)$ y en $5(23,81 \%)$ no sobrevivió ningún pichón. No se observaron diferencias significativas en la cantidad de nidos con pichones que sobrevivieron y en los que no sobrevivieron pichones entre los nidos parasitados y no parasitados (test de Fisher, $\mathrm{p}=0$,27). La intensidad de parasitismo máxima la alcanzaron entre los 4 y los 14 días, con una moda del día 10 y con un promedio de 9,25 días.

En los nidos exitosos con pichones parasitados, el promedio de la intensidad de parasitismo por pichón fue de 7,11 \pm 0,70 (2 - 16). En los nidos que produjeron volantones en la temporada reproductiva 2012 se registró una intensidad por pichón de 8,06 $\pm 1,02$ (2 - 16). En la temporada reproductiva 2013 la intensidad de parasitismo por nido fue de 14,58 $\pm 2,44$ (0 - 29) y de $5,17 \pm 0,78(0-9,67)$ por pichón.

La latencia de parasitismo en la nidadas tempranas fue de 5,54 $\pm 0,63(\mathrm{n}=26)$ y en las tardías de $6,76 \pm 0,84(\mathrm{n}=21)$.

No se observaron diferencias significativas en ninguna de las variables del crecimiento entre los pichones parasitados y no parasitados que lograron independizarse (Tabla 5.3, Figs. $5.8,5.9$ y 5.10$)$. 


\begin{tabular}{lllll}
\hline Variable & \multicolumn{1}{c}{$\begin{array}{c}\text { Nidos } \\
\text { parasitados }(\mathrm{n}=24)\end{array}$} & $\begin{array}{l}\text { Nidos no parasitados } \\
(\mathrm{n}=12)\end{array}$ & U Man-Whitney & $P$ \\
\hline k peso & $0,39 \pm 0,03$ & $0,39 \pm 0,03$ & 124 & 0,50 \\
A peso & $63,82 \pm 2,37$ & $64,56 \pm 2,17$ & 143,5 & 0,99 \\
Gmáx peso & $6,58 \pm 0,35$ & $6,20 \pm 0,43$ & 122 & 0,46 \\
k ala & $0,24 \pm 0,01$ & $0,24 \pm 0,00$ & 133,5 & 0,72 \\
A ala & $98,95 \pm 3,03$ & $103,76 \pm 2,14$ & 115 & 0,33 \\
Gmáx ala & $6,05 \pm 0,18$ & $6,27 \pm 0,12$ & 141 & 0,92 \\
k ala tarso & $0,37 \pm 0,01$ & $0,36 \pm 0,01$ & 106 & 0,20 \\
A ala tarso & $28,40 \pm 0,31$ & $29,00 \pm 0,38$ & 111 & 0,27 \\
Gmáx tarso & $2,64 \pm 0,08$ & $2,59 \pm 0,05$ & 220 & 0,42 \\
\hline
\end{tabular}

Tabla 5.3: parámetros del crecimiento de los pichones de estornino en los pichones parasitados y no parasitados. $\mathrm{K}=$ tasa de crecimiento, $\mathrm{A}=$ asíntota, Gmáx = tasa de crecimiento máxima.

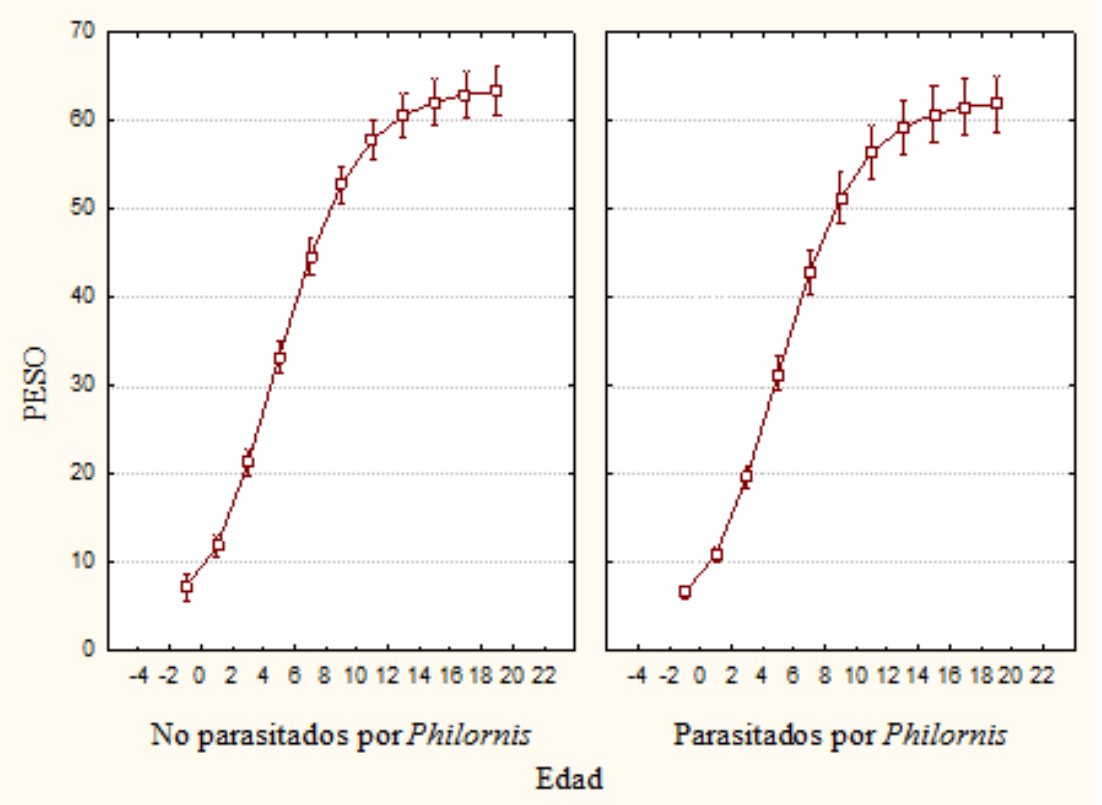

Fig. 5.8: curvas de crecimiento del peso de los pichones de Estornino Pinto. A la izquierda curva de crecimiento de pichones que no fueron parasitados por Philornis, a la derecha curva de pichones que fueron parasitados. 

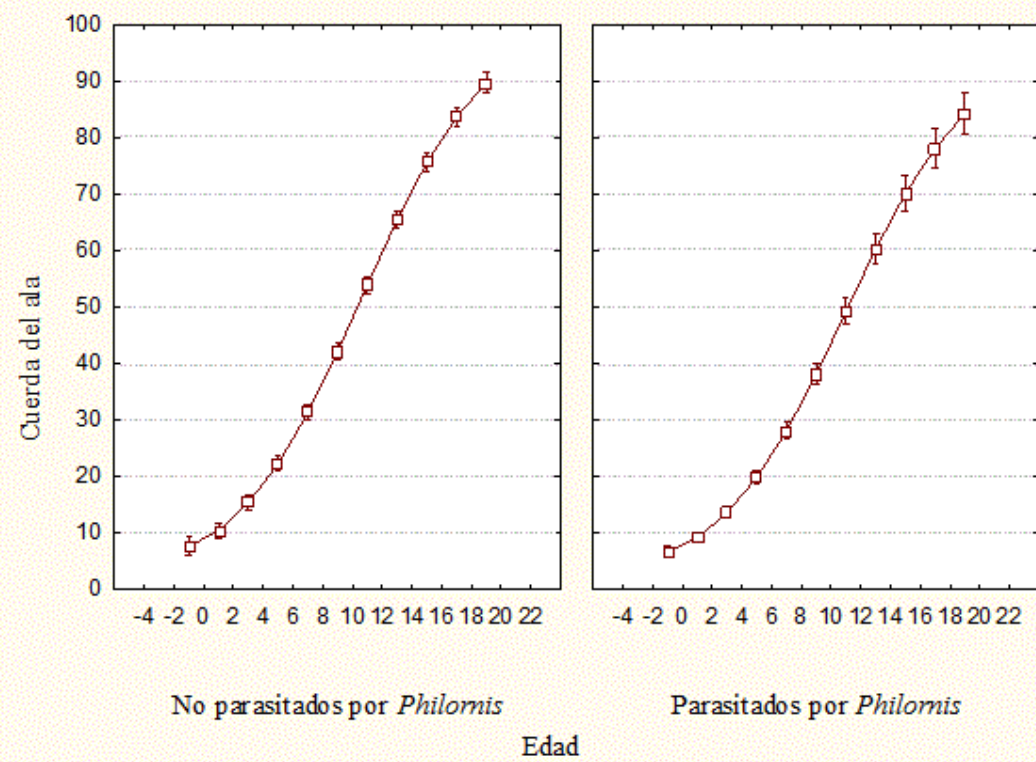

Parasitados por Philomis

Fig. 5.9: curvas de crecimiento (cuerda del ala) de los pichones de estornino. A la izquierda curva de crecimiento de pichones que no fueron parasitados por Philornis, a la derecha curva de pichones que fueron parasitados.
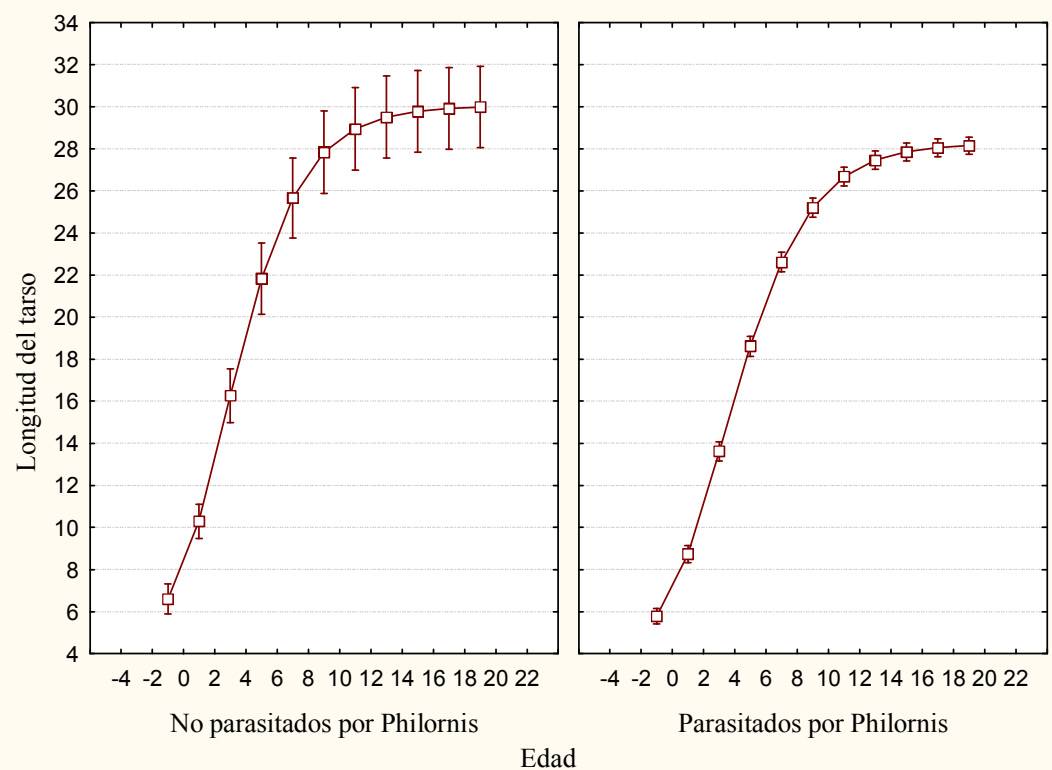

Fig. 5.10: curvas de crecimiento del tarso de los pichones de estornino. A la izquierda curva de crecimiento de pichones que no fueron parasitados por Philornis, a la derecha curva de pichones que fueron parasitados. 
La tasa de crecimiento del peso no se encontró afectada por las variables climáticas ni por el parasitismo de Philornis (GLM: intercepto: Wald=0,02, $P=0,88$; parasitado (sí/no): Wald= $0,58, P=0,45$, temperatura: Wald $=0,02, P=0,88$; precipitaciones: Wald $=0,79, P=0,37$ ). El peso asintótico alcanzado por los pichones disminuyó conforme aumentó la temperatura (GLM: intercepto: Wald $=244,70, P<0,01$; temperatura: Wald $=5,9, P=0,01)$ (Fig. 5.11). Las precipitaciones y el parasitismo de Philornis no afectaron a esta variable (parasitado (sí/no): Wald $=0,09, P=0,76, P=$; precipitaciones: Wald $=0,05, P=0,82)$. La tasa de crecimiento del ala no varió en función de las variables climáticas ni del parasitismo (GLM: intercepto: Wald $=44,3, P<0,01$; parasitado (sí/no): Wald $=0,78, P=0,38$, temperatura: Wald $=2,84, P=$ 0,09 ; precipitaciones: Wald $=1,21, P=0,27$ ).

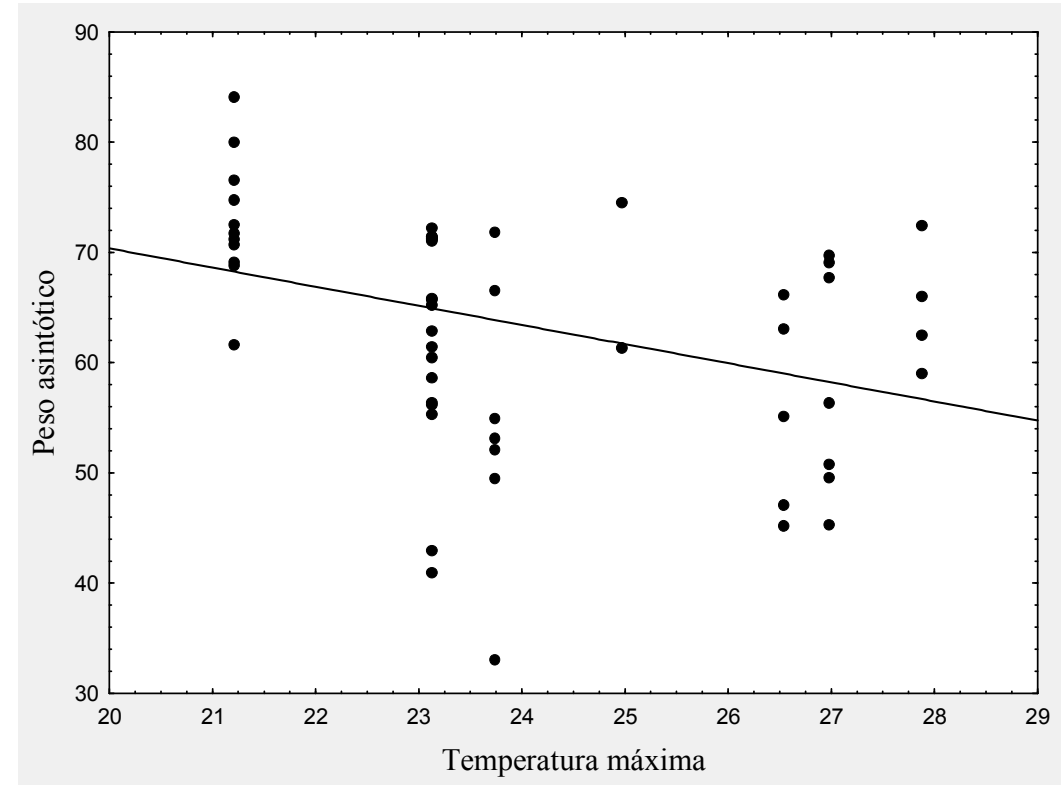

Fig. 5.11: Peso asintótico alcanzado por los pichones de estornino en relación a la temperatura máxima ambiental.

\section{DISCUSIÓN}

La prevalencia de Philornis observada en los pichones de estorninos en el parque Pereyra Iraola $(61,82 \%)$ es la más alta registrada hasta el momento en aves en Argentina. En trabajos realizados en otras especies en distintas áreas de la Argentina se observaron prevalencias de entre 11 y 58\% e intensidad de parasitismo entre 6,5 y 24,3 larvas por pichón (Fraga 1984, Nores 1995, Rabuffetti y Reboreda, 2007, Turienzo y Di Iorio, 2008, 2010; Antoniazzi y col. 2011, Segura y Reboreda 2011, Quiroga y Reboreda 2012). 
En la provincia de Buenos Aires varios trabajos observaron parasitismo de Philornis en distintas especies de aves, por ejemplo, Fraga (1984) registró prevalencias de Philornis de entre 6,2 y $33,3 \%$ en seis especies de aves nativas. En los nidos de Calandria Común Rabuffetti y Reboreda (2007) observaron una prevalencia de 58,3\% con una intensidad media de 24,3 larvas por pichón y en el Cardenal Común Paroaria coronata Segura y Reboreda (2011) observaron una prevalencia de Philornis del 28\% y una intensidad de 6,5 larvas por pichón. En la provincia de Santa Fé, Antoniazzi y col. (2011) observaron 13 especies de aves parasitadas por Philornis con una prevalencia entre 9 y 56 \%. En la misma provincia Quiroga y Reboreda (2012) observaron una prevalencia del $25 \%$ y una intensidad de parasitismo por pichón de 12,8 larvas en la Ratona Común Troglodytes aedon. En la provincia de Córdoba los nidos de Cacholote Pseudoseisura lophotes y de Leñatero Anumbius annumbi presentaron prevalencias de Philornis del 16,4 y $18 \%$ respectivamente con intensidades de 11,1 (Cacholote) y 8,8 (Leñatero) larvas por pichón. En la provincia de Misiones, Norris y col. (2010) registraron intensidades de Philornis de entre 9 y $14 \%$ en pichones del Trepatroncos Oscuro Dendrocolaptes platyrostris.

En las Islas Galápagos, donde Philornis es una especie introducida, se registran las prevalencias más altas de Philornis, con valores que superan los registrados en el parque Pereyra Iraola. Por ejemplo, Fessl y Tebich 2002 registraron prevalencias de hasta 97\% de Philornis en nidos de 12 especies de aves, ocho de ellas nativas de esa zona. En otro estudio, Dudaniec y col. (2007) observaron que el $100 \%$ de 131 nidos pertenecientes a seis especies de pinzones de Darwin se encontraban parasitados por Philornis.

Cabe destacar que tanto las aves nativas en las Islas Galápagos como el estornino en la Argentina adquirieron recientemente a Philornis como nuevo hospedador por lo que aún no han desarrollado, a través de un proceso de coevolución, estrategias de comportamiento e inmunológicas que les permita ser más resistentes a la infestación de Philornis y a sus efectos (Fessl et al. 2006b). En el caso del estornino, sin embargo, este nuevo parásito no constituyó una barrera para el asentamiento de la especie y su expansión en el país, aunque podría estar limitando su crecimiento poblacional al afectar negativamente la proporción de pichones que sobreviven.

Con respecto al momento en que los pichones son parasitados, en la ECAS se observaron pichones parasitados a partir de un día de edad, pero la intensidad de parasitismo máxima fue alcanzada entre los 4 y los 14 días con una moda del día 10 declinando posteriormente. De manera similar, en el Trepatroncos Oscuro la intensidad de parasitismo máxima alcanza un máximo a los 10 días de edad y luego declina hasta el momento en que los pichones dejan el nido (Norris y col. 2010), mientras que en la Ratona Común los pichones son parasitados entre los 6 y los 12 días de edad (Young 1993). En el Cacholote, el parasitismo por Philornis 
es una de las causas de mortalidad de pichones de entre 6 y 12 días de edad y en el Leñatero de pichones de entre 6 y 15 días (Nores 1995).

El efecto negativo del parasitismo de Philornis sobre el crecimiento de los pichones fue documentado por varios autores en distintas especies de aves (Arendt 1985a, Fessl 2006a, Rabuffetti y Reboreda 2007, Antoniazzi y col. 2011, Norris y col. 2010, Segura y Reboreda 2011, Quiroga y Reboreda 2012, Olah y col. 2013). También se ha observado que este parásito provoca una disminución en la supervivencia de los pichones (Fessl y Tebich 2002, Fessl 2006a, Rabuffetti y Reboreda 2007, Antoniazzi y col. 2011, Quiroga y Reboreda 2012) y aunque no existe evidencia concluyente, se cree que $P$. downsi estuvo implicado en la extinción local del Pinzón de Darwin gris Certhidea fusca en la Isla Floreana (Grant y col. 2005). De manera contraria, Nores (1995) no detectó efectos adversos de Philornis sobre la supervivencia de los pichones y al igual que Young (1993) solo reportó efectos adversos leves en el crecimiento causados por Philornis. Por su parte, Huber (2008) no encontró diferencias en el tamaño de los pichones ni en la tasa de crecimiento entre pichones parasitados y no parasitados por Philornis en pichones de Pinzón terrestre mediano Geospiza fortis. Al contrario, otros autores hallaron importantes efectos negativos del parasitismo por Philornis sobre las aves de las Islas Galápagos (Fessl y Tebich 2002, Dudaniec y Kleindorfer 2006, Fessl 2006a). En esa zona se ha registrado una disminución significativa en los niveles de hemoglobina del Pinzón Terrestre pequeño Geospiza fuliginosa y del Pinzón Terrestre mediano Geospiza fortis parasitados (Dudaniec y col. 2006, Fessl y col. 2006a). En esta última especie, Fessl (2006a) también registró una menor ganancia de peso y una disminución en la supervivencia de pichones. La mortalidad registrada por Fessl y col. (2006 b) en los pinzones de Darwin fue del 76\% y la atribuyeron a la anemia y a las heridas tisulares causadas por el parasitismo de Philornis. Las diferencias en los efectos provocados por el parasitismo de Philornis pueden atribuirse en parte a diferencias en las especies de Philornis, a las especies hospedadoras y a factores ambientales (Teixeira 1999). En algunos trabajos la intensidad de parasitismo fue un factor determinante en la supervivencia de los pichones (Arendt 1985b, Dudaniec y col. 2007), aunque en este trabajo y otros realizados en la Argentina no se encontró este efecto (Segura y Reboreda 2011, Quiroga y Reboreda 2012). Arendt (1985a) observó que el parasitismo de Philornis produce un retraso en el crecimiento y desarrollo de los pichones siendo este efecto leve a intensidades bajas y mayor cuando la intensidad de parasitismo es alta.

Una variable asociada al parasitismo de Philornis que se ha demostrado que tiene importantes consecuencias sobre el hospedador es la edad a la que los pichones son parasitados 
(Dudaniec y Kleindorfer 2006). En el parque Pereyra Iraola se observó que la proporción de pichones que sobreviven en los nidos varía en función de la latencia de parasitismo, de manera que los pichones de nidos parasitados a una edad más temprana presentaron una proporción menor de pichones que lograron independizarse. Otros autores también observaron esta asociación (Rabuffetti y Reboreda 2007, Segura y Reboreda 2011, Quiroga y Reboreda 2012). Esto se debería a que los pichones más pequeños son más vulnerables a los efectos del parasitismo (Arendt 1985a). Además en el parque Pereyra Iraola se observó que en el año donde se registró la mayor prevalencia e intensidad de parasitismo de Philornis los pichones fueron parasitados a una edad más temprana que los otros años, probablemente debido a una mayor cantidad de moscas de Philornis presentes en la zona.

El crecimiento en los pichones de estornino que lograron independizarse no se vió afectado por el parasitismo de Philornis este resultado sugiere que podría existir alguna estrategia que permita compensar el efecto del parasitismo. Una posible explicación se encontraría en la "hipótesis de la compensación parental" por la cual los pichones parasitados al perder parte de sus nutrientes a causa de los parásitos aumentarían el pedido de alimento a los padres, en consecuencia estos incrementarían la tasa de alimentación de manera que los efectos de los parásitos se verían compensados por un aumento en la ingesta de alimentos (Tripet y Richner 1997).

El incremento de la prevalencia e intensidad de Philornis al avanzar la temporada reproductiva fue observado en otras partes del mundo (Arendt 1985b, Young 1993, Fessl y Tebich 2002, Antoniazzi y col. 2011) y en la provincia de Buenos Aires (Rabuffetti y Reboreda, 2007; Segura y Reboreda, 2011). Este aumento estaría relacionado a un incremento en la temperatura ambiental, que se correlaciona positivamente con la intensidad de parasitismo de Philornis. En el parque Pereyra Iraola no se observó un efecto de la temperatura ambiental sobre la intensidad de Philornis pero se observó un incremento en la segunda nidada con respecto a la primera (primera nidada: $\mathrm{x}=6,61 \pm 1,27$, segunda nidada: $\mathrm{x}=12,22 \pm 3,01$ ). Las precipitaciones también se encontraron asociadas a la intensidad de parasitismo de Philornis por otros autores (Nores 1995, Dudaniec y col. 2007, Antoniazzi y col. 2011) aunque esto no se registró en el parque Pereyra Iraola.

El porcentaje de nidos parasitados por Philornis con supervivencia nula encontrado en este trabajo (60,7\%), es el mayor registrado hasta la fecha. Sin embargo, la falta de un efecto de la intensidad de Philornis sobre la supervivencia de pichones que se observó en los modelos analizados en esta tesis, estaría indicando que la mortalidad de los pichones de estornino de la población de estudio sería afectada por otros factores. Nores (1995) observó una mortalidad del 30,7\% de pichones de Cacholote y de $31 \%$ de pichones de Leñatero 
atribuidas al parasitismo de Philornis. Segura y Reboreda (2011) observaron que este parásito produjo la muerte de todos los pichones de Cardenal Común en el 17\% de los nidos estudiados. Por su parte, Quiroga y Reboreda (2012) observaron una mortalidad del 54\% en nidos de Ratona Común parasitados por Philornis. La mortalidad en los nidos de estornino parasitados es similar a la registrada en los pinzones de Darwin en las Isla Galápagos (Fessl y col. 2006), pero debido a que una gran variedad de factores pueden afectar a los pichones e interactuar entre sí, es difícil atribuir con certeza la causa de muerte de los pichones al parasitismo por Philornis (Dudaniec y Kleindorfer 2006).

Analizando las variables climáticas se observó una disminución en la proporción de pichones que sobrevivieron por nido al aumentar la temperatura ambiental, mientras que las precipitaciones favorecieron la supervivencia de los pichones. La temperatura ambiental podría tener un efecto negativo directo sobre los pichones, generando hipertermia en los pichones y afectando su metabolismo. También podría tener un efecto indirecto sobre la reproducción, por ejemplo, mediante la influencia en la disponibilidad de alimento. La abundancia de larvas de algunos ordenes de insectos como Coleoptera y Lepidoptera se ven favorecidos por un aumento en la temperatura ambiental mientras que algunas familias de insectos consumidas por los estorninos, como Tipulidae, se ven afectados negativamente por el aumento en la temperatura debido a su relación con la pérdida de humedad del suelo (Pearce-Higgins 2010). El efecto negativo de la temperatura sobre el peso asintótico alcanzado por lo pichones que se observó en este trabajo favorece la hipótesis del efecto de la temperatura sobre la disponibilidad de alimento, ya que los pichones que nacieron en períodos con temperaturas ambientales más elevadas alcanzaron un menor peso corporal que los nacidos anteriormente, por lo que podrían haber estado peor alimentados.

Para concluir podemos afirmar que el parasitismo por Philornis afecta negativamente la proporción de pichones que sobreviven cuando estos son parasitados a una edad temprana. Sin embargo, son las variables climáticas las que más afectan la supervivencia de los pichones. Serían necesarios futuras investigaciones para poder determinar si estos factores ejercen un efecto directo sobre los pichones o si se ven afectados indirectamente a través de las fluctuaciones en la disponibilidad de alimento relacionadas al clima. 


\section{CAPÍTULO 6: ALIMENTACIÓN DEL ESTORNINOPINTO}

\section{INTRODUCCIÓN}

El éxito reproductivo de las aves se encuentra limitado por la habilidad de los progenitores para alimentar a sus pichones, lo que determina el estado fisiológico de estos y su supervivencia. En consecuencia existe una importante fuerza selectiva sobre los padres en favor de convertirse en buenos proveedores de alimento (Krebs y Davies 1993). En relación a esto, se ha demostrado que los pichones que reciben una mayor cantidad de alimento presentan una mayor tasa de crecimiento (Boag 1987, Naef Daenzer y Keller 1999) y una mayor supervivencia (Dhindsa y Boag 1990, Richner 1992) que los pichones que tienen una menor disponibilidad de alimento.

La alimentación de las aves puede variar en los distintos momentos del año y en las distintas etapas de su vida de acuerdo a la disponibilidad de recursos y de sus propias necesidades fisiológicas. Por ejemplo, los pichones requieren grandes cantidades de proteínas para crecer, mientras que una hembra en la época reproductiva, además de necesitar proteínas, también requiere de una mayor cantidad de calcio para la formación del huevo (Williams 2005). En cuanto a la disponibilidad de recursos, se observan importantes variaciones en los distintos ambientes y en las distintas etapas de la temporada reproductiva y se ha comprobado que estas variaciones afectan la alimentación de los pichones en distintas especies de aves (Horne y Bader 1990, Naef-Daenzer y Keller 1999).

Además del consumo de alimento, la ingesta de piedras es un comportamiento común en las aves (Best y Gionfriddo 1991). Una de sus funciones es la de favorecer la eficiencia de la digestión (Gionfriddo y Best 1995, Gionfriddo y Best 1996). En relación a esto, varios autores han observado un incremento en la ingesta de piedras relacionada al consumo de material vegetal debido a la dificultad para digerir este alimento (Norris y col. 1975, Norman y Brown 1985, Gionfriddo y Best 1995). Otra función sería la de proveer calcio suplementario y otros minerales que son necesarios en las especies que presentan una alimentación baja en calcio (Norris y col. 1975, Feare 1984). 
Cuando una especie es introducida en un nuevo sitio, debe enfrentarse a nuevas condiciones ambientales y en muchos casos debe comenzar a explotar nuevos recursos (Duncan y col. 2003). Los trabajos donde se analizó el éxito de las especies exóticas en relación a su alimentación han demostrado que existe una correlación positiva entre la diversidad de la dieta de las distintas especies de aves y la probabilidad de establecerse exitosamente en el lugar donde fueron introducidas, siendo las aves más generalistas las más exitosas (Blackburn y col. 2009).

\section{Alimentación del Estornino Pinto}

Al estornino se lo considera una especie omnívora, pero se observa una diferencia estacional en su alimentación entre la época reproductiva y no reproductiva y en las distintas etapas de su desarrollo (Feare 1984). En la época reproductiva su dieta es principalmente insectívora (Linsey 1939, Coleman 1977, Moeed 1980, Tinbergen 1981, Feare 1984, Moore 1986). Las presas las obtiene principalmente del suelo mediante el comportamiento de "gapping" que consiste en la introducción del pico en el suelo, su apertura bajo tierra, la captura del alimento y la extracción del mismo (Tinbergen 1981, Feare 1984). Este comportamiento le permite al estornino obtener insectos que se encuentran bajo tierra en los estratos superiores, además de los insectos que obtiene de la superficie, ampliando de esta manera su nicho trófico (Tinbergen 1981). Para realizar este comportamiento los estorninos presentan adaptaciones a nivel del cráneo, del pico, de la posición de los ojos y de los músculos craneales (Feare 1984, Tinbergen 1981, Craig y Feare 2009). Los estorninos también pueden obtener frutos de los árboles (Tinbergen 1981) y se los ha observado atrapar insectos en vuelo (Brackbill 1952, Dunnet 1955, Tinbergen 1981).

La dieta de los estorninos, además de las variaciones estacionales en diversidad y composición, es influenciada por variaciones interanuales y por los patrones locales de abundancia de los alimentos (Coleman 1977, Feare 1984, Moore 1986).

La alimentación de los pichones de estornino ha sido estudiada por numerosos autores en distintas partes del mundo como Europa (Dunnet 1955, Coleman1977, Westerterp 1982, Tinbergen 1981), Norteamérica (Lindsey 1939, Moore 1986) y Nueva Zelanda (Moeed 1980). Se ha observado que las variaciones a escala geográfica en la alimentación de los pichones de estornino reflejan la distribución de las distintas especies de invertebrados (Feare 1984). En Argentina hasta el momento no se ha analizado la alimentación del Estornino Pinto. El conocimiento de la alimentación del estornino en cada lugar donde fue introducido es muy importante para conocer el nicho trófico que está ocupando y con qué especies podría estar compitiendo por los recursos alimenticios. 


\section{OBJETIVOS DEL CAPÍTULO}

a) Determinar el alimento que reciben los pichones de estornino en la zona de estudio.

b) Determinar si existen variaciones en los distintos momentos del período reproductivo y entre años en la alimentación de los pichones.

c) Analizar si existen diferencias en la proporción de alimento animal, vegetal y de piedras que ingieren los pichones en las distintas etapas de su crecimiento.

d) Analizar si variables ambientales como la temperatura y las precipitaciones influyen en la proporción de alimento vegetal y de artrópodos que reciben los pichones.

\section{MATERIALES Y MÉTODOS}

Para el análisis del contenido estomacal se utilizaron de 119 pichones de estorninos que se encontraron muertos durante la revisación de las cajas-nido en las temporadas reproductivas 2010,2011 y 2012 . Los pichones fueron conservados en freezer a $-20^{\circ} \mathrm{C}$ hasta que se realizo el análisis estomacal en el que se determinaron los items alimenticios. De 73 de 119 pichones se registró la edad que tenían el día en que murieron. Esto permitió establecer tres grupos de pichones: grupo 1: 0 - 7 días, grupo 2: 8 - 15 días, grupo 3: $>15$ días. Estas categorías fueron utilizadas para analizar si existieron diferencias en la alimentación de los pichones en las distintas etapas de su desarrollo.

En el laboratorio se realizó la disección de los ejemplares, se extrajo el tracto digestivo y se separó el estómago. Se extrajo el contenido estomacal y se separó en los siguientes ítems: alimento vegetal, artrópodos y piedras. Se obtuvo el peso húmedo de cada grupo con una balanza digital (precisión $0,001 \mathrm{~g}$ ). Los artrópodos encontrados en el contenido estomacal de 70 pichones de las temporadas reproductivas 2011 y 2012 fueron conservados en alcohol 70\% para su posterior identificación.

Se estimaron la cantidad de artrópodos presentes en los estómagos reconstruyéndolos a partir de los fragmentos encontrados. Los artrópodos fueron analizados con una lupa binocular $40 \mathrm{x}$ y determinados taxonómicamente por el Dr. Armando C. Cicchino de la Universidad Nacional de Mar del Plata. Se determinó la frecuencia relativa de cada especie y orden de artrópodo presentes en los estómagos de los pichones dividiendo la cantidad total de 
ítems de cada grupo encontrados en el total de los estómagos sobre la cantidad de estómagos analizados.

La técnica de análisis del contenido estomacal es ampliamente utilizada en estudios de alimentación de las aves y ha sido utilizada en trabajos realizados en pichones de Estornino Pinto (Lindsey 1939, Coleman 1977, Moeed 1980).

\section{Análisis estadístico}

Se calculó la proporción de artrópodos, alimento vegetal y piedras en los estómagos de los pichones dividiendo el peso de cada uno de estos ítems sobre el peso total del alimento de cada estómago. Se realizó un test no paramétrico de Kruskall-Wallis para comparar la cantidad de alimento total, la proporción de artrópodos, de alimento vegetal y de piedras que consumieron los pichones de los distintos grupos de edades. Este test también fue utilizado para determinar si existieron diferencias significativas en la proporción de cada tipo de alimento entre los años 2010, 2011 y 2012 y entre las distintas etapas del período reproductivo (separado por quincenas de la siguiente manera: quincena 1: 15 a 31 de octubre, quincena 2: 1 a 15 de noviembre, quincena 3: 16 a 30 de noviembre, quincena 4: 1 a 15 de diciembre, quincena 5: 15 a 31 de diciembre).

Para determinar si la proporción de artrópodos, de alimento vegetal y de piedras ingeridas se relacionó con la edad de los pichones, se realizaron correlaciones de Spearman. Para esto se utilizaron las edades a las cuales murieron los pichones sin agruparlas. También se realizó un análisis de Spearman para determinar si existieron correlaciones entre la proporción de artrópodos y de alimento vegetal que consumieron los pichones y las variables ambientales. En este último caso se utilizó el promedio de la temperatura máxima y la sumatoria de las precipitaciones de las quincenas en las que murieron los pichones. Los datos de temperatura y precipitaciones se obtuvieron de la estación meteorológica de Quilmes ( $\left.34^{\circ} 44^{\prime} \mathrm{S}, 58^{\circ} 14^{\prime} \mathrm{O}\right)$ (http://www.climasurgba.com.ar/).

\section{RESULTADOS}

Se encontró alimento en los estómagos de todos los pichones, con excepción de diez que murieron entre el 21 de noviembre y el 21 de diciembre de 2012 que tenían el estómago vacío. El peso medio del alimento total por pichón fue de $0,76 \pm 0,08 \mathrm{~g}$, se encontraron $0,57 \pm$ $0,07 \mathrm{~g}$ de artrópodos por pichón, $0,12 \pm 0,03 \mathrm{~g}$ de alimento vegetal y $0,06 \pm 0,03 \mathrm{~g}$ de piedras. 
El alimento vegetal consistió en semillas, pequeños trozos de hojas y fibras vegetales. En 58 de 119 estómagos (48,7\%) se encontraron semillas de Morera negra Morus nigra. El resto de las especies vegetales no fueron identificadas hasta el momento. Se encontraron piedras en 63 de los 119 estómagos analizados (53\%), El tamaño de las piedras varió entre muy fragmentado (no se midió el tamaño mínimo) hasta 10,43 mm de largo.

Se observaron en total ocho órdenes de artrópodos en el contenido estomacal de los pichones de estornino, siete de los cuales fueron insectos pertenecientes a los órdenes Coleoptera, Hymenoptera, Orthoptera, Homoptera, Hemiptera, Lepidoptera y Diptera. También se encontraron artrópodos del orden Araneae (Arachnida). Los órdenes de artrópodos encontrados con una mayor frecuencia fueron: Coleoptera, Hymenoptera, larvas de Lepidoptera y Araneae. Los otros cuatro órdenes se encontraron en frecuencias menores (Tabla 6.3). El orden del que se encontraron una mayor cantidad de ejemplares fue Hymenoptera, seguido por Coleoptera y Lepidoptera. Hymenoptera también fue el orden que presentó los ejemplares más agrupados (Tabla 6.3, Fig. 6.1). En el 61\% de los estómagos se encontraron larvas de insectos, de estas el 67,4\% fueron larvas de Lepidoptera, el 23\% larvas de Coleoptera y el 9\% larvas de Diptera (Fig. 6.2, Tabla 6.3). De los órdenes Homoptera, Hemiptera y Araneae se encontraron sólo uno o dos ejemplares por pichón (Tabla 6.3).

\begin{tabular}{lllllll} 
Orden & Estadio & Frec & $\mathrm{x} \pm \mathrm{EE}$ & Mín - máx & $N($ total $)$ & $N(\mathrm{P})$ \\
\hline Coleoptera & $\mathrm{A}$ & 0,49 & $1,59 \pm 0,18$ & $1-6$ & 52 & 34 \\
& $\mathrm{~L}$ & 0,14 & $2,6 \pm 0,43$ & $1-5$ & 27 & 10 \\
Hymenoptera & $\mathrm{A}$ & 0,54 & $4,94 \pm 0,7$ & $1-15$ & 163 & 38 \\
Orthoptera & $\mathrm{A}$ & 0,13 & $2 \pm 0,45$ & $1-4$ & 20 & 9 \\
Homoptera & $\mathrm{A}$ & 0,03 & $1,5 \pm 0,22$ & $1-2$ & 3 & 2 \\
Hemiptera & $\mathrm{A}$ & 0,06 & $1,67 \pm 0,67$ & $1-2$ & 6 & 4 \\
Lepidoptera & $\mathrm{L}$ & 0,41 & $3,24 \pm 0,45$ & $1-9$ & 94 & 29 \\
Diptera & $\mathrm{L}$ & 0,07 & $3 \pm 0,91$ & $1-5$ & 14 & 5 \\
Araneae & $\mathrm{A}$ & 0,34 & $1,21 \pm 0,08$ & $1-2$ & 29 & 24 \\
Total & & & & & 408 & \\
\hline
\end{tabular}

Tabla 6.3: Frecuencia de aparición de larvas (L) y adultos (A) de los distintos órdenes de artrópodos en los estómagos de los pichones de estornino. $N$ (total)= número de artrópodos totales registrados de cada orden, $N(\mathrm{P})=$ número de pichones donde se registró cada orden. 


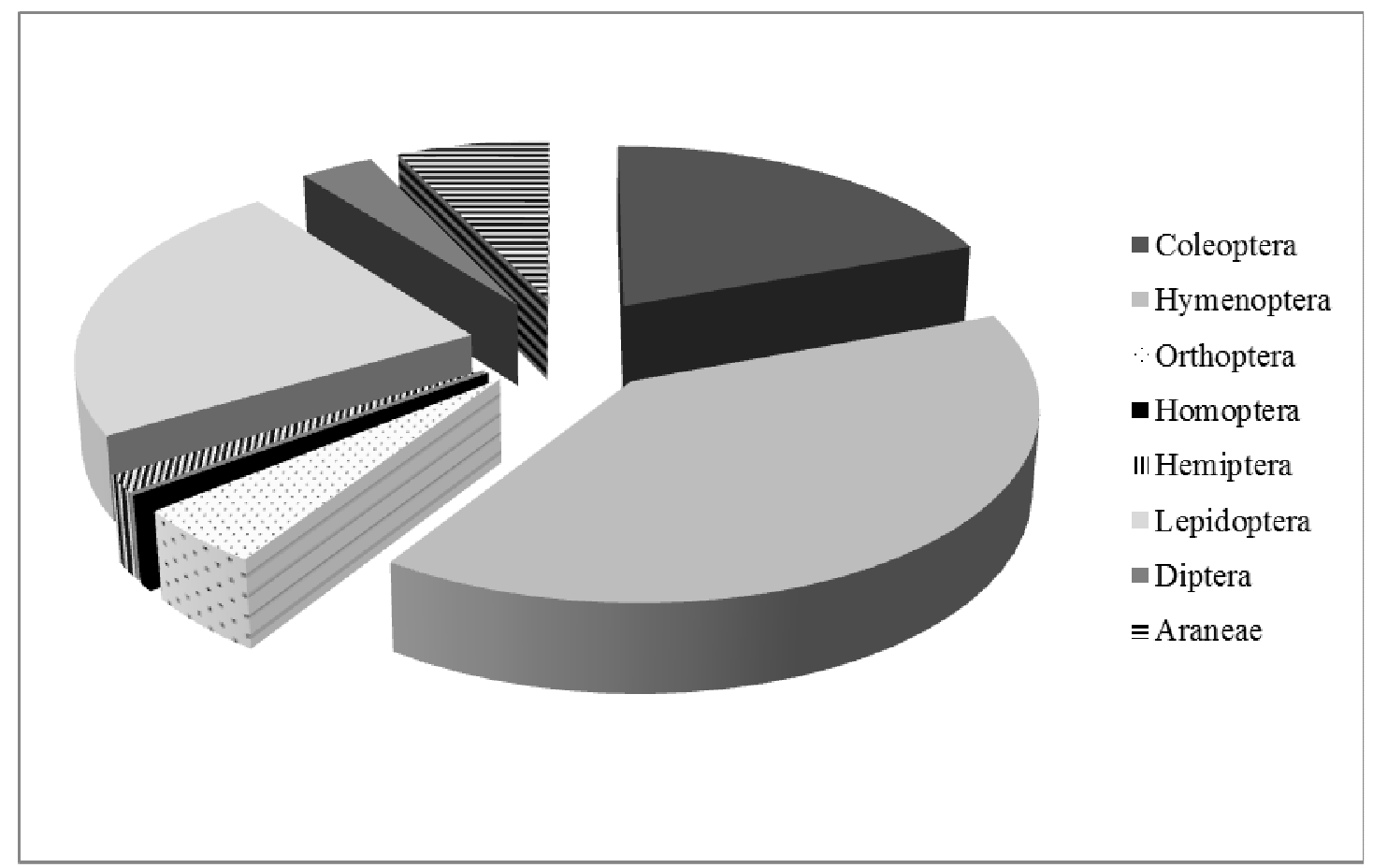

Fig. 6.1: Porcentajes de los distintos órdenes de artrópodos presentes en los estómagos de los pichones de estornino.

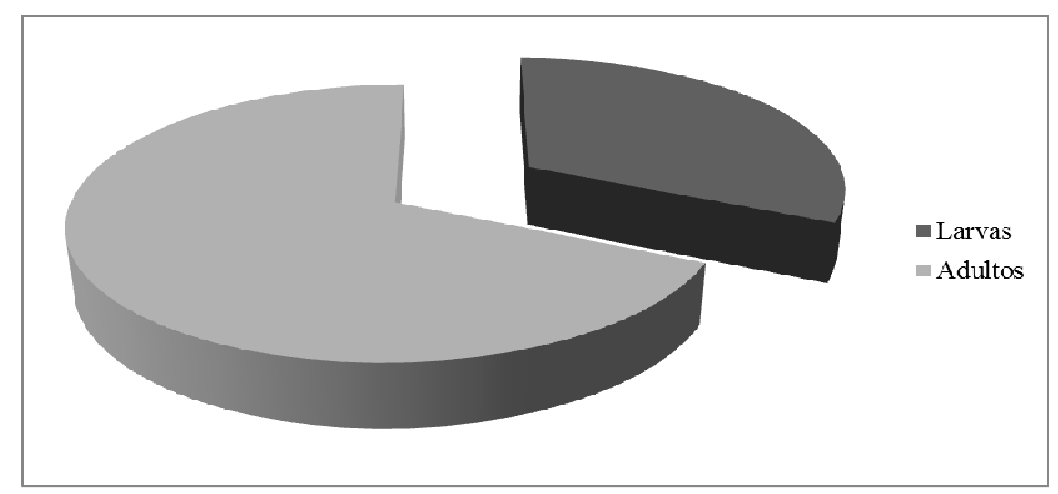

Fig. 6.2: Porcentajes de larvas y adultos de artrópodos presentes en los estómagos de los pichones de estornino.

El orden Coleoptera fue en el que se registraron la mayor cantidad de familias $(n=9)$, seguido del orden Hemíptera donde se identificaron cuatro familias. Se identificaron dos familias de los órdenes Diptera, Hymenoptera y Orthoptera y una de Hymenoptera y Homoptera además de una familia de arácnido. Las familias con mayor frecuencia de aparición fueron Formicidae seguida por Curculionidae. Los géneros y especies identificados pueden observarse en la tabla 6. 4 . 


\begin{tabular}{|c|c|c|c|c|}
\hline Orden & Familia & Especie & $\begin{array}{l}\text { Frecuencia } \\
\text { (n) }\end{array}$ & $\begin{array}{l}\mathrm{X} \pm \mathrm{EE} \\
\text { (mín-máx) }\end{array}$ \\
\hline \multirow[t]{25}{*}{ Coleoptera } & Curculionidae & Naupactus sp. & $0,06(4)$ & $2 \pm 1(1-5)$ \\
\hline & & Calendra sp. & $0,01(1)$ & 1 \\
\hline & & & $0,19(13)$ & $1,46 \pm 0,39$ \\
\hline & & N. I. & & $6)$ \\
\hline & Scarabaeidae & Liogenys sp. & $0,01(1)$ & 1 \\
\hline & & N. I. & $0,01(1)$ & $1,5 \pm 0,2(0-2)$ \\
\hline & Larva & & $0,07(5)$ & $2 \pm 0(2-2)$ \\
\hline & Trogidae & & $0,01(1)$ & 1 \\
\hline & Carabidae & Pachymorphus striatulus & $0,06(4)$ & $1 \pm 0(1-1)$ \\
\hline & & Popochila nigra & $0,01(1)$ & 1 \\
\hline & & Selenophorus sp. & $0,01(1)$ & 1 \\
\hline & & Galerita collaris & $0,01(1)$ & 1 \\
\hline & & Lineatopunctatum & $0,03(2)$ & $1 \pm 0(1-1)$ \\
\hline & & dyscinetus & & \\
\hline & & Scarites anthracinus & & \\
\hline & & Larva & $0,01(1)$ & 1 \\
\hline & & Notiobia cupripennis & $0,03(2)$ & $1 \pm 0(1-1)$ \\
\hline & Larva & & $0,01(1)$ & 4 \\
\hline & Cantharidae & Chauliognathus sp. & & \\
\hline & & Larva & $0,03(2)$ & $2,5 \pm 1,06(1-4)$ \\
\hline & Larva & & $0,04(3)$ & $3 \pm 0,87(2-5)$ \\
\hline & Cavognatidae & Taphropiestes plaumanni & $0,01(1)$ & 1 \\
\hline & Tenebrionidae & & $0,04(3)$ & $1 \pm 0(1-1)$ \\
\hline & Elateridae & & $0,01(1)$ & 1 \\
\hline & Dinastidae & & $0,03(2)$ & $1 \pm 0(1-1)$ \\
\hline N. & & & $0,01(1)$ & 1 \\
\hline \multicolumn{5}{|l|}{ I. } \\
\hline Larva & & & $0,01(1)$ & 3 \\
\hline \multirow[t]{2}{*}{ Hymenoptera } & Formicidae & Pheidole sp. & $0,06(4)$ & $9,5 \pm 2,1(5-15)$ \\
\hline & & Atta sp. & $0,09(6)$ & $6,67 \pm 2,5$ \\
\hline
\end{tabular}


13)

$0,13(9) \quad 3,78 \pm 1,37(1-$

Acromyrmex sp. 11)

N. I.

$0,20(14) \quad 3,64 \pm 1,5 \quad(1-$

10)

Orthoptera Grillotalpidae Scapteriscus sp.

$\begin{array}{ll}0,01(1) & 1 \\ 0,06(4) & 1,75 \pm 0,75(1-\end{array}$

Gryllidae

4)

$0,06(4) \quad 2,75 \pm 0,75(1-$

N. I.

4)

Homoptera Fulgoridae

$0,01(1) \quad 2$

N. I.

$0,01(1) \quad 1$

Hemiptero Coreidae Leptoglossus sp.

$0,01(1) \quad 2$

Cydnidae

$0,01(1) \quad 1$

Lygaeidae

$0,03(2) \quad 1 \pm 0(1-1)$

Pentatomidae

$0,01(1) \quad 1$

Lepidoptera Noctulidae

Larva

$0,01(1) \quad 1$

Coleophoridae

$$
\text { Larva }
$$

$0,03(2) \quad 6,5 \pm 1,06(5-8)$

N. I.

$0,37(26) \quad 3,08 \pm 1,15(1-$

Larva

9)

Diptera Muscidae

Larva

$0,03(2) \quad 4,5 \pm 0,35(4-5)$

Tipulidae

$0,04(3) \quad 1,67 \pm 0,29(1-$

Larva

2)

$0,04(3) \quad 1,33 \pm 0,29(1-$

Araneidae Lycosidae

2)

N. I.

$0,30(21) \quad 1,19 \pm 0,2(1-2)$

Tabla 6.4: Frecuencias relativas de las especies de artrópodos encontrados en los estómagos de los pichones de estornino. N. I.: items no identificados. 


\section{Variaciones estacionales y por edad en la alimentación de los pichones}

Se observó un aumento en la cantidad de artrópodos, de alimento vegetal (semillas, fragmentos de hojas, fibras vegetales) y de piedras entre los pichones de los grupos 1 y 2 que luego disminuyó en los pichones del grupo 3 (Tabla 6.1).

\begin{tabular}{lcll} 
& Grupo & $\mathrm{X} \pm$ E.E. & Mín - máx \\
\hline \multirow{4}{*}{ Artrópodos } & 1 & $0,8 \pm 0,13$ & $0,01-2,72$ \\
& 2 & $0,41 \pm 0,08$ & $0-1,62$ \\
& 3 & $0,14 \pm 0,1$ & $0-0,63$ \\
\hline \multirow{3}{*}{ Alimento vegetal } & 1 & $0,03 \pm 0,01$ & $0-0,24$ \\
& 2 & $0,24 \pm 0,07$ & $0-1,61$ \\
& 3 & $0,07 \pm 0,04$ & $0-0,24$ \\
Piedras & 1 & $0,02 \pm 0,01$ & $0-0,14$ \\
& 2 & $0,12 \pm 0,07$ & $0-2$ \\
Total & 3 & $0,04 \pm 0,02$ & $0-0,12$ \\
\hline & 1 & $0,86 \pm 0,13$ & $0,01-2,72$ \\
& 2 & $0,71 \pm 0,12$ & $0,00-2,80$ \\
& 3 & $0,11 \pm 0,06$ & $0-0,84$ \\
\hline
\end{tabular}

Tabla 6.1: Cantidad de artrópodos, alimento vegetal y piedras en los estómagos de pichones de estorninos de distintas edades (expresada en gramos). Grupo $1: n=35$, grupo 2 : $\mathrm{n}=34$, grupo $3: \mathrm{n}=14$.

En cuanto al alimento total recibido por los pichones se observó una disminución en los pichones del grupo 3 (Kruskall-Wallis, $\mathrm{H}=20,74, \mathrm{p}<0,01, \mathrm{n}=82$ ) con respecto a los pichones del grupo $1(\mathrm{z}=4,36, \mathrm{p}<0,01)$ y del grupo $2(\mathrm{z}=3,79, \mathrm{p}<0,01)$ (Fig. 6.3). 


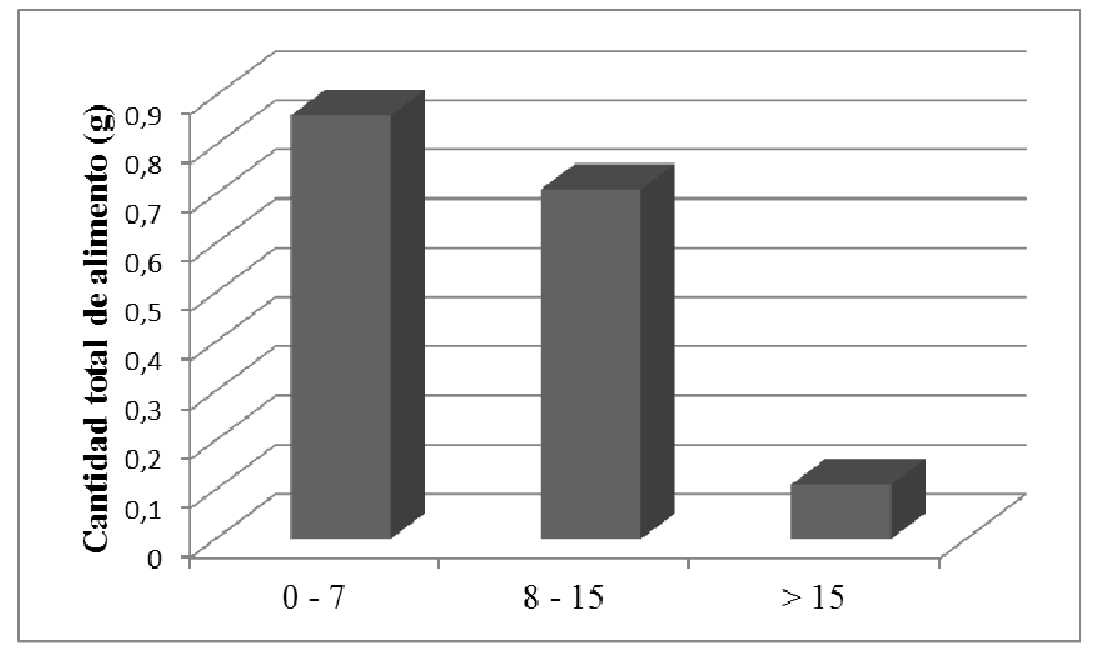

Fig. 6.3: Cantidad de alimento total (en gramos) presente en los estómagos de los pichones de estornino de tres grupos de edades, recolectados en la ECAS.

Los porcentajes del peso cada ítem consumido por los pichones de todas las edades en conjunto fueron las siguientes: $73 \%$ de artrópodos, $16 \%$ de alimento vegetal y $11 \%$ de piedras (Fig. 6.4 a). Se observó una disminución en la proporción de artrópodos y un aumento en la proporción de alimento vegetal con la edad de los pichones. En los pichones del grupo 1 $(\mathrm{n}=35)$ se observó una proporción de artrópodos de $0,89 \pm 0,02$, de $0,05 \pm 0,02$ de alimento vegetal y de $0,06 \pm 0,02$ de piedras (Fig. 6.4 b). En los pichones del grupo $2(\mathrm{n}=30)$ la proporción de artrópodos en la dieta fue de 0,59 $\pm 0,07$, de $0,27 \pm 0,05$ de alimento vegetal y de $0,15 \pm 0,05$ de piedras (Fig. 6.4 c). En los pichones del grupo $3(\mathrm{n}=7)$ la proporción de artrópodos fue de $0,48 \pm 0,20$, de $0,29 \pm 0,17$ de alimento vegetal y de $0,23 \pm 0,16$ de piedras (Fig. 6.4 d). (Fig. 6.4). 


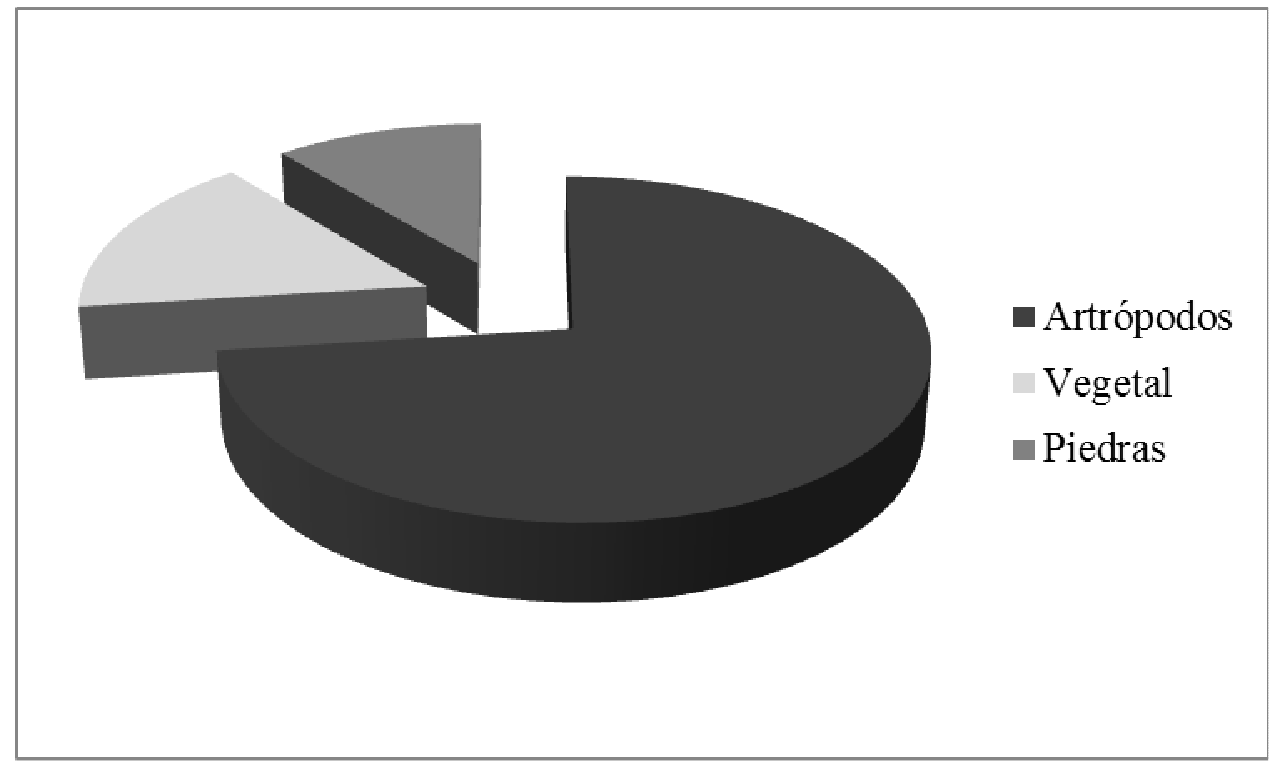

A) Total

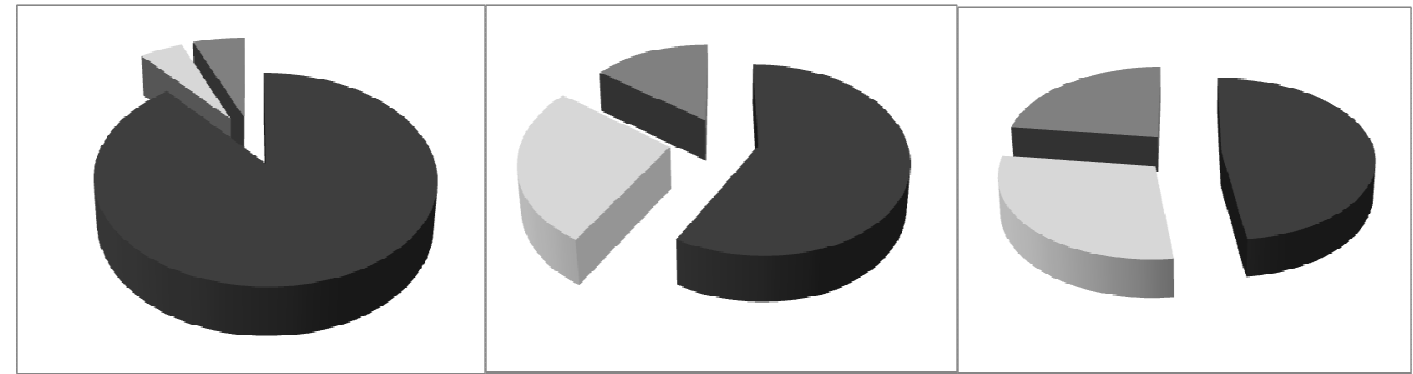

B) Grupo 1

C) Grupo 2

D) Grupo 3

Fig. 6.4: Porcentaje de artrópodos, de alimento vegetal y de piedras en las siguientes categorías: a) total de las muestras, b) pichones del grupo 1, c) pichones del grupo 2, d) pichones del grupo 3 .

La proporción de artrópodos encontrados en los pichones grupo 1 y 2 difirió significativamente (Kruskall-Wallis, $H=14,97, p<0,001$, grupo 1-2: $z=3,68, p<0,01$, grupo 1-3: $z=3,90, p=0,05)$ y no difirió entre los pichones del grupo 2 y $3(z=0,10 p=1,00)$. La proporción de alimento vegetal difirió entre los pichones del grupo 1 y 2 (Kruskall-Wallis, $\mathrm{H}$ $=18,23, \mathrm{p}<0,001, \mathrm{z}=4,16, \mathrm{p}<0,01)$ pero no se encontraron diferencias en esta variable entre los pichones del grupo 2 y $3(\mathrm{z}=1,19, \mathrm{p}=0,70)$. No se encontraron diferencias significativas en la proporción de piedras ingeridas entre los pichones de los distintos grupos de edades (Kruskall-Wallis, $\mathrm{H}=2,79, \mathrm{p}=0,24$, grupo 1- grupo 2: $\mathrm{z}=1,46, \mathrm{p}=0,43$, grupo 1 - grupo 3 : $\mathrm{z}=$ 0,94, $\mathrm{p}=1,00$, grupo 2- grupo 3: $\mathrm{z}=0,12, \mathrm{p}=1,00$ ) (Fig. 6.4).

La edad de los pichones se encontró correlacionada negativamente con la proporción de artrópodos que consumieron (Spearman, $\mathrm{r}_{\mathrm{s}}=-3,85, \mathrm{p}<0,01, \mathrm{n}=71$ ) y positivamente con la 
proporción de alimento vegetal (Spearman, $\mathrm{r}_{\mathrm{s}}=0,41, \mathrm{p}<0,01, \mathrm{n}=71$ ). El porcentaje de piedras ingeridas se correlacionó positivamente con la edad de los pichones, pero la confianza de esta relación cayó por debajo del límite de significancia convencional (Spearman, $\mathrm{r}_{\mathrm{s}}=0,22$, $\mathrm{p}=0,07, \mathrm{n}=73$ ). El porcentaje de piedras ingeridas no se correlacionó con la proporción de alimento vegetal consumido (Spearman, $\mathrm{r}_{\mathrm{s}}=0,15, P=0,13, \mathrm{n}=100$, Fig. 6.5) pero se asoció negativamente a la proporción de artrópodos (Spearman, $\mathrm{r}_{\mathrm{s}}=-0,57, \mathrm{p}<0,01, \mathrm{n}=100$ ).

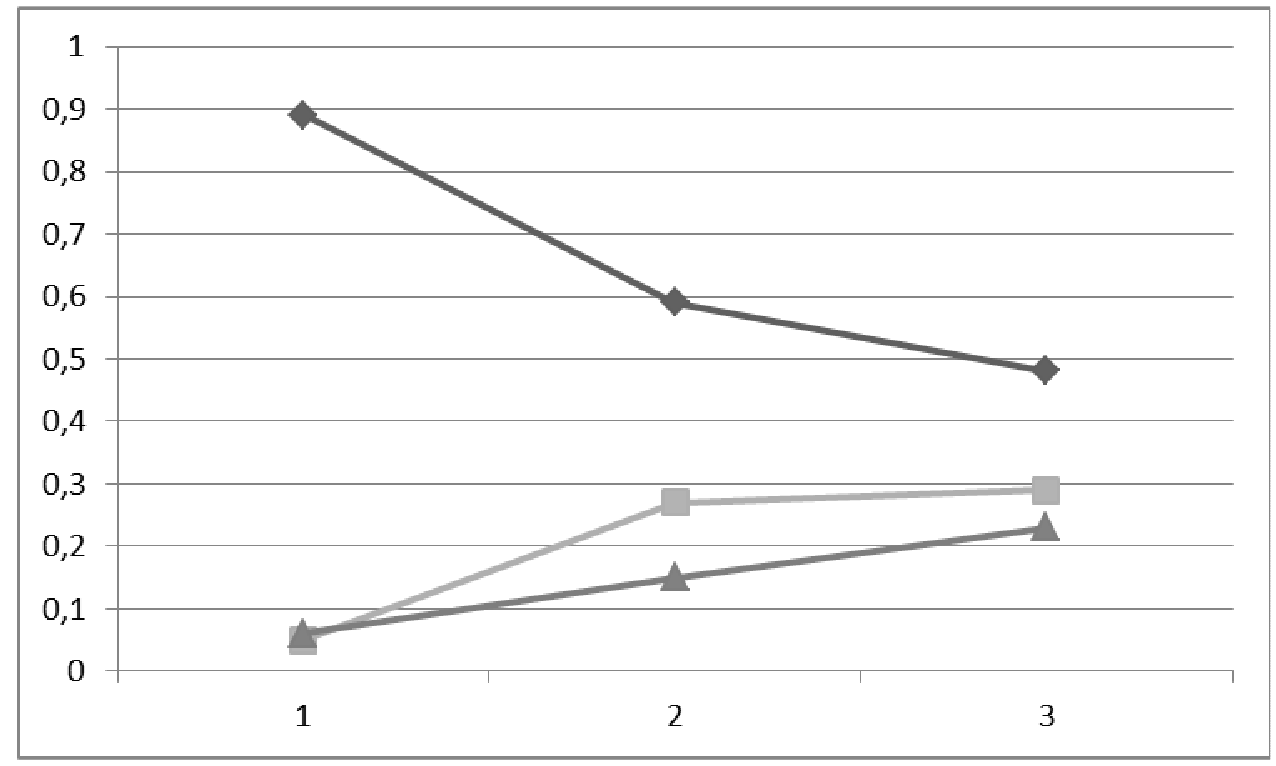

Fig. 6.5: Proporción de artrópodos (rombos negros), alimento vegetal (cuadrados grises) y piedras (triángulos grises) en relación al total de alimento encontrado en los estómagos de los pichones de estorninos en los tres grupos de edades.

Al avanzar la temporada reproductiva se observó una disminución en la proporción de artrópodos (Kruskall-Wallis, $\mathrm{H}=24,08, \mathrm{p}<0,01, \mathrm{n}=100$ ) y un aumento en la proporción de alimento vegetal (Kruskall-Wallis, $\mathrm{H}=19,31, \mathrm{p}<0,01, \mathrm{n}=100$ ) y de piedras (Kruskall-Wallis, $\mathrm{H}=12,20, \mathrm{p}=0,02, \mathrm{n}=100$ ) (Fig. 6.6) similar al que ocurre en los pichones de diferentes edades. El avance de la temporada se correlacionó positivamente a la edad de los pichones analizados (Correlación de Spearman: $r s=0,24, p=0,03$ ) 


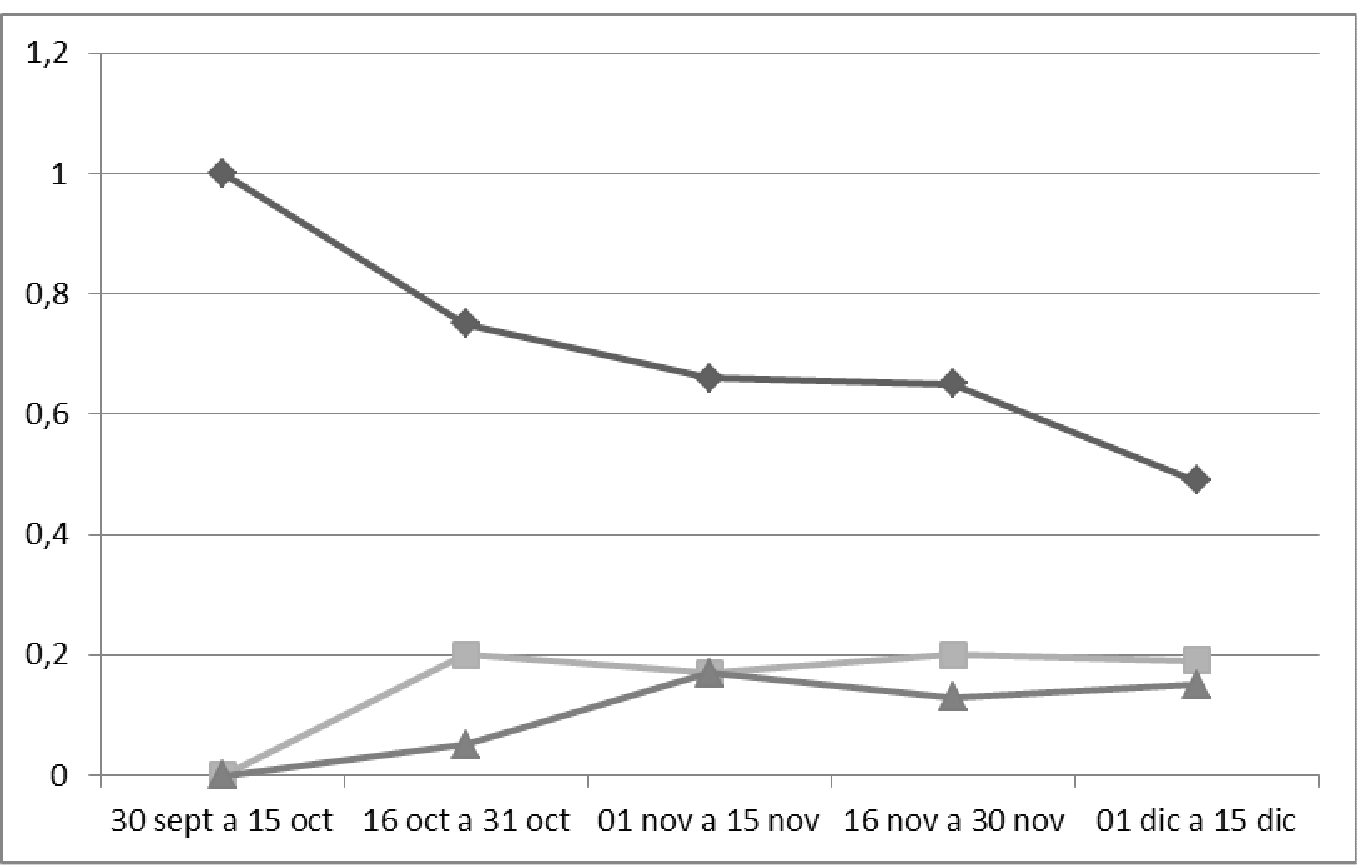

Fig. 6.6: Proporción de artrópodos (rombos negros), alimento vegetal (cuadrados grises) y piedras (triángulos grises) consumida por los pichones a lo largo de la temporada reproductiva.

La proporción de piedras encontradas en los estómagos de los pichones varió significativamente entre años (Kruskall-Wallis, $H=8,44, p=0,01$ ). Los contrastes mostraron que esta proporción fue significativamente mayor en el 2012 respecto del $2011(\mathrm{z}=2,69, \mathrm{p}=$ 0,02) y que no difirió entre el 2010 y $2011(\mathrm{z}=0,66, \mathrm{p}=1)$ ni entre el 2010 y $2012(\mathrm{z}=1,67$, $\mathrm{p}=0,29$ ). La proporción de artrópodos encontrados en los estómagos no difirió entre años (Kruskall-Wallis, $\mathrm{H}=575,00, \mathrm{p}=0,06, \mathrm{~N}=100$ ) como así tampoco la proporción de alimento vegetal (Kruskall-Wallis, $\mathrm{H}=2,20, \mathrm{p}=0,33, \mathrm{~N}=100$ ) (Fig. 6.7). 


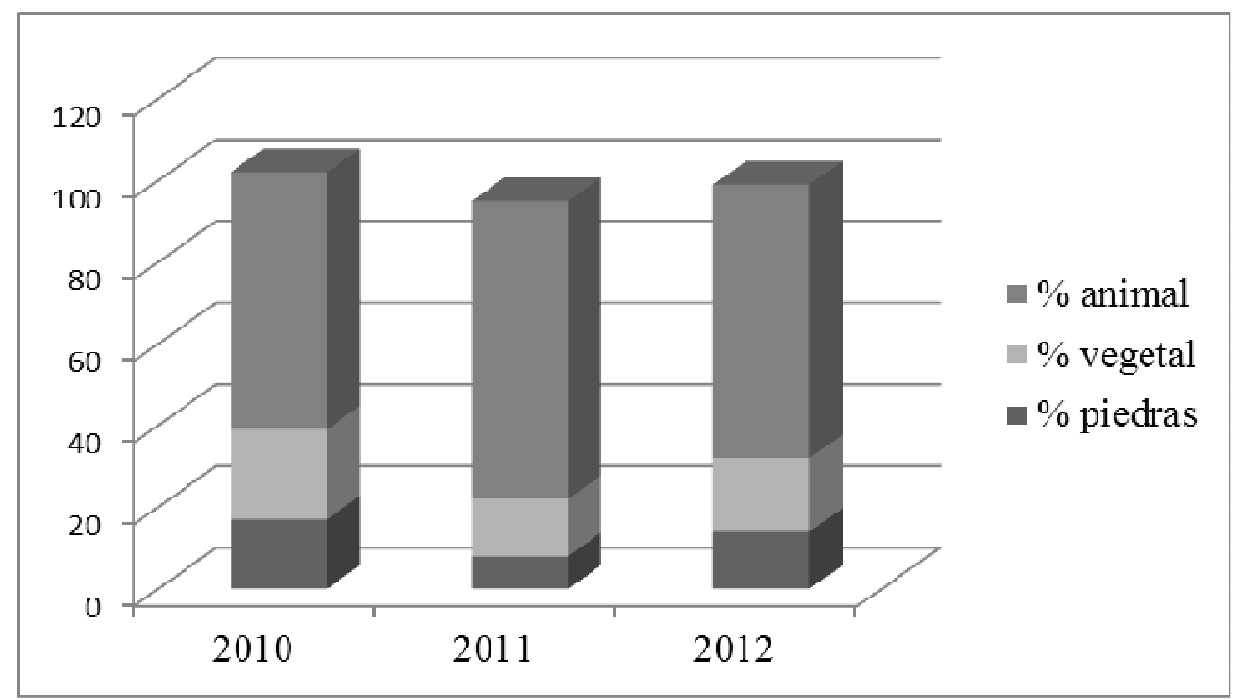

Fig. 6.7) Proporción de artrópodos, alimento vegetal y piedras en los contenidos estomacales de pichones en los distintos años.

La proporción de artrópodos se relacionó negativamente y el alimento vegetal positivamente con la temperatura máxima. Sin embargo la confianza de estas relaciones cayeron por debajo del límite de significancia convencional (Tabla 6.2). El resto de las variables ambientales no se correlacionaron ni con el porcentaje de artrópodos ni con el de ítems vegetales. (Tabla 6.2).

\begin{tabular}{lllll} 
& \multicolumn{2}{c}{$\%$ artrópodos } & \multicolumn{2}{l}{$\%$ vegetal } \\
\cline { 2 - 5 } & $\mathrm{r}_{\mathrm{s}}$ & $P$ & $\mathrm{r}_{\mathrm{s}}$ & $P$ \\
\hline Tmáx & $-0,18$ & 0,06 & 0,19 & 0,05 \\
Ppt & 0,05 & 0,58 & $-0,12$ & 0,23 \\
\hline
\end{tabular}

Tabla 6.2: Coeficientes de correlación de Spearman $\left(\mathrm{r}_{\mathrm{s}}\right)$ y valor de $P$ de la proporción de artrópodos y de alimento vegetal en relación a las variables ambientales: temperatura máxima (T máx) y precipitaciones (Ppt).

\section{DISCUSIÓN}

El análisis del contenido estomacal de los pichones de estornino en el parque Pereyra Iraola indicó que estos fueron alimentados principalmente con insectos y en menor proporción con alimento vegetal. La presencia de semillas de Morera negra en casi la mitad de los 
estómagos de pichones sugiere la posibilidad de que el estornino esté actuando como un dispersor de semillas de esta planta exótica, favoreciendo la modificación de la vegetación de la zona. Algunas de las semillas encontradas en los estómagos no fueron determinadas taxonómicamente, por lo tanto no podemos saber si el estornino está consumiendo otras especies vegetales nativas, exóticas o si se están alimentando en feedlots o cultivos de la zona. De todos modos, los daños causados por el ataque a cultivos o a la alimentación en feedlots ocurren principalmente luego de la época reproductiva cuando los juveniles se reúnen en grandes bandadas. Por lo tanto, sería necesario analizar la alimentación de los juveniles en la época post-reproductiva para determinar si los recursos alimenticios que están utilizando en esa época pueden ocasionar algún daño al hombre como la pérdida de producción, el desbalance del alimento del ganado o la transmisión de enfermedades al ganado o a las aves de corral.

La ingesta de artrópodos disminuyó al aumentar la edad de los pichones mientras que aumentó la ingesta de alimento vegetal y de piedras, aunque no se observó una correlación positiva significativa entre el consumo de vegetales y piedras, por lo cual no se puede afirmar que en este caso las piedras sean ingeridas con el fin de facilitar la trituración y digestión de los vegetales, como fue registrado por otros autores (Norris y col. 1975, Norman y Brown 1985, Gionfriddo y Best 1995, 1996). De manera similar, se observó una disminución en la proporción de artrópodos y un aumento de alimento vegetal y piedras al avanzar la temporada reproductiva. A su vez, se observó una correlación positiva entre la edad de los pichones analizados y la quincena de la temporada reproductiva. Por lo tanto la diferencia en la alimentación de los pichones de distintas edades probablemente reflejen diferencias en la disponibilidad de alimento y no los requerimientos nutricionales propios de los pichones. De manera similar, varios autores mencionan una variación en la alimentación de los pichones de acuerdo a la edad y a variaciones estacionales (Tinbergen 1981, Feare 1984, Moore 1986).

Fue llamativo observar que los pichones que murieron a edades más avanzadas (mayores a 15 días) presentaban una cantidad mucho menor de alimento total en sus estómagos, los cuales en algunos casos estaban vacíos, que los pichones que murieron a menor edad. Teniendo en cuenta que la demanda energética de los pichones aumenta con la edad (Moore 1986), estos resultados sugieren que los pichones de mayor edad podrían haber muerto debido a una falta de alimento. Sin embargo, los padres suelen reducir la cantidad de alimento que proveen a los pichones de edades avanzadas, para de esta manera de estimularlos a que abandonen el nido. 
Todos los artrópodos encontrados en el contenido estomacal de los pichones del parque Pereyra Iraola son especies que habitan en el suelo. No se registraron insectos voladores ni se observaron estorninos capturando este tipo de insectos, a diferencia de lo observado en Estados Unidos (Brackbill 1952) y en Europa (Dunnet 1955, Tinbergen 1981), donde este es un comportamiento habitual del estornino.

En Estados Unidos, Lindsey (1939) analizó el contenido estomacal de pichones de distintas edades y encontró que el $77 \%$ del contenido estomacal se encontraba conformado por insectos, mientras que el material vegetal constituyó el 4,9\% y el material mineral el $2,2 \%$. Estos valores son similares a los observados en este trabajo en los pichones de la primera semana de vida (alimento animal: $80 \%$, vegetal: $3 \%$ y piedras: $2 \%$ ), pero si tenemos en cuenta la alimentación de los pichones de todas las edades, en este trabajo observamos una mayor proporción de alimento vegetal y mineral (artrópodos: 73\%, alimento vegetal: $16 \%$ y piedras: $11 \%$ ).

Los pichones analizados en el parque Pereyra Iraola consumieron una gran variedad de artrópodos al igual que los pichones de estornino de Norteamérica, Europa y Nueva Zelanda (Lindsey 1939, Dunnet 1955, Coleman 1977, Westerterp 1982, Moeed 1980, Tinbergen 1981, Feare 1984, Moore 1986). Coleman (1977) encontró más de 50 especies de artrópodos en contenidos estomacales de pichones de estornino en Inglaterra.

Los ítems animales presentes con mayor frecuencia en los estorninos de la ECAS fueron en primer lugar coleópteros (larvas y adultos) seguidos por himenópteros de la familia Formicidae y en tercer lugar larvas de lepidópteros. En los trabajos realizados en otras partes del mundo los alimentos blandos como larvas de dípteros, lepidópteros y lombrices de tierra constituyeron la mayor proporción de la dieta de los pichones de estornino (Dunnet 1955, Westerterp y col. 1982). En Nueva Zelanda, Moeed (1980) encontró lombrices de tierra en todos los pichones que analizó, y los coleópteros y dípteros adultos formaron parte importante de su dieta.

En distintas partes del mundo los ordenes de insectos más consumidos por pichones de estornino fueron Lepidóptera y Coleóptera. En Norteamérica Lindsey (1939) y Moore (1986) observaron que los órdenes Lepidóptera y Coleóptera representaron en conjunto aproximadamente el $80 \%$ de la alimentación. En Inglaterra estos dos órdenes de insectos también fueron los más frecuentes (Coleman 1977).

Los insectos de la familia Formicidae fueron encontrados en más de la mitad de los estómagos de los pichones del parque Pereya Iraola y fue la familia de insectos de la cual se registró el mayor número de ejemplares a diferencia de lo que se observa en Estados Unidos (Lindsey 1939, Moore 1986) y Europa (Coleman 1977, Tinbergen 1981), donde los pichones 
de estornino no consumen insectos de esta familia a pesar de que los adultos se alimentan de ellos fuera de la temporada reproductiva. En Nueva Zelanda, Moeed (1980) también registró insectos de la familia Formicidae en la alimentación de los pichones.

Las larvas del díptero Tipula sp. y las lombrices (Annelida: Lumbricidae) constituyeron el 97\% de la dieta de pichones de estorninos en los Países Bajos (Westerterp y col. 1982). Mientras que Tinbergen (1981) en el mismo país observó que las larvas del lepidóptero Cerapteryx graminis constituyeron el segundo ítem en importancia luego de las larvas de Tipula sp. En Escocia las larvas de Tipula sp. también fueron el alimento más consumido por los pichones (Dunnet 1955). Este género de dípteros está presente en la zona del Parque Pereyra Iraola (Bachmann 2011) y se encontró en los pichones de la ECAS en una baja frecuencia en relación a la frecuencia observada en otros países.

Moeed (1980) en Nueva Zelya no registró pichones alimentándose con ortópteros a pesar de que dos especies de este orden de insectos fueron consumidas por estorninos adultos. En Estados Unidos, Lindsey (1939) observó que los ortópteros conformaban el 4,4\% de la alimentación de los pichones de estornino. Posteriormente Moore (1986) halló valores similares en el mismo país. En el parque Pereyra este orden de insectos constituye un $13 \%$ de la dieta, porcentaje mayor al observado en otras partes del mundo.

El orden Homóptera, se registró en muy baja cantidad en estorninos de Estados Unidos (Moore 1986) al igual que lo observado en este trabajo.

En cuanto al orden Hemíptera, en Estados Unidos, fue consumido con baja frecuencia por los pichones de estornino (Lindsey 1939, Moore 1986), mientras que en Inglaterra constituyen el tercer ítem en importancia luego de los insectos de las familias Lepidóptera y Coleoptera (Coleman 1977).

Los arácnidos son un ítem frecuente en la alimentación de los pichones en Inglaterra (Coleman 1977) y en Nueva Zelya (Moeed 1980). Coleman (1977) observó una frecuencia de $41,6 \%$ de arañas de la familia Lycosidae en estómagos de pichones de estornino. En Estados Unidos, la frecuencia de estos artrópodos solo constituye el 2,6\% de la dieta (Moore 1986). En este trabajo el orden Araneae se observó con una frecuencia del 34\% y los que pudieron ser identificados pertenecieron a la familia Lycosidae.

Los anélidos, que son un alimento frecuente en Europa (Coleman 1977, Westerterp 1982) no se registraron en los contenidos estomacales de pichones de estornino del parque Pereyra Iraola.

En Inglaterra, Coleman (1977) observó que las principales familias de coleópteros consumidas por los pichones son Scarabaeidae, Elateridae, Curculionidae. Estas tres familias también formaron parte de la alimentación de los pichones de este trabajo. Las familias de 
lepidópteros más frecuentes en Nueva Zelanda son Hepialidae, Pyralidae y Noctuidae. De estas tres, sólo Noctuidae se encontró en este trabajo a pesar de que las otras dos familias son cosmopolitas y se encuentran en la Argentina (Greco y col. 1998, Grehan 1989).

Moeed (1980) observó en Nueva Zelanda que entre los coleópteros, los pichones consumieron mayormente elatéridos, mientras que los adultos consumieron en mayor medida carábidos y curculiónidos. De manera opuesta, en los pichones del parque Pereyra Iraola las familias Carabidae y Curculionidae fueron las más consumidas por los pichones, mientras que sólo se encontró un espécimen de Elateridae.

\section{Conclusiones}

En el parque Pereyra Iraola los pichones de estornino son alimentados con una gran variedad de artrópodos y a diferencia de lo que se observa en otras partes del mundo el alimento vegetal constituye una parte importante de su alimentación especialmente en los pichones más grandes y al avanzar la temporada reproductiva. Se sugiere que la principal causa de esta variación se encontraría en cambios en la disponibilidad de alimento a lo largo de la temporada reproductiva En Nueva Zelanda Coleman (1977) observó variaciones estacionales en la alimentación de los estorninos que se encuentran relacionados a patrones locales de abundancia de especies. El análisis de esta relación merece futuros estudios, que no fueron abarcados en esta tesis.

Este es un primer estudio en el que se analiza el contenido estomacal de pichones muertos naturalmente, lo que brinda una información parcial sobre su alimentación durante la permanencia en el nido. Es necesario contrastar esta información con la obtenida mediante el empleo de otros métodos como lavados estomacales, el empleo de collares esofágicos o filmaciones. El consumo de grandes cantidades de insectos, podría beneficiar al hombre si las especies de las que se alimenta afectan a los cultivos. Pero más allá de este posible beneficio los riesgos potenciales por daños a cultivos y feedlots son mayores. 


\section{CAPÍTULO 7: ECTO Y ENDOPARÁSITOS PRESENTES EN EL ESTORNINO PINTO}

\section{INTRODUCCIÓN}

\section{Relación parásito-hospedador}

Los parásitos han sido ampliamente reconocidos como importantes amenazas de la preservación de las poblaciones de aves (Brown y col. 1995, Tompkins y Begon 1999) de debido a sus efectos sobre la mortalidad y la dinámica poblacional (Arendt 1985, Friend y col. 2001, Dudaniec y col. 2007). En cuanto a las especies invasoras, el parasitismo juega un rol muy importante en el impacto que pueden generar en el ecosistema donde fueron introducidas (Blackburn y col. 2009). Estas especies pueden transportar parásitos y transmitirlos a las aves nativas, o pueden actuar como reservorios de especies patógenas que ya se encontraban presentes en el área donde fueron introducidas (Poulin y Mory 2004). Los parásitos introducidos pueden afectar dramáticamente a las poblaciones de aves nativas (Fessl y Tebich, 2002). Un ejemplo de esto lo constituye el caso de las aves nativas de las Islas Hawaiianas que mostraron una importante declinación poblacional relacionada a la introducción del parásito Plasmodium (Apicomplexa) en 1986 (Van Riper y col. 1986). Por otro lado, si la especie de ave introducida no adquiere nuevos parásitos en el nuevo sitio, aumenta la probabilidad de que ésta incremente su tamaño poblacional (Blackburn y col. 2009). La "hipótesis del enemigo perdido" sugiere que el éxito de la introducción de especies exóticas se debe, al menos en parte, a la falta de enemigos naturales como parásitos y predadores (Torchin y col. 2003). Los parásitos más especialistas son los que se pierden con mayor facilidad debido a su dificultad para encontrar nuevos hospedadores intermedios y definitivos en una nueva área en el proceso de traslado del hospedador a un nuevo sitio (Blackburn y col. 2009).

Una vez que el parásito encuentra un nuevo hospedador pueden ocurrir dos cosas: el parásito podría dañar y hasta causar la muerte de su hospedador o podría a través de adaptaciones volverse menos dañino. Esto último disminuiría los costos del parasitismo y beneficiarían al parásito, debido a que éste mantendría por mayor tiempo su hábitat y disponibilidad de recursos (Newton 1998). La mayoría de los hospedadores sufren costos en su reproducción a causa del parasitismo, como por ejemplo la disminución de la tasa de 
crecimiento, masa corporal y supervivencia de pichones parasitados (Brown y Brown 1986, Møller y col.1990, O’Brien y Dawson 2008).

Como resultado de los costos del parasitismo, los hospedadores sufren una presión de selección que favorece la evolución de adaptaciones fisiológicas, inmunológicas y de comportamiento tendientes a reducir estos efectos negativos (Heeb y col. 1998, Agnew y col. 2000, Norris y col. 2010). Van Riper y col. (1986) observaron que las aves nativas de zonas insulares son más vulnerables a los efectos del virus introducido de la viruela aviaria que las aves introducidas.

\section{Endoparásitos}

Las aves son parasitadas por una enorme variedad de especies de endoparásitos pertenecientes a los filos Apicomplexa (protozoos) Levine 1970, Platyhelmithes (cestodes y trematodes) Gegenbaur 1859, Acanthocefala (acantocéfalos) Kohlreuther 1771 y Nematoda (nematodes) Rudolphi 1808 (CoX 1993). A los últimos tres filos se los denomina vulgarmente helmintos y pueden generar distintos efectos en su hospedador como alteración del crecimiento y desarrollo, daños tisulares y competencia con el hospedador por los recursos alimenticios (Atkinson y col. 2008).

El filum Apicomplexa (Protista) comprende un numeroso y heterogéneo grupo de parásitos intracelulares obligados entre los que se encuentran muchos de significancia médica y veterinaria como Eimeria sp., Cryptosporidium sp., Plasmodium sp. y Toxoplasma sp. (Duszynsky y col. 2000). Dentro de la familia Eimeriidae (Apicomplexa) se encuentran protozoos parásitos muy comunes en las poblaciones de aves silvestres (Kedra y Mazgajski 1998). Los géneros Eimeria e Isospora (Coccidia) son los más frecuentes entre las aves y parasitan una amplia variedad de familias. El 90\% de los coccidios presentes en paseriformes pertenecen al género Isospora (Schneider 1881). Este género comprende aproximadamente 140 especies presentes en una amplia variedad de familias de aves (Duszynski y col. 2000).

La mayoría de las especies de Isospora son consideradas parásitos especie-específicas (Atkinson y col. 2008). El ciclo de vida de Isospora es monoxeno y comprende una fase asexuada (merogonia) y una fase sexuada (gametogonia) dentro del hospedador y la esporogonia en el medio ambiente. Cuando el animal ingiere ooquistes esporulados, en el intestino delgado se liberan los esporozoitos que invaden las células epiteliales donde crecen y se reproducen para finalmente formar los ooquistes que se liberan a la luz intestinal y se elimina con las heces al medio ambiente. En el suelo, bajo condiciones adecuadas de temperatura y humedad, se produce la esporogonia mediante el proceso denominado esporulación, para dar la formación de esporozoitos (Basualdo y col. 1996). El ciclo de vida 
monoxeno de este parásito con transmisión fecal-oral favorece la alta tasa de contagio de los pichones y el grado de infección aumenta con la edad debido al aumento en la frecuencia de alimentación (Dolnik 2003). La infección por coccidios puede no presentar patología, pero si los individuos juveniles ingieren una alta cantidad de ooquistes en un tiempo corto, pueden desarrollar una coccidiosis (Atkinson y col. 2008), enfermedad caracterizada por diarrea, distención abdominal y hepatomegalia (Gill \& Paperna 2008, Arabkhazael \& Madani 2014).

La información acerca de los coccidios es escasa, y se restringe principalmente a la morfología de los ooquistes (Levine y col. 1980, McQuistion y Wilson 1989, McQuistion y Capparella 1992, Ball y Daszak 1997, Templar y col. 2004, Metzelaars y col. 2005, Atkinson y col. 2008).

Los hábitos alimentarios del estornino con una alimentación omnívora y la formación de grupos de alimentación heteroespecíficos favorecen la transmisión de parásitos (Sommer 1937, Hair y Forrester 1970). En Europa se registraron 79 especies de helmintos parasitando al estornino, mientras que en Norteamérica, donde el estornino fue introducido hace aproximadamente 120 años, se registraron 35 especies de este grupo de parásitos (Hair y Forrester 1970, Cooper y Crites 1976). Bernard (1987) encontró una prevalencia del 97,1\% de helmintos en estorninos procedentes de Bélgica y el norte de África, mientras que en Norteamérica Boyd (1951) encontró un 90\% de prevalencia de helmintos en esta ave introducida. En Argentina el único trabajo sobre parásitos internos en esta especie fue publicado recientemente (Valente y col. 2014). En ese trabajo encontramos seis especies de helmintos, las dos más frecuentes fueron Synhimantus nasuta (Nematoda) y Plagiorhynchus cylindraceus (Acantocéfala), con una prevalencia del 36,1\% cada una. En estos mismos ejemplares se determinó la presencia de ectoparásitos que se tratan en la próxima sección de este capítulo.

En cuanto a los coccidios en Europa y en Estados Unidos el estornino es parasitado por el género Isospora registrándose altas prevalencias en pichones y adultos (Boyd 1951, Kedra y Mazgajski 1998). En la Argentina hasta el momento no se estudió la presencia de este grupo de parásitos en el estornino.

\section{Ectoparásitos}

A diferencia de los endoparásitos, que viven en estrecha relación con sus hospedadores, los ectoparásitos se caracterizan por presentar ciclos de vida con estadios libres, en algunos casos como las pulgas (Siphonaptera), estas recurren al hospedador intermitentemente para alimentarse, mientras que en otros casos como el de las garrapatas (Ixodidae), permanecen constantemente unidos al hospedador (Heeb y col. 2000). 
Los nidos de las aves que se reproducen en cavidades proveen de un microhábitat ideal para albergar una gran diversidad de artrópodos, entre ellos ectoparásitos, con las condiciones necesarias para que estos se refugien y reproduzcan (Hansell 2000, Heeb 2000). Cuando la disponibilidad de cavidades es baja, las aves suelen reutilizar sus nidos, favoreciendo la multiplicación y transmisión de ectoparásitos (Mazgajski y Kedra 1997). Una estrategia que utilizan estas especies para disminuir la carga parasitaria del nido con la que tendrán que convivir los pichones y sus padres es la remoción del nido viejo (Pacejka y col. 1998, Mazgajski 2003b, Mazgajski 2007).

Los ectoparásitos de las aves incluyen varias especies de piojos (Mallophaga), ácaros y garrapatas (Arachnida), moscas (Díptera), pulgas (Siphonaptera) y chinches hematófagas (Hemíptera) que se alimentan principalmente de sangre (Newton 1998). Estos parásitos pueden causar daño tisular, anemia, reacciones alérgicas y actuar como vectores transmisores de otras enfermedades como el virus de la encefalomielitis equina, clamidias, el virus de Newcastle y el pox virus aviar. Además cuando la carga de ectoparásitos es muy alta pueden debilitar y matar a sus hospedadores (Fraga 1984, Arendt 1997, Newton 1998) o disminuir su éxito reproductivo (De Lope y col. 1993, Mazgajski 1998).

Los ácaros son un grupo de arácnidos muy diverso taxonómicamente con al menos 2500 especies pertenecientes a 40 familias que se encuentran en estrecha relación con casi todas las especies de aves ya que se las encuentra tanto en sus nidos como en sus cuerpos (Proctor y Owens 2000). Luego de que los pichones dejan el nido, los ácaros migran a la superficie donde pueden entrar en contacto con estorninos adultos que vuelven a visitar el nido (Powlesly 1978).

Los ácaros pueden relacionarse con las aves de manera de no causarles ningún daño o pueden generar distintas patologías como anemia (Gwinner 2000), dermatitis, daño o pérdida de plumas, inflamación de los tejidos subcutáneos o problemas en el tracto respiratorio (De Atkinson y col 2008). Entre los ácaros los géneros Dermanyssus y Ornithonyssus (Mesostigmata: Dermanyssidae) han sido los mejor estudiados (Proctor y Owens 2000). Se cree que el Gorrión Común (Passer domesticus), el Estornino Pinto y la Paloma Doméstica Columba livia fueron los responsables de la introducción en Norteamérica de algunas especies de ácaros que afectan a las aves de corral, como el ácaro de la gallina Dermanyssus gallinae De Geer 1778, el ácaro del norte Ornithonyssus sylviarum G.Canestrini y Fanzago 1877 y el ácaro tropical Ornithonyssus bursa Berlese 1888 (Atkinson y col. 2008). Esta última especie parasita diversas especies de aves principalmente en zonas cálidas tropicales y subtropicales (Denmark y Cromroy 2003). Además, los ácaros de los géneros Ornithonyssus y Dermanyssus causan importante pérdidas económicas al parasitar aves en granjas avícolas 
(DeVaney 1979, De Loach 1981) ya que causan numerosas enfermedades como la viruela aviar, la enfermedad de Newcastle, infecciones causadas por Pasteurella sp., virus de la encefalitis equina del oeste y Coxiella burnetti (Valiente Moro y col. 2005). Estos ácaros también pueden parasitar a los seres humanos generyo una dermatitis con un prurito severo (Bernard 1987, Bernard 1987, Rosen y col. 2002, Mazyad y Abel 2005).

El Estornino Pinto es parasitado por una gran diversidad de ectoparásitos en las distintas partes del mundo, entre los que se registraron once especies de ácaros (Boyd 1951, Powlesly 1978, Clark \& Mason 1988). En la época reproductiva de los estorninos, los ácaros se encuentran en los nidos con altas incidencias y cargas parasitarias (Powlesly 1977, Gwinner 2000. Gwinner y Berger 2005).

\section{Moscas ectoparásitas (Philornis sp)}

Dentro del grupo de los ectoparásitos de las aves, están incluidas las larvas hematófagas, pertenecientes a tres familias del Orden Diptera (Calliphoridae, Muscidae y Piophilidae) (Uhazy y Arendt 1986). El género Philornis Meinert, 1890 (Diptera: Muscidae) comprende aproximadamente 50 especies (Dudaniec y Kleindorfer 2006) que parasitan alrededor de 146 especies de aves (Teixeira, 1999) sin mostrar una alta especificidad (Couri 1991; Teixeira 1999). Este género presenta distribución Neotropical, con excepción de dos especies que extienden su distribución hasta el sur de los Estados Unidos (Couri y col. 2005).

Las moscas adultas son de vida libre y se alimentan de materia orgánica en descomposición (Teixeira 1999). En cuanto a las larvas, se observan tres hábitos diferentes dentro del género. En algunas especies el primer estadio larval y la primera etapa del segundo estadio viven bajo la piel de los pichones produciendo miasis, mientras que la última etapa del segundo estadio y el tercer estadio larval viven en el nido y se alimentan externamente de la sangre de los pichones (Dudaniec y Kleindorfer 2006, Fessl y col. 2006). Dos especies presentan larvas que viven libremente en nidos de aves que nidifican en nidos cerrados desarrollándose en la materia fecal de las aves y alimentándose de esta (Teixeira y col. 1990, Dudaniec y Kleindorfer 2006). El resto de las especies que representa el 82\% de las especies (Dudaniec y Kleindorfer 2006) presentan larvas subcutáneas que viven bajo la piel de los pichones respiryo a través de un orificio y alimentándose de sus tejidos y células sanguíneas (Uhazy y Arendt 1986, Young 1993). El desarrollo de las larvas se completa en 3-9 días (Arendt 1985b, Young 1993,), tiempo durante el cual éstas atraviesan tres estadios larvales y crecen hasta más de $1 \mathrm{~cm}$ de longitud (Fraga 1984, Arendt 1985a). Una vez que su desarrollo finaliza, las larvas abyonan al hospedador y forman un capullo con secreciones de sus 
glándulas salivales (Couri y col. 2005). Luego de que la larva permanece entre 1 y 3 semanas en estado de pupa, emerge la mosca adulta (Young 1993) (Fig. 7.1).

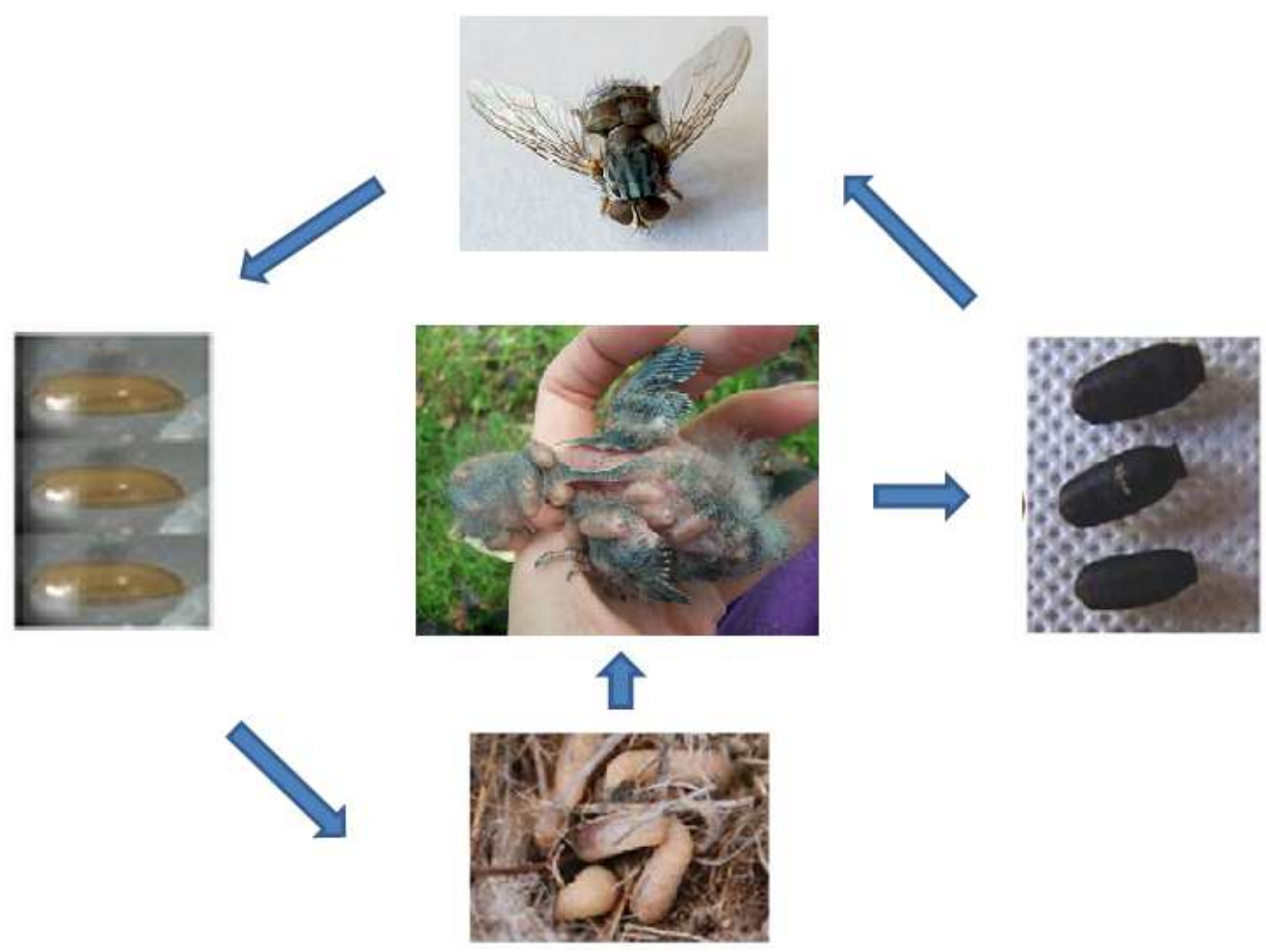

Fig. 7.1: Ciclo de vida de las especies de Philornis presentes en la zona del parque Pereyra Iraola.

En su área de distribución original los pichones de estornino son parasitados en estado larval por tres especies de dípteros de la familia Calliphoridae: Protocalliphora azurea (Hicks, 1959, 1962, 1971) y Protocalliphora falcozi. Estas especies junto a Trypocalliphora lindneri compacta se encuentran en infestaciones mixtas (Grunin, 1966). En Europa el estornino es parasitado por Carnus hemapterus (Diptera: Carnidae) (Liker y col. 2001). En Norteamérica, donde el estornino es una especie exótica, los pichones son parasitados por algunas especies de Protocalliphora (Collins y De Vos, 1966, Mumby 1979).

\section{OBJETIVOS DEL CAPÍTULO}

a) Determinar las especies de endoparásitos intestinales y su prevalencia en pichones de estornino.

b) Determinar las especies de ácaros y la prevalencia de infestación en estorninos. 
c) Determinar las especies de Philornis que parasitan a los pichones de estornino.

\section{MATERIALES Y MÉTODOS}

\section{Endoparásitos}

Se realizó un análisis coproparasitológico de 71 muestras de materia fecal de pichones nacidos en las temporadas reproductivas $2012(n=48)$ y $2013(n=23)$. De estas, 56 muestras (34 de la temporada 2012 y 22 de la 2013) fueron recolectadas directamente colocando un frasco de vidrio en la cloaca de los pichones para obtener muestras aisladas de cada pichón. Las 15 muestras restantes (14 del 2012 y una del 2013) se recolectaron de los nidos estando aún frescas. De las muestras recolectadas en la temporada 2012, 11 se conservaron en dicromato de potasio (K2Cr2O7) al 2,5\% para evitar la contaminación por hongos y bacterias y a su vez permitir la esporulación de los coccidios debido a que es necesaria la presencia de ooquistes esporulados para poder determinar el género al que pertenecen. El resto de las muestras de la temporada $2012(n=37)$ y todas las de la temporada 2013 se conservaron en formol al 10\%. En 26 muestras (10 del 2012 y 16 del 2013) se realizaron dos métodos de concentración: de flotación en solución saturada de sacarosa (Vignau y col. 2005) y de sedimentación de Ritchie modificado (Allen \& Ridley 1970). Estos métodos no fueron efectivos con muestras tan pequeñas de materia fecal por lo que todas las muestras fueron analizadas mediante observación directa de dos preparados.

Se utilizó un microscopio binocular Leyca DM 2000 y cámara fotográfíca digital incorporada para la detección y medición de ooquistes, huevos y larvas de los parásitos.

La prevalencia (proporción de muestras infectadas) fue interpretada y calculada de acuerdo a Bush y col. (1997)

\section{Ectoparásitos}

Para la determinación de los ectoparásitos presentes en estorninos se utilizaron tanto individuos vivos como muertos, y dos métodos de extracción de parásitos: 1) lavados de pichones, juveniles y adultos muertos y 2) utilización de acetato de etilo, solo en pichones vivos. En el primer caso se analizaron 68 estorninos (21 adultos y 47 juveniles de menos de un año de edad) que fueron facilitados por la Secretaría de Ambiente y Desarrollo Sustentable de la Nación y habían sido capturados en la localidad de Bernal en Noviembre de 2007. Además se analizaron 29 pichones que se encontraron muertos en los nidos durante la temporada reproductiva 2010 y 50 pichones encontrados muertos durante de la temporada reproductiva 2011. Todos estos ejemplares se conservaron en freezer a $-20^{\circ} \mathrm{c}$. Los ejemplares 
se descongelaron en el laboratorio y se les realizó un lavado con agua tibia y detergente frotando las plumas para facilitar la remoción de ectoparásitos. El agua obtenida se filtró utilizando un filtro metálico del diámetro suficiente para retener los ectoparásitos más pequeños. La técnica utilizada es una modificación de la técnica de Palma (1978). Luego se realizó la búsqueda de ectoparásitos en el material filtrado utilizando una lupa binocular 40x y de esta manera se determinó la presencia de ectoparásitos en las muestras.

El segundo método de recolección de ectoparásitos se utilizó para analizar muestras de ectoparásitos de 32 pichones vivos pertenecientes a 15 nidos durante la temporada reproductiva 2013. Para extraer los ectoparásitos se introdujo cada pichón dentro de una bolsa plástica que contenía un algodón embebido en acetato de etilo $(\mathrm{C} 4 \mathrm{H} 8 \mathrm{O} 2)$ y se lo sostuvo del cuello, manteniendo la cabeza del pichón fuera de la bolsa. Se le pasó un algodón con acetato de etilo por la cabeza y pasados 6 minutos se peinaron con las uñas las plumas de todas las zonas del cuerpo para favorecer la caída de los ectoparásitos que aún permanecían en las plumas hacia la bolsa. El material recolectado se conservó en frascos de vidrio en una mezcla de alcohol $70 \%$ y vinagre de alcohol $30 \%$.

Las muestras de ácaros fueron enviadas al CEPAVE (Centro de Estudios Parasitológicos y Vectores) para ser determinadas específicamente por la Dra. Marcela Lareschi.

\section{Moscas ectoparásitas (Philornis sp)}

Se contabilizaron las pupas de Philornis presentes en nueve nidos de estornino extraídos de cajas-nido una vez finalizada la temporada reproductiva del estornino, cuyo todas las moscas ya habían emergido. En todos los nidos analizados se produjo una sola nidada durante el período reproductivo del año 2010.

Además se extrajeron tres nidos de árboles que cayeron durante tormentas donde había estorninos nidificando con el objetivo de determinar si los pichones en nidos dentro de cavidades en árboles también son parasitados en la zona de estudio.

Con el objetivo de determinar que especies de Philornis parasitaron a los pichones de estornino en la ECAS, se obtuvieron moscas adultas emergidas de los nidos de estornino, las cuales fueron posteriormente determinadas. Para esto, durante la temporada reproductiva 2011 se extrajeron ocho nidos de las cajas donde hubo presencia de pichones parasitados por Philornis. En estos nidos se encontraban las pupas de Philornis que parasitaron a los pichones, por lo tanto, los nidos se extrajeron inmediatamente después de que los pichones murieran o abandonaran el nido para evitar que las moscas adultas emerjan de las pupas antes de ser capturadas. Estos fueron colocados en cajas de cartón y se los cubrió con un tul para evitar que al emerger las moscas se escapasen y a la vez permitir la entrada de aire para que 
las larvas vivan y se produzca la eclosión. Una vez que las moscas adultas emergieron, se colocó la caja con el nido dentro de una bolsa de nylon con un algodón embebido en éter en su interior y se la cerró. Posteriormente se colectaron las moscas y 100 de ellas se determinaron específicamente.

\section{RESULTADOS}

\section{Endoparásitos}

En el análisis coproparasitológico de 71 muestras de material fecal de pichones de estornino (temporadas 2012 y 2013) se observó una prevalencia de $26,8 \%$ de ooquistes de coccidios y $1,4 \%$ de huevos de cestodes. Se encontraron ooquistes esporulados (Fig. 7.2a) y no esporulados (Fig. 7.2b). Todos presentaban una forma esférica o levemente ovalada. Los ooquistes esporulados presentaron dos esporoquistes con cuatro esporozoitos dentro (Fig. 7.2a). Esta descripción corresponde al género Isospora sp. En el extremo de los esporoquistes se observaron cuerpos de Stieda y de substieda que permiten la salida de los esporozoítos. Los ooquistes presentaban una pared de $1 \mu$ con una capa más gruesa por dentro. La media de su longitud fue de $23,4 \pm 1,7 \mu(19,5-28,0 \mu)$ y un ancho medio de $22,6 \pm 1,6 \mu(19,5-25,5 \mu)$. Los esporoquistes presentaron forma de pera con un largo de $16,9 \pm 1,8 \mu(10,3-19,6 \mu)$ y un ancho de $11,6 \pm 0,8 \mu(10,3-13,4 \mu)$.

En la temporada reproductiva 2012 la prevalencia total de parásitos fue de 29,2\% (14 de 48 muestras). La prevalencia de coccidios fue del 27\% (13 de 48 muestras), pero en siete de estas $(53,8 \%)$ solo se encontraron uno o dos ooquistes. En las otras muestras la intensidad también fue baja, en todos los casos con menos de diez ooquistes por campo visual al observar con el microscopio con un aumento de 10x.

En la temporada reproductiva 2013 los únicos parásitos encontrados fueron ooquistes de Isospora sp. con una prevalencia de 21,7\% (5 de 23 muestras). En sólo una muestra de la temporada 2012 se encontraron huevos de cestodes (P: 2\%) y se tomaron las medidas de siete de ellos. Presentaron una longitud media de $56 \pm 3,2 \mu(51-59 \mu)$, un ancho de $54 \pm 2,9 \mu$ (50$57 \mu)$ y los ganchos del embrión hexacanto presentaron una longitud de 13,8 $\pm 0,51$ (12,514,8) $\mu$ (Fig. $7.3 \mathrm{a} \mathrm{y} \mathrm{b).}$ 


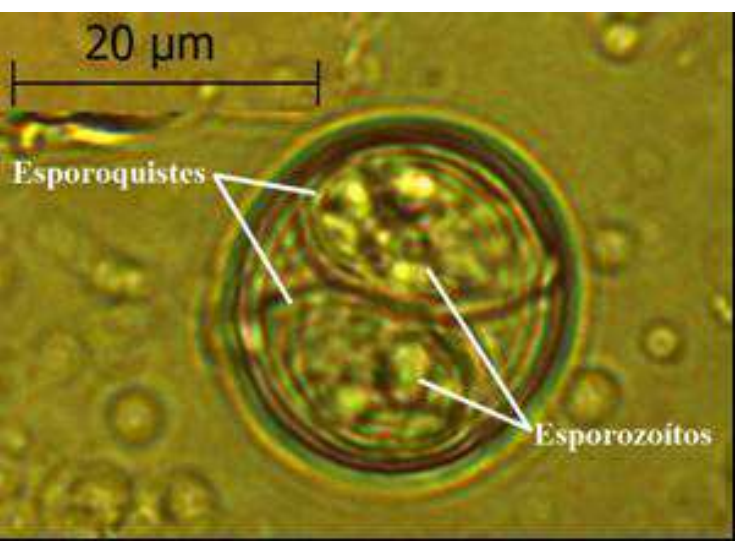

A)

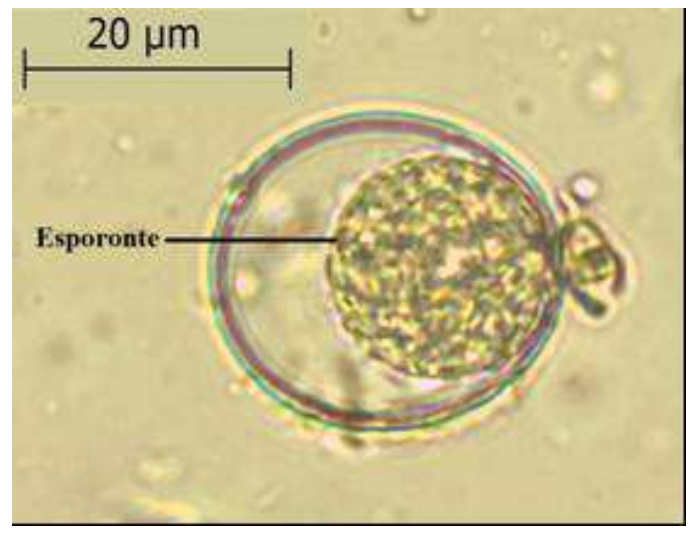

B)

Fig. 7.2. Endoparásitos intestinales de pichones de Estornino Pinto a) Ooquiste esporulado de Isospora sp. donde se observan los dos esporoquistes piriformes conteniendo cuatro esporozoitos y b) Ooquiste sin esporular.
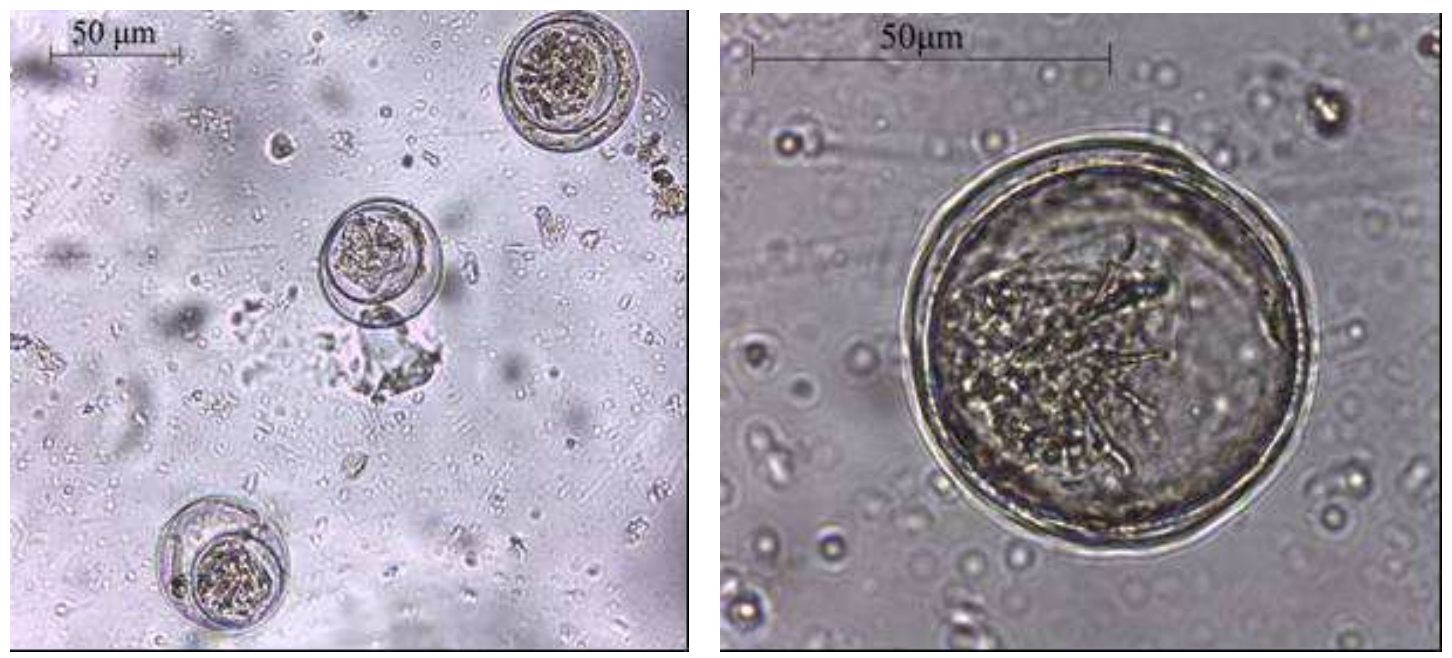

Fig. 7.3. Endoparásitos intestinales recolectados de la materia fecal de pichones de estornino a) Huevos de cestode, b) huevo de cestode donde se observan los 6 ganchos del embrión hexacanto.

\section{Ectoparásitos}

Se encontraron ácaros en el $100 \%$ de los ejemplares juveniles y adultos de estorninos analizados y en el 97,5\% (77 de 79) de los pichones encontrados muertos en los nidos. No se encontró ningún otro grupo de ectoparásitos como malófagos (Mallophaga) o pulgas (Siphonaptera). 
En el caso de los ectoparásitos extraídos de los pichones vivos sólo se encontraron ácaros en las muestras analizadas y todos ellos pertenecían a la especie Ornithonyssus bursa (Arachnida: Mesostigmata). Los ácaros aparecieron en el $73 \%$ de los nidos $(\mathrm{N}=15)$ y en el $62 \%$ de los pichones $(\mathrm{N}=29)$.

\section{Moscas ectoparásitas (Philornis sp)}

Se identificaron dos especies de moscas parásitas del género Philornis emergidas en los nidos de estornino: P. seguyi (García 1952) y P. torquans (Nielsen 1913). En el 87,50\% de los nidos (siete nidos) se encontró al menos una de las especies mencionadas. De estos, en el $62,50 \%$ (cinco nidos) se encontraron ambas especies, en un nido se encontró sólo $P$. seguyi y en otro P. torquans. Treinta moscas de dos nidos se identificaron como Philornis sp. pero no pudo determinarse la especie. De las 70 moscas restantes, el 50\% perteneció a $P$. seguyi y el otro $50 \%$ a $P$. torquans. Para $P$. seguyi la media fue de $5 \pm 2,29(0-18)$ moscas por nido. Para $P$. torquans la media fue de $5 \pm 2,78$ (0-21) moscas por nido.

En los nueve nidos de estornino extraídos de las cajas-nido que se analizaron en búsqueda de pupas de Philornis se encontraron un total de 465 pupas con una media de 51,7 \pm 17,22 pupas/nido (3- 207). En los nidos de cavidades naturales en árboles caídos se encontraron 356 pupas de Philornis. En otros dos nidos se encontraron 10 y 15 pupas respectivamente.

\section{DISCUSIÓN}

\section{Endoparásitos}

En el análisis de parásitos intestinales del Estornino Pinto mediante el análisis coproparasitológico sólo se observaron dos grupo de parásitos, coccidios y cestodes, ambos se encontraron en baja prevalencia e intensidad en las muestras.

Este era un resultado esperado teniendo en cuenta que las especies exóticas suelen perder enemigos naturales durante su captura, transporte e introducción en un área nueva (Blackburn y col. 2009).

La prevalencia de endoparásitos encontrada en el Estornino Pinto en la Argentina (Valente y col. 2014 y el presente trabajo) es la menor registrada hasta el momento si la comparamos con los registros de Norteamérica, el Noreste de África, Europa y el Oeste de Asia (Sommer 1937, Boyd 1951, Ballard y Ollsen 1966, Hair y Forrester 1970, Vincent 1972, Bernard 1987, Kedra y Mazgajski 1998). En Polonia Mazgaski y Kedra (1998), quienes también analizaron muestras de material fecal de pichones de estornino, observaron Isospora 
sp. en el $67 \%$ de los nidos, mientras que en diferentes localidades del Noreste de Estados Unidos los estorninos adultos presentan prevalencias del 75,3\% de Isospora sp. (Boyd 1951). Los valores de prevalencia observados en otras regiones del mundo exceden ampliamente los valores de la Argentina (26,8\%).

La intensidad de infección observada en esta tesis también es el valor más bajo registrado en los estorninos hasta el momento. En las muestras de materia fecal de los pichones del parque Pereyra Iraola la intensidad de parasitismo fue en todos los casos menor a 10 ooquistes por campo de visión 10x. Esta baja intensidad no permitió que se utilice una técnica de cuantificación. En Polonia, los estorninos presentan altas intensidades de ooquistes de Isospora sp. en el 23,8\% de las muestras. Esos valores exceden ampliamente las intensidades observadas en Argentina.

Los primeros estorninos introducidos en la Argentina podrían haber presentado bajas prevalencias e intensidades de coccidios en las primeras etapas del proceso de colonización, como se ha observado en otras especies introducidas (Torchin y Mitchell 2004), disminuyendo la probabilidad de que ocurra una transmisión entre individuos de la misma población. Además, los coccidios presentan una alta especificidad hacia sus especies hospedadoras (Dolnik y Loonen 2007), por lo que otras aves que comparten sus territorios de alimentación con los estorninos podrían no ser posibles tranmisores de nuevas especies de coccidos a los estorninos. Por otro lado, McQuistion (2000) analizó muestras de material fecal de 190 especies de aves de Sudamérica y observó una prevalencia de coccidios del 22,8\% en aves que obtienen su alimento del suelo. Si la prevalencia de coccidios de las aves que comparten la misma zona con los estorninos es menor a la que presentan otras especies de aves en otras partes del mundo, es probable aunque el estornino pudiera recibir parásitos de otras especies, las prevalencias de coccidios sean menores a las que presentan los estorninos de Europa o Estados Unidos.

El único género de coccidios encontrados hasta el momento en el estornino fue Isospora (Boyd 1951, Kedra y Mazgajski Kedra 1998, Dolnik 1999, Carlson y col. 2011). En Europa, Dolnik (1999) identificó a Isospora dilatata Schwalbach 1959 en heces de estornino, mientras que Isospora lacazei Labbé 1893 fue encontrada en estorninos en Polonia (Kedra y Mazgajski 1998) y en Estados Unidos (Boyd 1951). Según Dolnik y Loonen (2007) los coccidios se caracterizan por presentar una especificidad muy alta hacia su hospedador, solo pudiendo transmitirse entre especies del mismo género. Sin embargo I. lacazei se observó también en el Cardelino, Carduelis carduelis Linnaeus 1758 y en el Verderón Carduelis chloris Linnaeus, 1758 (Levine 1982). 
La descripción de los ooquistes presentes en las muestras en pichones del parque Pereyra Iraola son similares a los de Isospora lacazei (Labeé 1893) descriptos en otras partes del mundo y podrían corresponder a esa especie.

En cuanto a los cestodes se observa una gran pérdida de especies en la Argentina en comparación a las que presentan en Estado Unidos y Europa. En Europa se encontraron 12 especies de cestodes y ocho en los Estados Unidos, tres de ellos se encuentran en ambos continentes y dos fueron adquirido en el área colonizada (Boyd 1951, Hair y Forrester 1970, Cooper y Crites 1976). Al contrario, en Argentina Valente y col. (2014) no encontraron ningún cestode en el tracto gastrointestinal de 76 estorninos adultos y juveniles recolectados en Bernal, provincia de Buenos Aires (ubicado a $17 \mathrm{~km}$ del area de estudio) y en este trabajo solo se encontraron huevos de una especie de cestode. En cuanto a la prevalencia, Boyd (1951) encontró cestodes en el $71 \%$ de las muestras de Estados Unidos, mientras que en Argentina sólo encontramos huevos de cestode en una muestra (2\%). Los estorninos analizados por Hair y Forrester (1970) y por Boyd (1951) eran adultos que se encuentran más expuestos a las heces contaminadas de otras aves que los pichones. El hecho de que solo se hayan analizado pichones en este trabajo podría ser en parte la causa de la baja prevalencia e intensidad de coccidios y cestodes en las muestras del parque Pereyra Iraola. Sin embargo, la falta de cestodes en las muestras analizadas por Valente y col. 2014 confirmarían la baja presencia de cestodes en los estorninos de la provincia de Buenos Aires.

Hair y Forrester (1970) compararon las especies de helmintos en estorninos de Norteamérica con respecto a estorninos de Europa, Noreste de Africa y Oeste de Asia. Observaron que los ejemplares de Estados Unidos y Canadá habían perdido 26 species de 15 géneros de Trematoda, 24 especies de 14 géneros de Nematoda y seis especies de 4 géneros de Acanthocephala. Por otro lado, observaron la presencia de una nueva especie de Trematoda, siete especies de Nematoda y tres especies de Acanthocephala. Posteriormente, Cooper y Crites (1976) registraron cuatro especies nuevas de Nematoda en estorninos de Estados Unidos. En Argentina se encontraron una especie de Trematoda (Echinostoma revolutum), una de Acanthocephala (Plagiorhynchus cylindraceus) y cuatro de Nematoda (Synhimantus nasuta, Microtetrameres sp., Pterothominx exilis y Ornithocapillaria ovopunctata) en juveniles y adultos de una población de estorninos de Bernal (provincia de Buenos Aires) (Valente y col. 2014). Teniendo en cuenta esos resultados y los del trabajo presente, concluimos que todos los endoparásitos encontrados en estorninos de Argentina hasta el momento ya habían sido previamente registrados en aves de Europa, Asia, Norteamérica, lo que sugiere que el estornino no ha recibido nuevas especies parásitas en la provincia de Buenos Aires. Además, esas especies ya estaban presentes en aves de Argentina. 


\section{Ectoparásitos}

La única especie de ectoparásito que se encontró en los estorninos del parque Pereyra Iraola fue Ornithonyssus bursa. En Europa, donde el estornino es una especie nativa, se encontraron 17 especies de ácaros, entre ellos otra especie de Ornithonyssus (O. sylviarum) (Lesna y col. 2009). En Nueva Zelanda, los nidos de estornino presentan una alta prevalencia de O. bursa (Powlesly 1978). En Norteamérica, donde el estornino fue introducido hace 124 años, Boyd (1951) encontró 16 especies de ectoparásitos en el estornino, entre los que se encontraron nueve especies de ácaros, ninguna de ellas perteneciente al género Ornithonyssus. Posteriormente Knee y Proctor (2007) citaron a Ornithonyssus sylviarum en nidos de estornino en Estados Unidos.

$O$. bursa es una especie de ácaro que se encuentra con frecuencia en aves nativas de la Argentina. Por ejemplo, en la provincia de Buenos Aires, Aramburú y col. 2003 encontraron O. bursa en el $48 \%$ de pichones de la cotorra Myiopsitta monachus, siendo el ectoparásito más abundante. Además, Arrabal y col. (2012) detectaron infestaciones por O. bursa en 28 de 55 (50,9\%) especies de aves estudiadas en la provincia de Santa Fé. Las especies más afectadas fueron el Hornero, el Tordo Renegrido Molothrus bonariensis, el Jilguero Dorado Sicalis flaveola, el Músico Agelaiodes badius, la Ratona Común y el Benteveo Común Pitangus sulphuratus. Todas estas especies están presentes en el parque Pereyra Iraola y suelen alimentarse en grupos heteroespecíficos junto con el estornino (Obs. pers.). Este comportamiento podría estar favoreciendo la transmisión de ectoparásitos entre especies.

En relación a los posibles efectos negativos de O. bursa, Møller (1993) demostró que este ácaro afecta negativamente el éxito reproductivo de la Golondrina Común Hirundo rustica. Por su parte, Merino y Potti (1995) observaron que la supervivencia y el crecimiento (masa corporal y largo del tarso) de pichones del Papamoscas Cerrojillo Ficedula hypoleuca en España, era menor en los pichones con cargas de ectoparásitos más altas con respecto a los menos parasitados. Clayton y Tompkins (1995) estudiaron el parasitismo por ácaros en la Paloma Doméstica Columba livia y observaron que en nidos con altas cargas parasitarias de ácaros había una disminución en la eclosión de los huevos mayor al 75\%, debido a que los padres no incubaban el tiempo necesario y los pichones que lograban nacer sufrían un retraso en su crecimiento.

En relación al efecto de los ácaros en general, varios autores observaron en distintas especies de paseriformes que éstos afectan negativamente el crecimiento de las alas y el brillo de las plumas (Harper 1999, Figuerola y col. 2003). Sin embargo otros autores encontraron el efecto opuesto, con una correlación positiva entre la cantidad de ácaros y el brillo de las plumas (Blanco y col. 2001, Galván y Sanz 2006). Blanco y col. (2001) sugieren que los 
ácaros podrían otorgar un beneficio a las aves relacionado al consumo de microorganismos patógenos por parte de estos ectoparásitos.

Mazgajski y Kedra (2007) no observaron efectos adversos del parasitismo por distintas especies de ectoparásitos como ácaros y pulgas sobre el crecimiento de los pichones de estornino en Polonia. En Nueva Zelanda, Powlesland (1978) tampoco observó un efecto de la infestación por $O$. bursa en la tasa de crecimiento, la mortalidad, los parámetros sanguíneos ni las reservas de lípidos en pichones de estornino. Sin embargo, en un año en el cual el alimento fue escaso, los pichones con cargas parasitarias más altas presentaron una menor masa corporal que los menos parasitados, lo cual no se repitió cuando aumentó la disponibilidad de alimento. En base a estos resultados Powlesland (1978) sugiere que el estado de los pichones podría estar afectado por la interacción de la presencia de ácaros con otros factores como la disponibilidad de alimento.

\section{Moscas ectoparásitas (Philornis sp)}

Se encontraron dos especies de Philornis parasitando pichones de estornino en el parque Pereyra Iraola: P. seguyi y P. torquans. En cinco de los ocho nidos se encontraron ambas especies, por lo cual es muy posible que algunos pichones hayan sufrido una coinfección por ambas especies de moscas parásitas. En Argentina hasta el momento han sido descriptas ocho especies de Philornis: Philornis seguyi (Garcia 1952, P. torquans (Nielsen 1913), P. pici (Macquart 1854), P. umanai (Garcia 1952), P. angustifrons (Loew, 1861), P. blanchardi (Garcia 1952), P. nielseni (Dodge, 1958) y Philornis downsi (Dodge y Aitken 1968) (Tabla 7.2). Esta última especie fue registrada en Argentina en un nido de Jilguero Dorado o Común (Sicalis flaveola) y es la única de las ocho especies que presenta larvas con hábitos semihematófagos que viven libremente en el nido (Silvestri y col. 2011).

Las dos especies de Philornis encontradas en el parque Pereyra Iraola presentan hábitos similares a $P$. pici, $P$. umanai, $P$. angustifrons, $P$. blanchardi y $P$. nielseni, con larvas que transitan todos sus estadios en forma subcutánea hasta que abandonan el pichón y bajan al nido a empupar.

\begin{tabular}{lll}
\hline Especie & Localidad & Hospedador \\
\hline$P$. pici & Córdoba (Monte Cristo) & Pseudoseisura lophotes, Anumbius annumbi (2) \\
& Tucumán (Villa Luján) & Sporophila sp. (1) \\
& Santa Fé & No identificado (1) \\
\hline$P$. & Tucumán (Monte Bello) & Gallus gallus (1)
\end{tabular}


angustifrons

\begin{tabular}{|c|c|c|}
\hline \multirow[t]{4}{*}{ P. seguyi } & Córdoba (Monte Cristo) & \multirow{4}{*}{$\begin{array}{l}\text { Pseudoseisura lophotes, Anumbius annumbi (2) } \\
\text { Mimus saturninus (10), Troglodytes aedon, } \\
\text { Pitangus sulfuratus, Pyrocephalus rubinus, } \\
\text { Satrapa icterophrys, Molothrus bonariensis (5) }\end{array}$} \\
\hline & $\begin{array}{l}\text { Buenos } \\
\text { (Magdalena) }\end{array}$ & \\
\hline & $\begin{array}{l}\text { Buenos Aires (Punta } \\
\text { Indio) }\end{array}$ & \\
\hline & Misiones & \\
\hline & Santa Fé & $\begin{array}{l}\text { Troglodytes aedon (6, 15), Synallaxis frontalis, } \\
\text { Anumbius annumbi, Pitangus sulphuratus, } \\
\text { Phacellodomus striaticolis, Elaenia spectabilis, } \\
\text { Suiriri suiriri, Phacellodomus ruber, Saltator } \\
\text { coerulescens, Molothrus bonariensis, Paroaria } \\
\text { coronata, Pseudoseisura lophotes, Mimus } \\
\text { saturninus, Polioptila dumicola, Furnarius } \\
\text { rufus, Phacellodomus sibilatrix, Sicalis flaveola, } \\
\text { Taraba major, Agelaioides badius, Zenaida } \\
\text { auriculata(15) }\end{array}$ \\
\hline P. torquans & Córdoba (Bell Ville) & Mimus saturninus (1) \\
\hline $\begin{array}{l}P . \\
\text { blanchardi }\end{array}$ & Corrientes & No identificado (1) \\
\hline P. umanai & Corrientes & No identificado (1) \\
\hline $\begin{array}{l}\text { Philornis } \\
\text { downsi }\end{array}$ & \multicolumn{2}{|r|}{ Sicalis flaveola (14) } \\
\hline $\begin{array}{l}\text { Philornis } \\
\text { nielseni }\end{array}$ & Misiones & No identificado (16) \\
\hline \multirow[t]{4}{*}{ Philornis sp. } & Corrientes & Synallaxis spixi (1) \\
\hline & \multirow[t]{2}{*}{ Buenos Aires (Lobos) } & $\begin{array}{l}\text { Molotrhus badius, M. rufoaxillaris, } M . \\
\text { bonariensis, Polioptila dumicola, Anumbius } \\
\text { annumbi, Mimus saturninus (3) }\end{array}$ \\
\hline & & $\begin{array}{l}\text { Phacellodomus sibilatrix, Anumbius annumbi, } \\
\text { Satrapa icterophrys, Troglodytes aedon, Mimus }\end{array}$ \\
\hline & (Magdalena) & $\begin{array}{l}\text { saturninus, Sicalis flaveola, Zonotrichia } \\
\text { capensis (4) }\end{array}$ \\
\hline
\end{tabular}




\begin{tabular}{|c|c|}
\hline Misiones & Dendrocolaptes platyrostris (7) \\
\hline Santa Fé & $\begin{array}{l}\text { Troglodytes aedon, Sicalis flaveola, Tachycineta } \\
\text { leucorroha (8) }\end{array}$ \\
\hline Santa Fé & $\begin{array}{l}\text { Leptasthenura platensis, Schoeniophylax } \\
\text { phryganophila, Synallaxis frontalis, Certhiaxis } \\
\text { cinnamomea, Phacellodomus ruber, } \\
\text { Coryphistera alaudina, Sublegatus modestus, } \\
\text { Pitangus, sulphuratus, Mimus saturninus, } \\
\text { Molothrus badius, Paroaria coronata (11) }\end{array}$ \\
\hline Tucumán & No identificado \\
\hline Chaco & Aratinga acuticaudata (12) \\
\hline Mendoza & Diuca diuca (13) \\
\hline
\end{tabular}

Tabla 7.2: Especies de Philornis sp. presentes en la Argentina. Se indica la localidad donde fueron observadas y las especies de aves hospedadoras.

García 1952 (1), Nores 1995 (2), Fraga 1984 (3), Mason 1985 (4), Couri y col. 2005 (5), Quiroga y Reboreda 2012 (6), Norris y col. 2010 (7), Quiroga y col. 2012 (8), Segura y Reboreda 2011 (9), Rabuffetti y Reboreda 2007 (10), De la Peña y col. 2003 (11), Aramburú y col. 2013 (12), Mezquida 2003 (13), Silvestri y col. 2011 (14), Antoniazzi y col. 2011 (15), Couri y col. 2009 (16).

\section{Conclusión}

Por el momento, no podemos considerar al estornino como un vector transmisor de parásitos a especies nativas en la Argentina, debido a que las pocas especies encontradas en ejemplares del parque Pereyra Iraola son especies que ya se encontraban previamente en las aves nativas.

Por otro lado, la enorme pérdida de especies parásitas con respecto a las poblaciones de estorninos de Norteamérica y Europa podría estar facilitando su establecimiento y expansión en la Argentina. Sin embargo, al mismo tiempo, la adquisición de larvas de Philornis como nuevo parásito podría ser un factor que esté limitando su éxito reproductivo. 


\section{CAPÍTULO 8: DISCUSIÓN GENERAL}

Esta tesis constituye el primer estudio del Estornino Pinto en Sudamérica, e incluye distintos aspectos de la invasión de esta especie, como la competencia con aves nativas, la reproducción, la alimentación y las especies de parásitos que presenta.

El estornino reúne un conjunto de características típicas de especies con gran capacidad invasora como ser un estratega $r$ con tamaño pequeño y una alta tasa de reproducción, habitar distintos ambientes, formar bandadas numerosas, dispersarse rápidamente, ser generalista (tanto en la alimentación como en la reproducción) y aprovechar los recursos del hombre (Holway y Suarez 1999, McKinney y Lockwood 1999). Estas características permitieron al estornino utilizar, en el área de estudio, una gran variedad de cavidades en árboles vivos y muertos, fabricadas por carpinteros y generadas por degradación natural. También utilizó para nidificar construcciones humanas como techos de viviendas y luminarias y fue la única especie en utilizar las cajas-nido colocadas durante la realización de este trabajo. Actualmente, en la zona del parque Pereyra Iraola, es el ave que nidifica en cavidades con mayor densidad y las cavidades que utiliza presentan características similares a las que utilizan otras especies como carpinteros y varias especies de loros. Si bien hasta el momento no se ha demostrado que el estornino impacte negativamente sobre las aves nativas, las interacciones observadas con un hornero y con carpinteros muestran que la competencia con estas aves podría existir en la zona y podrían acentuarse en un futuro con el incremento del tamaño poblacional del estornino. Asimismo, su expansión a otras regiones de la Argentina podría generar su encuentro con nuevas especies con las que podría actuar como competidor por cavidades.

El estudio de la biología reproductiva del estornino en el parque Pereyra Iraola permitió observar diferencias en algunos parámetros reproductivos en comparación a su reproducción en Norteamérica, Europa y Nueva Zelanda como un menor tamaño de la puesta y del número de pichones por nido, especialmente en la primera parte del período reproductivo (Lack 1948 a, Dunnet 1955, Kessel 1957, Feare 1984, Collins y de Vos 1966). El porcentaje de fallas en la eclosión coincidió con el reportado por Briskie y Mackintosh (2004) en especies de aves introducidas en Nueva Zelanda y con el registrado en estorninos en su área de distribución original. Además la supervivencia de pichones y el éxito de los nidos también fue menor a lo observado en otros países (Dunnet 1955, Kessel 1957, Collins y de Vos 1966, Royall 1966, Feare 1984). Una de las mayores causas de disminución de la supervivencia de los pichones 
fue la reducción de nidada, que se registró en una gran cantidad de casos. Varias especies de aves dejan de alimentar al pichón más pequeño si el alimento disponible no es abundante (Lack 1954, Stouffer y Braun 1995). De esta manera, se aseguran de alimentar al resto de los pichones y evitar la pérdida de la nidada entera. Sin embargo, en este trabajo a pesar de utilizar esta estrategia, en la mayoría de los nidos los estorninos no pudieron evitar que se muera el resto de los pichones del nido.

En las temporadas reproductivas 2010 y 2011, mientras se estudiaba la biología reproductiva del estornino se observó una mortalidad de pichones muy alta. En base a estas observaciones se decidió en las siguientes temporadas reproductivas (2012 y 2013) evaluar distintos factores que podrían influir en el bajo éxito reproductivo del estornino y a partir de ahí surgieron los resultados más relevantes de esta tesis. Determinar en qué grado influye cada variable sobre el éxito reproductivo es una tarea compleja debido a la presencia de una gran cantidad de factores que pueden afectar a los pichones e interactuar entre sí. Uno de esos factores son las variables climáticas como la temperatura ambiental y las precipitaciones. Los resultados de esta tesis indican que el porcentaje de pichones que sobreviven en cada nido disminuyó al aumentar la temperatura ambiental. Esto podría ser causado por un efecto directo de la temperatura sobre los pichones, provocando un aumento excesivo de la temperatura corporal y derivando en la muerte (Nilsson 1986). Además la supervivencia de pichones varió en función de las precipitaciones. Ambas variables climáticas podrían tener un efecto sobre la disponibilidad de alimento, y la disminución de la supervivencia durante la segunda nidada podría ser causada en parte por falta de alimento como sugieren varios autores (Howe 1976, Rickleffs 1979, Broun y Hunt 1983, Feare 1984).

La presencia e intensidad del parasitismo de Philornis no mostró un efecto sobre la supervivencia y el crecimiento de los pichones, pero la edad a la que se produjo la infestación fue un factor influyente en la proporción de pichones que sobrevivieron en el nido. La falta de un efecto negativo de Philornis sobre el crecimiento podría explicarse mediante la "hipótesis de compensación parental" (Tripet y Richner 1997) según la cual los padres incrementarían el suministro de alimento a los pichones parasitados en respuesta a un aumento en el begging (comportamiento relacionado al pedido de alimento que involucra sonidos, movimiento de las alas, estiramiento del cuello, etc.) por parte de éstos.

La prevalencia de Philornis registrada en los nidos de estornino es la más alta con respecto a otras especies de aves en la Argentina (Fraga 1984, Nores 1995, Rabuffetti y Reboreda, 2007, Turienzo y Di Iorio, 2008, 2010; Antoniazzi et al. 2011, Segura y Reboreda 2011, Quiroga y Reboreda 2012). Esta mosca con distribución Neotropical adquirió recientemente al estornino como hospedador por lo que el tiempo de interacción entre ambas 
especies es muy corto evolutivamente para que el estornino haya adquirido herramientas inmunológicas o comportamientos que le permitan evitar al parásito o atenuar sus efectos negativos.

El análisis de la alimentación de los pichones demostró que el estornino encuentra en el parque Pereyra Iraola una gran variedad de artrópodos de los que se alimenta en la época reproductiva y en menor proporción alimento vegetal. Broun y Hunt (1983) observaron que los pichones de estornino alimentados con una mayor proporción de alimento vegetal presentaban menores tasas de crecimiento que los alimentados con artrópodos. En esta tesis se observó una mayor proporción de alimento vegetal al avanzar la temporada reproductiva que podría estar relacionado a una disminución en la disponibilidad de los artrópodos que consumen los pichones y ésto podría tener un efecto negativo sobre su crecimiento y supervivencia. En los trabajos realizados en otras partes del mundo los pichones de estornino consumen casi exclusivamente artrópodos y las variaciones en la dieta según la edad de los pichones se deben básicamente a diferencias en las especies de artrópodos (Coleman 1977, Feare 1984, Moore 1986). En el parque Pereyra Iraola se observó un aumento en la ingesta de alimento vegetal con la edad de los pichones. Teniendo en cuenta que los pichones de aves altriciales requieren grandes cantidades de proteínas para crecer, que obtienen principalmente de los insectos, la alimentación de los pichones en la zona de estudio podría ser deficiente y esto podría ser otro factor que afecte la supervivencia de los pichones de estornino. Además los pichones del parque Pereyra Iraola que murieron a mayor edad presentaban en promedio una cantidad significativamente menor de alimento total que los pichones que murieron más jóvenes o directamente su estómago se encontraba completamente vacío, por lo cual podrían haber muerto de hambre.

Otro factor que puede influir sobre la supervivencia de los pichones y que fue analizado en esta tesis fueron los ecto y endoparásitos que presentan los estorninos. Estos análisis demostraron que el estornino ha perdido la mayoría de las especies que lo parasitan en Europa, Australia y Norteamérica. Esta baja cantidad de especies podría haber facilitado el establecimiento del estornino en la zona de acuerdo a la "hipótesis del enemigo perdido" (Torchin et al. 2003). Además las pocas especies que se encontraron (con excepción del díptero Philornis, con distribución principalmente Neotropical) son cosmopolitas y estaban presentes previamente en las aves de la zona, por lo que el estornino no estaría actuando como un vector transmisor de nuevos parásitos a las aves nativas. 


\section{Consideraciones finales}

El Estornino Pinto presenta numerosos antecedentes como especie invasora y se ha demostrado que afecta la reproducción de otras especies de aves debido a la competencia por cavidades (Troeschler 1976, Peterson y Gauthier 1985, Weitzel 1988, Ingold 1989, 1994, 1996, Mazgajski 2003). Además ha generado grandes perjuicios económicos al hombre principalmente al alimentarse en campos de cultivo en numerosos países (Summers 1985, Feare y Douville de Franssu 1992, Johnson y Glahn 1994, Feare y Fransu, Tracey y Saunders 2003, Conover y Dolbeer 2007). En la zona del parque Pereyra Iraola no se encontraron estorninos en campos de cultivos, pero en esta zona los cultivos son principalmente de verduras de hojas verdes y otros vegetales como zapallito, repollo, brócoli, etc. (Ministerio de Asuntos Agrarios 2007) que podrían ser poco apetecibles para los estorninos y no forman parte de su alimentación en otros países. La llegada del estornino a otras provincias como Mendoza y San Juan podría poner en riesgo cultivos típicos de esas provincias como viñedos y olivares, como ha ocurrido en otras partes del mundo donde el estornino consume enormes cantidades de uvas y aceitunas.

En la Argentina la introducción del Estornino Pinto se produjo hace aproximadamente tres décadas (Navas 2002) pero en los últimos años aumentaron notablemente los registros de estorninos (en la mayoría de los casos nidificando) en distintas provincias del país (Peris et al. 2005, Jensen 2008, Grilli et al. 2011, Klavins y Álvarez 2012, Lucero 2013, Ortiz et al. 2013, Zanotti 2013) y ya se lo encuentra en Uruguay (Mazzulla 2013). Esto demuestra que el estornino se encuentra en expansión en la Argentina y en Sudamérica. Sin embargo, hasta el momento no se observó la explosión demográfica que ocurrió en otros países donde el estornino fue introducido, como en Sudáfrica, Estados Unidos y Nueva Zelanda, donde se registran dormideros de cientos de miles y hasta millones de ejemplares (Wood 1924, Craig y Feare 1984, Feare 1984). Los trabajos publicados sobre el Estornino Pinto describiendo distintos aspectos de su biología en distintas partes del mundo son numerosos, pero es importante estudiar a esta especie en cada sitio donde es introducida debido a que las características particulares de cada lugar como el clima, la disponibilidad de recursos, los parásitos y enfermedades presentes en las especies de la zona y el comportamiento de los individuos liberados ante estos factores determinan si la especie logra establecerse, su éxito reproductivo y el impacto que puede generar en el ecosistema. Es importante considerar también que la probabilidad de controlar a una especie introducida es mayor en las primeras etapas de su introducción (Williamson y Brown 1986), una vez que se convierte en invasora es muy difícil poder controlarla y prácticamente imposible erradicarla (Navas 1987). En 
distintos países de Europa, en Estados Unidos y en Nueva Zelanda se han realizado numerosos intentos por erradicar al estornino de las áreas de cultivos y de las ciudades utilizando diversos métodos para ahuyentarlos como pirotecnia, grabaciones de predadores, cetrería, espantapájaros. También recurrieron a métodos letales como el uso de cebos tóxicos, captura con trampas, rociado de dormideros con detergente, disparos y uso de explosivos en dormideros. Sin embargo, a pesar de que miles de estorninos murieron con estos métodos, esto no significó un descenso poblacional importante ni disminuyeron los daños ocasionados por esta especie (Garner 1978, Johnson y Glahn 1994, Linz et al. 2007).

Actualmente en la Argentina nos encontramos en una etapa del establecimiento del estornino en la que una estrategia de control aplicada a tiempo podría tener un efecto significativo sobre las poblaciones de estorninos. El uso de cajas-nido podría ser una opción que permitiría eliminar huevos, pichones y parejas reproductivas y de esta manera evitar el crecimiento poblacional. Otra estrategia posible es atacar a los dormideros en la ciudad, con la ventaja de poder atacar a cientos de estorninos de una vez, pero con la desventaja de que podría no solo verse afectada la especie blanco sino también otras aves que se encuentren en el lugar. En caso de atacar a los dormideros se requieren estudios que permitan determinar cuál es el método adecuado para evitar daños a la población humana aledaña y a otras especies. Por las características de la especie, la gran diversidad de cavidades que utiliza para nidificar y su alimentación omnívora muchas áreas de la Argentina estarían en riesgo de ser invadidas por el estornino. Por este motivo es necesario monitorear la presencia de esta especie en las distintas áreas del país, especialmente las áreas de cultivo de cereales y frutas, para evitar que comiencen a utilizar estos cultivos como recurso alimenticio e implementar alguna medida de control inmediata si esto ocurriera.

Los resultados de este trabajo podrían ser utilizados por las autoridades con el fin de desarrollar estrategias de control que permitan limitar el aumento poblacional y la expansión del estornino pinto a otras áreas del país. De no tomar medidas a tiempo podríamos en pocos años encontrarnos en una situación similar a la de otros países donde los daños provocados por el estornino tanto a la fauna nativa como al ser humano son muy importantes y limitarlos genera un gran esfuerzo y costo económico. 


\section{CAPÍTULO 9: REFERENCIAS BIBLIOGRÁFICAS}

Agnew P., J. C. Koella y Y. Michalakis, 2000. Host life history responses to parasitism. Microbes Infect., 2: 891-96.

Aitken K. E. y K. Martin, 2007. The importance of excavators in hole-nesting communities: availability and use of natural tree holes in old mixed forests of western Canada. Journal of Ornithology 148(2): 425-434.

Alabrudzinska J., A. Kalinski, R. Slomczynski, J. Wawrzyniak, P. Zielinski, P. y J. Banbura, 2003. Effects of nest characteristics on breeding success of Great Tits Parus major. Acta Ornithologica 38(2): 151-154.

Allen A. V. y D. S. Ridley, 1970. Further observations on the formol ether concentration technique for faecal parasites. Technical Methods 23:545-6.

Allendorf F. W. y L. L. Lundquist, 2003. Introduction: population biology, evolution, and control of invasive species. Conservation Biology 17: 24-30.

Amundsen T. y J. N. Stokland, 1990. Egg size and parental quality influence nestling growth in the shag. The Auk 111: 410-413.

Antoniazzi, L. R., D. E. Manzoli, D. Rohrmann, M. J. Saravia, L. Silvestri y P. M. Beldomenico, 2011. Climate variability affects the impact of parasitic flies on Argentinean forest birds. Journal of Zoology 283: 126-134.

Arabkhazaeli F. y S. A. Madani, 2014. Visceral coccisdiosis in a common mynah (Acridotheres tristis) due to Isospora sp. infection. Iranian Journal of Veterinary Medicine 8(1): 59-62.

Aramburú, R. M., S. Calvo, M. E. Alzugaray y A. Cicchino, 2003. Ectoparasitic load of monk parakeet (Myiopsitta monachus, Psittacidae) nestlings. Ornitología Neotropical 14: 415-418.

Aramburú R., I. Berkunsky, A. Formoso y A. Cicchino, 2013. Ectoparasitic load of bluecrowned parakeet (Aratinga A. acuticaudata, Psittacidae) nestlings. Ornitología Neotropical 24: 257-265.

Ardia D. R., J. H. Pérez y E. D. Clotfelter, 2006. Nest box orientation affects internal temperature and nest site selection by Tree Swallows. Journal of Field Ornithology 77(3): 339-344.

Arendt W. J., 1985 a. Philornis ectoparasitism of pearly-eyed thrashers. I. Impact on growth and development of nestlings. The Auk 102: 270-280.

Arendt W. J., 1985 b. Philornis ectoparasitism of Pearly-eyed Thrashers. II. Effects on adults and reproduction. The Auk 102: 281-292.

Arends A., 1997. External parasites and poultry pests. En: Calnek BW (ed.) Diseases of poultry, 10th edn. Iowa State University Press, Ames. Pp. 785-813.

Arrabal J., D. Manzoli, L. Antoniazzi, M. Lareschi y P. Beldomenico, 2012. Prevalencia del ácaro Ornithonyssus bursa Berlese, 1888 (Mesostigmata: Macronyssidae) en un ensamble de aves (Passeriformes) de bosques del centro de la Provincia de Santa Fe, Argentina. Revista Ibero-Latinoamericana de Parasitología 71: 172-178.

Atkinson C. T., N. J. Thomas y D. Bruce Hunter, eds. Parasitic diseases of wild birds. New York: Wiley-Blackwell, 2008.

Attanasi A., A. Cavagna, L. Del Castello, I. Giardina, T. S. Grigera, A. Jelić, A., ... y M. Viale, 2014. Information transfer and behavioural inertia in starling flocks. Nature physics 10: 691-696.

Bachmann A. O., 2011. A catalog of the types of craneflies (Limoniidae and Tipulidae)(Insecta, Diptera) deposited in the Museo Argentino de Ciencias Naturales, Buenos Aires. Revista del Museo Argentino de Ciencias Naturales 13. 
Ball J y P. Daszak, 1997. Isospora tiaris n. sp.(Apicomplexa: Eimeriidae) from the sooty grassquit (Tiaris fuliginosa), a passeriform bird of South America. The Journal of parasitology, 83(3): 465-466.

Ballard N. B. y O. W. Olsen, 1966. Helminths of the starling, Sturnus vulgaris vulgaris L., from northeastern Colorado. The Journal of Parasitology: 372-372.

Barras S. C., S. E. Wright y T. E. Seamans, 2003. Blackbird and starling strikes to civil aircraft in the United States, 1990-2001. En: Linz G. M. (ed.). Proceedings of symposium on management of North American blackbirds. U.S. Department of Agriculture, Animal and Plant Health Inspection Service, Wildlife Services, National Wildlife Research Center, Fort Collins, Colorado, USA. Pp. 91-96.

Basualdo J. A., C. E. Coto y R. A. de Torres, 1996. Microbiología biomédica: bacteriología, micología, virología, parasitología, inmunología. Ed. Atlante, Buenos Aires, 1188 pp.

Bergman D. L., M. D. Chandler y A. Locklear, 2002. The economic impact of invasive species to Wildlife Services' cooperators. En: Clark L., J. Hone, J. A. Shivik, R. A. Watkins, K. C. VerCauteren y J. K. Yoder (eds.). Human conflicts with wildlife: economic considerations. Proceedings, Third NWRC Special Symposium. USDA National Wildlife Research Center, Fort Collins, CO. Pp. 169-178.

Bernard J., 1987. Parasitic helminths of flying starlings (Sturnus vulgaris L.) in their nesting area. Archives de l'Institut Pasteur de Tunis 64: 477-499.

Best L. B. y D. F. Stauffer. 1980. Factors affecting nesting success in riparian bird communities. Condor 82:149-158.

Best L. B. y J. P. Gionfriddo, 1991. Characterization of grit use by cornfield birds. The Wilson Bulletin 68-82.

Blackburn T. M., J. L. Lockwood y P. B. Cassey, 2009. Avian invasions: the ecology and evolution of exotic birds. Oxford University Press.

Blackburn, T. M. y R. P. Duncan, 2001. Determinants of establishment success in introduced birds. Nature 414(6860): 195-197.

Blackshaw, R. P. y J. P. Moore, 2012. Within-generation dynamics of leatherjackets (Tipula paludosa Meig.). Journal of Applied Entomology 136(8): 605-613.

Blair R. B., 1996. Land use and avian species diversity along an urban gradient. Ecological applications 6: 506-519.

Blanco G., J. L. Tella, J. Potti y A. Baz, 2001. Feather mites on birds: costs of parasitism or conditional outcomes? Journal of Avian Biology 32(3): 271-274.

Boag P. T., 1987. Effects of nestling diet on growth and adult size of zebra finches (Poephila guttata). The Auk: 155-166.

Boyd E. M., 1951. A survey of parasitism of the starling Sturnus vulgaris L. in North America. The Journal of parasitology 37: 56-84.

Brackbill H., 1952. Starlings, Sturnus vulgaris, catching insects on the wing. The Auk 69: 8889.

Braun, B. M. y G. L. Hunt Jr, 1983. Brood reduction in black-legged kittiwakes. The Auk: 469-476.

Briskie, J. V. y M. Mackintosh, 2004. Hatching failure increases with severity of population bottlenecks in birds. Proceedings of the National Academy of Sciences of the United States of America 101(2): 558-561.

Brouwer L., J. Komdeur , 2004. Green nesting material has a function in mate attraction in the European starling. Animal Behavior 67:539-548

Brown C. R. y M. B. Brown, 1986. Ectoparasitism as a cost of coloniality in cliff swallows (Hirundo pyrrhonota). Ecology: 1206-1218.

Brown C. R., M. B. Brown, 1999. Fitness components associated with laying date in the cliff swallow. Condor: 230-245.

Brown C. R., M. B. Brown y B. Rannala, 1995 Ectoparasites reduce long-term survival of their avian host. Proc. R. Soc. Lond. B 262: 313-319. 
Bruun M. y H. G. Smith, 2003. Landscape composition affects habitat use and foraging flight distances in breeding European starlings. Biological Conservation 114: 179-187.

Burger J. y M. Gochfeld, 2000. Nest site selection in monk parakeets (Myiopsitta monachus) in Florida. Bird Behavior 13: 99-105.

Bush A., K. Lafferty, J. Lotz y A. Shostak, 1997. Parasitology meets ecology on its own terms: Margolis et al. revisited. Journal of Parasitology 83: 575-583.

Calvelo S. y S. Liberatore, 2002. Catálogo de los Líquenes de la Argentina. Kurtziana 29: $7-$ 170.

Camin, A. M., D. Chabasse y C. Guiguen, 1998. Keratinophilic fungi associated with starlings Sturnus vulgaris in Brittany, France. Mycopathologia143: 9-12.

Carere C., S. Montanino, F. Moreschin, F. Zoratto, F. Chiarotti, D. Santucci, E. Alleva, 2009. Aerial flocking patterns of wintering starlings, Sturnus vulgaris, under different predation risk. Animal Behavior 77: 101-107.

Carlson J. C., A. B. Franklin, D. R. Hyatt, S. E. Pettit y G. M. Linz, 2011. The role of starlings in the spread of Salmonella within concentrated animal feeding operations. Journal of applied ecology 48: 479-486.

Cetin H., Tufan O., Ozdemir T.A., Tay T., Candan M., Yanikoğlu A., Sümbül H. (2008): Insecticidal activity of major lichen compounds, $(-)$ and $(+)$ usnic asid, against the larvae of house mosquito, Culex pipiens L. Parasitology Research, 102: 1277-1279.

Cetin H, Tufan-Cetin O, Turk AO, Tay T, Candan M, Yanikoglu A y H. Sumbul, 2012. Larvicidal activity of some secondary lichen metabolites against the mosquito Culiseta longiareolata Macquart (Diptera: Culicidae). Natural Product Research 26: $350-355$.

Chatellenaz M. L. y L. I. Ferraro, 2000. Materiales vegetales y fúngicos en nidos de aves del noreste argentino y Paraguay. Facena 16: 103-119.

Chatellenaz M. L. y L. I. Ferraro, 2005. Usnea y Ramalina (Ascomycetes liquenizados) como principales componentes definidos de Parula pitiayumi (Aves, Parulidae): posible acción antibacteriana e insecticida. Universidad Nacional del Nordeste. Comunicaciones Científicas y Tecnológicas, resumen B-024.

Chebez J. C., 2005. Guía de las Reservas Naturales de la Argentina (Vol. 3). Editorial Albatros.

Clark A. B. y D. S. Wilson, 1981. Avian breeding adaptations: hatching asynchrony, brood reduction, and nest failure. Quarterly Review of Biology: 253-277.

Clark L. y J. R. Mason, 1985. Use of nest material as insecticidal and antipathogenic agents by the European starling. Oecologia 67: 169-176.

Clark L. y J. R. Mason, 1988. Effect of biologically active plants used as nest material and the derived benefit to starling nestlings. Oecologia 77(2): 174-180.

Clark L. y R. G. Mclean, 2003. En: Linz G. M. (Ed.). Proceedings of Symposium on management of North american blackbirds. U.S. Department of agriculture, animal and plant health Inspection Servic, Wildlife Services, Natrional Wildlife Research Center, Fort Collins. Colorado, USA. Pp. 103-108.

Clayton D. H. y D. M. Tompkins, 1995. Comparative effects of mites and lice on the reproductive success of rock doves (Columba livia). Parasitology 110: 195-206.

Clergeau P., J. P. L. Savard, G. Mennechez y G. Falardeau, 1998. Bird abundance and diversity along an urban-rural gradient: a comparative study between two cities on different continents. Condor 100: 413-425.

Clergeau P. y F. Quenot, 2007. Roost selection flexibility of European starlings aids invasion of urban landscape. Landscape and Urban Planning 80: 56-62.

Cocchietto M., N. Skert, P. Nimis y G. Sava, 2002. A review on usnic acid, an interesting natural compound. Naturwissenschaften 89: 137-146.

Cockle K., K. Martin y K. Wiebe, 2011. Selection of Nest Trees by Cavity-nesting Birds in the Neotropical Atlantic Forest. Biotropica 43: 228-236. 
Coleman J. D., 1973. Determination of the sex and age of starlings in Canterbury, New Zealand. Notornis 20: 324-329.

Coleman J. D., 1977. The foods and feeding of starlings in Canterbury. New Zealand Forest Service.

Collias N. E., 1997. On the origin and evolution of nest building by passerine birds. Condor: 253-270.

Collins V. B. y A. de Vos, 1966. A nesting study of the starling near Guelph, Ontario. The Auk: 623-636.

Congdon N. M. y J. V. Briskie, 2010. Effect of population bottlenecks on the egg morphology of introduced birds in New Zealand. Ibis 152: 136-144.Conner R. N., 1975. Orientation of entrances to woodpecker nest cavities. The Auk 92: 71-374.

Conover M. R. y R. A. Dolbeer, 2007. Use of decoy traps to protect blueberries from juvenile European starlings. Human-Wildlife Interactions: 88.

Cooper C. L. y J. L. Crites, 1976. Additional check list of the helminths of the starling (Sturnus vulgaris L.). American Midland Naturalist 95: 191-194.

Cornelius C., K. Cockle, N. Politi, I. Berkunsky, L. Sandoval, V. Ojeda, L. Rivera, M. Jr. Hunter y K. Martin, 2008. Cavity-nesting birds in neotropical forests: cavities as a potentially limiting resource. Ornitología Neotropical 19: 253-268.

Cornelius C., K. Cockle, N. Politi, I. Berkunsky, L. Sandoval, V. Ojeda, L. Rivera, M. Hunter y K. Martin, 2008. Cavity-nesting birds in neotropical forests: cavities as a potentially limiting resource. Ornitologia Neotropical 19: 253-268.

Courchamp F., T. Clutton-Brock y B. Grenfell, 1999. Inverse density dependence and the Allee effect. Trends in ecology \& evolution 14: 405-410.

Couri M. S., 1991. Philornis carinatus Dodge, 1968 (Diptera, Muscidae) data on morphology, biology and taxonomy. Revista Brasileira de Entomologia 35: 109-112.

Couri M. S., F. L. Rabuffetti y J. C. Reboreda, 2005. New data on Philornis seguyi Garcia (1952)(Diptera, Muscidae). Brazilian Journal of Biology 65: 631-637.

Couri M. S., L. R. Antoniazzi, P. Beldomenico y M. Quiroga, 2009. Argentine Philornis Meinert species (Diptera: Muscidae) with synonymic notes. Zootaxa 2261: 52-62.

Cox F. E., 1993. Modern Parasitology: A Textbook of Parasitology.

Craig A. J. y C. J. Feare, 2009. Family Sturnidae (starlings). En: Del Hoyo J., A. Elliot y D. A. Christie (eds.). Handbook of the birds of the world, Vol.14. Bush-shrikes to Old World sparrows. Lynx Editions, Barcelona. Pp. 654-758.

Culberson C. F., 1972. Improved conditions and new data for the identification of lichen products by a standardized thin-layer chromatographic method. Journal of Chromatography 72: 113-125.

Davies N. B., J. R. Krebs y S. A. West, 2012. An introduction to behavioural ecology. John Wiley \& Sons.

Dawson R. D., C. C. Lawrie y E. L. O'Brien, 2005. The importance of microclimate variation in determining size, growth and survival of avian offspring: experimental evidence from a cavity nesting passerine. Oecologia 144: 499-507.

Dayan F. E. y J. G. Romagni, 2001. Lichens as a potential source of pesticides. Pesticide Outlook 12.6: 229-232. DOI: 1039/b110543b

Deeming D. C. y M. W. Ferguson, 1991. Physiological effects of incubation temperature on embryonic development in reptiles and birds. Egg incubation: its effects on embryonic development in birds and reptiles: 147-171.

De Grazio J. W., 1978. World bird damage problems. En: Howard W. E. y R. E. Marsh (eds.). Proceedings of the Eighth Vertebrate Pest Conference University of California, Davis, CA. Pp. 9-24.

De la Peña M. R. 1995. Ciclo reproductivo de las Aves Argentinas. Centro de Publicaciones, Universidad Nacional del Litoral, Santa Fe, Argentina. 
De la Peña M. R., P. M. Beldoménico y L. R. Antoniazzi, 2003. Pichones de aves parasitados por larvas de Philornis sp. (Diptera: Muscidae) en un sector de la provincia biogeográfica del Espinal de Santa $\mathrm{Fe}$, Argentina. FAVE Sección Ciencias Veterinarias 2: 141-146.

DeLoach J. R. y J. A. DeVaney, 1981. Northern fowl mite, Ornithonyssus sylviarum (Acari: Macronyssidae), ingests large quantities of blood from white leghorn hens. Journal of medical entomology 18: 374-377.

DeLope F., G. González, J. J. Pérez y A. P. Møller, 1993. Increased detrimental effects of ectoparasites on their hosts during adverse environmental conditions. Oecologia 95: 234-240.

Denmark H. A. y H. L. Cromroy, 2003. Tropical Fowl Mite, Ornithonyssus bursa (Berlese)(Arachnida: Acari: Macronyssidae). Bulletin EENY-297. Univ. Florida, Gainesville.

DeVaney J. A., 1979. The effects of the Northern fowl mite, Ornithonyssus sylivarium on egg production and body weight of caged white leghorn hens. Poultry science 58: 191194.

Dhindsa M. S. y D. A. Boag, 1990. The effect of food supplementation on the reproductive success of Black-billed Magpies Pica pica. Ibis 132: 595-602.

Di Giacomo A. G., A. S. Di Giacomo y M. Barbaskas, 1993. Nuevos registros de Sturnus vulgaris y Acridotheres cristatellus en Buenos Aires. Nuestras Aves 29: 2-3.

Dlugosch K. M. y I. M. Parker, 2008. Founding events in species invasions: genetic variation, adaptive evolution, and the role of multiple introductions. Molecular Ecology 17(1): 431-449.

Dolbeer R. A., P. P. Woronecki, A. R. Stickley y S. B. White, 1978. Agricultural impact of a winter population of blackbirds and starlings. The Wilson Bulletin: 31-44.

Dolbeer R. A., D. F. Mott y J. L. Belant, 1995. Blackbirds and starlings killed at winter roosts from PA-14 applications, 1974-1992: implications for regional population management.

Dolnik O. V., 1999. Diurnal periodicity of oocysts release of Isospora dilatata (Sporozoa: Eimeriidae) from the common Starling (Sturnus vulgaris) in nature. Parasitologiya 33: 74-80.

Dolnik O. V., 2003. Some aspects of the biology and host-parasite interactions of Isospora spp. (Protozoa: Coccidiida) of passerine birds. Journal of Ornithology 144: 379-380.

Dolnik O. V. y M. J. Loonen, 2007. Isospora plectrophenaxia n. sp (Apicomplexa: Eimeriidae), a new coccidian parasite found in Snow Bunting (Plectrophenax nivalis) nestlings on Spitsbergen. Parasitology research 101: 1617-1619.

Dudaniec R. Y. y S. Kleindorfer, 2006. Effects of the parasitic flies of the genus Philornis (Diptera: Muscidae) on birds. Emu 106: 13-20.

Dudaniec R. Y., B. Fessl y S. Kleindorfer 2007. Interannual and interspecific variation in intensity of the parasitic fly, Philornis downsi, in Darwin's finches. Biological Conservation 139: 325-332.

Duncan R. P., T. M. Blackburn y D. Sol, 2003. The ecology of bird introductions. Annual Review of Ecology, Evolution, and Systematics 71-98.

Dunn P. O. y D. W. Winkler, 1999. Climate change has affected the breeding date of tree swallows throughout North America. Proceedings of the Royal Society of London. Series B: Biological Sciences 266: 2487-2490.

Dunnet G. M., 1955. The breeding of the starling Sturnus vulgaris in relation to its food supply. Ibis 97: 619-662.

Duszynski D. W., S. J. Upton y L. Couch, 2000. The Coccidia of the World. Department of Biology, University of New Mexico. Available at http://biology.unm.edu/biology/coccidia/home.html. 
Eeva T. y E. Lehikoinen, 1995. Egg shell quality, clutch size and hatching success of the great tit (Parus major) and the pied flycatcher (Ficedula hypoleuca) in an air pollution gradient. Oecologia 102: 312-323.Eggers S., M. Griesser y J. Ekman, 2005. Predator-induced plasticity in nest visitation rates in the Siberian jay (Perisoreus infaustus). Behavioral Ecology 16: 309-315.

Eggers S., M. Griesser, M. Nystrand y J. Ekman, 2006. Predation risk induces changes in nest-site selection and clutch size in the Siberian jay.Proceedings of the Royal Society B: Biological Sciences 273: 701-706.

Evans P. G. H. 1988. Intraspecific nest parasitism in the European starling Sturnus vulgaris. Animal Behaviour 36: 1282-1294.

Faggi A. y P. V. Perepelizin, 2006. Riqueza de aves a lo largo de un gradiente de urbanización en la ciudad de Buenos Aires. Revista del Museo Argentino de Ciencias Naturales 8: 289-297.

Fauth P. T., D. G. Krementz, J. E. Hines, 1991. Ectoparasitism and the role of green nesting material in the European starling. Oecologia 88: 22-29.

Feare C. J., 1976. Desertion and abnormal development in a colony of sooty terns Sterna fuscata infested by virus-infected ticks. Ibis 118: 112-115.

Feare C. J., 1984. The starling. Oxford University Press, Oxford.

Feare C. J., Douville de Farnseau P. y S. J. Peris, 1992. The starling in Europe: multiple approaches to and problem species. Proceedings of the Vertebrate Pest Management Conference 15: 83-88.

Feare C. J. y G. J. Forrester, 2002. The dynamics of a suburban nestbox breeding colony of starlings Sturnus vulgaris. BTO Research Report: 73-90.

Fessl B., S. Kleindorfer y Tebbich, 2006 a. An experimental study on the effects of an introduced parasite in Darwin's finches. Biological Conservation 127: 55-61.

Fessl B., B. J. Sinclair y S. Kleindorfer, 2006 b. The life-cycle of Philornis downsi (Diptera: Muscidae) parasitizing Darwin's finches and its impacts on nestling survival. Parasitology, 133: 739-747.

Fessl B. y S. Tebbich, 2002. Philornis downsi-a recently discovered parasite on the Galápagos archipelago-a threat for Darwin's finches?. Ibis 144: 445-451.

Figuerola J., J. Domenech y J. C. Senar, 2003. Plumage colour is related to ectosymbiont load during moult in the serin, Serinus serinus: an experimental study. Animal Behaviour 65: 551-557.

Flux J. E. C., y M. M. Flux, 1981. Population Dynamics and Age Structure of Starlings (Sturnus vulgaris) in New Zealand. New Zealand journal of ecology: 65-72.

Fraga R. M., 1984. Bay-winged Cowbirds (Molothrus badius) remove ectoparasites from their brood parasites, the Screaming Cowbird (M. rufoaxillaris). Biotropica 16, 223226

Friend M., R. G. McLean y D. F. Joshua Dein, 2001. Disease emergence in birds: challenges for the twenty-first century. The Auk 118: 290-303.

Fritis M. C., C. R. Lagos, N. Q. Sobarzo, I. M. Venegas, C. S. Sánchez, H. C. Altamirano, L. E. Catalan y W. Q. Palma, 2013. Depsides and triterpenes in Pseudocyphellaria coriifolia (lichens) and biological activity against Trypanosoma cruzi. Natural Product Research 27: 1607-1610.

Galvan I. y J. Sanz, 2006. Feather mite abundance increases with uropygial gland size and plumage yellowness in Great Tits Parus major. Ibis 148: 687-697.

Garner K. M., 1978. Management of blackbird and starling winter roost problems in Kentucky and Tennessee. Proceedings of the Vertebrate Pest Conference 8:54-59.

Gjerdrum C., C. S. Elphick y M. Rubega, 2005. Nest site selection and nesting success in saltmarsh breeding sparrows: the importance of nest habitat, timing, and study site differences. The Condor 107: 849-862. 
Gill F. y D. Donsker (Eds). 2014. IOC World Bird List (v 4.3). http://www.worldbirdnames.org/ioc-lists/master-list-2/

Gill, H. y I. Paperna, 2008. Proliferative visceral Isospora (atoxoplasmosis) with morbid impact on the Israeli sparrow Passer domesticus biblicus Hartert, 1904. Parasitology research 103: 493-499.

Gionfriddo J. P. y L. B. Best, 1995. Grit use by house sparrows: effects of diet and grit size. Condor 57-67.

Gionfriddo J. P. y L. B. Best, 1996. Grit-use patterns in North American birds: the influence of diet, body size, and gender. The Wilson Bulletin: 685-696.

Gionfriddo J. P. y L. B. Best, 1999. Grit use by birds. En Current ornithology. Springer US. Pp. 89-148.

Greco N. M., S. J. Sarandon, P. C. Pereyra, 1998. Parasitism of Diatraea saccharalis (Lepidoptera: Pyralidae) eggs by Trichogramma exiguum (Hymenoptera, Tricogrammatidae): influence of Zea mays leaf pubescence. Ecologia Austral 8: 3135.

Gregory R. D., N. I. Wilkinson, D. G. Noble, J. A. Robinson, A. F. Brown, J. Hughes, D. Procter, D. W. Gibbons, C. A. Galbraith, 2002. The population status of birds in the United Kingdom, Channel Islands and Isle of Man: an analysis of conservation concern, 2002-2007. British Birds 95: 410-448.

Grehan J. R., 1989. Larval feeding habits of the Hepialidae (Lepidoptera).Journal of natural history 23: 803-824.

Grilli P. G., L. J. Marti y R. F. Jensen, 2011. Una actualización del análisis de la expansión territorial del estornino pinto (Sturnus vulgaris) en Argentina: más de 20 años de avance ininterrumpido. Reunión Argentina de Ornitología, Formosa.

Gwinner, H. 1997. The function of green plants in nests of European starlings Sturnus vulgaris. Behaviour 134: 337-351.

Gwinner H., M. Oltrogge, L. Trost y U. Nienaber, 2000. Green plants in starling nests: effects on nestlings. Animal Behaviour 59: 301-309.

Gwinner H. y S. Berger, 2005. European starlings: nestling condition, parasites and green nest material during the breeding season. Journal of Ornithology 146: 365-371.

Hair, J. D. y D. J. Forrester, 1970. The helminth parasites of the starling (Sturnus vulgaris L.): a checklist and analysis. American Midland Naturalist 83: 555-564.

Hammer Ø, D. A. T. Harper, P. D. Ryan et al. 2001. PAST Paleontological Statistics software package for education and data analysis. Paleontología electronica 4: 9.

Hammer Ø., D. A. T. Harper y P. D. Ryan, 2009. PAST-PAlaeontological STatistics, ver. 1.89. University of Oslo, Oslo.

Hansell M. H., 1996. The function of lichen flakes and white spider cocoons on the outer surface of birds' nests. Journal of Natural History. 30: 303-311.

Hansell, M. 2000. Bird nests and construction behaviour. Oxford: Oxford University Press.

Hardy A. R., 1990. Vertebrate pests of UK agriculture: present problems and future solutions. En Proceedings of the fourteenth vertebrate pest conference 1990 (Davis L.R. y R.E. Marsh (eds.). Davis: University of California.Pp. 181-185.

Harper D. G., 1999. Feather mites, pectoral muscle condition, wing length and plumage coloration of passerines. Animal Behaviour 58: 553-562.

Haywood S. y Perrins C. M., 1992. Is clutch size in birds affected by environmental conditions during growth?. Proceedings of the Royal Society of London. Series B: Biological Sciences 249: 195-197.

Heeb P., I. Werner, M. Kölliker y H. Richner, 1998. Benefits of induced host responses against an ectoparasite. Proceedings of the Royal Society of London. Series B: Biological Sciences 265: 51-56.

Heeb P., Kölliker M. y H. Richner, 2000. Bird-ectoparasite interactions, nest humidity, and ectoparasite community structure. Ecology 81: 958-968. 
Hicks E. A., 1959. Check-list and bibliography on the occurrence of insects in birds'nests. (Iowa State College Press: Ames, US).

Hicks E. A., 1962. Check-list and bibliography on the occurrence of insects in birds'nests. Supplement I. Iowa State College Journal of Science 36: 233-348.

Hicks, E. A. 1971. Check-list and bibliography on the occurrence of insects in birds nests. Supplement II. Iowa State College Journal of Science 46: 123-338.

Hildenbrandt H., C. Carere y C. K. Hemelrijk, 2010 Self-organized aerial displays of thousands of starlings: a model. Behavioral Ecology. 21: 1349-1359.

Hilton G. M., M. H. Hansell, G. D. Ruxton, J. M. Reid, y P. Monaghan, 2004. Using artificial nests to test importance of nesting material and nest shelter for incubation energetics. The Auk, 121: 777-787.

Hilton-Taylor C., C. M. Pollock, J. S. Chanson, H. M. Stuart, Butchart, E. E. Thomasina, 2009. Old feld Katariya and Vineet State of the world's species 2008. En: J.-C. Vié, C. Hilton-Taylor, S. N. Stuart (eds.). Wildlife in a Changing World: An Analysis of The IUCN Red List of Threatened Species IUCN, Gland, Switzerland.

Hobbs R. J., H. A. Mooney, 1998. Broadening the extinction debate: population deletions and additions in California and Western Australia. Conservation Biology 12: 271-283.

Holway D. A. y A. V. Suarez, 1999. Animal behavior: an essential component of invasion biology. Trends in Ecology and Evolution 14: 328-330.

Howe H. F., 1976. Egg size, hatching asynchrony, sex, and brood reduction in the Common Grackle. Ecology: 1195-1207.

Hoyt D. F., 1979. Practical Methods of Estimating Volume and Fresh Weight of Bird Eggs The Auk 96: 73-77.

Huber S. K., 2008. Effects of the introduced parasite Philornis downsi on nestling growth and mortality in the medium ground finch (Geospiza fortis). Biological Conservation 141: 601-609.

Ibañez L, M. del Huerto, V. D. Fiorini y D. Montalti, 2011. Reproducción del Estornino Pinto (Sturnus vulgaris), una especie exótica, en Buenos Aires. Resúmenes XIV Reunión Argentina de Ornitología Formosa: 89.

Ingold D. J., 1989. Nesting phenology and competition for nest sites among Red-headed and Red-bellied Woodpeckers and European Starlings. The Auk 209-217.

Ingold D. J., 1994. Influence of nest-site competition between European Starlings and woodpeckers. The Wilson Bulletin 106: 227-241.

Ingold D. J., 1996. Delayed nesting decreases reproductive success in Northern Flickers: Implications for competition with European starlings. Journal of Field Ornithology 67: 321-326.

Ingold D. J., 1998. The influence of starlings on flicker reproduction when both naturally excavated cavities and artificial nest boxes are available. The Wilson Bulletin 110: $218-225$.

Ingold D. J. y D. A. Ingold, 1984. A study of possible niche preferences of cavity-nesting birds in the Colorado Rockies. NM Ornithol. Soc. Bull 12: 1-9.

Inouye D. W., 1976. Nonrandom orientation of entrance holes to woodpecker nests in aspen trees. Condor 78: 101-102.

Inouye R. S., N. J. Huntly y D. W. Inouye, 1981. Non-random orientation of Gila Woodpecker nest entrances in saguaro cacti. Condor 83: 88-89.

IUCN 2014. IUCN Red List of Threatened Species. Version 2014.1. www.iucnredlist.org Downloaded on 12 June 2014.

Jensen R. F., 2008. Nuevos registros de estornino pinto (Sturnus vulgaris) para el sureste de la provincia de Entre Ríos, Argentina. Nuestras Aves 53: 22.

Johnson R. J. y J. F. Glahn, 1994. European starlings. En: Hygnstrom S. E., R. M. Timm y G. E. Larson (eds.). Prevention and control of wildlife damage, vol. 2. University of Nebraska, Lincoln, NE. Pp. E109-E120. 
Källander H. y J. Karlsson, 1993. Supplemental food and laying date in the European starling. Condor: 95: 1031-1034.

Kashiwadani H. y Kalbj K., 1993. The genus Ramalina in Brazil. Lichenologist 25(1): 1-31.

Kedra A. H. y T. D. Mazgajski, 1998. Endoparasite Isospora sp.(Coccidia, Eimeriidae) affects the growth of starling Sturnus vulgaris nestling. Acta Parasitologica 43: 214-216.

Kerpez T. A. y Smith N. S., 1990. Competition between European Starlings and native woodpeckers for nest cavities in saguaros. The Auk 107: 367-375.

Kessel B., 1953. Distribution and migration of the European starling in North America. Condor 55: 49-67.

Kessel B., 1957. A study of the breeding biology of the European Starling (Sturnus vulgaris L.) in North America. The American Midland Naturalist 58: 257-331.

Kilham L., 1958. Territorial behavior of wintering red-headed woodpeckers. The Wilson Bulletin 70: 347-358.

Klavins J. y D. Álvarez, 2012. El estornino pinto (Sturnus vulgaris) en la provincia de Córdoba, Argentina. Nuestras Aves 57: 27-29.

Knee W. y Proctor, 2007. Host records for Ornithonyssus sylviarum (Mesostigmata: Macronyssidae) from birds of North America (Canada, United States, and Mexico). Journal of medical entomology 44: 709-713.

Koenig W. D., 2003. European Starlings and Their Effect on Native Cavity-Nesting Birds. Conservation Biology 17: 1134-1140.

Kolar C. S. y D. M. Lodge, 2001. Progress in invasion biology: predicting invaders. Trends in Ecology \& Evolution 16: 199-204.

Krist M. 2011. Egg size and offspring quality: a meta-analysis in birds. Biological Reviews 86: 692-716.

Lack D., 1948. Natural selection and family size in the starling. Evolution: 95-110.

Lack D., 1954. The natural regulation of animal numbers. Clarendon Press. Oxford, Inglaterra.

Lack D. L., 1968. Ecological adaptations for breeding in birds.

LeJeune J., H. J. Homan, G. M. Linz y D. L. Pearl, 2008. Role of the European starling in the transmission of E. coli O157 on dairy farms. In Proceedings of the Vertebrate Pest Conference (23): 31-34.

Levine N. D., S. Riper y C. Riper, 1980. Five New Species of Isospora From Hawaiian Birds. Journal of Eukaryotic Microbiology 27(3): 258-259.

Liker A., M. Márkus, M., A. Vozár, E. Zemankovics y L. Rózsa, 2001. Distribution of Carnus hemapterus in a starling colony. Canadian Journal of Zoology 79(4): 574-580.

Lindsey A. A., 1939. Food of the Starling in Central New York State. The Wilson Bulletin 51: 176-182.

Linz G. M., H. J. Homan, S. M. Gaukler, L. B. Penry, W. J. Bleier, 2007. European Starlings: A review of an invasive species with far-reaching impacts. En: Witmer G. W., W. C. Pitt, K. A. Fagerstone (eds.). Proceedings of an international symposium on Managing vertebrate invasive species, Fort Collins. Pp. 378-386.

Long, J. L. 1981. Introduced birds of the world: the worldwide history, distribution and influence of birds introduced to new environments. Reed A.H. y A.W. Reed. Sydney, Australia.

Lovette I. J. y D. R. Rubenstein, 2007. A comprehensive molecular phylogeny of the starlings (Aves: Sturnidae) and mockingbirds (Aves: Mimidae): congruent mtDNA and nuclear trees for a cosmopolitan avian radiation. Molecular phylogenetics and evolution 44: 1031-1056.

Lowe S, M. Browne, S. Boudjelas y M. De Poorter, 2000. 100 of the world's worst invasive alien species: a selection from the global invasive species database (p. 12). Species 
Survival Commission, World Conservation Union (IUCN), Auckland, New Zealand: Invasive Species Specialist Group.

Lucero F., 2013. Nuevas aves, primeras evidencias y localidades para las provincias de San Juan y Catamarca, Argentina. Ecoregistros 3(14).

Lumsden H. G., 1976. Choice of nest boxes by Starlings. The Wilson Bulletin 88: 665-666.

Lundberg P., 1987. Breeding Seasons of North Scandinavian Starlings (Sturnus vulgaris): Constrained by Food or Time?. The Journal of Animal Ecology: 847-855.

Luniak M., 1977. Abundance and productivity of broods of the starling Sturnus vulgaris in Warsaw. Acta Ornithologica 16: 241-274.

Lustick S., M. Kelty, 1979. Effects of the roost site on the energetics of blackbirds and starlings. Bird Control Seminars Proceedings. Pp. 260-272.

Maccarone A. D., 1987. Age-class differences in the use of food sources by European starlings. The Wilson bulletin 99: 699-704.

Mainwaring M. C., I. R. Hartley, M. M. Lambrechts y D. C. Deeming, 2014. The design and function of birds' nests. Ecology and Evolution.

Manchester S. J. y J. M. Bullock, 2000. The impacts of non-native species on UK biodiversity and the effectiveness of control. Journal of Applied Ecology 37: 845-864.

Marples B. J., 1934. The winter starling roosts of Great Britain, 1932-1933.The Journal of Animal Ecology 187-203.

Martin T. E., 1987. Food as a limit on breeding birds: a life-history perspective. Annual review of ecology and systematics 18: 453-487.

Martin T. E., 1988. Nest placement: implications for selected life-history traits, with special reference to clutch size. American Naturalist 132: 900-910.

Martin T. E. 1993. Nest predation and nest sites. BioScience 43: 523-532.

Martin T. E., y P. Li, 1992. Life history traits of open-vs. cavity-nesting birds. Ecology 73: 579-592.

Martin T. E., 1995. Avian life-history evolution in relation to nest sites, nest predation and food. Ecological Monographs 65: 101-127.

Martin K., K. E. Aitken, y K. L. Wiebe, 2004. Nest sites and nest webs for cavity-nesting communities in interior British Columbia, Canada: nest characteristics and niche partitioning. The condor 106: 5-19.

Martin T. E. y J. J. Roper, 1988. Nest predation and nest-site selection of a western population of the Hermit Thrush. Condor: 51-57.

Martins T. L. y J. Wright, 1993. Brood reduction in response to manipulated brood sizes in the common swift (Apus apus). Behavioral Ecology and Sociobiology 32: 61-70.

Mason P., 1985. The nesting biology of some passerines of Buenos Aires, Argentina. Ornithological monographs 36: 954-972.

Mazgajski, T. D. y A. H. Kedra, 1997. Are nestlings of hole-nesting birds affected by ectoparasites? A review. Wiadomości Parazytologiczne 43(4).

Mazgajski T. D., 2000. Competition for nest sites between the starling and other cavity nesters. Acta Ornithologica 35: 103-107.

Mazgajski T.D., 2003a. Nesting interaction between woodpecker and starlings-delayed commensalisms, competition for nest sites or cavity kleptoparasitism? En: P. Pechacek y W. D'Oleire-Oltmanns (eds.). Proceedings International Woodpecker Symposium,Forschungsbericht- Nationalparkverwaltung Berchtesgaden. Pp. 133138.

Mazgajski T. D., 2003b. Nest site choice in relation to the presence of old nests and cavity depth in the starling Sturnus vulgaris. Ethology Ecology \& Evolution: 15(3): 273281.

Mazgajski T. D., 2007 a. Effect of old nest material on nest site selection and breeding parameters in secondary hole nesters - a review. Acta Ornithologica 42: 1-14. 
Mazgajski T. D., 2007 b. Effect of old nest material in nestboxes on ectoparasite abundance and reproductive output in the European Starling Sturnus vulgaris (L.). Polish Journal of Ecology 55: 377-385.

Mazyad S. A. y E. K. M. Abel, 2005. Ornithonyssus (Acari: Macronyssidae) mite dermatitis in poultry field-workers in Almarg, Qalyobiya governorate. Journal of the Egyptian Society of Parasitology 35: 213-222.

Mazzulla J., 2013. Primeros registros de estornino pinto Sturnus vulgaris (Linnaeus, 1758) (Aves, Passeriformes, Sturnidae) en Uruguay. Achará 3: 13-17.

Mccarty, J. P y D. W. Winkler, 1999. Relative importance off environmental variables in determining the growth off nestling Tree Swallows Tachycineta bicolor. Ibis 141: 286-296.

McNeely J. A. (Ed.), (2001). Global strategy on invasive alien species. IUCN.

McKinney M. L., 2006. Urbanization as a major cause of biotic homogenization. Biological Conservation 127: 247-260.

McKinney M. L. y J. L. Lockwood, 1999. Biotic homogenization: a few winners replacing many losers in the next mass extinction. Trends in ecology \& evolution 14: 450-45

McLaren W. D., 1963. A preliminary study of nest-site competition in a group of hole-nesting birds. M.Sc. thesis, Univ. British Columbia, Vancouver, British Columbia.

McNeely J. A., H. A. Mooney, L. E. Neville, P. Schei, J. K. Waage (eds.) 2001. Global Strategy on Invasive Alien Species. Gland, Switz./Cambridge, UK: IUCN on behalf of Global Invasive Species Program.

McQuistion T. E. y M. Wilson, 1989. Isospora geospizae, a new coccidian parasite (Apicomplexa: Eimeriidae) from the small ground finch (Geospiza fuliginosa) and the medium ground finch (Geospiza fortis) from the Galapagos Islands. Systematic Parasitology: 14: 141-144.

McQuistion T. E. y A. Capparella, 1992. Two new coccidian parasites from the slate-colored grosbeak (Pitylus grossus) of South America. The Journal of parasitology: 805-807.

McQuistion T. E., 2000. The prevalence of coccidian parasites in passerine birds from South America. Transactions of the Illinois State Academy of Science 93: 221-227.

Meathrel C. E., I. J. Skira, J. S. Bradley y R. D. Wooller, 1993. The influence of egg-size, mass and composition upon hatching success in the short-tailed shearwater Puffinus tenuirostris (Aves: Procellariiformes). Journal of Zoology 230: 679-686.

Mennerat A., P. Mirleau, J. Blondel, P. Perret, M. M. Lambrechts y P. Heeb, 2009a. Aromatic plants in nests of the blue tit Cyanistes caeruleus protect chicks from bacteria. Oecologia 161: 849-855.

Mennerat A., P. Perret, P. Bourgault, J. Blondel, O. Gimenez, D. W. Thomas, P. heeb y M. M. Lambrechts, 2009b. Aromatic plants in nests of blue tits: positive effects on nestlings. Animal Behaviour 77: 569-574.

Merino S. y J. Potti, 1995. Mites and blowflies decrease growth and survival in nestling pied flycatchers. Oikos 73: 95-103.

Metzelaars H., T. Spaargaren, T. E. McQuistion y A. P. Capparella, 2005. Isospora iridosornisi, a new coccidian parasite (Apicomplexa, Eimeriidae) from the yellowthroated tanager, Iridosornis analis of South America. Acta Parasitologica 50: 191193.

Mezquida E. T., 2003. La reproducción de cinco especies de Emberizidae y Fringillidae en la Reserva de Nacuñán, Argentina. Hornero 18: 13-20.

Ministerio de Asuntos Agrarios, 2007. Informe de Postulación para integrar la Red Mundial de Reservas de Biósfera (MAB-UNESCO), pp. 105.

Moeed A. y D. G. Dawson, 1979. Breeding of Starlings (Sturnus vulgaris) in nest boxes of various types. New Zealand Journal of Zoology 6: 613-618. 
Moeed A., 1980. Diets of adult and nestling starlings (Sturnus vulgaris) in Hawke's Bay, New Zealand. New Zealand journal of zoology 7: 247-256.

Møller A. P., K. Allander y R. Dufva, 1990. Fitness effects of parasites on passerine birds: a review. In Population biology of passerine birds (pp. 269-280). Springer Berlin Heidelberg.

Møller A. P., 1993. Ectoparasites increase the cost of reproduction in their hosts. Journal of Animal Ecology 62: 309-322.

Monaghan P. y R. G. Nager, 1997. Why don't birds lay more eggs? Trends in Ecology and Evolution 12: 270-274.

Moore J., 1984. Starling reproduction in central New Mexico. Journal of Field Omithology 55: 254-257.

Moore J, 1986. Dietary variation among nestling starlings. The Condor 88: 181-189.

Moschione F.N. y M. I. Barrios M.I., 1995. Aves del Parque Provincial Pereyra Iraola provincia de Buenos Aires. Ministerio de la Producción, La Plata.

Moss R. y A. Watson, 1984. Maternal nutrition, egg quality and breeding success of Scottish ptarmigan Lagopus mutus. Ibis 126: 212-220

Mumby P., 1979. The starling (Sturnus vulgaris) in North America: a review of its biology, economic status, and control. MS Thesis, Simon Fraser University. Burnaby, British Columbia. (Citado por Ransome 2010).

Murray B. G., 1985. Evolution of clutch size in tropical species of birds. Ornithological Monographs: 505-519.

Naef-Daenzer B. y L. F. Keller, 1999. The foraging performance of great and blue tits (PARUS MAJOR and P. CAERULEUS) in relation to caterpillar development, and its consequences for nestling growth and fledging weight. Journal of Animal Ecology 68: 708-718.

Narosky T. y R. L. Carman, R. L., 2009. El hornero ave nacional. Editorial Albatros: Buenos Aires.

Navas J. R., 1987. Los vertebrados exóticos introducidos en la Argentina. Revista del Museo Argentino de Ciencias Naturales 'Bernardino Rivadavia' Zool. 14: 7-38.

Navas J. R., T. Narosky, N. A. Bó y J. C. Chébez, 1991. Lista patrón de los nombres comunes de las aves argentinas. Asociación Ornitológica del Plata, Buenos Aires, Argentina.

Navas J. R., 2002. Las aves exóticas introducidas y naturalizadas en la Argentina. Revista del Museo Argentino de Ciencias Naturales Nueva Serie 4: 191-202.

Newton I., 1998. Population limitation in birds. Academic press, London.

Nice M. M., 1957. Nesting success in altricial birds. Auk 74: 303-321.

Nilsson S. G., 1984. The evolution of nest-site selection among hole-nesting birds: the importance of nest predation and competition. Ornis Scandinavica: 167-175.

Nilsson S. G., 1986. Evolution of hole-nesting in birds: on balancing selection pressures. The Auk 103: 432-435.

Nores A. I., 1995. Botfly ectoparasitism of the Brown Cacholote and the Firewoodgatherer. The Wilson Bulletin: 734-738.

Norman F. I., y R. S. Brown, 1985. Gizzard grit in some Australian waterfowl. Wildfowl 36: $77-8$.

Norris E., C. Norris y J. B. Steen, 1975. Regulation and grinding ability of grit in the gizzard of Norwegian willow ptarmigan (Lagopus lagopus). Poultry science, 54: 1839-1843.

Norris A. R., K. L. Cockle y K. Martin, 2010. Evidence for tolerance of parasitism in a tropical cavity-nesting bird, planalto woodcreeper (Dendrocolaptes platyrostris), in northern Argentina. Journal of Tropical Ecology 26(06): 619-626.

Novak S. J., 2007. The role of evolution in the invasion process. Proceedings of the National Academy of Sciences 104: 3671-3672.

O'Brien, E. L., \& Dawson, R. D. (2008). Parasite-mediated growth patterns and nutritional constraints in a cavity-nesting bird. Journal of Animal Ecology 77: 127-134. 
Ojanen M., M. Orell y J. Hirvelä, 1979. The breeding biology of the starling Sturnus vulgaris in northern Finland. Ecography 2: 81-87.

Olah G., G. Vigo, L. Ortiz, L. Rozsa y D. J. Brightsmith, 2013. Philornis sp. bot fly larvae in free living scarlet macaw nestlings and a new technique for their extraction. Veterinary parasitology 196: 245-249.

Ortiz D., P. Capllonch, S. Aveldaño, J. Mamaní, O. Quiroga, T. Moreno Ten, 2013. Los passeriformes de Tucumán, Argentina: lista, distribución y migración. Biológica 16: $39-71$.

Osorio H. S., 1979. Contribution to the Lichen Flora of Argentina . VIII . Lichens from Punta Lara, Buenos Aires Province. The Bryologist 79(3): 358-360.

Pacejka A. J., C. M. Gratton y C. F. Thompson, 1998. Do potentially virulent mites affect house wren (Troglodytes aedon) reproductive success?. Ecology 79(5): 1797-1806.

Palma R. L., 1978. Slide-mounting of lice: a detailed description of the Canada balsam technique. New Zealand Entomologist 6: 432-436.

Parker M., J. N. Thompson, y S. G. Weller, 2001. The population biology of invasive species. Annual Review of Ecology and Systematics 32: 305-32.

Parsons J., 1976. Factors determining the number and size of eggs laid by the Herring Gull. Condor 78: 481-492.

Pearce-Higgins J. W., 2010. Using diet to assess the sensitivity of northern and upland birds to climate change. Climate Research 45: 119-130.

Pell A. S. y C. R. Tidemann, C. R., 1997. The impact of two exotic hollow-nesting birds on two native parrots in savannah and woodland in eastern Australia. Biological Conservation 79: 145-153.

Pérez J., 1988. Estornino pinto en la Capital Federal. Nuestras Aves, 17: 14.

Peris S., Soave G., Camperi A., Darrieu C. y Aramburu R., 2005. Range expansion of the European Starling Sturnus vulgaris in Argentina. Ardeola 52: 359-364.

Perrins C., 1979. British Tits, London: Collins, New Naturalist, 304 pp.

Perrins C. M., 1996. Eggs, egg formation and the timing of breeding. Ibis 138: 2-15.

Peterson B. y G. Gauthier 1985. Nest site use by cavity-nesting birds of the Cariboo Parkland, British Columbia. Wilson Bulletin 97: 319-331.

Pimentel D., R. Zuniga y D. Morrison, 2005. Update on the environmental and economic costs associated with alien-invasive species in the United States. Ecological economics 52: 273-288.

Poulin R. y S. Morand, 2004. Parasite biodiversity. Smithsonian Books.

Powlesland R. G., 1978. Behaviour of the haematophagous mite Ornithonyssus bursa in starling nest boxes in New Zealand, New Zealand Journal of Zoology 5: 395-399.

Prentis P. J., J. R. Wilson, E. E. Dormontt, D. M. Richardson y A. J. Lowe, 2008. Adaptive evolution in invasive species. Trends in plant science 13: 288-294.

Proctor H. y I. Owens, 2000. Mites and birds: diversity, parasitism and coevolution. Trends in ecology \& evolution 15: 358-364.

Quiroga M. A. y J. C. Reboreda, 2012. Lethal and sublethal effects of botfly (Philornis seguyi) parasitism on House Wren nestlings. The Condor 114: 197-202.

Quiroga M. A., J. C. Reboreda y A. H. Beltzer, 2012. Host use by Philornis sp. in a passerine community in central Argentina. Revista Mexicana de Biodiversidad 83: 110-116.

Rabuffetti F. L. y J. C. Reboreda, 2007. Early infestation by bot flies (Philornis seguyi) decreases chick survival and nesting success in chalk-browed mockingbirds (Mimus saturninus). The Auk, 124: 898-906.

Ransome D. B., 2010. Investigation of starling populations in British Columbia and assessment of the feasibility of a trapping program in the lower mainland. DBR Forestry-Wildlife Integrated Management. Kamloops, British Columbia. viii +49 p. 
Rebolo Ifrán N. y V. D. Fiorini, 2010. European starling (Sturnus vulgaris): population density and interactions with native species in Buenos Aires urban parks. Ornitología Neotropical 21: 507-518.

Remeŝ V y T. E. Martin, 2002. Environmental influences on the evolution of growth and developmental rates in passerines. Evolution 56: 2505-2518.

Rendell W. B. y R. J. Robertson, 1989. Nest-site characteristics, reproductive success and cavity availability for Tree Swallows breeding in natural cavities. Condor 91: 875885.

Rendell W. B. y R. J. Robertson, 1994. Cavity-Entrance Orientation and Nest-Site Use by Secondary Hole-Nesting Birds. Journal of Field Ornithology 65: 27-35.

Renton K y S. J. Brightsmith, 2009. Cavity use and reproductive success of nesting macaws in lowland forest of southeast Peru. Journal of Field Ornithology 80: 1-8.

Richner H., 1991. The growth dynamics of sexually dimorphic birds and Fisher's sex ratio theory: does sex-specific growth contribute to balanced sex ratios? Functional Ecology 5: 19-28.

Richner H., 1992. The effect of extra food on fitness in breeding carrion crows. Ecology 73: 330-335.

Ricklefs R. E., 1967. A Graphical Method of Fitting Equations to Growth Curves. Ecology 48: 978-983.

Ricklefs, R. E. 1977. Variation in size and quality of the Starling egg. The Auk: 167-168.

Ricklefs, R. E. y S. Peters, 1979. Intraspecific variation in the growth rate of nestling European starlings. Bird-Banding: 338-348.

Ricklefs R. E., 1984. Variation in the size and composition of eggs of the European Starling. Condor: $1-6$.

Rizzo F. 2010. Utilización de nidos de Hornero (Furnarius rufus) por el Estornino pinto (Sturnus vulgaris). Nuestras Aves 55: 33-35.

Robertson G. J. y F. Cooke, 1993. Intraclutch egg-size variation and hatching success in the common eider. Canadian Journal of Zoology 71: 544-549.

Robinson R. A., G. M. Siriwardena y H. Q. Crick, 2005. Status and population trends of Starling Sturnus vulgaris in Great Britain: Capsule Starling populations have declined markedly since 1964, with the greatest declines in pastoral areas in the south and west of Britain. Bird Study 52: 252-260.

Robinson R. A., G. M. Siriwardena y H. Q. P. Crick, 2006. The population decline of the starling, Sturnus vulgaris, in Great Britain: patterns and causes. Acta Zoologica Sinica 52: $550-553$.

Roff D., 1992. The evolution of life histories: theory and analysis. Chapman y Hall, New York, Estados Unidos.

Rosato V. G. y N. C. Scutari, 2000. On the presence of Ramalina complanata (Sw.) Ach (Lecanorales, lichenized Ascomycotina) in Argentina. Mycotaxon. 74: 141-151.

Rosen S., I. Yeruham y Y. Braverman, 2002. Dermatitis in humans associated with the mites Pyemotes tritici, Dermanyssus gallinae, Ornithonyssus bacoti and Androlaelaps casalis in Israel. Medical and veterinary entomology 16: 442-444.

Royall W. C., 1966. Breeding of the starling in central Arizona. Condor:196-205.

Ruda Vega M., 2004. Fotografías curiosas y novedades de aves silvestres. Nuestras Aves 47: 10.

Sax D. F. y J. H. Brown, 2000. The paradox of invasion. Global Ecology and Biogeography 9: 363-371.

Sax, D. F. y J. H. Brown, J. H., 2000. The paradox of invasion. Global Ecology and Biogeography 9: 363-371.

Santamaria L., J. Pericás, M. Carrete y J. L. Tella 2009. La ausencia de enemigos naturales favorece las invasiones biológicas. En: Vilá M., F. Valladares, A. Traveset, L. Santamaria y P. Castro (eds.). Invasiones biológicas. Pp. 91-101. CSIC, Madrid. 
Schmidtuz C. y C. Agulían, 1988. Nidificación del estornino pinto. Nuestras Aves 17: 13.

Scutari N. C., 1992. Los géneros foliosos y fruticosos de Physciaceae, Candelariaceae y Teloschistaceae (Ascomicotina liquenizados) de la provincia de Buenos Aires. Tesis Doctoral, Facultad de Ciencias Exactas y Naturales, Universidad de Buenos Aires, Buenos Aires.

Seddon P. J. y Y. Van Heezik, 1991. Effects of hatching order, sibling asymmetries, and nest site on survival analysis of Jackass Penguin chicks. The Auk: 548-555.

Segura L. N. y J. C. Reboreda, 2011. Botfly parasitism effects on nestling growth and mortality of Red-crested Cardinals. The Wilson Journal of Ornithology 123: 107-115.

Shea K. y P. Chesson, 2002. Community ecology theory as a framework for biological invasions. Trends in Ecology \& Evolution 17: 170-176.

Sheldon B. C. y S. Verhulst, 1996. Ecological immunology: costly parasite defences and trade-offs in evolutionary ecology. Trends in Ecology \& Evolution 11: 317-321.

Sibley C. G. y J. E. Ahlquist, 1984. The relationships of the starlings (Sturnidae: Sturnini) and the mockingbirds (Sturnidae: Mimini). The Auk 101: 230-243.

Sibley D. A., 2001. The Sibley Guide to Bird Life and Behavior. Knopf, Toronto.

Silvestri L., L. R. Antoniazzi, M. S. Couri, L. D. Monje y P. M. Beldomenico, 2011. First record of the avian ectoparasite Philornis downsi Dodge \& Aitken, 1968 (Diptera: Muscidae) in Argentina. Systematic parasitology 80: 137-140.

Skowron C. y M. Kern, 1980. The insulation in nests of selected North American songbirds. The Auk 97: 816-824.

Slagsvold T., 1976. Annual and geographical variation in the time of breeding of the Great Tit Parus major and the Pied Flycatcher Ficedula hypoleuca in relation to environmental phenology and spring temperature. Ornis Scandinavica: 127-145.

Slagsvold T., 1982. Clutch size variation in passerine birds: the nest predation hypothesis. Oecologia, 54: 159-169.

Smith E. L., I. C. Cuthill, R. Griffiths, V. J. Greenwood, A. R. Goldsmith y J. E. Evans, 2005. Sexing Starlings Sturnus vulgaris using iris colour. Ringing \& Migration 22: 193197.

Sockman K. W., 1997. Variation in life-history traits and nest-site selection affects risk of nest predation in the California Gnatcatcher. The Auk: 324-332.

Sol D. y L. Lefebvre, 2000. Behavioural fexibility predicts invasion success in birds introduced to New Zealand. OIKOS 90: 599-605.

Solonen T., J. Tiainen, E. Korpimäki y P. Saurola, 1991. Dynamics of Finnish starling Sturnus vulgaris populations in recent decades. Ornis Fennica 68: 158-169.

Sommer J. B., 1937. Parasites of the european starling in Illinois. Auk 54: 50-54.

Sorace, A. 2001. Value to wildlife of urban-agricultural parks: a case study from Rome urban area. Environ. Manage. 28: 547-560.

Spalding M. G., J. W. Mertins, P. B. Walsh, K. C. Morin, D. E. Dunmore y D. J. Forrester, 2002. Burrowing fly larvae (Philornis porteri) associated with mortality of Eastern Bluebirds in Florida. Journal of Wildlife Diseases 38(4): 776-783.

StatSoft Inc., 2003. STATISTICA (data analysis software system), version 7.1. www.statsoft.com.

Stauffer D. F. y L. B. Best, 1982. Nest-site selection by cavity-nesting birds of riparian habitats in Iowa. The Wilson Bulletin 329-337.

Stickley A. R., R. A. Dolbeer y S. B. White, 1976. Starling damage to sprouting wheat in Tennessee. En: Bird Control Seminars Proceedings pp. 48.

Stouffer P. C. y H. W. Power, 1991. An experimental test of the brood-reduction hypothesis in European Starlings. Auk 108: 519-531.

Summers R. W., 1985. The effect of scarers on the presence of starlings (Sturnus vulgaris) in cherry orchards. Crop Protection 4: 520-528. 
Tay T., A. Ö. Türk, M. Yılmaz, H. Türk y M. Kıvanc, 2004. Evaluation of the antimicrobial activity of the acetone extract of the lichen Ramalina farinacea and its $(+)$-usnic acid, norstictic acid, and protocetraric acid constituents. Zeitschrift für Naturforschung 59: 384-388.

Teixeira D.M., 1990. Notas sobre a biologia de Philornis rufoscutellaris Couri, 1983 (Diptera: Muscidae) e sua associação com ninhos de aves. Revista Brasileira de Entomologia 34(2): 271-275.

Teixeira, D. M. (1999). Myiasis caused by obligatory parasites. Ib. General observations on the biology of species of the genus Philornis Meinert, 1890 (Diptera, Muscidae). Myiasis in man and animals in the Neotropical Region. Bibliographic database.

Templar A. C., T. E. McQuistion y A. P. Capparella, 2004. A new coccidian parasite, Isospora andesensis, from the common bush tanager (Chlorospingus ophthalmicus) of South America. Acta protozoologica 43(4): 369-372.

Thomas, L., S. T. Buckland, E. A. Rexstad, J. L. Laake, S. Strindberg, S. L. Hedley, J. R. B. Bishop, T. A. Marques y K. P. Burnham, 2010. Distance software: design and analysis of distance sampling surveys for estimating population size. Journal of Applied Ecology 47: 5-14. doi: 10.1111/j.1365-2664.2009.01737.x

Tinbergen J. M., 1981. Foraging decisions in starlings (Sturnus vulgaris). Ardea 69: 1-69.

Tompkins D. M. y M. Begon, 1999. Parasites can regulate wildlife populations. Parasitology today $15: 311-313$.

Torchin M. E., K. D. Lafferty, A. P. Dobson, V. J. McKenzie, A. M. Kuris, 2003. Introduced species and their missing parasites. Nature 421: 628-630.

Torchin M. E. y C. E. Mitchell, 2004. Parasites, pathogens, and invasions by plants and animals. Frontiers in Ecology and the Environment 2: 183-190.

Tracey J. P. y G. Saunders, 2003. Bird damage to the wine grape industry. Orange: Vertebrate Pest Research Unit, NSW Agriculture.

Tripet F. y H. Richner, 1997. Host responses to ectoparasites: food compensation by parent blue tits. Oikos 78: 557-561.

Troetschler R. G., 1976. Acorn woodpecker breeding strategy as affected by starling nest-hole competition. Condor 78: 151-165.

Turienzo P. y O. R. Di Iorio, 2008. Insects found in birds' nests from Argentina: Anumbius annumbi (Vieillot, 1817) [Aves: Furnariidae]. Zootaxa (1871): 1-55.

Turienzo P. y O. R. Di Iorio, 2010. Insects found in birds' nests from Argentina. Furnarius rufus (Gmelin, 1788) [Aves: Furnariidae] and their inquiline birds, the true hosts of Acanthocrios furnarii (Cordero and Vogelsang, 1928) [Hemiptera: Cimicidae]. Zootaxa, (2700): 1-112.

Uhazy L. S. y W. J. Arendt, 1986. Pathogenesis associated with philornid myiasis (Diptera: Muscidae) on nestling Pearly-eyed Thrashers (Aves: Mimidae) in the Luquillo rain forest, Puerto Rico. Journal of Wildlife Diseases 22(2): 224-237.

Uysal H., D. Altun, H. Aşkın, A. Aslan, 2009. Effects of water extract of Usnea longissima Ach. on some development stages of Drosophila melanogaster. Fresenius Environmental Bulletin 18: 450-455.

Valente R., L. M. Ibañez, E. Lorenti, V. D. Fiorini, D. Montalti y J. I. Diaz, 2014. Helminth parasites of the European starling (Sturnus vulgaris) (Aves, Sturnidae), an invasive bird in Argentina. Parasitology research: 1-6.

Valiente Moro C. V., C. Chauve y L. Zenner, 2005. Vectorial role of some dermanyssoid mites (Acari, Mesostigmata, Dermanyssoidea). Parasite 12: 99-109.

VanBalen J. H., C. J. Booy, J. A. Vanfraneker y E. R. Osieck, 1982. Studies on hole-nesting birds in natural nest sites. 1. Availability and occupation of natural nest sites. Ardea 70: 1-24. 
Van Horne B. y A. Bader, 1990. Diet of nestling Winter Wrens in relationship to food availability. Condor 92: 413-420.

Van Riper C., S. G. Van Riper, M. L. Goff y M. Laird, 1986. The epizootiology and ecological signif cance of malaria in Hawaiian land birds. Ecological monographs 56: 327-344.

Veit R. R. y M. A. Lewis, 1996. Dispersal, population growth, and the Allee effect: dynamics of the house finch invasion of eastern North America. American Naturalist 148: 255274.

Veltman C. J., S. Nee y M. J. Crawley, 1996. Correlates of introduction success in exotic New Zealand birds. American Naturalist 147: 542-557.

Vera P., M. Marín, E. J. Belda y J. S. Monrós, 2009. Estructura y composición del nido del Escribano Palustre Iberoriental Emberiza schoeniclus witherbyi. Revista Catalana d'Ornitologia 25: 43-48.

Verhulst S., J. H. V. Balen y J. M. Tinbergen, 1995. Seasonal decline in reproductive success of the Great Tit: variation in time or quality? Ecology 76: 2392-2403.

Vié J. C., C. Hilton-Taylor y S. N. Stuart (Eds.),2009. Wildlife in a changing world: an analysis of the 2008 IUCN Red List of threatened species. IUCN.

Vignau M. L., L. M. Venturini, J. R. Romero, D. F. Eiras y W.U. Basso, 2005. Parasitología práctica y modelos de enfermedades parasitarias en los animales domésticos. Facultad de Ciencias Veterinarias, Universidad Nacional de La Plata.

Vincent A. L., 1972. Parasites of the starling, Sturnus vulgaris, in San Diego County, California. The Journal of parasitology 58: 1020.

Vinayaka K. S., P. S. V. Kumar, P. T. R. Kekuda, Y. L. Krishnamurthy, N. Mallikarjun, D. Swathi, 2009. Proximate composition, antioxidant, anthelmintic and insecticidal activity of a macrolichen Ramalina conduplicans Vain. (Ramalinaceae). European Journal of Applied Sciences. 1: 40-46.

Webb D. R., 1987. Thermal tolerance of avian embryos: a review. Condor 89: 874-898.

Weitzel N. H., 1988. Nest-site competition between European Starlings and native breeding birds in northwestern Nevada. Condor 90: 515-517.

Wesołowski T., 1989. Nest-sites of hole-nesters in a primaeval temperate forest (Białowieza National Park, Poland). Acta Ornithologica 25: 321-351.

Wesołowski T., 2007. Lessons from long-term hole-nester studies in a primeval temperate forest. Journal of Ornithology 148(2): 395-405.

Westerterp K., W. Gortmaker y H. Wijngaarden, 1982. An energetic optimum in broodraising in the starling Sturnus vulgaris:an experimental study. Ardea 70: 153-162.

Williams T. D., 1991. Ageing criteria in the Starling Sturnus vulgaris. Ringing \& Migration 12: 113-117.

Williams T. D., 1994. Intraspecific variation in egg size and egg composition in birds: effects on offspring fitness. Biological Reviews of the Cambridge Philosophical Society 68: $35-59$.

Williams T. D., 2005. Mechanisms underlying the costs of egg production. Bioscience 55: $39-48$.

Williamson M. H. y K. C. Brown, 1986. The analysis and modeling of British invasions. Philosophical Transactions of the Royal Society of London, Series B, Biological Sciences 314: 505-521.

Wimberger P. H., 1984. The use of green plant material in bird nests to avoid ectoparasites. Auk 101(3): 615-618.

Winkler D. W., 1993. Use and importance of feathers as nest lining in Tree Swallows (Tachycineta bicolor). The Auk 110: 29-36.

Winkler D. W., O. Dunn y C. E. McCulloch, 2002. Predicting the effects of climate change on avian life-history traits. Ecology 99:13595-13599.

Wirth, V. 1995. Die Flechten baden-württembergs Vol. 2, pp. 1-2. Stuttgart: Ulmer. 
Wood C. A., 1924. The starling family at home and abroad. Condor 26: 123-136.

Yildirim E., A. Aslan, B. Emsen, A. Cakir y S. Ercisli, 2012 a. Insecticidal effect of Usnea longissima (Parmeliaceae) extract against Sitophilus granarius (Coleoptera: Curculionidae). Int J Agric Biol 14: 303-306.

Yildirim E., B. Emsen, A. Aslan, Y. Bulak y S. Ercisli, 2012 b. Insecticidal activity of lichens against the maize weevil, Sitophilus zeamais Motschulsky (Coleoptera: Curculionidae). Egyptian Journal of Biological Pest Control 22: 151-156.

Yom-Tov Y., M. I. Christie M. I. y G. J. Iglesias, 1994. Clutch size in passerines of southern South America. Condor 96:170-177.

Young B. E., 1993. Effects of the parasitic botfly Philornis carinatus on nestling house wrens, Troglodytes aedon, in Costa Rica. Oecologia 93, 256-262. doi:10.1007/BF00317679

Young B. E., 1994. Geographic and seasonal patterns of clutch-size variation in House Wrens. Auk 111: 545-555.

Zamorano M., G. Aguerre, P. F. Petracci y G. Daniele, 2002. Descripción del ambiente utilizado por el Estornino Pinto (Sturnus vulgaris) en la zona del Partido de La Plata. In: Encuentro de Estudiantes de Biología y Carreras Afines. Universidad Nacional de Luján.

Zanotti M., 2013. Presencia del estornino pinto (Sturnus vulgaris) en la provincia de Mendoza, Argentina. Nuestras Aves 58: 5-7.

Zavaleta E. S., R. J. Hobbs y H. A. Mooney, 2001. Viewing invasive species removal in a whole-ecosystem context. Trends in Ecology \& Evolution 16: 454-459.

Zeleny L., 1977. Song of hope for bluebird. National Geographic151(6): 855-865.

Zuccon D., E. Pasquet y P. G. Ericson, 2008. Phylogenetic relationships among PalearcticOriental starlings and mynas (genera Sturnus and Acridotheres: Sturnidae). Zoologica Scripta 37: 469-481.

Zwartjes P. W. y S. E. Nordell, 1998. Patterns of cavity-entrance orientation by gilded flickers (Colaptes chrysoides) in cardon cactus. The Auk 115: 119-126. 